\title{
Primary Headteachers: new leadership roles inside and outside the school
}

Susan Robinson

A thesis submitted in partial fulfilment of the requirements of Birmingham City University

for the degree of Doctor of Philosophy.

May 2009

Faculty of Education, Law and Social Sciences

Birmingham City University

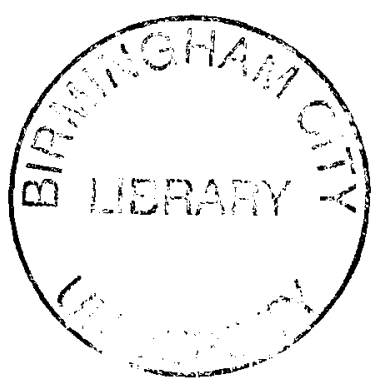




\section{ACKNOWLEDGEMENTS}

My undertaking a $\mathrm{PhD}$, while I hope it offers something to the school system in terms of my improved professional understanding is nevertheless hugely self-indulgent and has had an impact on the lives of others. I am deeply indebted to all those who have been involved both personally and professionally in enabling me to complete it. My special thanks to:

\section{My supervisors}

My heartfelt gratitude goes to my supervisors Professor Richard Hatcher and Professor David Hellawell for their humour, patience, goodwill, guidance and support. They were unfailingly generous with their time and encouragement to believe in myself and the worth of my research.

\section{My interviewees}

I am also grateful to all those who allowed me to interview them and to quote their views and opinions.

\section{Colleagues at school}

I would also like to express my gratitude to the staff and governors at Cherry Orchard Primary School in Birmingham. In particular I wish to acknowledge my appreciation of the personal and professional support I was given by our Chair of Governors Clifford Fryer and Vice Chair Raj Gogna and to Fiona Wilson; Alison Taylor; Liz Regan; Peter Harper; and Sue Flannery who have been the best friends and colleagues I could have wished for.

My family.

My love and thanks to Arthur, my father, and late mother Jess for fostering my passion for learning and to my husband Graham whose unconditional constant support, encouragement and belief in me gave me the will and time to complete this thesis. 


\begin{abstract}
This thesis is the result of an investigation into the issues impacting on the role of the primary headteacher. The research is framed within the calls in the early years of the $21^{\text {st }}$ century to redesign the school system leading to a degree of earned autonomy and new roles for headteachers.
\end{abstract}

The theme underpinning educational policy was that transformational and systemic change was identified as necessary due to:

- The 'standards' plateau at the end of KS2.

- The need to provide a suitable workforce for the knowledge economy.

- The problem of succession management caused by the retirement of the "baby boomer' generation and a reluctance of aspirant leaders to apply for headship.

Calls for system redesign were partly predicated on recognition of the importance of the role of the headteacher in leading and delivering the reforms in schools. This has led to changes in the role of the headteacher. Themes underpinning that change were:

- The opportunities for new internal and external roles.

- The leadership skills and practice required to manage change effectively.

The research design is qualitative involving semi-structured interviews of 21 primary headteachers, over two rounds of interviews from 2005-2008. The headteachers from nine different Local Authorities and different contexts were purposively sampled because of their validation as very good, excellent or outstanding leaders in their latest Ofsted inspections. In the second round heads were also sampled for the degree to which they had a new internal or external role.

My research suggests that government policy has led to opportunities imposed on or offered to headteachers to undertake new roles. New internal roles include coleadership and managing a children's centre on site and external roles include system leadership such as the roles of National Leader of Education and other forms of executive headship, and School Improvement Partner and Consultant Leader. In 
addition there are other external leadership roles in networks and with non government departmental agencies.

System redesign has led to new roles for other staff and new ways of working in order for the headteachers to build the capacity in their schools to manage their new roles. However they can only do this while maintaining their Ofsted rating as effective leaders and so the impact of accountability and performativity is crucial. This leads to a managed compliance to the educational policy agenda for accountability made more critical due to the increased public reputation they experience. Despite this there is evidence of courage to lead particularly in those areas which have not yet been incorporated into governmental micro-management within the school system. My results consider implications for the system as a whole and in particular with regards to system leadership. 


\section{GLOSSARY}

\begin{tabular}{|c|c|}
\hline AST & Advanced Skills Teacher \\
\hline AHT & Assistant Headteacher \\
\hline BECTA & British Educational Communications and Technology Agency \\
\hline BSS & Buildings Services Supervisor \\
\hline CL & Consultant Leader \\
\hline CPD & Continuous Professional Development \\
\hline CVA & Contextual Value Added \\
\hline DCS & Directors of Children's Services \\
\hline DCSF & Department for Children, Schools and Families \\
\hline DfES & Department for Education and Skills \\
\hline $\mathrm{EiC}$ & Excellence in Cities \\
\hline $\mathrm{ECM}$ & Every Child Matters \\
\hline EYFS & Early Years Foundation Stage \\
\hline FMSIS & Financial Management Systems in Schools \\
\hline HLTA & Higher Level Teaching Assistant \\
\hline HMI & Her Majesty's Inspectors \\
\hline ISP & Intensive Support Programme \\
\hline LA & Local Authority \\
\hline LEA & Local Education Authority* \\
\hline NDGA & Non Departmental Government Agency \\
\hline NCSL & National College for School Leadership \\
\hline NLENSS & National Leader of Education National Support School \\
\hline NPQH & National Professional Qualification for Headship \\
\hline Ofsted & Office for Standards in Education \\
\hline OECD & Organisation for Economic Cooperation and Development \\
\hline PCT & Primary Care Trust \\
\hline PER & Primary Evaluative Review \\
\hline PLP & Primary Leadership Programme \\
\hline PPA & Planning Preparation and Assessment \\
\hline PSCL & Primary Strategy Consultant Leader \\
\hline QTS & Qualified Teacher Status \\
\hline RIG & Rewards and Incentives Group \\
\hline SBD & School Business Director \\
\hline SBM & School Business Manager \\
\hline SEF & School Evaluation Form \\
\hline SIO & School Improvement Officer (LA) \\
\hline SIP & School Improvement Partner \\
\hline SLT & Senior Leadership Team \\
\hline SSAT & Specialist Schools and Academies Trust \\
\hline STRB & School Teachers Review Board \\
\hline TA & Teaching Assistant \\
\hline TDA & Teachers Development Agency \\
\hline TTA & Teachers Training Agency \\
\hline TES & Times Educational Supplement \\
\hline TLR & Teaching and Learning Responsibility \\
\hline WAMG & Workforce Agreement Monitoring Group \\
\hline
\end{tabular}

*Note: LEAs became known as LAs during the course of the research as education was integrated as part of Children's Services following the Children's Act (2004) Participants in the research used the terms LA and LEA interchangeably as they were becoming more accustomed to the change of terminology. 


\section{CONTENTS}

Chapter One: The context, structure and significance of the research ................1

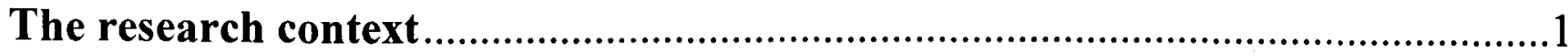

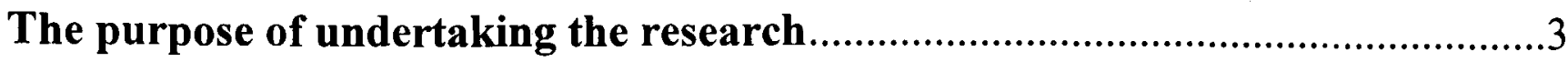

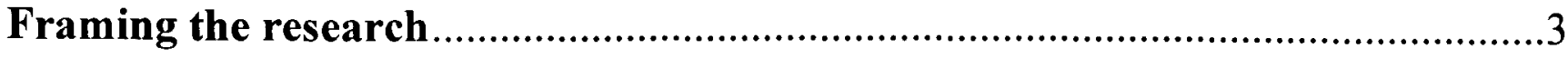

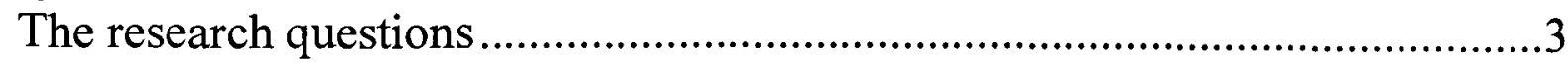

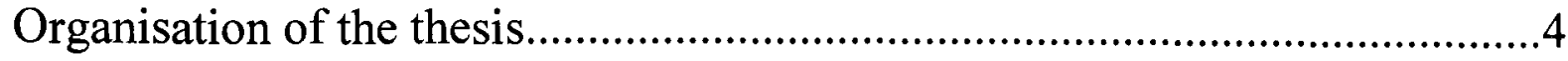

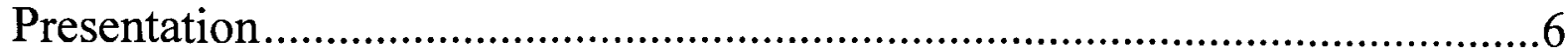

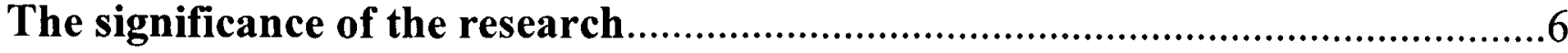

The significance of my role as practising headteacher and

'system leader' as a contribution to the research .........................................

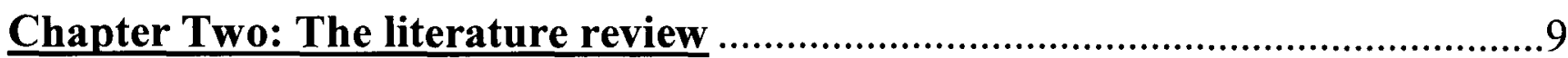

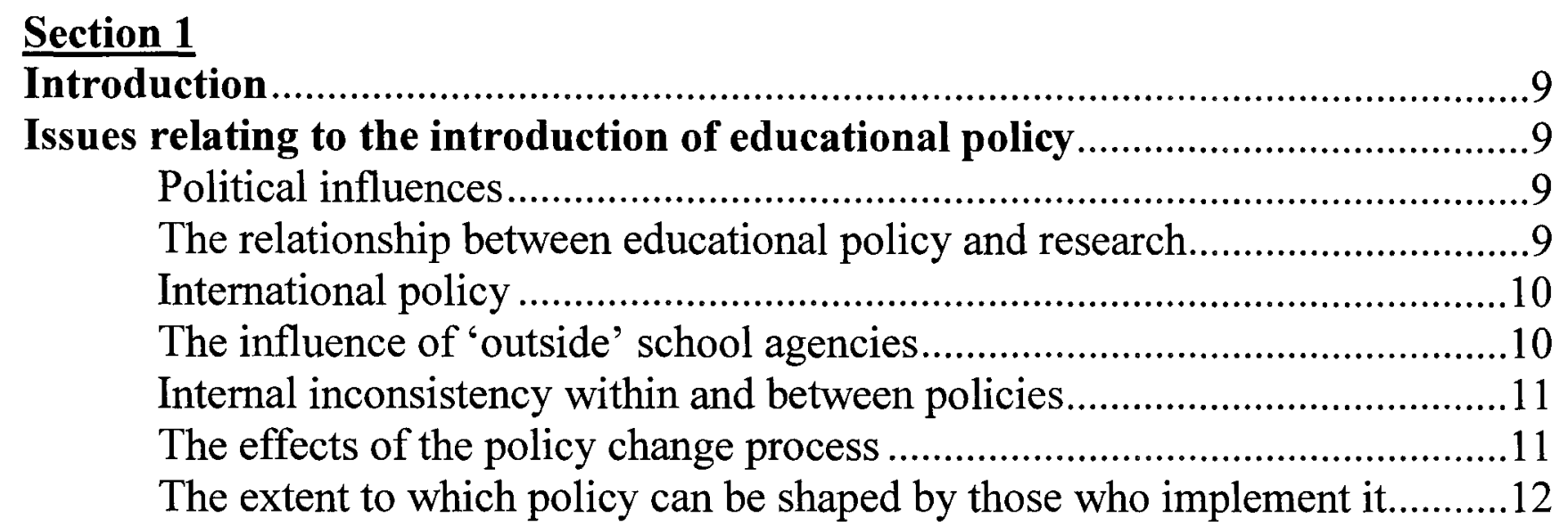

Section 2

The historical context of the role of the headteacher.........................................12

1944-1976: A professional partnership. The government, LEAs and the role of

the headteacher............................................................ 12

Partnership and consensus ..................................................................12

Towards more state control and the 'Moment of 1976' (Batteson, 1997).....14

Educational policy 1979-1997 and its impact on the role of the headteacher .....15

The role of the headteacher: changing the balance of power.........................15

The Education Reform Act (1988) and the Education (Schools) Act (1992). 17

The reduction in the power and influence of the LEA................................18

Tensions in the role of headteacher ...........................................................19

The rise of the entrepreneurial headteacher .............................................22

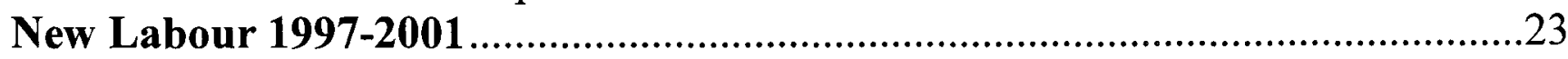

A new partnership with the profession or more of the same?.......................23

The prospect of a 'Third Way' ........................................................................24

The continuation of market ideology and the continuing decline of the power and influence of the LEAs .............................................................25

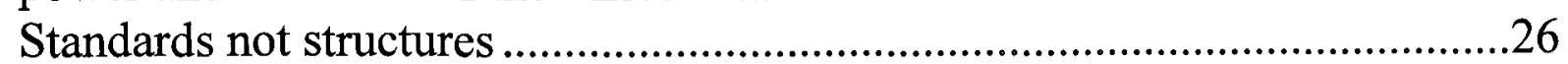

\section{Section 3}

Labour 2001: The Call for System Redesign.................................................28

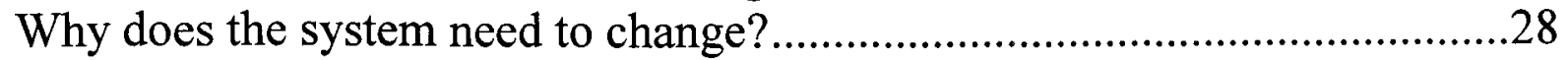

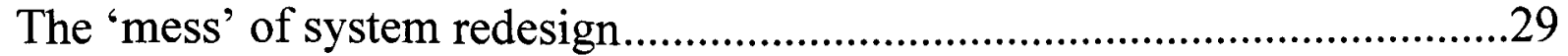

What is not working in terms of the system which exists currently ...............32

Disengagement of headteachers and solving the crisis of succession ............33 


\section{Section 4}

Policies and themes impacting on the role of the primary headteacher .............35

Changing professionalism: The competency based approach to leadership...35

Changing professionalism by reforming the workforce ..............................37

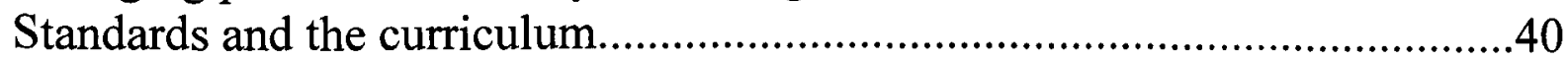

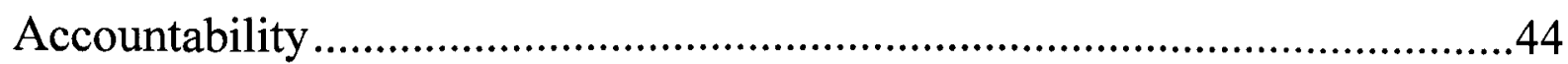

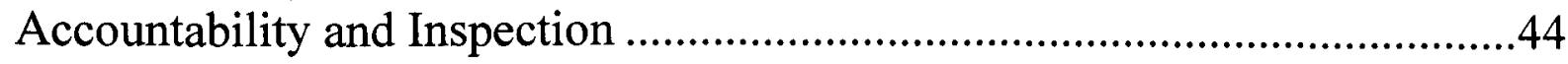

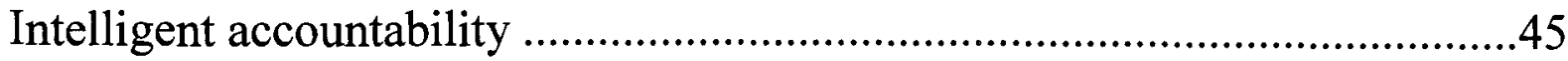

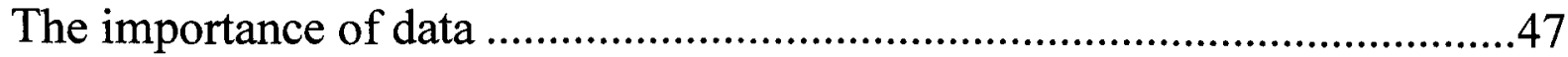

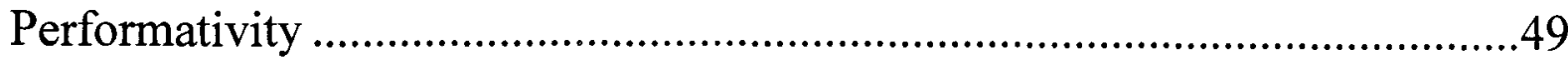

The role of new models of organisation and of school leadership in

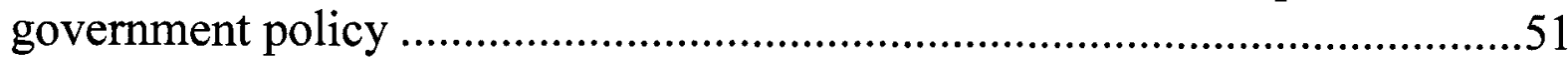

How has system leadership been reflected in government policy .................53

Factors impacting on the success of system leadership ................................55

New Models of school leadership of a single school...................................56

\section{Section 5}

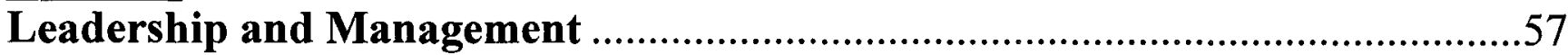

The difficulty of definitions: leadership and management ..........................58

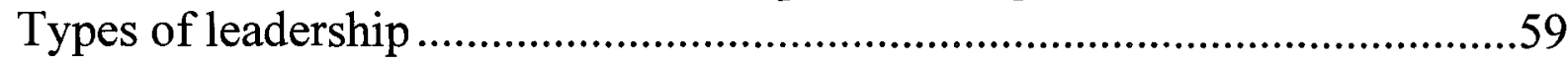

Transactional Leadership .................................................................6

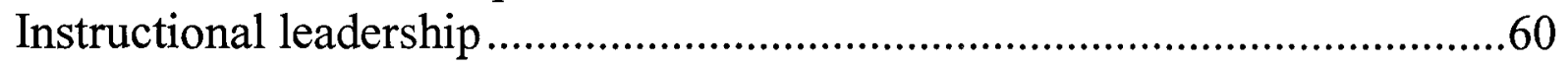

Transformational Leadership ..............................................................6

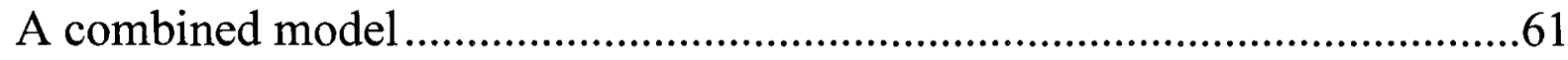

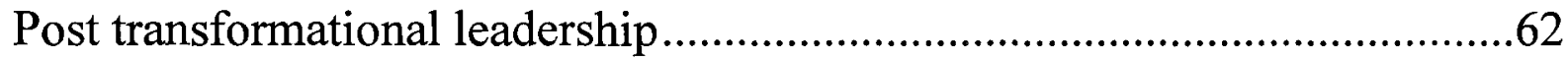

Distributed Leadership........................................................................63

Collegiality, collaboration and system leadership .....................................64

Collegiality and collaboration within schools.............................................64

The moral dimension or values led leadership ........................................65

Management of change, compliance, strategy and guilt ................................66

Compliance and change .......................................................................66

Mediating change and manipulating policy ...........................................67

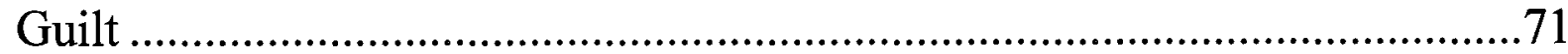

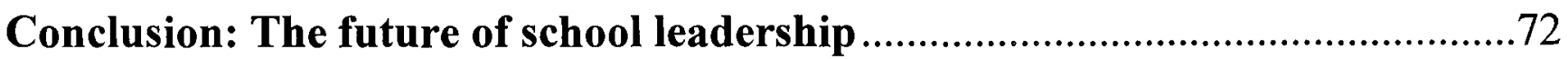

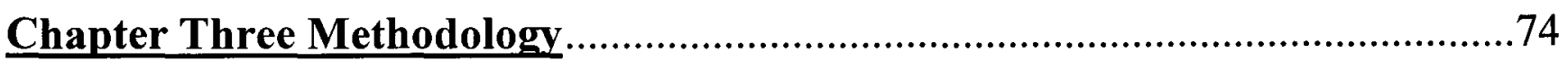

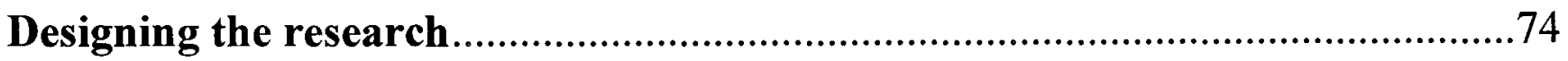

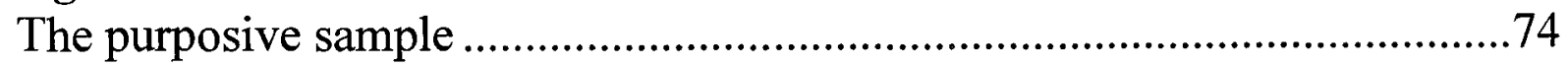

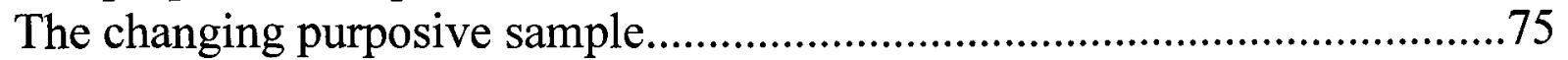

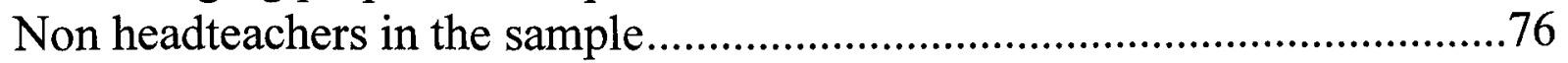

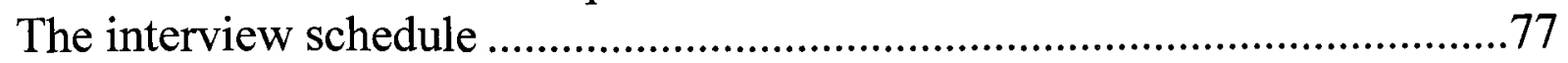

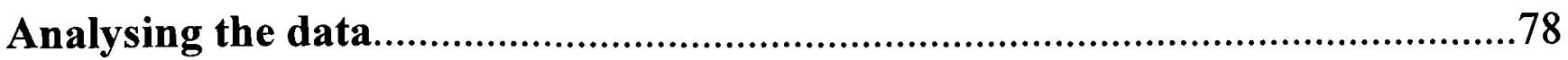

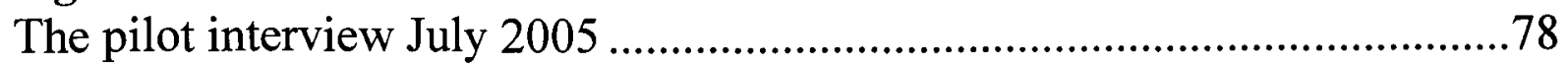

The first round of interviews September 2005-September 2006 ...................80

NCSL as a factor in changes to the research..............................................83

The second round of interviews April 2007-February 2008........................83

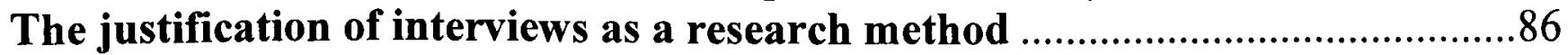

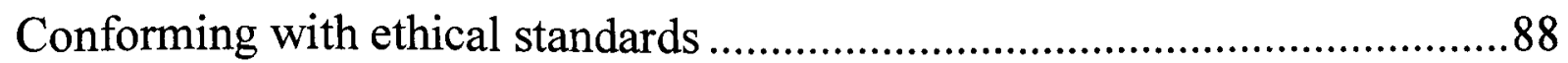

Qualitative analysis: Grounded theory...................................................89 
My position as an insider researcher.........................................................90

Ensuring the accuracy and honesty of the data analysis ..............................92

How the research could have been improved .....................................................94

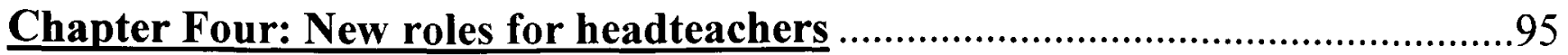

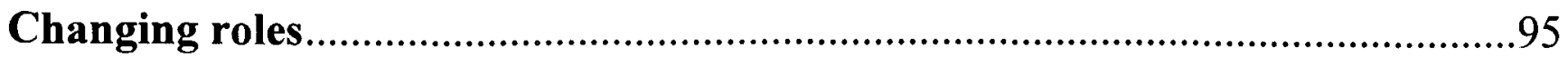

Headteachers' vision of the development of school leadership..........................96

The pivotal role of the headteacher in future school leadership ....................98

Headteachers - lead learners or chief executives?.....................................100

New roles developing to spread 'best practice' ..........................................101

New roles as a solution to the potential lack of school leaders

in the future ............................................................................................ 102

Changing the role of headteacher as a way of addressing its demands ........105

The development of new internal roles for headteachers ...........................107

Multi-agency work and an increase in heads' responsibilities .....................109

Extended Schools.......................................................................................111

Other new models of school leadership in a single institution ....................111

The development of new external roles for headteachers............................112

National Leaders of Education (NLEs) ......................................................114

Leading a federation ..............................................................................115

The advantages and disadvantages of a federation of schools....................117

Headteacher's motivations for undertaking new roles....................................118

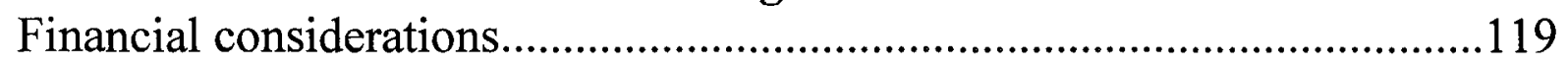

Professional challenge and development ................................................120

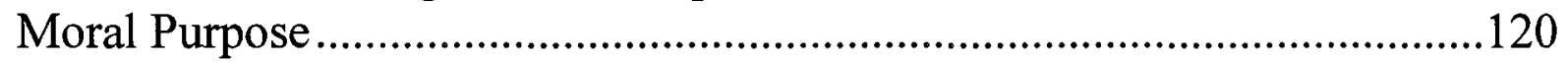

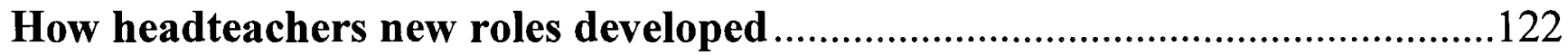

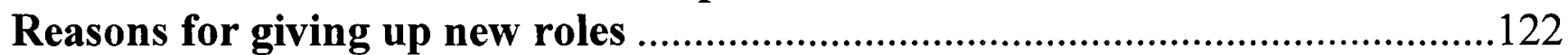

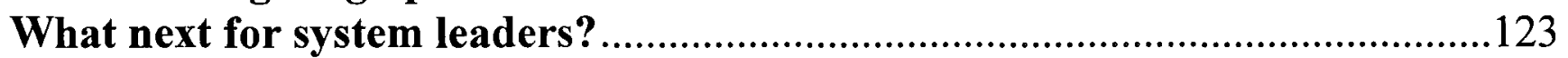

Chapter Five: Standards, accountability and the role of the

primary headteacher .................................................................................. 126

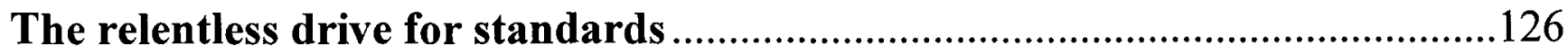

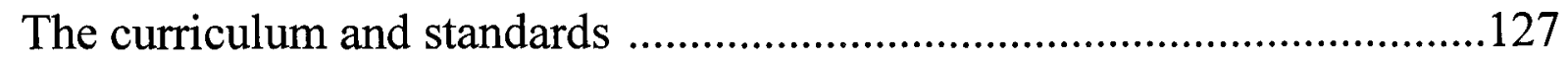

A creative curriculum and maintaining standards ...................................128

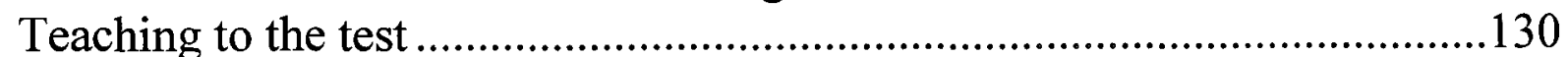

Assessment and standards.................................................................130

The 5 outcomes of ECM, standards and the curriculum............................132

Tensions in the government's agenda between standards and inclusion......132

Accountability of the headteacher.....................................................................133

The perceived need for external accountability .............................................. 134

Ofsted and 'The New Relationship with Schools' ...............................................135

The increased importance of data in determining the

outcome of inspections ..........................................................................136

The Value Added (VA) and Contextual Value Added (CVA) factor...........137

The accuracy of data and inspection judgements ......................................140

The increased importance of self evaluation systems................................. 144

Stress and inspection.........................................................................146

The new relationship with schools and new accountability partnerships:

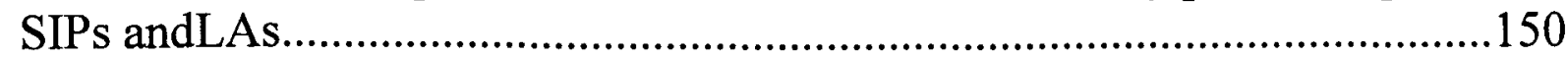

Relationship between SIPs and Ofsted ................................................152 


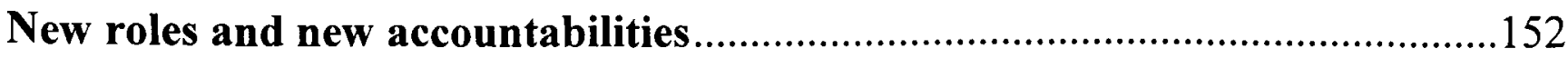

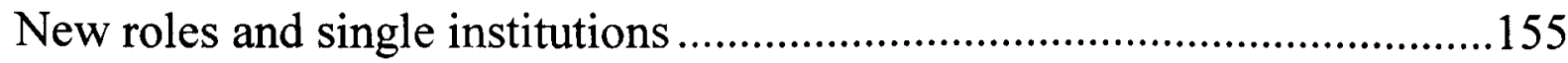

Work intensification and new roles for headteachers ....................................156

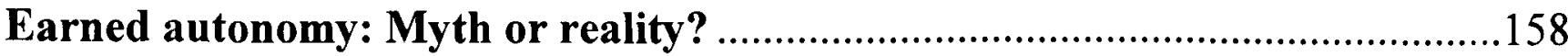

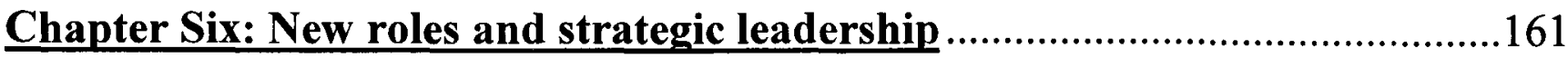

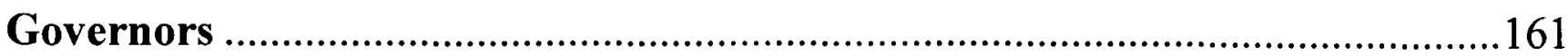

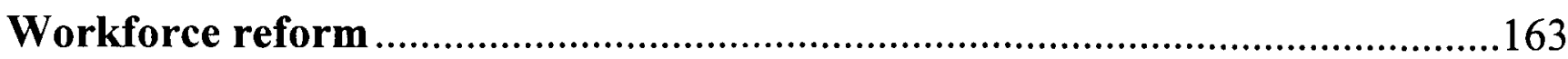

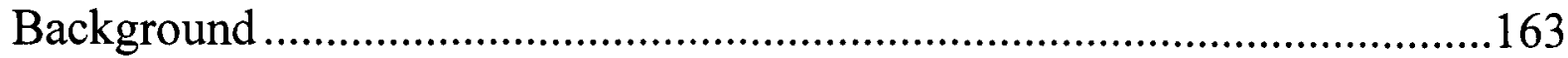

Performance Management .......................................................................163

Workforce reform: Planning, Preparation and Assessment (PPA) ..............164

Remodelling the workforce.....................................................................166

The role of the LA and the unions in remodelling the workforce ................168

The financial implications of workforce reform .......................................170

School organisation.........................................................................171

Role of the Teaching Assistant (TA) ....................................................172

Using workforce reform to build capacity to sustain heads' new roles .............173

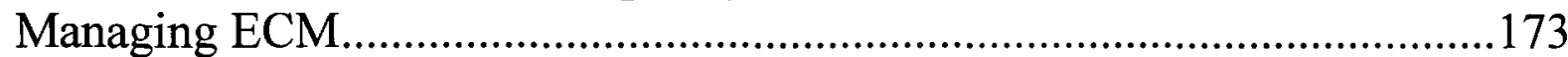

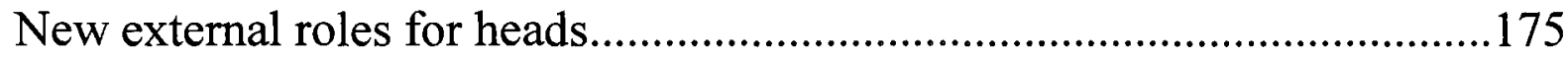

The changing role of deputy and assistant headteachers ...........................177

The increase in the use of non teaching support staff................................179

Building capacity through distributed leadership ....................................180

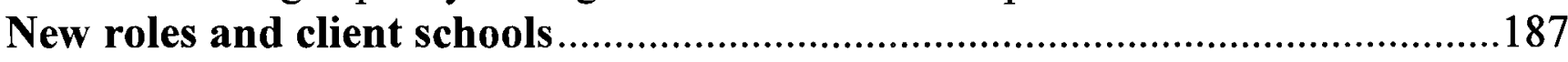

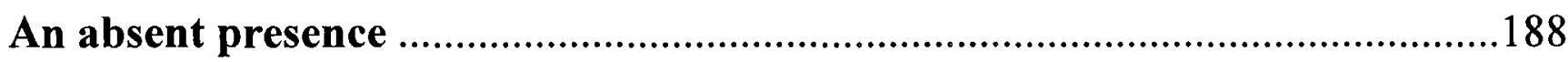

Long term effects of system leadership on schools .........................................190

Chapter Seven: Findings, conclusions and implications .................................193

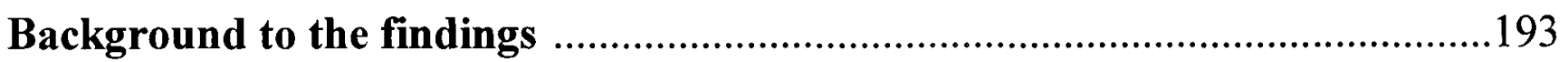

Key finding 1: The development of new internal and external roles for

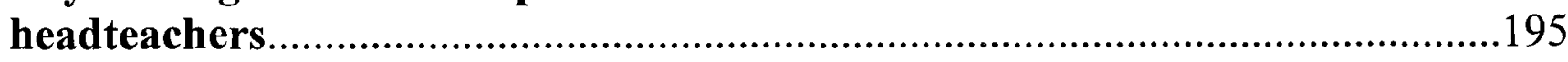

Headteachers' perceptions of change.....................................................196

Types of new roles.............................................. 197

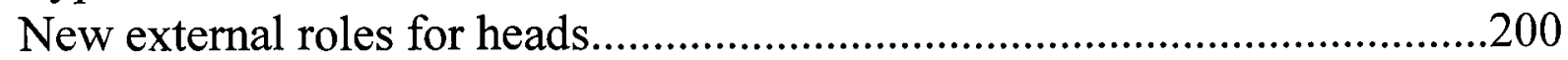

School Improvement Partner (SIP) ......................................................201

National Leaders of Education (NLE) ..................................................202

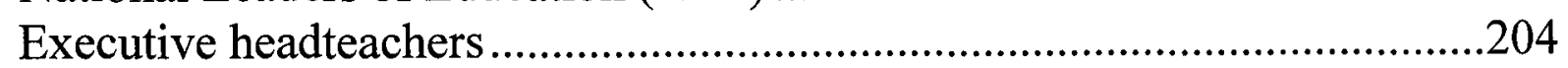

New internal roles for heads and ECM.................................................204

Issues arising in using system leadership to build capacity in the system....206

Importance of context and 'local responsiveness' makes work difficult

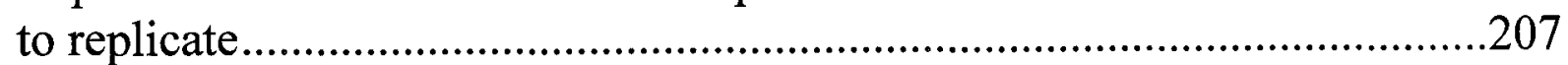

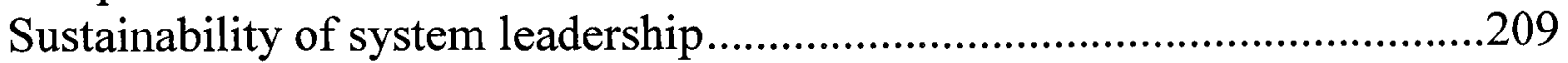

Recruitment, retention, training and future leaders ..................................210

System leadership as recruitment and retention........................................212

Government policy should generate a flexible and responsive system to deal

with change due to new roles...............................................................2213

Headteachers' motivation for new roles ................................................214

Financial implications of new roles .......................................................215

Key finding 2: There have been changes to the role of governors as a result of changes to the role of headteachers...................................................216

The governors internal and external role ...............................................216 
Governors and accountability

Key finding 3: New roles for headteachers have led to new and changing relationships with Local Authorities and other agencies ................................219

Changing relationships with Las.............................................................219

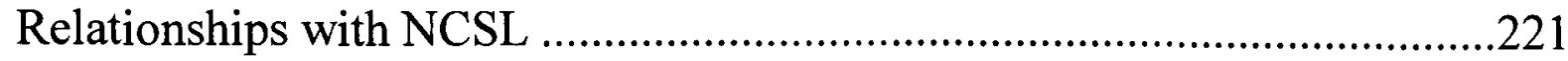

Key finding 4: There has been an increase in the strategic role

of the headteacher and the development of new roles for staff .......................221

Background to the finding .................................................................222

An emerging change of terminology .................................................223

New roles for teaching staff..................................................................223

New roles for teaching and administrative support staff .........................224

New roles for staff with ECM................................................................226

Building capacity, distributed leadership and delegated tasks...................227

The strategic and operational role of the headteacher ...............................230

The extent of headteachers involvement in monitoring and evaluation .......231

Managing absence...........................................................................232

Power and centrality of headteachers ...................................................233

Key finding 5: Leadership styles have been adapted to manage new roles and

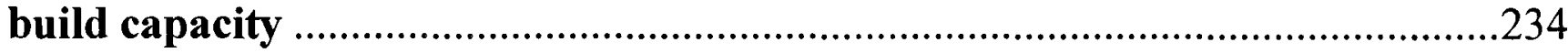

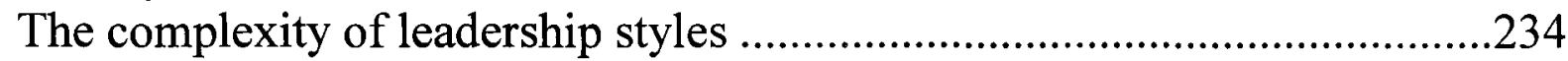

Leadership styles, system leadership and control ...................................236

Leadership Practice and system leadership............................................238

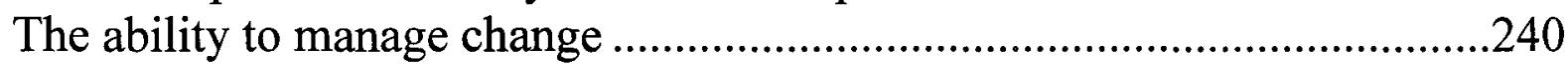

Courage to prioritise ........................................................................242

Key finding 6: The effects of accountability have impacted strongly on the actions and reactions of headteachers with consequences for the future of

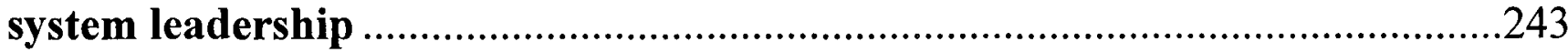

The importance of performance ........................................................243

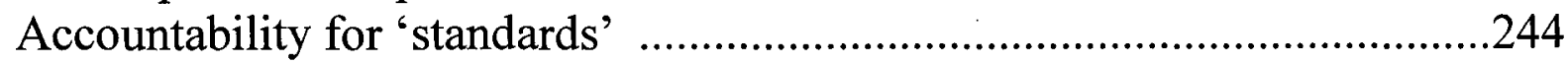

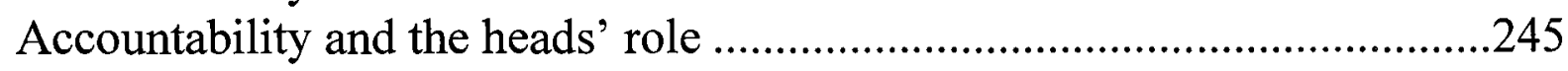

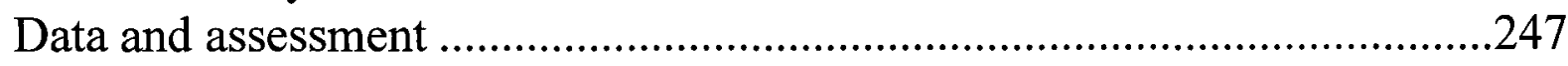

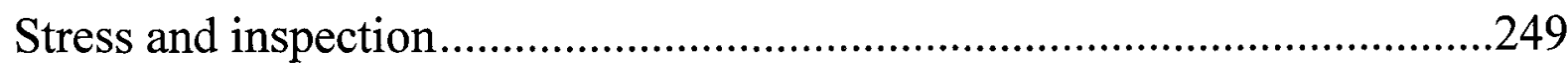

Workload and stress .......................................................................250

The drug of leadership ....................................................................251

Implications of my findings for the government on the impact of

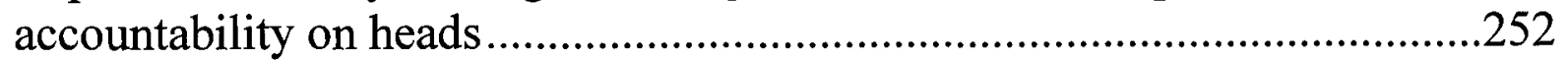

The effectiveness of 'The New Relationship...........................................253

Key finding 7: There is evidence of earned autonomy and heads implementing government policy with a mixed picture of compliance,

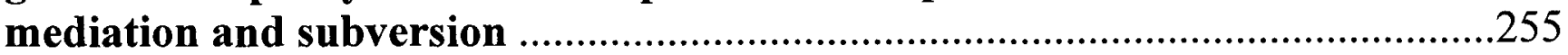

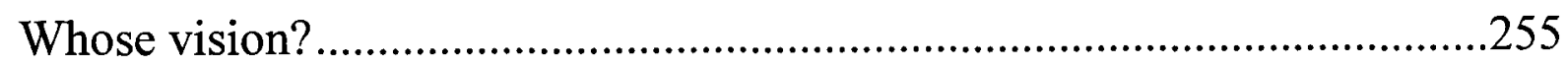

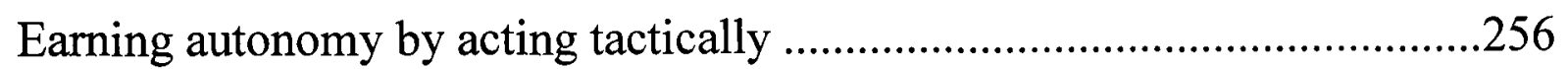

Compliance, Mediation and Resistance.................................................257

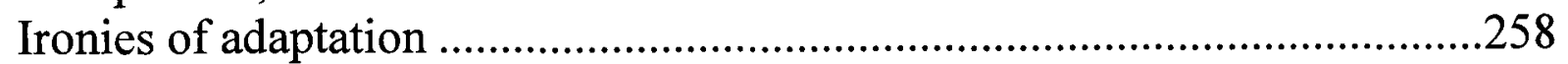

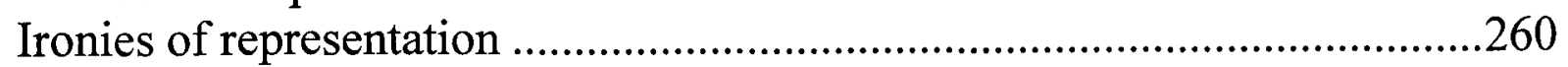

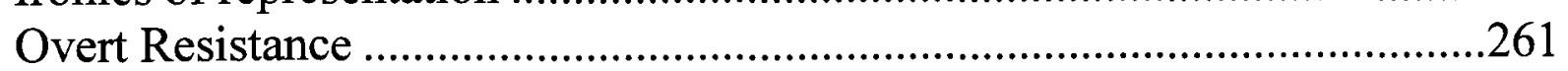

Simultaneous compliance and resistance ..............................................262

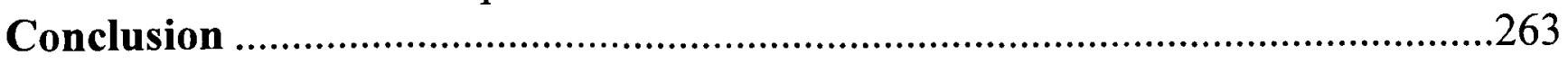

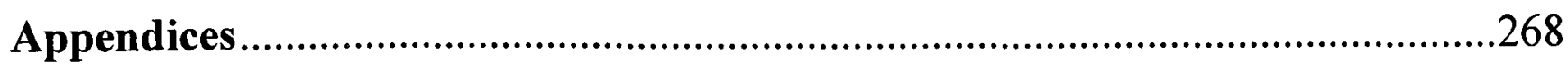

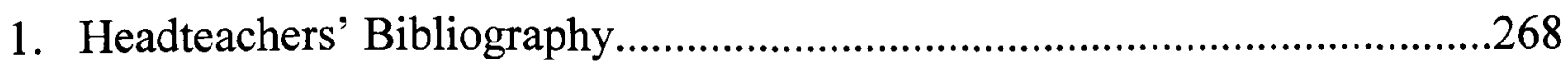

2. Interview list linked to roles $1-11$ end of round One ...............................270 
3. Interview list linked to roles $1-21$ end of round Two .............................271

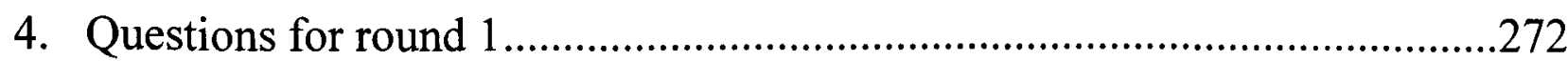

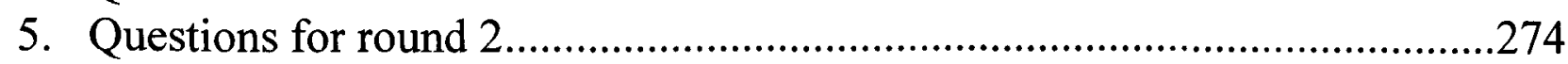

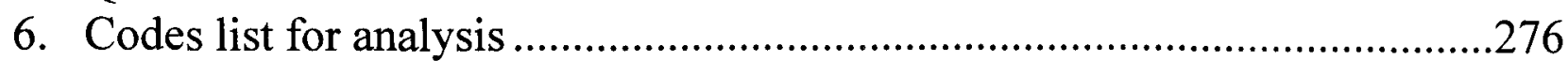

7. Example of coded analysis table ...........................................................279

8. Chart of main issues identified by interviewees ........................................28

9. Table of numbers of heads identifying each main issue ..............................282

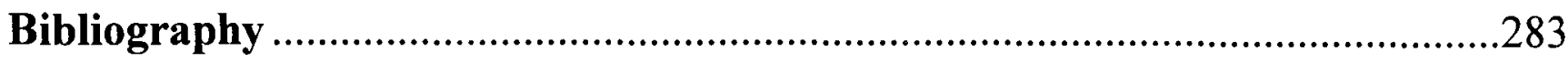




\section{CHAPTER ONE: The context, structure and significance of the research}

\section{The research context}

It was the contention of many writers in the early years of this century that the school system was inadequate to manage the current and future pressures placed upon it (Chapman, 2002; Bentley, 2003; Hargreaves, 2003; Mulford, 2003; Barber, 2002a, 2002b; Fullan, 2004, 2005; Caldwell, 2006a, 2006b; Hopkins, 2006). There were several linked issues causing problems which it was perceived the school system was unable to solve without change.

- The need to create different organisations to cut across multi agency boundaries (Bentley, 2003) and promote social justice and children's well being through collaborative working (Hargreaves, 2003; Hopkins, 2006).

- The need to raise 'standards' from a perceived 'plateau' (Barber, 2002a, 2005; Fullan, 2004, 2005) to ensure a suitable workforce for the future (Barber, 2001; Hargreaves, 2003; Hopkins, 2006).

- The management of succession to address both the retirement of the 'baby boomer' generation and the perceived lack of interest from staff in wishing to step up to leadership (Fullan, 2003; Gronn, 2003; Hargreaves, 2005a, 2005b; Hopkins, 2006; Caldwell, 2006a, 2006b). This formed part of the NCSL's (2006b) advice to the Secretary of State on succession planning.

In 1997 the country elected New Labour. The mantra 'Education, Education, Education' (Blair, 1996) was meant to herald a time where education was identified as a crucial area for development to provide for British success in the global market place. The link between education and the needs of a modern western capitalist economy were still being emphasised in the years after New Labour came to power. Mulford (2003) cited the OECD (2001) to reinforce his argument about the importance education played in the current political situation. Istance and Kobayashi (2003, p.12) writing for OECD/CERI argued that while education was being 'transformed' it needed to continue to be 'responsive' to be more able to meet the needs of the knowledge economy. The theme was similarly stated in November 2006 when OECD/CERI reported on the third phase of the Futures Thinking Programme 
about England. The imperative needs of the globalisation agenda were expressed in its introduction:

'As is with all western economies, there is both a need and a duty to respond quickly to the pressures and opportunities of globalisation and the knowledge economy.' (OECD/CERI 2006 n.p)

It has always been necessary to provide a workforce educated to the point where it can service the economy and is a reason state education developed so quickly from the 1870s as the government began to see a gap between England and other European countries. Despite this traditional requirement of education it is claimed that the skill level of every child now needs to be higher to compete in a knowledge economy (Barber, 2001; Davis, 2002; Mulford, 2003; Caldwell, 2006b). The perceived necessity to create higher skill levels in education has clear implications for the profession because catering for the requirements of a knowledge economy 'needs more people to be more creative and this will in itself require new approaches to teaching.' (Hargreaves, 2003, p.21). If we accept this argument, it has significant implications for the education system. Given the centrality of headship in English schools (Menter et al. 1995; Hall and Southworth, 1997; Bell, 1999; Day et al. 2000; Bell and Rowley, 2002; Southworth, 2008), together with the importance of effective school leadership in raising standards for children (Sammons et al. 1995; Southworth, 2008; Ofsted, 1999, 2003) then effective school leadership is crucial.

While heads are central to the leadership and management of the school the 'hero' head who undertakes a strong operational role is a form of leadership that is being discredited as unsustainable, as well as undesirable (; Harris, 2003; West-Burnham 2005, 2007; Spillane, 2006; PwC, 2007, Southworth, 2008). Calls for system redesign are partly predicated on recognition of the importance of the role of the headteacher in leading and delivering the reforms in schools and also that this role, is itself, in need of reform. The aims of government in changing the role of head to help create a fit for purpose education system have led to opportunities for headteachers to undertake new roles either offered or imposed on them. The preparation of these for school leaders formed one of the challenges for the NCSL in its Corporate Plan NCSL, 2005b, 2006a). Opportunities for system leadership such as NLEs and CLs and the leadership of extended schools have been made available since the calls for system reform and form part of the research base of NCSL (2005a, 2005c, 2005d, 2005e, 2007a). 


\section{The purpose of undertaking the research}

My decision to undertake this research in the summer of 2005 was the result of my reaction to a successful Ofsted inspection in December 2004. Following this inspection, the school had been graded as excellent in almost all areas and for the second time was placed by Ofsted on a list detailing successful schools.

For the six months following the inspection I began to feel increasingly that the requirements of government policy were having a stronger influence on the way in which our leadership team led the school than I had experienced previously. I was also aware from experience that new internal and external roles were being made available to headteachers who were perceived through validation at Ofsted to have a degree of earned autonomy and to be in a position to influence the system.

I decided that I wanted to find out more about the impact of government policy on primary headteachers in a similar position to mine, to see if there were any similarities or differences in the way in which their roles were changing.

\section{Framing the research}

I have framed the research with the early $21^{\text {st }}$ century call for system redesign (Hargreaves, 2003; Mulford, 2003; Fullan, 2005; Caldwell, 2006a, 2006b; Hopkins, 2005, 2006, 2007; Hopkins and Higham, 2007) and the granting of 'earned autonomy' (Morris, 2001) to headteachers. I have integrated the literature on the educational policy agenda for change, the role of the headteacher and leadership theory.

I have used this conceptual framework to guide me in choosing appropriate methods to discover evidence to answer my research questions:

\section{The research questions}

I used a qualitative approach to conducting this research because its use is appropriate to investigate my main area of enquiry (see Chapter 3). My aim was to discover to what extent there was a match of government educational policy for change with the issues identified by the headteachers as impacting on their role. This led to the formulation of the following research questions: 
1. What are the main issues which primary headteachers perceive as impacting on their role from September 2005 - February 2008 ?

2. How are the roles of these headteachers changing?

3. How do managing standards and new internal and external roles impact on leadership in school?

4. What are the characteristics and skills of these headteachers who are perceived to manage 21 st century school leadership effectively?

These research questions were driven by my aim to discover what issues impacted on headteachers who had achieved a degree of recognition and validation from Ofsted and how this affected their roles. The third question emerged during the course of the research following my initial analysis of interviews when I discovered the extent to which both new roles were emerging and the impact a performance culture had on them. I have used the experiences, understanding, opinions, beliefs and reflections of headteachers to discover their views and the actions they are taking to manage their changing roles. I have tracked how heads are working in new partnerships and pursuing distributed and collegiate leadership.

\section{Organisation of the thesis}

To address the research questions I have organised the thesis as follows:

Chapter One introduces the study, setting the context for the research and describing the approaches used.

Chapter Two is a review of the literature and provides a conceptual framework to underpin my interview questions:

- Section 1: A consideration of issues relating to the introduction of education policy. This section identifies that educational policy is introduced for reasons that are in addition to those which are purely educational and these limit, complicate or alter its effects. 
- Section 2: A review of the aims and focus of government educational policy for change from 1944-2001 and the role of the headteacher. The significance of this section lies in the identification of the issues relating to the introduction of policy which aims to colonise the discourse and control the actions of the profession.

- Section 3: In this section I have concentrated on the rationale behind the calls to redesign the education system from 2001.

- Section 4: This section analyses the impact of educational policy on the role of headteachers as identified through my interviews. I concentrate on Labour policy from 2001-2008 but include earlier policy if it is appropriate to support my argument. Particular emphasis is given in this examination as to how policy has changed the role of headteachers regarding impact of accountability, its impact on professionalism and the new models of leadership being promoted by government as a result of system redesign.

- Section 5: A review of the different theories of leadership and management which have been identified as appropriate for the current and future role of headteachers by the policy makers and which can be identified in my research.

Chapter Three describes and defines the methodology used in this study and includes:

- The research design including how the sample and methods of data collection were chosen.

- The impact of my role as an insider researcher

- An analysis of how the data was interpreted

Chapters four, five and six are an analysis of the data as follows:

- Chapter 4 identifies that new roles are being created for headteachers and the extent to which they are aware of these and the reasons behind the creation of 
opportunities and the extent to which they are being undertaken.

- Chapter 5 analyses the data which shows that these new roles are in some ways dependent for their creation on the success headteachers have in managing the process of accountability and maintaining their own and the schools' reputation for excellence or continuous improvement.

- Chapter 6 examines the evidence that in creating new roles for headteachers there is a consequential need to create, manage and sustain new roles for others through the building of capacity in either one or more schools.

Chapter Seven constructs findings from the data and the implications of these for the headteachers and the system. I have not attempted to make judgements as to the personal qualities of these individuals and have concentrated on their leadership behaviours and practices as a consequence of educational policy and the opportunities afforded by it.

\section{$\underline{\text { Presentation }}$}

The Chapters are bold and underlined. The sections are bold with sub-sections within these underlined. Italics are used for the quotations of the interviewees to differentiate clearly these quotations from the literature. Occasionally I have used italics for my own emphasis but this is clear from the text. I have used acronyms throughout the thesis and have included a glossary located after the abstract.

\section{The significance of the research}

Kogan (2002) argues that government depends on four kinds of knowledge to understand what is happening in the system, three of which are:

- knowledge of standards from Ofsted and testing

- advice from quangos and large numbers of government sponsored advisers

- a limited amount of findings from research. 
What is missing according to Kogan (2002) is a fourth kind of knowledge, that of practitioners, i.e. teachers and other professionals who deliver education. Other writers (Southworth, 1995b; Maguire et al. 2006) have also commented on the dearth of accounts of headship. While this has increased with the accounts of the research associate headteachers, and other leaders for NCSL, the problem is compounded by the variety of different contexts in which heads operate and in particular the speed at which the current field changes.

The change literature focuses on changes in terms of increased bureaucracy and the impact of constraining national curriculum innovations (Brehony, 2005) such as the Literacy and Numeracy strategies (DfEE, 1998c, 1998d). With some exceptions (Flintham, 2003; Earley and Weindling, 2006; Harris et al. 2006; Hopkins and Higham, 2007; Chapman et al. 2008) there is little research focusing on the changing structure of school leadership due to the headteachers themselves taking up a widening choice of opportunities and even less regarding what motivates them to do so.

There are few examples in the literature about the extended roles of heads based on researching them in the field. Hopkins and Higham (2007, p.150) comment that much of the enthusiasm for system leadership is based on 'aspiration' and early signs of individual success 'rather than systemic evidence.' Earley and Weindling (2006, p.40) wrote about consultant leadership but conceded that research regarding it was 'sparse' with a clear need for future research and Chapman et al. (2008) agreed the evidence was 'patchy' when writing about new patterns of school leadership. Harris et al. (2006, p.399) wrote about the case of one executive head in the secondary phase noting that 'first hand accounts of executive leadership are rare and therefore the insights are worth capturing'. They are even rarer in the primary context. There is even less evidence for system leadership. Recent exceptions are Hill and Matthews's (2008) report into the effectiveness of NLEs and Southworth (2008), who confirms that the knowledge of system leadership in primary schools is in its early stages.

The significance of my role as practising headteacher and 'system leader' as a contribution to the research 
I am able to deliver a degree of 'hot knowledge' (Rein, 1973 in Kogan, 2002) which is a significant contribution to the research. This is achieved as a combination of my awareness of the theoretical perspective of the national educational agenda through my extensive reading of the relevant literature and my role as a practising headteacher and system leader.

I have been a headteacher since 1996 working in other schools as a consultant since 2002. I was made a Primary Strategy Consultant Leader (PSCL) in 2003 and a CL in more than my own authority from 2005-2007 working on behalf of NCSL. I became a National Leader of Education (NLE) in 2007 and our school is a National Support School. In addition I have worked on national leadership programmes for the NCSL such as the Associate Headteacher's and Primary Leadership Programmes and lead a school with an attached children's centre.

During the course of my study I discovered that my career had developed in many ways similar to those of the headteachers I was investigating. While not using my experience as a case study I have the advantages (not withstanding the potential disadvantages of insider research, see Chapter 3) of an understanding of the field that first hand knowledge brings giving me a valuable and added perspective as a researcher to the issues surrounding new roles for headteachers. 
** * Communication Result Report (23. Sep. $200911: 38$ ) * * *

Date/Time: 23. Sep. $200911: 31$

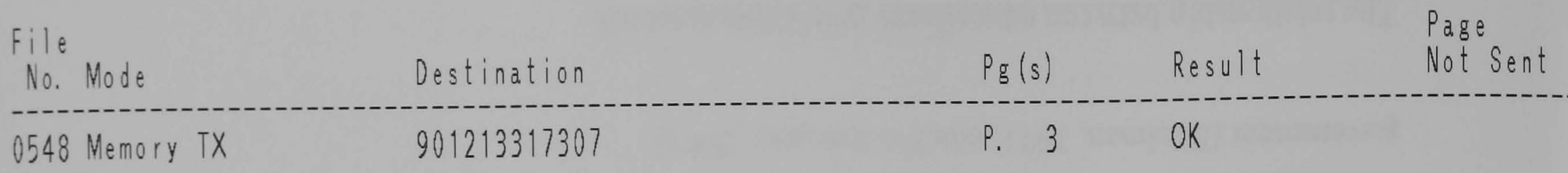

\section{TE Cherry Grehard Nrimary School and Childeren's Centre}

Cherry Orchard Road, Handsworth Wood, Birmingham B20 2LB Headieachers. Dr. Susan Robinson
Deputy Headseachers: Mirs. F. Wilson B.Ed (Hons) and Ms A Taylar B.Ed (Hons)

School Bussiness Manager. Mr Peter Haper CSBM
Childeren's Centre Manager: Mirs J Marthara B.Ed NPQICL

Felephone: $01121-5540862$

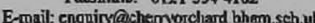

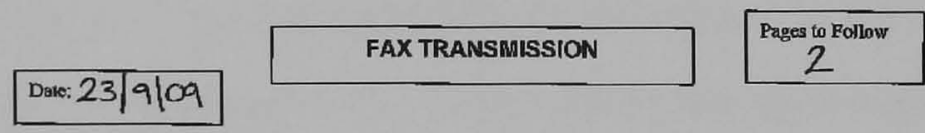

\begin{tabular}{|l|l|}
\hline $\begin{array}{l}\text { From: Alison Taglor } \\
\text { Fax: (0121) 5544162 }\end{array}$ & $\begin{array}{l}\text { To: Locise Wheatoroft } \\
\text { Fax: 0121 331 7307 }\end{array}$ \\
\hline
\end{tabular}

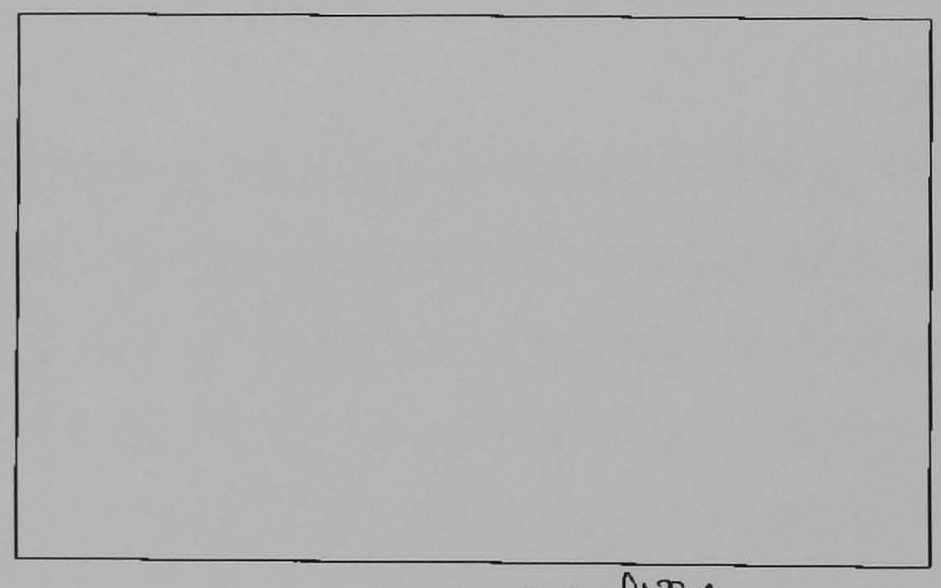

Signed:_llifioger.

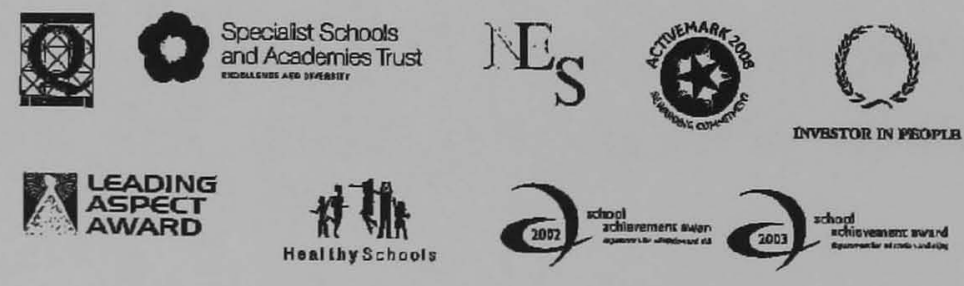




\section{CHAPTER TWO: The literature review}

\section{Section 1}

\section{Introduction}

To understand the changes which shape the current role of the primary headteacher it is necessary to understand the educational policy context in which headteachers operate. While conscious that this is not a historical study, it is important to note that educational policy doesn't start in a vacuum as 'officials always have to start with existing legislation' (Wallace, 1981, p.290). Therefore it is not possible to make sense of the ideology behind the issues impacting on current government policy without an understanding of the education system and national policy context which existed before, and the tensions, dilemmas and change to which current national policy is responding (Jones, 2003).

While this study is concerned with the aims of educational policy and the impact it has had on the role of the primary headteacher, it is necessary to consider that the issues associated with the introduction of educational policy complicates its design and implementation.

\section{Issues relating to the introduction of educational policy}

\section{$\underline{\text { Political influences }}$}

The government needs to be re-elected. Therefore it has to please the voting public and in addition is 'under intense pressure from competing interests' that means there is a strong political dimension to reforms which doesn't necessarily make them desirable educationally (Levin, 2003a, p.37). Managing the relationship between those policies which are primarily to gain an advantage with the electorate and those which genuinely seek to find solutions to educational issues is a problem for the government (Edelman, 1971, cited in Brehony, 2005).

The relationship between educational policy and research. 
A feature of New Labour policy towards primary schools is that the policies are grounded in research or 'what works' (Brehony, 2005). However as he continues, this ignores the 'asymmetries of power' and its 'operation' and it rests on the belief that what works can be identified precisely (p.41). It also ignores the possibility of interpreting the research in the ways most suited to the needs of the policy, ignoring the findings altogether, or finding ways of criticising those conclusions which don't suit. An example of how grounded research solutions have been ignored is illustrated by Tymms and Coe (2003) whose study showed how David Blunkett criticised the research on homework when it didn't offer the evidence he preferred.

\section{International policy}

Some policy thrusts are international (Bottery, 2007b). For example, increased 'emphasis on standards, accountability and testing has been a feature of reforms' for governments in many countries during the last twenty years (Levin, 1998, p.133; Barnett, 2001; Green 1999 in Glatter, 2003) and depict a 'world wide trend' (Hoyle and Wallace, 2007, p.9) attractive to those of varying ideologies (Whitty et al.1998). To transfer policies out of context can potentially cause difficulties in that the context in which the policies were originally formed may not be suitable for the purpose for which they are now intended (Levin, 2003a, Levin, 2003b in Bottery, 2007a). An example of how context changes the effects of policy is how this country uses Ofsted as part of the accountability process. While other countries have had similar reforms they haven't had a similar form of accountability (Levin, 2006).

\section{The influence of 'outside' school agencies}

Educational policy texts are 'official texts which operate to influence public perception of a policy agenda' and include Acts of Parliament and texts generated from them and those provided by influential agencies such as Ofsted (Scott, 2000, p.18). Brehony (2005) believes that the influence of Ofsted in helping to formulate policy shouldn't be underestimated. Wyse (2003 in Brehony, 2005) argues that elements of the literacy strategy are a mixture of Ofsted evidence and school effectiveness investigation. In addition must be added the influence of commissioned research both from and on behalf of agencies such as NCSL and the professional associations. Texts such as the National Strategies aim to give the reader the 
impression that they are the result of 'the careful sifting of evidence' and not 'political rhetoric' (Scott, 2000, p.18) and therefore have more credibility with the teaching profession.

\section{Internal inconsistency within and between policies}

Powell and Edwards (2005) suggest that overt meanings given to a policy may not be the same as the consequences or outcomes of that policy, therefore policies can still be at variance with one another due to unforeseen consequences. These can occur due to the lack of 'foresight' of the policy-makers as they misunderstand the consequences of the implementation of their policy (Scott, 2000, p.22) or suffer from tensions between policies which are working to competing agendas. Hopkins and Levin (2000, p.6) argue that there needs to be 'joined up thinking' regarding policies which are informed 'from the same values base' (Hopkins and Levin 2000, p.28). Examples of non aligned policies are those regarding standards and inclusion and competition and collaboration. Another issue regarding inconsistency within policies is that 'policy text is never complete and may be multi-authored' which can lead to 'fragmentation' due to 'inconsistencies' and 'unfinished arguments.' (Scott, 2000, p.20).

\section{The effects of the policy change process}

Clarke and Newman (1997) point out that the perception by those who wished to change the public sector system in the 1980 s was to see it as reactionary, unresponsive and undesirable and for there to be a visionary, idyllic future. However this has created problems because the design and intention of policy is not necessarily what actually happens. The trajectory of change is difficult to predict (Clarke and Newman, 1997). Change is not undifferentiated and it is not a uniform and linear process (Clarke and Newman, 1997; Chapman, 2002) and this too complicates the successful introduction and implementation of policy.

March and Olsen $(1989$, p.65) describe how difficult it is to bring about change which is controlled and intentional. 'It is easier to produce change through shock than it is to control what new combinations of institutions and practices will evolve from the shock.' Dispersal of power to managers through empowering them just exacerbates the unpredictable nature of change through delivery. 
Fundamental to the success of change is the impact of those who shape it. Policies can be manipulated by those implementing them changing them or extending them beyond the original intention (Scott, 2000). Bowe et al. (1992 p.120 in Hatcher and Troyna 1994, p.162) believes that the power of the state to influence is 'strongly circumscribed by the contextual features of organisations'. This is disputed by Hatcher and Troyna (1994, p.162) who while acknowledging the 'processes of institutional reinterpretation' believe that the power of the state to control implementation of policy to practice is greater than the weight given to it by Bowe et al. (1992). I want to discover in my research to what extent have the headteachers got the opportunity to manage the policy and develop it to suit their contexts and to what extent are they driven by statute or influence to comply?

\section{$\underline{\text { Section } 2}$}

\section{The historical context of the role of the headteacher}

Historically the role of the headteacher was that of the 'headmaster tradition' of school leadership (Grace, 1995, p.11) and its culture was the expression of the middle and upper class tradition from where most headteachers were drawn and the values which they exemplified. It was a role which was not 'deflected by external accountability' except for that expected of reporting to parents on speech day (Weindling, 1992, p.63) or of being a 'servant of the managers' (Grace, 1995, p.13). This changed due to the social crises of the 1920s and headteachers, still predominantly male, became more involved with social education and pedagogy following the rise of the elementary school (Grace, 1995).

\section{4-1976: A professional partnership: The government, LEAs and the role of the headteacher.}

\section{Partnership and consensus}

There is a degree of popular belief in the existence of the period following the Education Act (DE, 1944) until the 1970s as being a 'golden age' (Hobsbawn, 1994) 
where headteachers traditionally led in 'partnership' with the LEAs and government (Chitty, 2002).

Most studies reporting on the role of the headteacher before 1988 are small scale as no major large scale investigations had been commissioned (Hall and Southworth, 1997). Building on the findings of Coulson (1976) and echoing the findings of Nias et al. (1989), Hall and Southworth (1997, p.153) and Southworth (2008) define heads before the ERA (1988) as being 'pivotal, proprietal and paternalistic'. The main role of headteachers was defined by Coulson (1976) and Hughes (1988) as that of lead professional rather than chief executive although Ribbins (1993, p.35 in Bell and Rowley, 2002, p.198) argues that heads always had 'a set of administrative tasks' associated with a chief executive role.

The traditional role of the head involved setting the direction of the school by influencing the organisation of the curriculum, teaching pedagogy and monitoring children's progress (Mortimore et al. 1988; Grace, 1995) and in addition they were often a leading exemplar (Davies, 1987). The curriculum was determined by the schools and the headteachers with some influence but not direction by the LEAs (Lowe, 2002) and influential educationalists (Plowden, 1967). Autonomy was however located within fairly narrowly defined parameters in comparison with the role of current headteachers.

Headteachers were central to the leadership of schools and the key players in the power relations (Coulson, 1976; Hughes, 1988; Nias et al. 1989; Hall and Southworth, 1997). Other managers in school 'operated in the shadow of the head and largely with his/her permission.' (Southworth, 2008, p.414). The accountability of headteachers was largely defined in terms of that to parents and the LEA, and they were largely unaffected by direct accountability to government (Grace, 1995; Crook, 2002; Lawton, 2004). Autonomy in the head's role and profession as a whole may have been partly a result of a 'laissez faire' attitude from government towards the curriculum (Chitty, 2002) and its planning 'except that required to enable some schools to respond to the demands of external assessment' (Bell, 1999, p.202).

To what extent this period actually represented a 'partnership' (Chitty, 2002) between the government, LEAs and schools is debatable. One view is that the 'whole system 
was underpinned by a strong social democratic ethic shared by the major political parties' (Bell, 1999, p.202). A contrasting view is that the use of the term consensus to describe the $1940 \mathrm{~s}-1960$ s may lie more in the fact that neither of the main parties could really decide what they wanted (Lawton, 1992). Chitty (2002) argues that because the number of 'powerful interest groups' at this time were few in number this afforded a greater opportunity for consensus to reign and in addition it reduced the breadth and diversity of consultation (Batteson, 1999).

\section{Towards more state control and the 'Moment of 1976' (Batteson, 1997)}

Any 'partnership' which still existed (Chitty, 2002) can be seen to have faded away in the 1970s (Jones, 2003) with a loss of the power and influence of the LEAs (Crook, 2002; Lowe, 2002) and a growing trend towards the demands of parents (Simon, 1991; Lawton, 1992, Bell, 1999; Chitty, 2002). There was also a growing backlash against the perceived failure of progressive education (Cox and Dyson, 1969a, 1969b; Kogan, 2002; Philips and Harper-Jones, 2002). Batteson (1997) argues that to some extent these concerns regarding the state of education at the time were justified but this is contested by Chitty (2004). The origins of the separation of the 'partnership' were most evident during the economic recession of the 1970s (Batteson, 1999; Bell, 1999; Tomlinson, 2001; Jones, 2003; Chitty, 2004). Tomlinson (2001) argues that the profession was at this time being made a 'scapegoat' for an economic problem not of their making:

Important for my research is that Kogan (2002) argues reasons for change include the debate about the rights of the teaching profession to make decisions about teaching and learning. The echoes of this are still being felt in the early 21 st century with the Labour government's desire to micro manage the education system with the National Strategies (Phillips and Harper-Jones 2002). Clarke and Newman (1997) point to an active hostility to the professional who was being perceived to act out of self interest and having an unwarranted power over the consumer and 'insulated' from 'real world' pressures by not having to survive in the market.

A build up of these concerns led to a turning point in educational policy making with a speech by the then Prime Minister James Callaghan at Ruskin College Oxford in 1976 regarded as 'one of the defining moments in the UK's educational policy 
making' (Bell, 1999, p.205), which laid out the framework for debate for the next 25 years (Phillips and Harper-Jones, 2002). Callaghan's speech launched the 'Great Debate' in education which has been described as neither a debate nor very great (Lawton, 1980, in Bell, 1999). However of importance to my research is that questions were being asked whether enough was being done 'at all levels' regarding standards (Chitty, 2002). Callaghan raised this issue in his speech when he suggested that the education establishment had not yet realised that higher standards were needed in a complex world. Later calls for educating for a knowledge economy echo this view (Blair, 1996).

Callaghan's speech 'is usually taken to have signalled the beginning of the accountability movement in this country.' (Hoyle and Wallace, 2007, p.9). There followed a 'discourse of derision' (Ball, 1990) against the profession resulting in a 'shifting the blame' from the state to individual school leadership (Whitty, 2002, p. 13) which continues today. Legislation which followed the election of the Conservatives needs to be viewed in the context of this turning point for the profession (Jones, 2003).

\section{Educational policy 1979-1997 and its impact on the role of the headteacher}

The role of the headteacher: changing the balance of power

From the 1980s education and the role of the headteacher became framed within a changing political ideology. Schools with education systems similar to that in England were increasingly viewed by government and industry as 'unresponsive, bureaucratic and monopolistic' (Lee, 1993 in Leithwood 2001, p.221) because they were not 'accountable to those whom they serve' (Walsh, 1994, p.63). Calls for reform towards a 'market driven service fuelled by purchasers and customers', came prominently from the business sector (Murgatroyd and Morgan, 1992, p.1 in Jones 1999b, p.441). This was 'based on the notion that the application of market principles can improve their quality' (Walsh, 1994, p.69). A revolution in terms of considering the needs of the consumer was necessary due to a growing belief that schools could not provide the necessary economic competitiveness (Peters, 1987, Barnett, 2001). This would be accomplished by transforming schools from "domestic" to "wild" organizations, who 
have to 'forage for their fodder'(Carlson, 1965 no ref, in Leithwood et al. 1999a, p.20) and so only those fit enough would survive in the market.

The shift of government attitude to education policy had an increasingly controlling influence on the actions of headteachers (Batteson, 1997; Bell, 1999; Chitty, 2004; Whitty, 2008) as it moved towards a system which became more centralised and regulated and based less on 'trust and cooperation' and more on 'accountability and sanctions' (Chitty, 2004).

The reforms designed to make schools more accountable for their performance needed to be set in a climate of more centralised control of the profession which may otherwise seek to subvert them (Graham, 1993, in Trowler 1998; Poulson, 1998). As professional accountability was becoming discredited and seen to be ineffective (Hoyle and Wallace, 2007) it was deemed necessary to strengthen accountability to make schools 'become more responsive' to the changing expectations and demands put upon them (Barnett, 2001, p.2). The level of accountability increased until the idea of professionals being held to account (Leithwood et al. 1999a, Leithwood, 2001; Ranson, 2003; Hoyle and Wallace, 2007) became the dominant mechanism of accountability.

Legislation to accomplish this began with The Education Act (DES, 1980) which empowered governors and involved them more directly in schools, causing concerns that governors might be trying to 'manage schools rather than 'govern' them'(Mortimore and Mortimore 1991, p.vii). The White Paper Better Schools (DES, 1985a) was not only a discussion of the importance of the role of the headteacher in managing their schools but also of the contribution which appraisal of the teaching force could make to this. This is a forerunner to the workforce reform legislation of the 21st century. These aims were further developed in Quality in Schools: Education and Appraisal (DES, 1985b). One of the strongest measures of control over the profession came in the establishment of the Teachers Pay and Conditions Act (DES, 1987) which abolished the negotiating procedures set up in 1965. A reduction of individual teachers' autonomy was accompanied by an increase in the role of headteachers monitoring their schools (Bell, 1999). In the Teachers Pay and Conditions Act (DES, 1987), heads were given responsibility for formulating the aims of their schools and monitoring and evaluating the quality and standards of teaching 
and learning. It is an important development because such monitoring has become increasingly apparent and dominates the current role of headteachers.

\section{The Education Reform Act (1988) and the Education (Schools) Act (1992)}

From its inception the ERA (DES, 1988) dominated education policy and practice (Chitty, 1989, 2002, 2004; Lawton, 1989, 1992, 2004; Ball, 1990; Simon, 1991; Paterson, 2003). The significance of the ERA for headteachers was that it heralded a period when the external policy agenda impinged on their role to a much greater extent than it had done previously (Grace, 1995; Webb and Vulliamy, 1996b; Hall and Southworth, 1997; Webb, 2005).

The ERA introduced the prescriptive national curriculum and made it easier to provide for a framework of accountability based on a national system of testing and the production of league tables (Hatcher and Troyna,1994; Jones, 2003) and ultimately through the market forces of parental choice high achieving schools succeed and low achieving fail and close (Cox, 1988; Ranson, 2003; Jones, 2003). However 'failing schools' didn't close due to the operation of market forces because the market will only work as a mechanism if parents make rational decisions or access sufficient information to make the decision (Croninger and Lee, 1995 in Leithwood et al. 1999a). In addition parents can only exercise choice of where to send their child to school if there are sufficient places available in that school. Facilitating parental choice as a means of controlling the system is an enduring preoccupation for government as evidenced by the School Report Card Consultation (2008) following the Children's Plan (2007).

The ERA gave further direction regarding the delegation of school budgets to individual governing bodies which transferred control of much of government funding from the LEAs directly to schools. The increase in deregulation but with centralised control is seen by many writers (Lawton, 1992; Tomlinson, 2001; Jones, 2003) as one of the major tensions in the ERA. There was a perceived need to maintain control over the system which might otherwise be lost with too much delegation and deregulation and so the outcomes of education had to be regulated through increased accountability and bureaucracy (Troman, 1996). 
A mechanism was needed so that those who are successful in the system and who 'get results' (Pollitt 1993, p.53) could be more easily identified. The (School Teacher Appraisal) Regulations (1991) helped to develop the embryonic system of control but it was The Education (Schools) Act (DfE, 1992b) which set up Ofsted and strengthened the accountability of the profession. Its role was monitoring the effectiveness of individual school performances against the requirements of the national policy agenda. As a framework for accountability it was considered ineffective by Eric Bolton the then Senior Chief Inspector. He argued that it had 'serious shortcomings' and was too 'prescriptive', 'inflexible' and unable to capture the beginning of 'grass roots' problems or developments in schools and highlighted the independence of the newly created Chief Inspector of Schools (HMCI) as a potential difficulty (Bolton,1998, p.53). The independence of Ofsted as opposed to the traditional system of HMI was the intention of the government as HMI were seen to be part of the:

'liberal educational conspiracy which had presided over long-term declining standards'(Pierson, 1998, p.138).

\section{The reduction in the power and influence of the LEAs}

LEAs are important to my research because of how their role is currently changing and impacting on that of headteachers. There was an erosion of the power of the LEAs during the Conservative terms of office because they were seen to be a force of opposition to the government and its existence was contrary to its market policies of power to the consumer (Chitty, 2002). This led to a move from a partnership between headteachers and LEAs and a transfer of power. However it was not a simple transfer from producer to consumer but led to a mixture of traditional roles of old public administration with those of new managerialism as a result of a 'dispersal' of power from the LEAs 'directly to schools and quangos' such as Ofsted and TTA in the late 1980s and early 1990s (Radnor et al. 1997, p.206) echoing the views of Clarke and Newman (1997); Tomlinson (2001), Jones (2003) and Southworth (2008).

There were changes to admission criteria in favour of parents, increased powers for governing bodies and the assisted places scheme, (Education Act, DES, 1980). The Education Act (1986) required LEAs to submit plans for inset for teachers for approval with national priority areas having been laid down by government. Local 
Management of Schools as part of the ERA transferred control of much of government funding from the LEAs directly to schools. This served to weaken the LEAs and at the same time strengthen the position of schools in the market place (Trowler, 1998; Jones, 2003; Whitty, 2002). LEAs' relationship with schools was further eroded with The White Paper Choice and Diversity: A New Framework for Schools (DfE 1992a) which allowed schools to apply for grant-maintained status. LEAs no longer had the role of inspection of maintained schools which was transferred to Ofsted (DfE 1992b). The DfEE (1996, p.48) laid out quite clearly the government's attitude to partnership with LEAs claiming that it wasn't the 'task of LEAs to control or run schools'. The changed relationship required heads to 'reconstruct their relationships with LEAs and governing bodies thus changing the balance of power (Radnor et al. 1997).

\section{Tensions in the role of headteacher}

The role of headteacher was 'pivotal' during the last twenty year period of reform and through it the government drove its agenda for reform (Hall and Southworth, 1997; Southworth, 2008). This was acknowledged by government agencies with the then HMCI in his Annual Report 1994/1995 viewing the leadership of the headteacher as 'the critical factor in raising standards of pupil achievement' (Ofsted, 1996, p.10).

Bell (1999, p.211) sees the period as a time when heads were both 'freer than were their predecessors and more constrained'. This is because the devolvement of resources gave heads an opportunity to direct funding as best suited the needs of their school but they were simultaneously constrained by the creation of the statutory national curriculum and Ofsted.

Other tensions were that on the one hand heads had greater independence from the local authority but at the same time were more accountable to governors for their performance and that of their schools. However the relationship headteachers had with governors was crucial to how their accountability to them impacted on headteachers' stress (Levacic, 1995). The accountability of heads is more complicated than it would be in a wholly business environment because heads are accountable to the community as members of it and so have a form of democratic accountability as well as the accountability through the market aspects of their role to the governing 
body and to a lesser and varied extent to the LEA. This is further complicated by the fact that the governors are at once parents and part of market accountability and the community. Heads had to reconcile being accountable to the needs of their community while being subject to market forces (Radnor et al. 1997).

Fulfilling the requirements of the ERA and subsequent legislation was daunting and intensified the work of the headteacher (Mortimore and Mortimore, 1991).The work became more diverse especially for the small school or teaching head (Dunning, 1993) with decisions based on more than teaching and learning alone (Boyle and Woods, 1996).

In the early stages of reform there was some degree of difference of opinion as to how welcomed by headteachers were the continuing moves towards managerialism (Hellawell, 1991). However either way following the ERA the chief executive role became an increasing part of the head's role (Hellawell, 1991; Grace, 1995; Boyle and Woods, 1996; Bell and Rowley, 2002).

The chief executive role was not expected to be at the expense of the head's role as lead professional and curriculum leader which were still seen as being paramount by government policy (Webb and Vulliamy, 1996b; Webb, 2005). Alexander et al. (1992, p.48) argue that 'all headteachers should teach' because in doing so they 'lead by example' and so 'exemplify their vision of what the school might become'. Boyle and Woods (1996) citing Jones and Hayes (1991) and McHugh and McMullan (1995) argued that heads found the pressures acute when faced with dealing with legislation and having to teach a class. Ribbins (1993) disagrees with the need to give more time to the administrative aspect of their role believing that heads were now more used to the administrative demands of the reforms and were more able to concentrate on curricular matters. His view however doesn't take into consideration the work intensification caused by the need for headteachers to fulfil the requirements of the managerial aspects of their role such as financial concerns and the demands of the pace of change and reform.

However younger teachers who hadn't known a managerial system may not be as affected by the constraints of accountability or changing professionalism as those nearing the end of their careers (Gronn, 2003). The concerns voiced by some heads 
over work intensification were not universal. Boyle and Woods (1996) and Bell and Rowley (2002) both suggest that length of service may be a factor in the impact of work intensification on headteachers' sense of professionalism with those newer to headship who had not known an alternative to headship under a managerial system seeming to enjoy more the challenges of the job. I don't think they necessarily enjoy the challenges but they have possibly internalised the need for them.

The degree of stress in managing the tension between their lead professional and chief executive role worsened in the 1990s as heads became more accountable to parents and the government. Southworth (2008) argues that as the pressure to undertake both roles intensified their work, heads increasingly chose one role at the relative expense of the other. However in my experience as a head since 1996, I think the extent to which heads could choose was determined by their need to respond to mandated government policy and the choice was more prioritising within both aspects of the job. My view concurs with the findings of Jones (1999a, 1999b) and Webb (2005) who identified that to fulfil these demands of work intensification heads were working longer hours and in holidays and had to make choices by prioritising the demands of the job.

Hall and Southworth (1997) argued that although heads were victims of work intensification and that some of their work was different from that of their predecessors, they still remained as pivotal and central figures in their schools Therefore they conclude that there doesn't seem to be 'a different wholesale change of approach to headship' (Hall and Southworth, 1997 p.159). The role of head was being identified by others in the late 1990s as 'pivotal' and 'omnipresent' (Boyle and Woods, 1996, p.554) with the government promoting this model where heads were seen as 'central' to reform (Alexander et al. 1992, p.54) and Ofsted, (1998) but not all commentators felt it to be desirable.

Lloyd (1985, in Hall and Southworth, 1997) identified that there were calls for a move away from the centrality of the head. Boyle and Woods (1996, p.565), building on an argument by Pollard et al. (1994), highlight that heads in their study use a 'top down' approach to management as part of a 'headteacher survival strategy'. Bell (1999, p.211) highlights the unfairness of the 'burden' of 'individual rather than collective responsibility' of the headteacher. In trying to alleviate stress and work intensification 
by finding a balance between the two roles, Webb and Vulliamy (1996b), found in their study of headteachers' roles that they were increasingly delegating curriculum matters to others such as senior curriculum managers and deputy headteachers, and possibly becoming 'deskilled' in the process (Bell and Rowley, 2002). However in practice in the 1990s the move away from the centrality of the headteacher may be mainly rhetorical as Hall and Southworth (1997, p.153) found that heads felt they needed to 'soften their dominance' whereas in reality, the power relations in school stayed the same.

\section{The rise of the entrepreneurial headteacher}

Parents will choose to send their children to particular schools for many pragmatic reasons such as local convenience. However following the reforms offering more parental choice in schooling, it became increasingly important for heads to be successful in marketing their schools as potentially (such as in situations where there were falling roles) they could be working in competition for places due to the formula funded nature of school finances. Those leaders who were seen as successful in market conditions were more likely to be 'entrepreneurial' (Menter et al. 1997; Leithwood, 2001, Groundwater and Sachs, 2002). Not all commentators see this entrepreneurialism as desirable and Grace (1995) views changes in headship as a response to the needs of the government's agenda to be a move from a moral approach to a market driven entrepreneurship. Heads' responses may not have been polarised as either morally or entrepreneurially driven as Grace (1995) argued but there was nevertheless a dilemma for heads being expected to adopt at least to some extent an entrepreneurial role as part of managerialism which required action through legislation in various White Papers and Education Acts. This dilemma has been expressed as:

'... the extent to which headteachers must choose to be or not to be entrepreneurs; and the extent to which a positive choice inevitably compromises their identity and activity as leading professionals, as well as their ability to be critical of the system of which they are a part' (Hall and Southworth 1997, p.151).

It must also be taken into consideration that school leaders facing the same conditions might through virtue of their own philosophies or beliefs act differently in the same competitive conditions (Leithwood, 2001). So the response each headteacher has to 
working effectively in a specific context may differ according to their response as individuals (Leithwood et al. 2006a) There is an emergence in the 1990s of headteachers who succeed as managers but retain their professional core values. Jones (1999a, p.334) argues that this evidence, rather than supporting the view of the deprofessionalisation of the headteacher, instead 'suggests a more subtle and complex process of adaptation.'

\section{New Labour 1997-2001}

\section{A new partnership with the profession or more of the same?}

New Labour made its focus clear from the beginning with its manifesto proclaiming that 'Education will be our number one priority...' (The Labour Party, 1997, p.5). The New Labour victory at the General Election in 1997 was greeted in many quarters 'with hope, optimism and expectancy' (Chitty, 2004, p.201) that there would be a more consensual and harmonious relationship between central government and the teaching profession (Halpin, 1997). This belief can be contrasted with findings from Rutherford's (2004, p.287) study which showed that headteachers were disappointed subsequently that their hope for a 'sympathetic and knowledgeable' response to their needs had not been realised. The first term of the Labour government instead presided over another era of rapid change in education which saw a 'real enthusiasm for intervention in the detail of educational processes' (Whitty, 2006, p.6) through a 'newly activist and interventionist' Department of Education (Husbands, 2001, p.9). Jones (1999b, p.441) saw 'little prospect of a moratorium on reforms,' and that the 'challenges for heads will continue unabated'. Given therefore the importance of headship to the delivery of the reforms (Ofsted 1998, 1999) it prompted another shift in the role of headteacher.

Many writers consider that New Labour's policy focus was similar to that of the Conservatives when they were in office (Demaine, 1999; Ball, 1999; Docking, 2000; Phillips, 2001; Jones, 2003; Chitty, 2004; Elkins and Elliott, 2004; Walford, 2005) leading to the observation that Labour was merely 'the Conservatives dressed up in New Labour's clothes.' (Docking, 2000, p.32). Tony Blair was happy for this comparison: 
'Some things the Conservatives got right. We will not change them. It is where they got things wrong that we will make change' (Labour Manifesto, 1997, p.3).

Bottery (2007a, p.154) argues that there are continuities and discontinuities between Labour and its Conservative predecessors 'as New Labour has attempted to balance the very different demands' of globalisation, the responsibility of the individual and greater structural flexibility. I wish to concentrate at this point on the ideology behind one of the main differences because of the impact the concept of 'social redress' (Bottery, 2007a) within policy has on my research in terms of creating new roles for headteachers.

\section{The prospect of a 'Third Way'}

Giddens $(1998,2000)$ the 'guru' of Labour ideology sees in the third way a 'mixed economy'. It rejects an unfettered neo liberal market and sees the third way as a response to a changing world. The aim is articulated in legislation where it is argued that to succeed in a knowledge economy it is necessary to 'unlock the potential of every young person.' (DfEE, 1997a, p.3) and to provide 'a healthy and just democracy [and] a productive economy' (DfEE and QCA, 1999, p.10).

The third way is a challenge, 'dilemma' (Tomlinson, 2001) or 'paradox' (Wright, 2001) for New Labour due to the need to reconcile increased competitiveness with social justice (Jones, 1996). There are mixed views regarding the government's success and motives. Brehony and Deem (2003) and Brehony (2005) argue that the third way is a continuation of Conservative policy with the inclusion of the more traditional social democratic policies of the old Labour party, a definition which Phillips (2001, p.22) refers to as 'flattering'. Others have described the concern with social inclusion as a 'detour' (Elkins and Elliott, 2004, p.17) or a 'crusade to overcome social disadvantage and improve economic performance' (Bell, 1999, p.212). It should be noted that Levitas (1998, cited in Jones, 2003), stresses that social inclusion is not the same as social equality.

Tomlinson (2001) and Phillips (2001) building on the argument of Daugherty et al. (2000), argue there were not only fiscal restraints to policies but that Labour had 
taken a more pragmatic approach to pleasing the electorate the reason for which lies in the electoral disasters suffered by the party while out of office.

A commitment to social justice can be identified in Labour policies such as ensuring the inclusion of children with special needs in mainstream education, and initiatives such as Sure Start, Excellence in Cities, Education Action Zones and possibly in the various schemes to support children in before and after school clubs. The aim was also to encourage innovation from the grass roots in challenging areas with the introduction of the Action Zones which was an idea from the then principal adviser to the government Michael Barber. These were to be part of the public private initiatives fostered by New Labour and seen as such are a way they differed from other attempts by Labour to reduce poverty by educational policy such as the Education Priority Areas in the 1960s (Paterson, 2003).

Most notably for the role of headteachers, any initiatives which have been considered to bring social redress have been:

'accompanied by heavy central steerage, most notably through the early testing strategies, target setting, Ofsted, the neutering of LEAs, and the stranglehold of the TTA over teacher training, which all depress the ability to vocalize and implement different visions, aims and strategies, and of responding flexibly to more parochial issues.' (Bottery 2007a, p.154).

The continuation of market ideology and the continuing decline of the power and influence of the LEAs

While there are strong continuities between New Labour and the Conservative governments, they are not characterised by minimal state intervention (Walford, 2005, Bottery, 2007a) as Labour felt that the importance of economic and social well-being was too much to be left to chance.

While LEAs may still have had a strong role at the local level (Southworth, 2008) this depended on their capacity and their national role continued to be diminished. The New Labour government enhanced the influence of the private sector by undermining the role of LEAs with a number of privatising measures (Paterson, 2003; Chitty, 2004) including the establishment of City Academies funded directly by the government. Sidelining the LEAs can be seen to have developed even further with the 
White Paper Schools Achieving Success (DfES, 2001a) which giving some of its reasoning as the varied quality of LEAs promoted diversity in the system with the requirement for all new schools to be advertised so that non LEA bodies could apply to manage them.

The relationship between the government and the LEAs also changed as a result of policy regarding target setting and the plans the LEAs had to produce to respond to the Government's agenda for raising standards complete with a Code of Conduct to ensure the LEA's compliance (DfEE, 1997b, 1998b). As the LEAs were supposed to monitor these targets with schools as well, it changed the relationship it had with headteachers and became, in this way at least, more challenging. Radnor and Ball (1996) argued that LEAs were unsure of their role and accountability following the reforms of recent years. By 1998 the government had helped them to see their place in the accountability process as their approach to schools and pupil performance was now directly dependent on government imposed targets.

\section{$\underline{\text { Standards not structures }}$}

In the Labour Manifesto (1997) there was a strong emphasis on improvements being made through the primary system (Chitty, 2004, p.62) and much of government policy was steered towards this (Bottery, 2007a).

A way of achieving improvements was to concentrate on 'standards' not 'structures' (The Labour Party, 1997). There is some agreement among commentators that Labour didn't concentrate on 'standards' to the exclusion of 'structures'. Chitty (2004, p.67) suggests that as standards and structures are 'interrelated' they can only be understood 'in relation to each other' and Walford (2005, p.4) argued that 'what was planned related to both'. Furthermore, Bottery (2007a) argues that while the Blair government had been talking about flexibility, its policy had been largely structural. It concentrated less on the opportunity for 'professional discretion' and more on 'alternative governance, staffing arrangements and partnerships', and then preferably if 'schools embrace more private sponsorship' (Bottery, 2007a, p.155).

An example of New Labour's commitment to standards was its creation of the Standards and Effectiveness Unit in 1997 under Michael Barber. Its remit was to work 
in partnership with schools and LEAs and others committed to developing and implementing the government's various strategies to raise standards.

The government was to be relentless in its pursuit of high standards of pupil achievement. The White Paper Excellence in Schools (DfEE, 1997a) called for the elimination of underachievement and the overcoming of social disadvantage and intention of strengthening accountability. The position of the headteacher in the government's reforms was reinforced by the same White Paper:

'The vision for learning set out in this White Paper will demand the highest qualities of leadership and management from headteachers. The quality of the heads can often make a difference between the success or failure of schools. Good heads can transform a school; poor heads can block progress or achievement.'(DfEE, 1997a p.46).

By the time of the publication of the Green Paper: Schools Building on Success: Raising Standards (DfES, 2001b), the government was able to report on the improvement of literacy and numeracy. This was measured by the end of KS2 Sats with 75\% of children achieving L4 and above in English compared to 57\% in 1996 and $72 \%$ in maths in 2000 compared with $54 \%$ in 1996.

In measuring the effectiveness of the policy it should be noted that although the standards initially improved, according to Barber (2002a, p.182) due to the 'success' of the National Strategies and the 'training program' which accompanied them, they 'plateaued in the second term of the Labour Government' (Hopkins, 2006, p.5) endorsing the views of Hargreaves (2003) and Fullan (2004). Barber (2002a) notes that they plateaued at a higher level nevertheless KS2 results for English remained static at $75 \%$ for three years. In 2002 the Government failed to reach its original literacy and numeracy targets at the end of KS2 that $80 \%$ of children in English and $75 \%$ of children in maths would reach L4+. The response to this by the government was to extend the time for attaining these targets to 2004 and David Blunkett failed to resign despite his previous threat to do so if the targets weren't met.

Power and Whitty (1999) believe that government policy was based on populism and what was easy rather than what worked best for the system. Paterson (2003) feels this view is unfair, suggesting that within the narrow confines of improving standards through testing, at least until 2002, the policy did work, as the targets for performance 
in 2002 were only 'slightly' adrift of those set. This calls into question whether it was the quality of education which improved or the understanding of schools about how to secure a good performance.

New Labour and the Conservatives had much in common in 1997 but by 2002 particularly with the plateauing standards at the end of Key Stage 2, it was considered that the system needed to change.

\section{$\underline{\text { Section } 3}$}

\section{Labour 2001: The Call for System Redesign}

Why does the system need to change?

It has been the contention of many writers that approximately coinciding with the second term of the Labour government the system was becoming inadequate to manage the current and future pressures placed upon it. These were identified as the need to educate for a knowledge economy, the impact of succession management due to the impending retirement of the 'baby boomer' generation, and the plateauing standards at the end of KS2 tests from 2000 (Chapman, 2002; Bentley, 2003; Hargreaves, 2003; Barber, 2005; Fullan, 2005; Caldwell, 2006b). What is a significant feature of the calls for change is that they include those who might be considered as friendly critics of the government such as Tom Bentley of Demos and David Hopkins, Chief Adviser on Schools Standards (2002-2005).

A recognition of the importance of effective school leadership to the needs of the economy produced managerialism and a form of compliance by schools and 'designer leadership' of headteachers in order that the government could manage their role within the system (Gronn, 1999, 2003). Managerialsm has dominated the school system over the last twenty years through the setting of targets for performance and the measurement of them by the government through its accountability systems and the individual schools through the monitoring of performance by headteachers and their teams. Those who perform successfully are rewarded those who don't are sanctioned (Gronn, 2003; Bottery, 2004). The aim is to 'create an error-free' and 'risk-less organisation' in which professionals don't need to be trusted because the 
system is so carefully controlled and micro managed (Bottery, 2004, p.25). The effects of managerialism increased bureaucracy (Clarke and Newman, 1997) and so the aims of the private sector to create a lean and fit organisation which can move faster in a global and fast changing world hadn't transpired (Farrell and Morris, 2003). Therefore the system needed to change in order to provide leadership which is both effective and knowledgeable enough to respond to complex and rapid change (Bentley, 2003; Caldwell, 2006a, 2006b).

Hopkins and Levin $(2000$, p.5) wrote that it was:

'an irony of breathtaking proportions that the dramatic increase in educational reforms in most western countries over the last decade is having insufficient impact on student achievement'.

Bentley (2003, p.9) suggests 'government-by-target' while still having a place as part of the 'toolkit' for improvement or reform can no longer be 'the dominant principle for reforming large, partly autonomous organisations.' Consequently it was argued that the system needed to be redesigned through government policy which has necessitated changes to the role of headteacher and created new patterns of school leadership. As my research has identified new roles for headteachers were developing after 2002, I wanted to find out what the literature could tell me about the type of roles being made available to headteachers and what issues their creation was addressing.

\section{The 'mess' of system redesign}

One of the difficulties for the education system lies in the nature of the problems and issues it is trying to solve. Chapman (2002) describes the differences between a 'mess' using Ackoff's term (1974) and a 'difficulty'. They are complementary terms and shouldn't be seen as being in competition with each other. Difficulties are problems which have general agreement on what the problem is and what some or part of the solution would look like. Chapman (2002) sees them as 'bounded' (original emphasis) by time and resources needed to resolve them. Messes however are unbounded with no clear agreement as to what the problem is and uncertainty or ambiguity in how to resolve them (Chapman, 2002). The problems the system faces have been referred to as a 'complex adaptive challenge' (Heifetz 1994, in Fullan, 
2005; Hopkins, 2006, 2007; Hopkins and Higham, 2007) and that previous or known technical solutions are no longer appropriate.

Senge (1990, p.44) referred to a system as 'the key relationships that influence behaviour over time.' In addition a:

'. . defining characteristic of a system is that it cannot be understood as a function of its isolated components. . . the system doesn't depend on what each part is doing but on how each part is interacting with the rest. ...' (Kofman and Senge, 1995, p.27 in Hopkins and Higham 2007, p.157).

Thinking systemically avoids the reductionist method of giving simple answers to complex questions (James et al. 2005). Chapman (2002) sees the reductionist method as being appropriate for use in difficulties such as in repairing a car because the problem can be reduced to its component parts. However the soft systems approach within systems thinking is needed to tackle the complexities of a 'mess'. The most that can be expected with a 'mess' is 'to provide an agenda for improvement' or a process to use to move forward but this can 'still appear inadequate to someone wedded to the idea of an instant solution' (Chapman 2002, pp. 27, 28). It is also difficult for a government which is wedded to micro managing the solutions and lacks trust in headteachers on the ground to identify and implement solutions. This is still an issue despite attempts to design leadership through a combination of government policy and continuous professional development from NDGAs.

Instead of a single solution to a single problem, successful system change entails thinking about whole and interrelated systems. In the light of this it is important to consider how the main policies which impact on the current agendas of headteachers manifest whole system change or small piecemeal fragments. It isn't appropriate to reduce 'complex problems into separate rationally managed components.' (Hargreaves, 2003, p.71). Chapman (2002, p.20) refers to this as difficulties in predicting the consequences of policy because of the "non linear interactions among the components of the system which endorses Clarke and Newman's (1997) earlier argument about the trajectory of change being difficult to predict or to bring about change which is controlled and intentional (March and Olsen, 1989). Successful system change is about moving beyond individual leaders and individual organisations (NSBA n.d) and is not therefore just incremental improvement 
(Caldwell, 2006a) described 'as 'traditional and ingrained in the way schools work' (Davis, 2002, p.196).

That these conditions haven't been in place can be identified by a sharp increase in the creation of policies as governments have sought to control an 'unstable field of policy delivery' (Clarke and Newman 1997, p.145). This has been exacerbated by the over abundance of policies introduced by New Labour since their election in 1997. When these haven't worked they have required yet more policies to correct them described as a form of 'crisis mismanagement' (Hay, 1996, p.162 in Clarke and Newman, p.145). Policy modification and often the components of the policies themselves have been described as '...inevitably a process of bricolage' and 'compromise' (Ball 1998, p.126) and more of what can be done than should be done (Levin, 2003a). Clarke and Newman (1997, p.145) describe a 'policy vacuum' where attempts to 'integrate a fragmented policy domain' have led to them being affected by 'contradictory pressures.'

For systemic change to work it needs to be a cyclical process in which the impact of change on all parts of the whole and their relationships to one another are taken into consideration' (NSBA n.d). In doing so there is less likelihood of tensions in policy making caused between competing issues such as competition for school places between schools on one hand and collaborative working between them on the other. Unintended consequences can cause a failure in educational policy because innovation is transformed by those involved in the social processes especially if managers are trying to overcome the 'perverse effects' of fragmentation (Clarke and Newman 1997, p.152). In addition the interests of different stakeholders may well be different (Chapman, 2002) and not anticipated again causing unintended consequences.

As organisations adapt slowly, March and Olsen (1989) maintain that change is therefore best developed over time. Managerialism however tends towards short term solutions such as the Literacy and Numeracy Strategies because performance management and other forms of measurement such as the Sats results and league tables are short term goals. Organisations may also have to adapt quickly if they have been subsequently seen to fail and headteachers have to impose change designed for school improvement to which the school has to adapt quickly. 
Due to the difficulties of short termism 'whole systems' need to be equipped to cope with ongoing changes effectively (Bentley, 2003). Hargreaves (2003) argues that there is no doubt that centralisation of policy making has led to improvements in the system. However the micro management of policy implementation is more likely to cause the unintended consequences created in the tensions for example between standards and inclusion which are an example of the poor linkage of some policies. Direct intervention, or centrally imposed policy reform which controls what happens, is considered by Bentley (2002) as being unsuitable for the complexities of the situation because this sort of system tends to control the actions and values of people and in fact their 'active consent' (Hargreaves, 2003, p.72) is needed. This also resonates with the ideas of Clarke and Newman (1997) who argued that for change to be implemented successfully it needs hearts and minds to embrace it and see it as inevitable.

The importance of participants in the system playing their part in transforming it has been identified by Fullan (2004), Hopkins (2006; 2007) and Caldwell (2006a, 2006b) and illustrated below in that to transform the system requires:

'...a different kind of leadership from the centre; new, disciplined responsibilities from school leaders; and new roles and organisation from the 'middle tier', currently occupied by the Local Education Authorities.... (Hargreaves, 2003, p.19).

\section{What is not working in terms of the system which exists currently?}

Bentley (2003, p.11) notes that while 'output' from schools has improved through measures which include performance management and targeting, together with professional development and competition, the 'basic parameters of schools have changed relatively little'. The 'resilience' to change of institutions is 'sustained by public expectations, funding legacies, professional culture and standing structures of accountability and control'. Working in these situations needs constant adaptations to the changes brought to bear on the system but the structure of the system itself has not changed. Fullan (2005) was concerned that externally imposed vision can limit the scope of school improvement approaches which could otherwise develop but would be constrained due to a 'contrived coherence'. So any improvements made will be put at risk by over prescription and centralisation of education. Davis (2002, p.199) 
endorses this argument by maintaining that 'Excessive compliance reduces the scope for creativity and limits performance.'

\section{Disengagement of headteachers and solving the crisis of succession}

The situation is complicated by a shortage of school leaders. The dearth of school leaders was a 'trickle of concern' in the 1990s but not yet a 'flood' (Gronn, 2003, p.61). Hargreaves (2003); Caldwell (2006b); NCSL, (2005b, 2005e, 2006b) and Bottery, (2007b) have identified that there is a real concern that by 2009 there will be a shortage of school leaders as up to $45 \%$ of them will then be eligible for retirement, which has been identified as a reason for system change. Finding solutions to this problem should be planned for in schools (Hargreaves, 2005a, 2005b) and became one of the principal goals of the NCSL identified in its Corporate Plans from 2005 with a part of its website devoted to 'Growing Tomorrow's Leaders Today'.

Some reasons for this issue are seen as the consequences of the retirement of the 'baby boomer' generation (Gronn, 2003) but other reasons have been identified as a growing disengagement of leaders (Hargreaves, 2007a, 2007b, 2007c) with a 'reluctance' on the part of senior managers to become leaders (Gronn, 2003, p.51) and so 'shunning headship' (Jones, 1999c, p.488).

Despite the importance of younger professionals being encouraged to aspire to leadership there is some concern over their ability to do so based on their lack of experience (Williams, 2001 in Gronn, 2003). This may explain the current raft of leadership programmes and training opportunities offered to aspiring leaders such as those by the NCSL (Leadership Pathways; Associate Heads Programme; Leading From the Middle) many of which require the involvement and experience of practising headteachers for their delivery.

\section{Earned autonomy}

The requirement for change in terms of leadership is that there is a degree of autonomy needed for school leaders to deal with the mess which is on the ground and that the necessary level of autonomy is not available in the system to enable them to 
do so. In which case, a different relationship between the government and school leadership has to be built up through an 'earned autonomy' (Morris, 2001).

The Education Act (DfES, 2002a) was the first sign of the government giving 'active permission' to change by giving schools the power to innovate thus creating the right climate for change (Hargreaves, 2003, p.35). The extent to which this is successful is determined by the tensions which exist in the system between policies which were implemented in the 1980s and 1990s and based on 'competitive pressures' (James et al. 2005, p.9). Hargreaves (2003) argues that many people feel that they live in a blame culture and cites the 'style' of Ofsted, league tables and naming and shaming as reasons for it. This together with the imposition of centrally driven top down initiatives can he argues lead to 'a climate of blame, characterised by playing safe with resentful dependency.' (Hargreaves, 2003, p.34). Radical change is needed (Bentley 2002, Hargreaves, 2003) to improve the plateauing standards and to increase the skill level of children to service the knowledge economy effectively as anything else could be construed as 'tinkering' around the edges (Huberman's 1992 term used by Hargreaves 2003, original emphasis).

While many school leaders are indeed 'courageous' in their actions they may also have a strong sense of self-preservation for themselves and their schools and so may be reluctant to prioritise for the best instead taking the least risky solution. It will be an underused and according to Hargreaves (2003, p.36) symbolic change if it's not accompanied by a 'wider change in climate'. Hargreaves (2003) echoed by Fullan (2005) argues that mistakes must be encouraged and forgiven and not hidden so they can be turned into opportunities and lead to improvement. However to lead to improvement, the required change has to be understood (Clarke and Newman, 1997) and may need to be balanced by the consequences of failure.

If individual schools are allowed to work independently there is the danger of the kind of piecemeal or fragmented approach to system change outlined earlier and so therefore this argument requires the innovation to be at system level. This argument is leading to the opportunities for schools to collaborate as part of a system wide initiative for school improvement. How have these aims been translated into government policy? 


\section{$\underline{\text { Section } 4}$}

\section{Policies and themes impacting on the role of the primary headteacher}

As the system transforms there are fundamental changes taking place for primary headteachers in their role and relationships with others through multi-agency work; workforce reform, the pressures of accountability and succession management. Solving these issues is leading to changing patterns of school leadership within the system. In this section I will analyse the issues and themes of government policy currently impacting on the role of the headteacher with regard to the areas identified by my research and in the previous section on system redesign which are:

- Changing professionalism

- Standards and the curriculum

- Accountability

- New patterns of school leadership

While the impact of government policy on the role of the headteacher is analysed mainly in this section from the perspective of New Labour policy, I have also included references to previous policy if it is still impacting on the current role of the headteacher.

\section{Changing professionalism: The competency based approach to leadership}

Since the 1990s there can be seen the 'rapid, even dramatic rise to eminence' of the 'competency movement' (Brundrett, 2000, p.358) 'in the form of a nationally defined design specification for school leaders' (Gronn, 2003, p.3) which grew as a result of concerns about the suitability of management training leading to the development of generic job related standards for managers (Jones and Connolly, 2001). Early signs could be detected when Michael Barber articulated his vision of a reconstructed teaching profession to include state sponsored CPD and a GTC (Barber, 1995, 1996). Examples of this development are the introduction of NPQH and the Standards for Headteachers (TTA 1997; 1998; DfES, 2004d) outlining what is expected of the professional in terms of professional wisdom, skills, and performance (Leithwood, 
2001) all of which forms part of the accountability process and bureaucratic surveillance.

With the existence of these sets of standards the government is using a 'reductionist and technical-rational approach' to in-service education in controlling the leadership of the profession (Bottery and Wright 2000, p.475; Leithwood, 2001). This was particularly evident through entry to headship regarding the introduction of NPQH in 1996 'which is designed to prepare aspiring leaders for the ultimate challenge' (Millett, 1997, n.p). Due to the imposition of these standards by the government the role of the headteacher has changed. Furthermore it has implications for how school leaders present themselves, if, as Mahony and Hextall (2000, p.79) suggest, that to 'meet the standards' professionals have to be able to work according to the guidelines for meeting the standards. Further evidence that the role of headteacher is now being 'defined by the state' (Whitty, 2006, p.3) is that they are perceived to need 'a different body of knowledge and skills' (Jones, 1999a, p.325). Support for this notion can be found by referring to the views of Anthea Millett (1997, n.p) the then Chief Executive of the TTA who claimed that:

'...a new breed of headteacher' is needed 'who... is one who recognises the tried and tested methods of raising standards in the classroom'.

Notwithstanding the constraints of standards for teachers on controlling the profession, not everyone agrees they and other aspects of workforce reform necessarily 'de-skill' or 'deprofessionalise' teachers and indeed have been seen to have the 'potential to expand rather than restrict the professionalism of teachers' (Whitty, 2006, p.11) and helping to equip school leaders for the tasks they face (Barnett, 2001). In doing so however they are limited to enskilling the profession within the confines of practice legitimated by the standards themselves which is 'morally repugnant since it denies notions of professional autonomy' (Brundrett, 2000, p.359). Even if the standards and competencies are partly a result of 'best practice' research from reflective practitioners, Gronn $(2003, \mathrm{p} .22)$ building on the work of (Argyris and Schon, 1978), questions the validity of information gathered for the production of standards which relies 'solely on informants self reports about their behaviour' and so lacks information from unbiased observation by assuming that we 
work in a market or situation governed by 'specific knowable and predetermined rules' (Bell, 1999, p.211) an argument supported by Brundrett (2000).

However even with the challenges of the NCSL working towards the new models of school leadership with system leadership programmes and succession planning initiatives (NCSL, 2005b, 2005c, 2005d, 2005e, 2006b, 2007a, 2007b) it cannot guarantee that leaders will behave as anticipated. Standards and competencies 'ignore the role of context' (Jones and Connolly 2001, p. 55) and will be interpreted by headteachers in their way and will not be 'immune from the exigencies of localism.' (Gronn, 2003, p.9). This will possibly see a need to change or modify the standards for heads with a 'rebalancing of the standards and inclusion agendas' (Whitty, 2006, p.12). In addition to this it may be that in the future the standards and competences between the professions may converge leading to a 'democratic professionalism' or collaborative culture across groups which would be appropriate in a multi-agency context (Whitty, 2006). However it should be borne in mind that it is moral integrity rather than adherence to a list of competencies which leads to the trust and loyalty which underpins effective leadership (Gold et al. 2003 in Bottery, 2007a).

\section{Changing professionalism by reforming the workforce}

Having designed the standards required of the profession it was an important aspect of customising leadership (Gronn, 2003) for headteachers to 'monitor the progress of staff towards the achievement of professional standards' (Leithwood, 2001, p.225). Gunter (2008) argues that workforce reform has been part of government policy for the past twenty five years to construct a workforce which is trained to deliver its strategies. Reforms in the second term of the Labour government, therefore, build on a raft of reform from the early 1990s which can be identified as having changed the role of headteachers and other staff.

The reforms of the 1990s changed relationships rather than structures (Ball, 2003) and Case et al. (2000, p.607) point to the effects of managerialism 'compromising the professional status' of members of staff as well as altering 'role relationships'. However since they were writing there has also been 'significant organisational change' (Hammersley-Fletcher, 2006, n.p). As a practising headteacher since 1996 I am aware that the use of appraisal by the end of the 1990s was mostly unregulated, 
and if it wasn't a process with which heads chose to engage, they were unlikely to be forced to do so by the LA or Ofsted. This situation began to change with the publication of the Green Paper 'Teachers Meeting the Challenge of Change' (DfEE, 1998a). One of its aims was to modernise the teaching profession (Husbands, 2001, 2003; Rutherford, 2004) and this was encapsulated in two main policies which were changes to appraisal and remodelling the workforce.

From 2000 a new pay system through performance management and threshold and post threshold scales was the mechanism by which the government's strategy for appraisal and beginning to remodel the workforce was implemented. There is a need to verify compliance to these standards for crossing the threshold as headteachers were not trusted by government to make unverified decisions and so the government created a framework of quality assurance of heads' work by using outside assessors or experts to provide an audit trail (Gronn, 2003; Elkins and Elliott, 2004).

Haynes et al. (2003) in their study of headteachers' perspectives and Hopkins (2006) are largely positive about performance management if it is linked to a focus on teaching and learning, coaching and collaboration. Not all agree with the merits of appraisal and Ball (2003) argues that a rigorous form of appraisal meant that the worth of the profession was being determined by performance comparisons artificially and inaccurately determined. Targets and monitoring strategies merely imposed on staff by headteachers are unlikely to be a successful recipe for raising standards. However Ball's (2003) view doesn't account for the importance of the way in which performance management is undertaken as a process in schools and the approach to it taken by the headteacher. This will differ in terms of the quality of targets set for appraisal, the extent to which they are monitored and/or used for managing the performance of staff and the climate of trust and extent of collaboration established when they are identified and implemented.

By 2003, the government's emphasis had moved from performance management to concentrate on remodelling the workforce (Rutherford, 2004) which is part of the government's strategy to raise standards and to support the aims of the 1998 Green Paper. Earlier reforms were complemented by the workforce reform legislation in the form of The National Agreement on Raising Standards and Tackling Workload: A National Agreement (DfES, 2003c). This was designed to raise standards while at the 
same time tackle what was being acknowledged ( $\mathrm{PwC}, 2001)$ as an unmanageable workload for teachers and headteachers and one which threatened a crisis in recruitment and retention in the profession.

Having implemented it, I can attest to workforce reform legislation being a slow process because it was often challenged by the employee associations with the agreement of the Workforce Agreement Monitoring Group (WAMG) being a necessary part of the reform process. The Agreement (DfES, 2003c) was finally signed by all the unions and associations except the NUT. However the NUT while not part of the Rewards and Incentives Group (RIG) was still actively advising its members on the implications and obligations of workforce reform legislation. The reforms for tackling workload were implemented between 2003 and 2005 and included the removal of administrative tasks for teachers (2003), changes to cover arrangements for teachers with the use of support staff (2004) and the operation of PPA (2005). The latter also included dedicated time for headship as part of the strategy for the retention of heads. However it missed the point that heads are accountable for their role and required to complete tasks irrespective of dedicated headship time. So while it may legitimise time headteachers take to reflect on school improvement issues it doesn't alleviate the problems of work intensification and therefore doesn't contribute to the recruitment and retention of headteachers.

One way of overcoming the workload of headteachers is to lead more strategically (PwC, 2007). If heads are to lead more strategically more of their role needs to be distributed to others in school and workforce reform can be used to accomplish this. The reforms contained in The Agreement (DfES, 2003c) have led to increased responsibilities in school for support staffs who have taken over some of the workload of teachers and headteachers most notably those which are administrative (Whitty, 2006; Gunter, 2008). The changes to the roles of support staff are a manifestation of an earlier argument by Barber (1995, p.77) who asked:

'If teachers are overworked, which they are...could we make better use of administrators and paraprofessionals?'

Changes to the role of non teaching staff also facilitated the opportunity for schools to become multi-agency organisations and as such a fundamental part of the extended schools reform. This links with New Labour's policy of redesigning the system to 
create new patterns of school leadership and the arguments of Bentley $(2002,2003)$ to create cross agency organisations.

\section{Standards and the curriculum}

The Government has been able to use the National Curriculum to help achieve an assessment of schools' performance because of its emphasis on reaching prescribed measurable standards (Hatcher and Troyna, 1994, Elkins and Elliott, 2004) which the inspection team can use as part of a 'mechanism of accountability' (Poulson, 1998, p.429) and parents can use to compare schools. The Labour government has strengthened this policy through the requirement for headteachers to ensure that systematic evidence is gathered and presented (Chitty, 2004) in a system which has an alignment between standards, the curriculum and assessment (Apple, 2001, p. 605) which is more 'punitive' than its predecessors in its use of targets (Broadfoot, 2001, p.136), Bell (1999) and Paterson (2003).

Detailed guidance on target setting for literacy and numeracy was published (DfEE, $1997 b$ ) in an attempt to eliminate the risk of variable quality between schools. Bell (1999) argues that its introduction is an indication that the importance of improving standards was not to be left to the professionalism of headteachers in leading the curriculum of schools. The relentless pursuit of higher standards continued with the introduction of The Standards and Framework Act (DfEE, 1998b). It retained much of Conservative policy regarding the standards agenda i.e. league tables, testing, national curriculum and local management of schools.

The government later built on them in the production of the prescriptive Literacy (DfEE, 1998c) and Numeracy (1998d) Strategies introduced into schools in September 1998 and 1999 respectively. Their introduction was intended to ensure primary children reached agreed targets (Jones, 2003; Chitty, 2004; Walford, 2005; Brehony, 2005; Bottery, 2007a). This legislation impacted on the professional autonomy of headteachers because it not only prescribed content, but delivery (Docking, 2000) restricting headteachers' impact on pedagogy in schools. This strategy produced a 'performance culture' identified early on in Labour's policies (Campbell, 2001, p.32 original emphasis). It was up to the individual responses by 
headteachers as to how successfully their autonomy was eroded (see Section 5, Management of change, p.66).

In 1997 the QCA reviewed the curriculum with the specific intention of introducing changes which would support the drive to raise standards in literacy and numeracy so that schools could be supported to meet government targets for 2002. In 2000, following the QCA Curriculum Review, headteachers were able to cut back on time given to music, $\mathrm{PE}$ and art to give more to literacy and numeracy. In doing so they caused 'an imbalance in the curriculum of primary schools (Brehony, 2005, p.35).

The Government, perhaps sensitive to the need to ensure such a large piece of legislation would be successful, commissioned a report into the effectiveness of the Strategies (Earl et al. 2000, 2001, 2003) which was largely positive regarding its effects in raising standards. However the time heads then had to devote to the strategies in the school's curriculum as a result of the QCA curriculum review establishing a reduced non core primary curriculum in 2000 may itself have contributed to the pattern of improved attainment in these areas rather than any innate quality of the strategies. On the other hand Ofsted (2002a) and (2002b) while recognising that substantial improvements had been brought about by the strategies commented in respect of the numeracy strategy that heads lacked understanding of how it could be used for school improvement and had followed the strategies without enough questioning.

However I would cast doubt on the way the strategies were introduced in schools. As a practising headteacher at the time I can confirm that it was known the strategies were not statutory but they were heavily supported by LEAs and Ofsted expected headteachers to report on them. If headteachers were certain of the high performance of their children at the end of Key Stage 1 or Key Stage 2 they were in a more secure position to ignore the strategies. I would therefore agree with Bottery (2007a, p.160) who suggests that one reason for the agenda being followed so closely:

'may be the build-up over two decades of detailed, micro-managed legislation, backed by an external inspectorate with a highly punitive approach to the teaching profession.' 
Heads were therefore under considerable pressure to conform despite the comment of the then HMCI David Bell in his annual report for Ofsted (2004a, p.4) that he was surprised that 'again in 2002-2003 there had been no improvement on the previous year' in the primary Sats. The pressure on the primary curriculum of meeting targets for English and mathematics which put pressure on the delivery of other aspects of the curriculum was something he found surprising given the opportunities schools had to divert from them.

There was growing recognition that being overly explicit in the management of headteachers and the curriculum was not likely to provide the creativity and innovation a knowledge economy needed (Hartley, 2003) and was leading to a form of 'test mania' contrary to the 'genuine' development needs of children (Jupp et al. 2001, n.p) by headteachers desperate to secure a high performing school. Brehony (2005, p.37) highlights a conclusion in the last report by Earl et al. (2003) which while being largely positive of the government's literacy and numeracy strategy identified 'the limitations of New Labour's top down approach' by concluding that, 'setting ever-higher national targets may no longer serve to mobilise and motivate, particularly if schools and local education authorities see the targets as unrealistic'.

The publication of The White Paper Schools Achieving Success (DfES, 2001a) followed by the Education Act (DfES, 2002a) denoted a change of tone by the government which may be associated with the plateauing of standards (Jones, 2003, Elkins and Elliott, 2004). The aim of Michael Barber, the 'key architect' of the reform strategy of the Labour government (Hopkins, 2007, p.41), was that there should be ongoing improvement of standards which was appearing difficult to attain once they had plateaued. He was coming to recognise that social issues might also be reasons for the plateau and not just the failure of schools (Barber, 2002b in Brehony 2005). However in Barber (2002a) he comments:

'Moreover progress is both literacy and numeracy has been fastest in the most disadvantaged areas of the country. In other words we are narrowing the achievement gap'.

Despite these contradictory responses, later in the Labour period of office Whitty (2006, p.1) cites Kelly (2005) who found that while results overall had improved to date the 'relative attainment of children from poorer socio-economic backgrounds' 
had not. Whitty (2005, p.5) building on the argument of Plewis and Goldstein (1998) believes that this points to a flaw in the school improvement process that it fails to consider 'the importance of structures and the systematic effects of, for example, social class and ethnicity on children's attainment.' It is a sad irony given that the social policies such as those regarding Education Action Zones initiated by Michael Barber and which were meant to address the needs of those from low income families that as late as 2006 Hopkins (2006, p.9) still needed to argue that transforming the system to cope with the lack of attainment by children from poor social backgrounds is a challenge for government and that a 'strong public realm' is essential to making 'social fairness and cohesion a reality'. It could be argued that the result of this can be seen in the requirements of Ofsted from September 2008 to report on school's promotion of social cohesion.

In May 2003 there was the launch of Excellence and Enjoyment: A Strategy for Primary Schools (DfES 2003b) which 'was a clear indication that the Government was aware of the widespread hostility towards the regime of targets at the primary level' (Chitty, 2004, p.133). However while in it there was some acknowledgement of the need for more flexibility and innovation it wasn't meant to return to a period of 'child centred theories' (Miliband, 2004). There was therefore a tension in the 'irresolvable contradiction' between 'excellence and enjoyment' of the curriculum (Brehony, 2005, p.29) for the role of the headteacher because calls for them to have more autonomy in the content and delivery of the curriculum in schools on the one hand has been affected by the requirement to frame it within a rigorous system of tests, league tables and inspection on the other (Alexander, 2004).

Charles Clarke did not see the new policy thrust as a move towards 'dismantling the whole system of targets in the primary school' (Chitty, 2004, p.133). Nevertheless targets were moved back again in that while it was no longer necessary for $85 \%$ of primary school pupils to achieve L4+ in English and maths by 2004, the Government kept it as an aspiration for 2006. Key Stage 1 tests however were to be based on a combination of teacher assessment and tests.

There is a perceived need to equip a workforce to adapt to the demands of a rapidly changing world in the 21 st century framed by the requirements of the knowledge economy (Barber, 2001) which has led to calls for a change in 'top down' government 
planning of the curriculum and its organisation to one which is more contextually based where the reform is determined 'school to school' (Miliband, 2004). Possibly because the government didn't know the way this was to be achieved Miliband's (2004) calls for personalising learning have been described as 'somewhat' vague (Demaine, 2005, p.121). However it didn't remain vague and documents have been published for schools detailing exactly how to do it and include Guidance for Assessment (DfES, 2004a).

There is little for headteachers in the Five Year Strategy (DfES, 2004c) to 'moderate their hostility to the regime of targets, testing and inspection' (Brehony, 2005) and headteachers were forced to adopt coping or mediating strategies (Woods and Jeffery, 2002). By 2008 it appears that the need to review the prescriptive nature of the curriculum to allow for more creativity has been recognised with the introduction of the Rose review although I would suggest that as the pressure of league tables remains for headteachers so too will the pressures of accountability for standards outlined in this section.

\section{Accountability}

Preedy et al. (2003, p.9) build on the work of (Simkins, 1997; Leithwood, 2001) to identify forms of accountability as government control; community participation; managerial control, professional accountability. The headteachers in my research are particularly affected by their accountability for the standards reached at the end of each of KS1 and KS2 because of the effect this has on the way their school is viewed during inspection and consequently on how they are perceived as school leaders. While acknowledging the different forms of accountability for headteachers, I will, therefore, concentrate mainly in this review on government controlled and managerial accountability as it impacts on the role of headteachers, with reference to standards and specifically accountability measured through inspection.

\section{$\underline{\text { Accountability and Inspection }}$}

The assessment of a school's performance and with it of the leadership of the headteacher, has been one of the main features underpinning New Labour policy (Chitty, 2004). It continues a tradition started in 1992 by being regulated through 
Ofsted, the 'absent presence' (Troman, 1996) of which can be seen to permeate decisions headteachers take in leading schools.

There are various views about the purpose and effectiveness of Ofsted in its role of holding the profession to account. Leithwood (2005, p.6) argues that holding school leaders 'publicly to account' is a 'relatively weak strategy for school improvement' while acknowledging that it can be politically 'difficult to resist'. Inspection as a means of informing parental choice is a key strategy of successive governments endorsed by Ofsted. Woodhead (1999, n.p) argues that inspections 'make an important contribution to higher standards' and Ofsted continued to endorse its own value in school improvement (Ofsted, 2004a). Chapman (2001) builds on the work of West (2000) and Harris (2001) to argue that there is 'growing' evidence regarding the successful role of effective external school support for improving schools. An independent review carried out on behalf of Ofsted, supports this claim by arguing that Ofsted had made a 'substantial contribution' to school improvement (Matthews and Sammons, 2004, p.153). Studies by Cullingford and Daniels (1999); Kelly (1999); Case et al. (2000); Shaw et al. (2003); and Elkins and Elliott (2004) offer a different view regarding the accountability of schools for results in that their studies showed that inspection was not seen to have a positive effect on attainment in tests and may even make results worse due to the attention schools had to pay to preparing for them and the 'heavy handedness' Case et al. (2000, p.618) of inspection.

Drawing attention to failing schools is a process undertaken because it is perceived that headteachers will work more effectively if their performance and results are more transparent and a form of 'sanctions' or 'incentives' are made in accordance with the inspection or assessment results (Webb, 2006). A 'key issue' identified by Thrupp (2005, p.38) may make it irrelevant whether or not the inspection is fair and accurate due the motives of the government being more about bringing a 'climate of accountability to bear on schools' and therefore of control of the profession in addition to those of merely raising test results.

\section{Intelligent accountability}

There can be conflict where the requirements of the job affect the sense of autonomy of the professional. Thrupp (2005, p.33) sees Ofsted under Labour's first term in 
office until the departure of Chris Woodhead as HMCI in 2000 as being much like the Conservatives but 'more severe'. From the beginning of its second term of office, the rhetoric of government emphasises its understanding of the bureaucratic workload of teachers as it began to discuss the need for self-evaluation and shorter inspections known as 'light touch' for schools deemed to be effective (Morris, 2001). This view was reflected also in the calls by the then HMCI Mike Tomlinson (Learner, 2001, n.p) for schools 'to be playing an active part rather than being a passive recipient' of the inspection process. However he wished to reassure observers that '...none of the proposals will affect the rigour and objectivity of inspections'. Indeed this was emphasised in Miliband's (2004) speech to the North of England Conference when he argued the 'legitimacy' of accountability and the need to move away from questioning its validity although acknowledging also that the time had come to 'respond to those who want it to work better to promote high performance.'

While acknowledging the role of inspection in raising standards Hopkins (2007), echoing Hargreaves (2003) and Miliband (2004), suggests that there have been criticisms of the accountability system in that it has encouraged schools to promote teaching to the test. Hopkins (2007) echoing Barber's $(2002,2005)$ call for 'informed professionalism' argues that the answer to the problem of over dependence on external accountability was seen to make the system of accountability more 'intelligent' and for there to be a greater balance between external and internal accountability. This was the motivation for David Miliband's (2004) speech who stated that:

'Intelligent accountability serves two functions: it helps the system learn from itself; and it shows the public that they are getting value for money (Miliband, 2004).

It has been described in practice thus:

'Intelligent accountability recognizes that there are two aspects to accountability and, despite a degree of tension between them, both have to be accomplished. One involves transparent, external accountability to the public and to government as the public's agency (sometimes called assessment of learning or summative assessment); the other concerns the use of data on student learning as a strategy for directly improving teaching and learning (called assessment for learning or formative assessment).' (Barber and Fullan, 2005, p.5, original emphasis). 
The New Relationship with Schools (DfES/Ofsted, 2004) built on Miliband's (2004) speech and was introduced as a solution to some of the problems outlined above as being identified with inspection. Improvements were to be achieved through a combination of schools self assessment by producing a report (SEF) and external assessment working together. Schools engage in a 'single conversation' with a SIP who was to be the basis of this new relationship working in partnership with schools towards school improvement (Hopkins, 2005, 2008). An 'implementation dip' of new practices and changes in the post-inspection period has been identified by Chapman (2001, p.48) and although not described as such by the government the role of SIP could also be seen to be part of a solution to solve any dips in performance not picked up between inspections masked in the user friendly terms of a critical friendship. This would enable a degree of confidence on the part of the government that schools are being monitored if inspections became less frequent.

In addition to these changes to accountability were added changes to the inspection regime which doubled the number of inspections by halving the time between them to three years but shortened their length to two days. There is some evidence that the proposed autonomy is correspondingly likely to strengthen accountability. Wohlstetter and Sebring (2000, p.174 cited in Glatter, 2003, p.53) comment:

'An underlying premise of SBM is that school-level participants trade increased autonomy for increased accountability'.

\section{The importance of data}

The importance of data became even more crucial following the introduction of 'intelligent accountability'. The impact of a strengthening of accountability for headteachers can be identified in the increased role they have in gathering evidence for performance in the form of data for the SEF to inform inspection judgements.

David Blunkett the then Education Secretary of State visualised this:

'...I think there is real scope for making better use of data now available to inspectors before they visit schools - which can enable better, more focused, more rigorous and more helpful inspections.' (Blunkett 2001b, p.6).

Blunkett's (2001) view of the need to make better use of data was echoed by Miliband (2004) who identified it as 'the most valuable currency in school improvement'. 
A useful question is for whom is the new inspection more helpful? The increase in data may be more helpful to inspectors gathering evidence before inspection as a shorter time is spent in school but there have been concerns expressed as to the validity of the data used by inspectors (Fitz-Gibbon, 2002; Gorard, 2006) and the impact on the performativity of headteachers in gathering it. For example Fitz-Gibbon (2002, p.96) argues that the methods of gathering data are not 'evidence-based' and that by the time of her writing there have not been any studies 'of the adequacy of the sampling, or the validity of the judgements' evidence leading to a potential lack of accuracy in judging a school's performance. If this is true then judgements will be made about school improvement which may be 'incorrect' or important 'opportunities may be missed' (Chapman, 2001, p.42).

Elmore (2005) highlights a problem for policy makers in that he believes they view progress as being reliably assessed on 'cross-sectional' annual evidence of performance. He sees improvement as being a developing process. It is the need to continually respond to changing circumstances and to be able to adapt to different requirements and not just to do more of the same because it worked one year and with different children.

A convincing argument for a degree of unfairness around accountability for headteachers lies in the expectation that they can raise standards for pupils irrespective of context (Leithwood et al. 1999a). It was recognised that a system of accountability based on attainment was perceived not to be delivering the 'transformation of educational performance anticipated' (Harris, 2005, p.73) and so a system of value added information based on contextual factors was needed. There has been some attempt by the Government to offset the problems of context by introducing contextual value added (CVA) data to use to judge schools' performance. This was expected to go some way to iron out the disadvantages of some contexts. However to do so necessitates the accurate gathering and interpreting of data and that it is used as a guide (Bell, 2003) rather than the main determinant of an inspection outcome. In 2009 it was reported in the TES (Stewart, 2009) that two 'leading academics' (Steven Gorard and Harvey Goldstein) had condemned data collected to measure performance and 'CVA' as "meaningless". Reporting such evidence therefore will defeat its aims in that parents will not be able to have the confidence in 
the performance of schools being compared on a 'like for like' basis as promised in Miliband's (2004) speech.

Fullan (2005, p.93) argued that:

'System development occurs not just when good data are available but when people agree on the meaning and use of data.'

The issues surrounding the inaccurate and negative use of data would suggest that the aims of intelligent accountability to create the conditions for professional autonomy and fair accountability and therefore system development have not been realised.

\section{Performativity}

Performativity has underpinned the policies of successive governments and impacts on the role of the headteacher (Broadfoot, 2001; Ball, 2003; Bottery, 2004; Chitty, 2004; Elkins and Elliott, 2004; Webb, 2006). Chitty (2004, p.202) argues that what supports much of New Labour's policy has been the idea of 'performativity'. He cites Broadfoot (2001, pp.136-137) to describe performativity in being:

"a rationalistic assumption that it is possible - and - desirable - to "measure" performance, whether this be of the individual pupil, or of the institution as a whole'.

This sets the climate and system for a culture of performativity in that the performance of the profession is measured against the performance of the children according to pre-determined tests (Elkins and Elliott, 2004) as part of 'the mechanics of performativity' (Ball, 2003, p.220) and control through the surveillance of Ofsted of teachers' performance which Bottery (2004, p.87) argues 'forces individuals into the playing of a game.' This manifests itself in the need for 'fabrication' (Ball, 2001) where heads put on a performance for 'stage managed public accountability' (Case et al. 2000, p.605), likened to that of preparing for a wedding (Woods et al. 1997). This is a behaviour criticised as partly the fault of the profession for 'misunderstanding' expectations:

'I know Ofsted worries that schools too often insist on greatly over-preparing for inspections and they are looking for ways to reduce that.' (Blunkett, 2001, p.6). 
While noting the dangers attached to performativity such as a feeling of self-betrayal and guilt, Bottery (2004, p.92) draws on Sergiovanni (2001) to comment on the usefulness of adapting and using 'strategic deceptions' or a form of 'impression management' (Webb, 2006, p.201) which is used to reconcile the demands of the education agenda and the interests of the school. In addition I would add the importance of 'impression management' in the way heads manage the individual relationships between themselves and inspectors.

The shorter inspection was expected during the period of reform from 2001 to reduce the need for performativity and fabrication (Thrupp, 2005). Following the increase in the use of performance data and inspectors relying on pre inspection self evaluation data, which in a primary school relies on attainment data through Sats, there is indeed a reduction in scope for the type of 'fabrication' argued by Ball (2001). There is far more specific data expected by Ofsted to support contextual value added.

Although there is less time to prepare and worry for a known inspection, shorter notice inspections 'will probably put schools under pressure throughout the period that an inspection could fall due' (Thrupp, 2005, p.45) and so the need for heads to prove themselves made harder by such a short inspection window is unlikely to have reduced the impact of performativity on them. If this is true then excess performativity which can lead to a decrease in the 'creativity and risk taking' needed in a successful 'learning organisation' (Bottery, 2004, p.94) will not help to create the climate for system redesign outlined earlier and which requires headteachers to be able to act free of 'resentful dependency' (Hargreaves, 2003, p.34).

Why comply with this form of coercion? Apart from the obvious, that the school will be judged to fail if heads don't comply with the requirements of standards based inspection is also the idea of being eliminated from the game (Lyotard 1984 in Webb, 2006). If heads are not acceptable in terms of what is expected of school leaders then they may be excluded from participation in much of the wider field of play such as opportunities to be recognised as system leaders. This is relevant to the idea of making mistakes. Fullan (2005) has suggested that mistakes should be welcomed providing that lessons are learned from them. However if we only value the contributions of the profession based on how they perform within the standards agenda then it is harder for headteachers to do other than 'play the game'. 
Improving education by collaboration between schools improving the system has led to changes to the role of the headteacher in their being used and encouraged to solve system wide issues such as succession management and spreading 'best practice' (Hargreaves, 2003; 2007a, 2007b, 2007c) and not just issues pertaining to their own schools. This aim can be identified through the legislation of the Labour Government from its second term.

One way of achieving this was to grant more autonomy to those heads that had proved themselves as effective through inspection. An indication of this can be seen in the White Paper Schools Achieving Success (2001a, p.6) where 'well led' schools were to be able to 'take full responsibility for their mission' thus suggesting a degree of 'earned autonomy' (Morris, 2001) and later the suggestion that the 'best schools' will be used to 'lead the system' (DfES, 2001a, p.37). This view presupposes that Ofsted is the best mechanism to determine the effectiveness of schools and as outcomes are now so predetermined by data attached to performance this may not be an effective way for primary schools of determining autonomy. That is unless effectiveness in headship is only to be determined according to the performance of children at the end of Sats.

To facilitate the spread of best practice within the school system requires:

'an underlying network structure that is rich in hubs, namely the small number of super-connected individuals (our champions) who spread a disease (innovation and best practice) to many others' (Hargreaves, 2003, p.62).

While he is describing this infrastructure in terms of secondary education the examples given by Hargreaves (2003) of professional networks are appropriate to the primary sector. They include SSAT, Becta, EiC consortia, NCSL networked learning communities, collegiates and federations as examples of professional networks.

Hargreaves'(2003) 'champions' (p.62) are echoed in the need to produce 'Level 5 leaders' (Collins, 2001) to provide system leadership' (Fullan, 2005). They are required to build capacity in the system which requires new ways of working by government and new forms of leadership from outstanding school leaders to meet the 
challenge (Hopkins, 2006). Hargreaves (2003) identifies 'practitioner-champions' such as headteachers who have devised and successfully applied innovation and 'advocate-champions' such as LA advisers or researchers who can evaluate the success of the innovation. Such champions are a recurring theme and can be identified in the need to move towards using the informed professional when headteachers form part of a 'critical mass' of school leaders envisaged as part of the process of 'tri level reform' (Fullan, 2005) and (Barber and Fullan, 2005). The use of best practice by headteachers as system leaders is an argument endorsed by Hopkins $(2006,2007)$ and Hopkins and Higham (2007).

One question to be asked is who is to be considered 'informed' and about what? Is the suggestion to allow a degree of freedom for all heads to act as 'informed professionals' or only those who are informed in the right way and about the required areas as the kind of designer leadership described by Gronn (2003)? There is still the concern being acknowledged on the part of policy designers that innovation must be 'disciplined' and in doing so avoid 'unleash[ing] a spate of innovation that will run wild in the 1960s spirit of letting a thousand flowers bloom' (Hargreaves, 2003, p.37; Fullan, 2004) endorsed by Hopkins (2007). Hargreaves (2003) suggests the dangers inherent in this are that there will not be a strong evidence base of how to improve and that dissemination to others may be 'weak'.

The use of system leadership is pragmatic as it offers a solution to the twin dilemmas of spreading effective practice and 'stretching' leadership to attempt to solve the looming retirement crisis. To facilitate these issues those in public service organisations need to be dedicated 'to social outcomes beyond the reach of their formal accountability' Bentley (2003, p.10). 'Moral purpose is the link between systems thinking and sustainability' (Barber and Fullan 2005, p.3) and in an argument endorsed by Hopkins (2006) system leaders are seen to express it by constantly striving for improved learning outcomes for all children across the system. Crawford (2007, p.523) notes that:

'it could be argued that concerns over recruitment in primary headship, rather than a strong research base, have lead to calls for alternative models of headship, such as system leadership.' 
This may be true but alleviating the problems attached to early retirement doesn't detract in itself from the value of spreading the ideas of effective leaders.

\section{How has system leadership been reflected in government policy?}

System leadership aims to share the expertise of 'effective practitioners' with 'less experienced colleagues' or those who need support to overcome 'the challenges they or their schools face.' (Southworth, 2008, p.422). According to Hopkins (2006) several types of system leadership roles are happening in England:

- Executive or federative headship of more than one school.

- Leading a school currently in extremely challenging circumstances or becoming an Academy Principal.

- A 'civic leader' in a collaborative network such as leading Educational Improvement Partnership or cluster of Extended Schools.

- Working as a 'change agent' such as a 'consultant leader' or as a 'School Improvement Partner'.

(Adapted from Hopkins, 2006, pp.14-15, original emphasis).

The government clearly wishes to use headteachers and the final stage of headship is recognised by NCSL as being 'consultant leadership' actively encouraging heads to pursue these roles. Ways of supporting school leaders to 'lead outside their own institution' was firstly a challenge of NCSL's (2005b) Corporate Plan and continues to be so with literature produced to support it (NCSL, 2007a, 2007b). The role of consultant leader was recognised by the DfES in both the role of Primary Strategy Consultant Leader (PSCL) and consultant leadership through the London Challenge (DfES, 2003e). PSCLs were introduced through the Primary Leadership Programme (DfES 2003d) which was launched as part of the Primary National Strategy, with training provided by the NCSL through LAs for heads to act as consultants in schools deemed as vulnerable. A national consultant leader course of 5 days was also available, delivered by the NCSL in addition to the PSCL training via the LAs.

This is seen by Earley and Weindling (2006) as part of the government's use of heads to implement its strategies and Thrupp (2005 p.43) agrees but sees it less benignly, suggesting that the PLP and PSCLs to deliver it was an initiative introduced 'after 
Ofsted blamed weak headteachers for low results in literacy and numeracy in 2002.' (Ofsted, 2004b). There was an expectation by government that such vulnerability would distinguish itself through low results and hence these schools would be targeted. The fact that the training and brokerage for such a programme came via the local authorities meant that they had a high degree of opportunity to shape the programme and placement of consultants according to local need. The variable quality and capacity of LAs will also have impacted on the effectiveness of the intiative. Thrupp (2005) alludes to Ofsted's criticism of the scheme and cites Curtis (2004, n.p) who criticised what he called the 'primary superhead scheme'. This judgement however is to misunderstand both the purpose of the work at local level and also the impact due to the agency of the heads involved. The role has implications for 'role clarity' (Earley and Weindling 2006) in that the level of direct impact and power depends on the remit of the consultant leader heads who work as CLs and PSCLs.

NLEs have been identified as 'school leaders who have the talent and experience... [and] with the ability to run our most challenging schools;' (DfES, 2005a, p.100) who would be encouraged to work outside their own school collaborating with others. In order to facilitate this, the Government in the same White Paper proposed that NCSL working with the National Strategies would train and develop leaders of 'complex schools' and 'federations' and it became part of their remit letter following the end to end review (DfES, 2004b) and NCSL (2005d) pledged its support to developing NLEs and to ensuring they were placed in the most complex and challenging schools.

The quality of leadership is an Ofsted judgement which is used by NCSL as part of its decision as to whether a headteacher is suitable to become an NLE. As well as this they use references both from another headteacher and the prospective system leader's LA. Hopkins (2006) and Hopkins and Higham (2007) claimed that other 'change agents are School Improvement Partners (SIPs) initially identified by Miliband (2004).

Federation is a term often applied quite 'loosely' and is used to include school amalgamations and 'hard' and 'soft' federations (Southworth, 2008, p.418) which are dependent on the role of the governing body. A hard federation is usually under the leadership of a single headteacher and governing body where soft federations can 
range from those with no joint governance to soft federations with some joint committees followed by more formal or fixed joint governance and finally a hard federation with a single governing body (PwC, 2007).

\section{Factors impacting on the success of system leadership}

Although the field is recognised in the literature as new, the evidence is sparse (Hopkins and Higham, 2007; Chapman et al. 2008) in determining the reasons why heads undertake these roles and how successful they are when doing so.

Government policy would suggest a favourable climate for encouraging heads to undertake roles as system leaders but it has been identified that they also have to have the required knowledge and understanding (NCSL, 2007b) of how to do so. In addition they need to be encouraged to do so for the policy to succeed. Gunter and Forrester (2008) noted that headteachers had taken up consultancy and are working on behalf of the government in facilitating the implementation of their reforms. A question to ask however is to what extent is undertaking system leadership a conscious attempt by headteachers to facilitate reforms on behalf of government because they believe in them for their intrinsic worth, or are there other more extrinsic forms of motivation? Why would headteachers seek to extend their role in ways which could be seen to lead to further work intensification (Earley and Weindling, 2006)? These are questions my research addresses.

Another factor for successful system leadership is related to the capacity within the school that needs to be built and secured so that the system leadership of the headteacher does not adversely impact on the school in which they are substantive head (Spillane et al. 2005; Spillaine, 2006; Harris et al. 2006; Hopkins and Higham, 2007, NCSL 2007b). The use of the NLENSS form of system leadership stems from recognition by government of the need for sustainability of the reform and the move away from 'superheads' to the use of support schools. In using the experience of the staff of the support school it places less pressure on the consultant headteacher to be the sole means of school improvement in the supported school and thus alleviates some of the criticism of the use of a single 'superhead'. Ways in which schools can be seen to build capacity are to become a 'learning organisation' (Mulford, 2003), to distribute leadership (Leithwood, 2001; Spillane et al. 2005; Harris et al. 2006; 
Spillane, 2006) and to ensure an effective process for succession management (Hargreaves, 2005a, 2005b).

\section{New Models of school leadership of a single school}

In addition to new roles for headteachers as system leaders, new models of school leadership of single and multiple institutions have developed. This includes shared headship and headship involving multi agency partnerships (Coleman, 2006; NCSL, 2007a) such as children's centres; co-locations of different settings such as special schools and mainstream schools on one site, and all through 0-19 provision all of which impact on the leadership 'capacity' of the headteacher to manage them (Southworth, 2008, p.422 original emphasis). As many of these developments are new there is a dearth of research concerning them. Much of the research therefore lacks perspective over time and the scope of the literature is often limited to policy and practice researched by and on behalf of NCSL or TDA.

However the origins of new roles can be traced to the calls for system redesign and Labour policy which aims to raise standards of performance and children's well-being using a whole systems approach to integrating education and children's services. Bentley (2003) suggests that different organisations will be needed in the 21 st century which will cut across boundaries of health and education for example and will need organisations and institutions to work collaboratively (Hargreaves, 2003; Hopkins, 2006). Mulford (2003) cites the OECD to describe how the role of schools is changing in that they are becoming 'multi-service establishments, incorporating child care and pre-school as well as formal schooling and recreational services' (OECD, 2001, p.47).

Labour's commitment to early provision to ensure a minimising of social deprivation is to be found in the Sure Start scheme which has led to the introduction of children's centres. Children's centres provide support to families for childcare, family support and employment help through Job Centre Plus and many are located on school sites with implications for changing the role of the headteacher. It was the first phase of 'joined up' multi agency services which was to be further developed in the Green Paper Every Child Matters (2003a) followed by the Children's Act (DfES, 2004e) which ensured the ' 5 Outcomes' of safety, health, enjoying and achieving, economic 
awareness and making a positive contribution were embedded into schools' provision. Following the Childcare Act (DfES, 2006) implications for EYFS to further ensure the 5 Outcomes for young children and reduce inequality to be in place by September 2008. Finally, the publication of The Children's Plan (DfES, 2007a) clearly indicates that the continued moves towards extended services and the continuance of an inclusive approach to child care and education is to be driven through school leadership.

Demaine (2005) argues that the aim of the government is to provide 'flexible, seamless and consistent services' for families and Whitty (2006) sees the role of LAs as bringing together social care and education. Davis (2002) sees the need for schools to provide social capital but it is location and cultural capital which continue to advantage children the most in term of 'securing elite routes' (Demaine 2005, p.120). To help to secure the delivery of its agenda the government has made training for Directors of Children's Services (DCS) part of the remit of NCSL from 2009. In March of that year there began a consultation on a change of name for the College to reflect its expanded remit.

\section{Section 5}

\section{Leadership and Management}

My research is concerned with the role of headteacher and how it is changing to meet the demands of 21 st century leadership. While changing the working practices of heads, the reforms of the last twenty years did not change the centrality of their role in school (Menter et al. 1995; Hall and Southworth, 1997; Bell, 1999; Bell and Rowley, 2002; Southworth, 2008). The headteacher's role continued to be pivotal throughout the 1990s as Ofsted continued to see the leadership of the headteacher as a key aspect of a school's success as:

'The leadership qualities and management skills of the headteacher are a major factor contributing to a school's performance.' (Ofsted, 1998, p.4).

The establishment of NCSL in 2000 has been recognised as further evidence of the government's commitment to school leadership and the leadership of headteachers in 
particular (Bush, 2003; Southworth, 2004; Earley and Weindling, 2004; Harris, 2005). 'Leadership development' such as that provided by the NCSL 'has become the fundamental building block for the next stage of reform' (Barber, 2002a, p.185).

The difficulty of definitions: leadership and management

I wish to understand the framework of leadership and management and its practice that underpins the actions of, and interactions with others of, headteachers. Therefore it is necessary to ask, what are educational leadership and educational management?

Leadership was often seen as 'a subset of management' particularly with the emphasis on the managerial role of the headteacher but increasingly over the last decade it has been more dominant in its own right (Earley and Weindling 2004, p.14). An issue in compiling a literature review of leadership and management theory is the plethora of leadership definitions and models defined (Leithwood et al. 1999a, 1999b; Bush and Glover, 2003; Harris, 2005). There are differing and competing views and positions in leadership theory and its practices and the 'leadership territory' is 'an arena of struggle' (Gunter 2001, p.1). Yukl (2002, p.5) while accepting some definitions are more useful than others believes there is 'no correct one' and Leithwood et al. (1999b, p.4) argue that discovering the qualities of good leadership can be no more than discovering the 'basic skills' of leadership because 'outstanding leadership is exquisitely sensitive to the context in which it is exercised.'

Headteachers both before and after the managerialist reforms of the last twenty years will have demonstrated aspects of leadership such as distributing leadership and being strategic and collegiate. However my research of the literature at this point is not to make a comparison between traditional and managerial leadership but to discover what has been identified as being required for the effective practice of leadership, to understand how the headteachers in my research practice leadership and management to allow them to manage their new roles. I therefore wish to find out from the literature which types of leadership have been identified as fitting the current school contexts for change. These are essentially collegiate in their approach together with a requirement for headteachers to be strategic. 
Applying a definition is also complicated in that 'Writers on educational management and leadership are still exploring recently charted territory' (Day et al. 2000 p.7) and this can lead to potential confusion regarding definitions of leadership in that several different labels are applied by commentators to the 'same conceptual terrain' (Harris, 2005) i.e. instructional leadership being a 'variant' of transactional leadership (Webb, 2005) which is sometimes called by commentators (Southworth, 2005) 'learning centred leadership'.

In addition leadership and management has been painted as a 'fabricated binary' in that management prior to the ERA was seen as both 'strategic and visionary' (Gunter, 2008, p.262). Despite this and even though research is 'inconclusive about exactly how leadership influences school and student outcomes' due to the diverseness and variable quality of studies into leadership 'School leadership has recently established a new primacy' (Harris, 2005, p.73). The leadership of heads is viewed as critical for driving forward the policies of the government. This is an example of leadership being 'reworked and developed over time to sustain political and economic interests' (Gunter, 2001, p.9).

There has been an increased knowledge brought to the field of leadership and management by practitioner researchers following the introduction of NCSL and its opportunity for school leader research associates although these are small scale. It is claimed there are still echoes of the problems of understanding what leadership is which was articulated by Bennis (1959, p.259 in Harris, 2003, p.15):

'Of all the hazy and confounding ideas in social psychology, leadership theory undoubtedly contends for the top nomination.'

Gronn (2000) while accepting this doesn't see it as a reason for ignoring the idea of leadership.

\section{Types of leadership}

How school leaders exercise leadership is of central importance to the debate due to their use as an 'instrument' (McEwen et al. 2002) 'implementor' (Gunter, 2008) or 'lever' (Harris, 2005, Barber and Fullan 2005, Hopkins, 2007) for government policies for raising standards and transformation. However in doing this it would 
possibly suggest that what are the generic skills of leadership is a known concept which is also why there is considerable guidance on how to lead produced by the College and in the national standards for headteachers (DfES, 2004d).

Literature concerned with educational leadership has been considerably influenced by those working in the field of school improvement and school effectiveness (Earley and Weindling, 2004; Harris, 2005; Webb, 2005). These include Grace (1995), Sergiovanni (1998) and Hopkins, $(2001,2003)$. However as most models stem from either transactional or transformational leadership (Burns, 1978) I will turn to a brief consideration of them before moving to the areas of leadership which are most relevant to my research.

\section{Transactional Leadership}

A transactional leader is concerned with the 'key outcomes of an organisation and focuses their attention on ensuring the tasks needed to be done are completed usually through delegation to others' (Harris, 2005 p.78). The disadvantage with this form of leadership during a period of rapid change which has been evident during the 1990s and 2000s is that it isn't able to adapt quickly enough (Day et al. 2000). In support of this notion Gronn $(2003$, p.17) points to the leader in the 'new world order of the restructured, learner-centred, self-managing school...[being] transformational leaders, because transformation is the extent of the change and level of engagement demanded by school systems and principals' employing authorities.'

\section{Instructional leadership}

Instructional leadership is a 'variant' of transactional leadership (Harris, 2005) which with its emphasis on the efficiency of management systems is the preferred choice of policy makers because school improvement exponents such as Hopkins (2003) believe that raising standards in schools is dependent on focusing on the processes of teaching and learning (Webb, 2005). Harris (2005, p.83) cites Leithwood and Louis (1999, p.502) who suggest instructional leadership 'is now a dying paradigm' because it is too heavily classroom focussed. However, the introduction of 'learning centred leadership' (Southworth 2005), would suggest that instructional leadership is no longer 'a dying paradigm'. 


\section{Transformational Leadership}

Unlike transactional leadership 'transformational leadership entails a change in the leader-follower relationship for mutual benefit and good' (Harris, 2005 p.79). Transformational leaders are seen as people who can inspire and enable others (Kouzes and Posner, 1987, in Leonard and Leonard, 2001). Through working in this way by 'building relationships' and enabling and empowering others, such leaders are able to build internal capacity (Leithwood et al. 1999a) seen as essential for today's leaders (Hargreaves, 2003). This doesn't preclude the view that such leaders existed in the past merely emphasises their importance now and in the future. However not all observers believe it is always for mutual benefit as transformational leaders can become obsessed with their own vision (Bryman, 1992) and this can lead to less of a shared and more of an imposed vision.

\section{A combined model}

Burns (1978) separated transactional and transformational leadership. This view of them as distinct is not shared by more recent observers as the pace of change and rise of managerialism has increased the complexity of the leadership of the headteacher. Southworth (1998a) sees transactional and transformational leaders as 'complementary and supplementary' rather than in opposition to one another.

Leadership is contextualised and contingent (Leithwood et al. 1999a; Leithwood et al. 1999b; Bush and Glover, 2003; Leithwood et al. 2006a, 2006b) and within the same school context, headteachers are likely to include most types of leadership in their practice. Day et al. (2000 p.163) considers that heads in their study were transactional leaders by ensuring 'systems were maintained and developed' and 'targets met' and combining this with transformative leadership by building on 'esteem, competence, autonomy and achievement' within their school. Transformational leadership may be required to influence others where a school has been identified as failing, and needs to change quickly, but the practice used may be uni-directional in terms of managing people and transactional. This combination of leadership practices has led to the argument for valuing an integrated model due to distinctions between forms of leadership being 'artificial' in these circumstances (Bush and Glover 2003, 
p.12).While an integrated model has the potential for less confusion, it may however lead to reductionism (Harris, 2005).

\section{$\underline{\text { Post-transformational leadership }}$}

Day et al. (2000, p. 158) have suggested a new theoretical framework for a model of leadership which they have called 'post transformational leadership'. They argue the need for this new model is because 'existing rational theories of leadership do not adequately reflect or explain the current practice of effective leaders.'

Underpinning this framework is the understanding that there are dilemmas and tensions around competing agendas for school governance and therefore for educational leaders referred to by Glatter (2003, p.47) as being between:

- Integration and fragmentation

- Competition and co-operation

- Central and local decision making

Headteachers need to ensure the cooperation of staff and their alignment (Harris, 2003, p.19). It is in winning 'hearts and minds' rather than managing people that distinguishes post transformational leadership from transformational leadership (Day et al. 2000). If so it could be argued that leadership is being viewed in terms of influence. Influence can be 'intentional' (Yukl, 2002) and it is used as such in this sense, as it is exerted over others and generated in the form of relationships or expertise. Simkins (2005) suggests that collaboration and the use of co-operation will be more necessary than the use of formal hierarchical power in the future of leadership in this way. This would support Harris (2003) in her argument that effective leaders in the post transformational model 'share power' and have 'moral purpose'. Alternatively heads may be less benign in their approach to winning hearts and minds and become manipulative in their approach to complying with the national agenda for the sake of compliance. Webb $(2005, \mathrm{p} .76)$ 'questions whether seemingly conflicting and contradictory models at the rhetorical level really can be readily combined in practice' and argues the increase in managerialism has been at the expense of educative leadership and led to a dominance of transactional leadership. 


\section{Distributed Leadership}

Bryman (1992) suggests that the transformational leader often demonstrates a 'charismatic' style of leadership which if it leads to a 'hero' head approach rather than a collegiate one has been discredited (West Burnham, 2005, 2007; Southworth, 2008). If the influence of leaders is only uni-directional from the headteacher to staff as it is being suggested, in the singular hero head model then the leadership of the head would be difficult to sustain with the extensive managerial agenda of current headship. Day et al. (2000, p.160) are 'unequivocal' in their belief in the 'centrality of leadership' in an effective school. This is not of course the same as that centrality being located in the position of headteacher but is instead located in a group of school leaders. Therefore, 'Leadership is being redefined to encompass notions of distributed or devolved leadership' (Harris, 2003, p.22) by some commentators (Spillane et al. 2001; Spillane et al. 2005; Spillane, 2006; Gronn, 2003; Harris, 2003). System redesign considered necessary (Bentley, 2003; Hargreaves, 2003; Hopkins, 2006) is unlikely to be successfully implemented through the top down 'command and control' (Harris, 2003, p.22) approach to leadership synonymous with the sole leadership of the headteacher. In addition headteachers have been identified as requiring 'emotional intelligence' (Goleman, 1995). However while having emotional intelligence may give headteachers a degree of understanding of situations it doesn't guarantee that they necessarily exercise it in their leadership.

Harris $(2007,2008$, p. 173) cautions against the use of distributed leadership as a 'catch all' term to describe any form of shared leadership in schools or that 'everyone leads'. Nevertheless, distributing leadership through empowering and motivating others to lead, and that leadership is not just located in the role of an individual such as the headteacher, has been identified as a mechanism for creating effective organisational change (Spillane, 2006). This doesn't in itself mean that the role of the formal leadership of headteachers is 'redundant' but those in formal roles would act as 'gatekeepers' to the practice of distributed leadership in schools (Harris, 2008, pp. 174-175). The extent to which distributed leadership is allowed to happen in schools however is still located in the power of the headteacher (Hatcher, 2005).

School leaders are now being exhorted through training programmes (e.g. Consultant Leaders Programme, NCSL, 2005; Associate Heads Programme 2008) to develop a 
coaching and mentoring approach suited to the collegiate or moral model of leadership. In addition leadership has been distributed to senior management teams due to the increasing complexity of the leadership of headteachers with system leadership and multi-agency working causing their work to be intensified. This has been facilitated by the Government introducing the role of Assistant Headteacher and the Leadership Group in its Green Paper (DfEE, 1998a). The role of those in middle leadership positions has therefore been recognised as an important contributory factor to school improvement and effectiveness which is evident from the leadership programme devoted to middle leaders 'Leading from the Middle' (NCSL).

\section{Collegiality, collaboration and system leadership}

Collegiality and collaboration are being promulgated as forms of leadership which are more suited to the stress on changing leadership with an emphasis on schools working together rather than in competition as a result of the failure of standards based reform (Harris, 2005, Hoyle and Wallace, 2007). 'Collaborated leadership' requires a "reciprocal" interdependency where the practice of different leaders requires input from one another to produce a particular leadership practice' (Spillane et al. 2005, p.39) and this can be applied as a concept across schools. Collaboration is a form of leadership particularly encouraged for those engaged in system leadership. Harris et al. (2006, p.406) use Gronn's (2003) term ‘conjoint agency' to describe executive leadership in that 'it requires considerable negotiation about what occupants of a role space actually do in practice.'

\section{Collegiality and collaboration within schools}

Within school collegiate practice can be seen to take place when groups of teachers make decisions or feed their ideas to the whole staff (Webb, 2005). Superficially this may appear to be a benign culture of collaboration. However heads may directly or indirectly control the work of such groups for their own ends or for expediency. For this reason Hargreaves (2001, p.189) councils caution. He maintains that there are 'no such things as "real" or "true" collaboration or collegiality'. A pertinent question then - is where is the locus of control? If it is a 'contrived' and headteacher led form of cooperation then collaboration within this would become 'contrived collegiality' (Hargreaves, 2001, p.191) undertaken for the benefit of the headteacher and not the 
obvious empowerment of staff. However if heads find their role 'isolating, positional and powerful' (Southworth, 1999, p.61) the fact that they are being encouraged to be collegiate and share their leadership with others such as the SLT (Wallace, 2001, Spillane et al.2001, Spillane et al. 2005, Spillane, 2006) will result in tension.

Circumstances may dictate the degree of collegiality headteachers can undertake in that some situations of failure may mean that staff need to be more directed.

Collegiality is complicated when there are other imperatives which drive headteachers such as their accountability for the national agenda. There is a hybrid, which is the operation of a collegial approach by headteachers until it becomes necessary to take action to satisfy the requirements of externally mandated policy (Wallace, 2001). Webb (2005) observes that inspection could be one such example of an imperative driving leadership. In such circumstances leadership teams which operate in a manner which fosters collegiality and a professional approach can also promote a degree of hierarchy with the need to assure the quality of practice prior to Ofsted inspection. Therefore there is a tension between the distribution of leadership and the need for headteachers to maintain their hierarchical power (Hatcher, 2005).

\section{The moral dimension or values led leadership}

McEwen et al. (2002, p.150) maintains that the actions of heads 'are framed within the context of sets of values'. Webb (2005) uses Grace (1995) to illustrate that the moral dimension has been seen to be a part of educative leadership but that he argues this moral dimension causes dilemmas for headteachers because such moral actions indicating commitment to community and social justice are not considered indicative of successful schools. However this seems to be changing as recently writing on effective leadership has concentrated on headteachers making a difference.

The current strap line of NCSL (2009) is 'inspiring leaders; improving children's lives' and so emphasises moral leadership and moral purpose (Fullan, 2001, 2002, 2003; Harris, 2003). While these are not directly measurable by Ofsted they are considered to be a part of what makes successful leadership which in turn contributes towards making a successful school. Webb (2005) believes that 'the values and purposes of schools are derived externally from the recommendations on curriculum and teaching made by government agencies'. Practice changes according to 
adjustments made by teachers affected by the systems and routines imposed on them to accommodate the agenda. The current agenda for moral purpose is to be found in the need to raise the bar of achievement for pupils and close the gap between them (Hopkins, 2003; Barber and Fullan, 2005).

\section{Management of change, compliance, strategy and guilt}

\section{Compliance and change}

Headteachers have had to manage constant unremitting change since the ERA which has become increasingly complex in the way it has changed the roles of headteachers. Change in the last twenty years has been both 'simultaneous' and 'multiple' (Southworth, 1998b; 2008) and brought with it tensions between welcomed or opposed change and anticipated and unplanned change (Garrett, 1997).

The management of change in schools is an important aspect of successful managerial leadership and essential to implement government legislation. Whether the changes to the headteacher's role have been chosen by them, such as the decision to undertake an external role, or imposed on them such as the introduction of a children's centre on site, the way in which headteachers interpret change through their judgement of it, and commitment to it, must affect the way they implement its requirements. The question to which I seek the answer from the literature is to what extent are headteachers committed to implementing change through intrinsic belief in the policy or because they have to comply?

Elmore (2005) suggests that improvement can be highly complex and that the knowledge needed to implement change may come from outside the organisation. In primary schools this knowledge can come from a variety of sources either imposed advice from inspectors or SIPs or that sought by headteachers, either by themselves or on their behalf, from advisers and consultants or from research.

Preedy et al. (2003, p.6) have identified the requirement for heads to balance internal demands of an individual school in terms of its 'values, purposes and priorities' whether these are the heads own or gathered collegially, with 'externally initiated innovation' such as conforming with the strategies, or interpreting and analysing data 
or preparing for inspection. Moore et al. (2002) used the term 'principled pragmatism' to describe the position adopted by some headteachers in their sample who tried to find a balance between managing the education reform agenda and their own educational philosophy. In this way they are open to new ideas but also aware of, and take account of, the way in which these will impact on the needs of their pupils. Wright (2003) would disagree that in doing so they are exercising leadership because it cannot be properly exercised through the will and autonomy of the leader according to their moral purpose because they need to work within a strict legislative/political framework. However I would suggest that leadership is not an absolute and that absolute autonomy will never exist and leadership is greater if it exercised against the odds.

Fullan (1991) has been cited in Leithwood (2001) to illustrate that variation in the amount of improvement impacting on schools from reforms is due to the differing abilities of school leaders to make sense of the reforms and to use them effectively in their schools. This is assuming of course that the reform measures themselves would effect school improvement. It may be the case that it is the measures rather than heads failure to understand them or implement them effectively which is the root of any failure to implement them successfully. In this case the blame for failure should be attached to the system and not the individual.

Despite whether the reforms themselves are effective, to be successful as a headteacher demands an ability to adapt school improvement initiatives and accountability practices to the aims and goals of one's own school and to fit them to one's own individual context. If so, a question to be asked is to what extent is the choice to implement change available to heads? Preedy et al. (2003, p.8) argue that the management of imposed change gives headteachers 'little room for manoeuvre'. Apple's (2001, p.606) view concurs with this arguing that it is simplistic to assume that 'the possibility of human agency and influence is always there' (Apple 2001, p.606). This issue in the literature is particularly important because I wanted to discover the extent to which the heads in my study exercise choice and if policy has to be initiated then to what extent can they mediate it?

\section{Mediating change and manipulating policy.}


Where policy has been imposed on headteachers there have been some opportunities for manoeuvre either provided consciously or unconsciously by the policy makers or taken by the headteachers who have interpreted the policy to suit the requirements of their context. Examples of this are marketisation and open enrolment polices which have meant that headteachers have had to act not only 'as mediators between government policy and their staff, but as agents between the school and its 'clientele', finding ways of making the school attractive and distinctive in ways other than through appeals to largely mandated programmes of study.' (Moore et al., 2002, p.175).

Opportunities for interpreting government policy can be due to its maintaining a degree of remoteness from the lives of those who enact it within schools (Leggett, 1997). This distance could allow for the creation of "spaces for teacher and headteacher manipulations of policy thus limiting the impact of managerialism.' (Moore et al. 2002, p.180 original emphasis). An example is what Suchman (1995, p.43) called 'workarounds' which is cited by Gronn (2003 p.22) to refer to the way school leaders can work around the standards by the way they adapt on the job revealing the tensions 'between the standards for a job and the realities of doing the work.'

The extent to which heads manage externally imposed change successfully is dependent on their ability to interpret the requirements of the external agenda and respond to it as an organisation which is a key component of environmental leadership (Goldring, 1997 in Preedy et al. 2003). This means that school leaders need to be proactive in mediating and shaping external demands and thus their 'agency' at local level becomes important (Moore et al. 2002). Preedy et al. (2003, p.4, original emphasis) suggest leaders use three strategies to shape external demands for change. Firstly, they reduce ways in which the organisation is 'dependent on its environment'. This can involve alternative funding or managing the way external agencies are involved with or influence the school. Secondly, they can 'adapt the environment' or form partnerships with stakeholders and work together. Thirdly, they can redefine the environment' by trying to attract a different type of 'customer'.

A further question regarding headteacher's exercise of choice is to what extent are heads consciously choosing to act in a given situation because they have weighed up 
the factors and feel a course of action is the best one to take and to what extent are they a product of training and design to respond in a certain way? In terms of designer leadership the knowledge of the extent to which heads perceive they are designed is important. With the increase in the use of the national leadership programmes and practice advocated by those who largely accept the policy framework termed 'official school improvement' (Hatcher 1998, p. 490), managerial practice becomes internalised and so causes questions to be asked regarding the extent to which it is the headteachers' vision or their response to one suggested for them by training.

Bottery (2007a, p.162 original emphasis) agues that 'there will always be some room for interpretation, selection and mediation of policy directives' even with the most 'deterministic' of government policy, total control over implementation is not practical. He cites Day et al. (2000) and Gold et al. (2003) to argue that 'perhaps the core issue in good leadership - is the moral integrity of the individual' in the way in which they manage external policies. Such moral integrity will need to be shown for example as Leithwood (2001) suggests in that school leaders will need to demonstrate moral courage and to do so in building support for a suitably balanced curriculum in the face of the challenges of a tests based agenda.

Moore et al. (2002) in their study of head's motivations, while accepting Convery's (1999) notion that people can hide unpalatable truths from themselves, still feel that the head's vision was ideologically based over the years, rather than routed in managerial discourse. They question:

'the extent to which heads may be acceding to managerialist functions at the expense of educational values or authentic leadership roles...' (Moore et al. 2002, pp.179-180).

If Moore et al. (2002) are correct then headteachers in maintaining their own core values are acting in a form of 'principled infidelity' (Hoyle and Wallace 2007).

If the heads in my study are being compliant with the agenda knowingly then to what extent are they doing this as a form of 'strategic pragmatism' (Moore et al. 2002), 'strategic compliance' (Lacey, 1977, cited in Boyle and Woods, 1996) or 'ironies of adaptation' (Hoyle and Wallace, 2007, p.18 original emphasis)? How are heads as professionals working around the expectations and prescriptions to which they are 
subject and in doing so allow them some space to do that which they feel is in the best interests of their school's or their own survival? One way of doing this (Osborn et al. 2000, p.68) is to mediate the pressures of the test environment. Another way would be to teach creatively beyond the constraints of the national curriculum (Woods, 1995) referred to as 'strategic redefinition' (Boyle and Woods, 1996, p.558). Heads accommodate changes. This would suggest that in managing change they may not agree with, or is difficult to implement via a 'pragmatic response', preserves some sort of 'visionary stability' in the school (Moore et al. 2002).

That headteachers mediate policy is really important in terms of my research because if heads can subvert policy through pragmatism or 'ironies of adaptation' (Hoyle and Wallace (2007, p.18 original emphasis) they can influence how they implement it (Bottery, 2007a). Such subversive action also occurs when headteachers 'represent' their work to the 'agencies of accountability' to look as though they are meeting expectations referred to as 'ironies of representation' (Hoyle and Wallace (2007, p.18 original emphasis).

There is also a consideration which needs to be made by headteachers in managing imposed change regarding the consequences of not doing so. The SEF is an example of policy which has been imposed but isn't mandatory. Only the self evaluation of the school is mandatory. However not to do so is a risk for heads because of the expectation by Ofsted that it will be in place:

'Evidence of how effectively schools undertake self-evaluation and the use they make of it helps inspectors to evaluate the quality of management in the school and the capacity of the school to improve.' (Ofsted, 2005, p.9)

The consequences of failing to produce a SEF is the potentially negative view inspectors will take of school's leadership and the impact this will have on the school's grading in inspection. This in turn will impact on the extent to which heads will be able to exercise their autonomy.

Leithwood et al. (1999b) argues that the type of attributes and skills that leaders display needs to change accordingly as times change. Leadership has to react to 'officially prescribed leadership definitions to which school leaders are currently being steered.' as well as those identified by research (Bottery 2004, p.2). Support for 
this argument comes from Webb $(2005, \mathrm{p} .77)$ who refers to 'approaches to leadership... [being] legitimised and encouraged by the extent of government prescription'. Examples of this might be Ofsted's views of effective leadership for example (Ofsted, 2003) and those of NCSL. A pessimistic view of the results of official steering is what Wright (2001) calls 'bastard leadership' because the 'vision' and 'direction' of the school sits with those who determine policy rather than the school leaders themselves. I wanted to discover in my research the extent to which heads were responding to government mandated change because they felt they had no alternative or because they had internalised the need for it.

\section{Guilt}

Some guilt 'can be good for one' when it spurs people on to do better but it can also lead to 'burnout' and 'exit' (Hargreaves, 2001, p. 142). Compliance with the implementation of externally mandated reform and performativity may lead to feelings of guilt and self-betrayal (Bottery, 2004). In this form guilt becomes unproductive both at a personal and system level. Davies (1989, in Hargreaves, 2000, p. 143) describes two forms of guilt which are 'persecutory' and 'depressive' guilt.

\section{Persecutory guilt}

This is the type of guilt experienced by headteachers when they are pushed to comply with an agenda which is at odds with their beliefs and have failed to accommodate it pragmatically to their satisfaction (Hargreaves and Tucker, 1991 in Boyle and Woods, 1996; Hargreaves, 2000; Moore et al. 2002). Examples of this can be identified in tensions which may exist in the conflict between doing what headteachers feel is essentially right and in the best interests of the children and the need for the school to compete through the market for places and implement management processes to do so (Moore et al. 2002).

Another aspect of persecutory guilt is caused through failing to achieve expectations and is often found as a result of 'accountability demands' or 'bureaucratic controls' (Hargreaves, 2000, p.143). Boyle and Woods (1996) described this as being manifested for the heads in their research as guilt arising from failing to fill in forms. Similarly Riddell (2005) describes the guilt felt by the profession who fail to raise 
standards in schools especially when the government exaggerates the effect of their agency in doing so as they possibly do in some urban situations of deprivation.

Leithwood (2001, p.226) argues that the consequences involved in failing to achieve can create incentives for cheating, a sense of guilt and possibly 'a sense of dissonance and alienation'. It is the guilt which causes compliance to the agenda by headteachers and leads to stress from work intensification and persecutory guilt because the job is never finished.

\section{Depressive guilt}

'Depressive guilt' is one where 'individuals feel they have ignored, betrayed or failed to protect the people or values that symbolise their good internal objective' (Davies, 1989 in Boyle and Woods, 1996, p.564). Headteachers may feel guilty at having to comply with those aspects of the agenda they disagree with such as 'teaching to the test' to obtain maximum results but feel they must in the best interests of their school succeeding in the market place. In this they have failed to protect the best interests of the children.

\section{Conclusion: The future of school leadership}

The lack of flexibility in the system was recognised in 2001 in the calls to redesign the system (Bentley, 2002; Hargreaves, 2003; Fullan, 2005; Caldwell, 2006; Hopkins, 2006, 2007). A dilemma for those who wished to change the system was that innovation and creativity if it was not 'well developed, represents a major political risk' (Hopkins, 2007, p.42) and to trust headteachers as a whole might result in unleashing the fears associated with letting a thousand flowers bloom (Hargreaves, 2003 , p. 37). However not to trust them didn't allow for finding solutions to complex adaptive problems by those who operated at the micro-level of education. A degree of 'earned autonomy' therefore needed to be offered to those whom the government could trust (Morris 2001).

New models of school leadership are being introduced into the school system as a solution to the issues of succession management (Hargreaves, 2007a, 2007b, 2007c) and the need to reduce school variation by spreading best practice (Southworth, 2008). There is an increase in the use of headteachers as system leaders (Earley and 
Weindling, 2006; Hopkins, 2006; 2007; Southworth, 2008). My research has involved interviews with those headteachers who fit the criteria through validation by Ofsted of school leaders the government might trust to implement its policies. Bottery, (2004, p.89) notes that Morris's (2001) speech is 'devoted to governmental difficulties in trusting teachers' and not about the difficulties teachers have in trusting the government and so consequently is unlikely to meet the needs of teachers to remedy this.

I wanted to discover the extent to which the agenda for change has impacted on their role and actions. To what extent have they recognised and taken advantage of the new roles which have been offered to or imposed on them through the redesign of the system? What has been the impact on their leadership in having to accommodate these new roles? And what have been the implications for the system? 


\section{CHAPTER THREE: Methodology}

\section{Designing the research}

I aimed to find answers to my research questions through qualitative social research using semi-structured interviews. The interview approach was appropriate because my findings couldn't be arrived at by statistical procedures (Corbin and Strauss, 1990). In common with the research methodology of Bottery (2007b, p.93) I accept that the impact of government policy on headteachers 'cannot be assessed solely on the basis of interviews with them.' However like him I was interested in the 'perceptions' of headteachers. In the case of my research it is their perceptions of the educational agenda and how it had changed and was continuing to change their leadership and providing new roles for them. Unlike quantitative research I hoped to analyse concepts, relationships and issues (Pollard and Tann, 1993) therefore statistical representations were not relevant.

My perspective as a headteacher has contributed to the construction and articulation of findings gained from a range of interviews in two rounds from 2005-2008. While there may be some differences in focus regarding representation of headship and length of study, my research method in is in common with others researching in the area of the role of headteachers (Webb and Vulliamy, 1996d; Jones 1999b, 1999c; Bottery 2007b) in using semi structured interviews for all or part of the research.

\section{The purposive sample}

I engaged in purposive sampling and in some cases a 'snowballing' approach where the interviewees suggested others (Drever 1995). This occurred with reference to the executive headteachers. I was aware of the need to have a guiding principle with regard to my sample to avoid the criticism of bias (Drever 1995). I wanted to guide the sampling to ensure that there was a selection of respondents according to gender and experience and geographical context who would enable me to answer my research questions (see appendix 1). Harris et al. (2006) focused on the findings of one case study, but it wouldn't have been sufficient for me to do so as this would not have shown any trends or patterns in changes to the professional lives or identities of heads. Due to the nature of my study it was possible like Hopkins and Higham (2007) 
to choose a number of heads and to make generalisations within this defined 'population' (Drever 1995).

Context is an important factor in the actions of school leaders (Leithwood et al. 1999a; Leithwood et al. 1999b; Leithwood et al. 2006a 2006b; Southworth, 2004) and so I made context a determining factor in the choice of interviewee. One overriding contextual factor was that I have limited this study to those heads that have been judged to be effective. The definition for my purposes is taken as being those who have been validated by Ofsted inspectors or HMI as 'very good, 'excellent' (pre 2005) or 'outstanding' (post 2005) either in their current schools, or a previous one. This would reduce the variables for analysis as I chose to assume that any degree of earned autonomy for heads was likely to be granted to those who were validated by Ofsted. This is not to assume that I believe that this is the only determinant of the effectiveness of a headteacher but I am not trying to make generalisations across the scope of headship. Like Harris et al. (2006) and Hopkins and Higham (2007) who interviewed executive headteachers I am constructing findings across a specific and tightly controlled range which in my case is headteachers who have been validated by Ofsted.

Within the confines described above I ensured that I had a range of stages of headship, gender and social context. This was more difficult when I was looking for evidence of system leadership. Harris et al. (2006), Hopkins and Higham (2007) and Chapman et al. (2008) have all highlighted that the data in this area is sparse.

I haven't analysed responses according to which local authority any of the headteachers worked within as there was too small a sample to make this worthwhile. To have included more headteachers in each authority was beyond the scope of my resources. It would however be useful for future research to discover the extent to which LAs are changing as a result of the changing role of the headteachers who work in them.

\section{The changing purposive sample}

My intention was to interview as many of the sample as logistically possible within the constraints of my resources in two rounds. The purpose of the second round of 
interviews after a year's gap was to track the views of the headteachers to answer my research questions over time and to investigate the extent to which government educational legislation had impacted on their role.

In the first round heads were chosen at random from a list of effective headteachers and to compile this I drew on Ofsted data for leadership of the headteacher using LA recommendations or what Hopkins and Higham (2007, p.151) referred to as 'local intelligence'.

The choice of which heads to interview in the second round was more strategic due to my professional though not personal knowledge of all of the headteachers and in order for the sample to match my changed requirements of purposively sampling system leaders. The sample was compiled as a result of what I know of the system in terms of a list of NLEs or consultant leaders from LAs or NCSL.

My decision to concentrate on headteachers with new roles in the second round is justified in that I have conducted this research at a critical time for system leadership (see Chapter 2). As $95 \%$ of the sample of headteachers are system leaders, this has allowed me to draw some conclusions about how heads manage these roles and build capacity in their schools which have implications for future research (see Chapter 7). This high percentage of system leaders also strengthens my research and the depth with which I have been able to probe the interviewees. I believe these advantages of sampling outweigh the disadvantage of using a sample where 'statistical confidence will be low' (Drever 1995, p.33).

\section{Non headteachers in the sample}

I chose other non headteacher interviewees to give added first hand information regarding the national agenda, above that which I could gain from reading and as an opportunity to triangulate data (Cohen and Manion 1994).

Steve Munby the then Chief Executive of NCSL was purposively selected because of the knowledge and understanding he would bring to the debate regarding national challenges and the Government's reaction to them as supported by the work of NCSL. 
I included one expert practitioner for workforce reform to give added background information to my literature review. He both had extensive local authority experience and had undertaken work in this area for TDA.

I interviewed two principal officers of an LA who were chosen due to their seniority, experience with the workforce agenda and the supporting and monitoring roles of the LA. The two principal officers were also able to locate the changing role of the LA in terms of its movement from an education service to a children's service and their attitudes and responses to new models of leadership. I interviewed representatives from one local authority. I intended to include other LAs in my research design but after the first interviews I realised that to include other LAs would widen the scope of the research beyond that which was needed to answer my research questions. Consequently I decided to restrict my findings to the perceptions of headteachers in terms of their role and the future of leadership.

\section{The interview schedule}

I conducted 32 interviews from July 2005 to February 2008. Of these, 26 interviews were with headteachers in order to have enough in my sample to ensure a suitable range and comparison. Of the 26 interviews with headteachers 22 were with individuals and 4 were revisits as these headteachers matched my changed criteria and were available for interview in the second round.

Three interviews were with Steve Munby the then Chief Executive of NCSL and were staggered over the years 2005, 2006 and 2007. The remaining three interviews with the senior officers in the LA and the expert practitioner for workforce reform were conducted in September and November 2005 respectively.

I intended to locate the interviews mainly in the English Midlands which included areas within a 100 mile radius of Birmingham. However due to the purposive nature of my sampling and the need to let my data guide me, I extended my reach in the second round. The heads were from nine different authorities, seven of which were predominantly urban. One authority was in the North West, one in the South East, one from the East Midlands, two from the South West, one from the North East, and three from the West Midlands conurbation. I included in my interview schedule a range of 
heads in LAs beyond my own because I believed that attachment to an authority may have had an impact on the level of engagement headteachers had with both their LA and NCSL.

I staggered the interviews of heads beginning with a pilot interview and then in a batch of 11 for the first round before analysing the results to ascertain the emerging issues and themes and construct preliminary findings around them. Following this initial analysis I revisited 4 of the first batch and an additional 10 heads making a total of 26 headteacher interviews in all. These were staggered at different times during the course of the school year and in two rounds (July 2005- September 2006, and April 2007-February 2008) due to my wish to discover if the emerging educational agenda for change had impacted in the interim, practicalities of availability and my own time constraints.

\section{Analysing the data}

\section{The pilot interview July 2005}

As befits the Glaser $(1978,1998)$ model of grounded theory I simultaneously collected, coded and began to analyse the data from the beginning. I was particularly glad that I did so because the data I obtained and the analysis of it shaped my research into three phases. These were the pilot, the first round of interviews, and following my analysis of these, I shaped the second round of interviews.

I began the data analysis in July 2005 having conducted a pilot interview. Pilots can be useful as a 'trial run' (Drever, 1995) and as preparation prior to the start of research (Sampson, 2004). It is also possible that issues may arise during the pilot that haven't been taken into account in the design of the research or in the original questions which can then be used in the main interviews (Drever, 1995; Sampson, 2004) giving me the opportunity to frame questions appropriately from the beginning of the interviews (Ball, 1993 in Sampson, 2004). I found this was an accurate prediction.

I started my research by using a headteacher for a pilot interview. I used a structured form of questioning which I found led the interviewee along the lines of thoughts I 
had myself recognised as a disadvantage of interviewing (Drever, 1995). This led me to a realisation of the extent to which I should let the research unfold (Cassell and Symon, 1994 in Sampson, 2004). I concluded that while I wished to find out the extent to which heads were constrained by, or motivated because of, the national educational agenda, I would discover this match more readily if I allowed heads to drive the interviews. As a result of the pilot I asked headteachers in the rest of the interviews what they felt their issues were rather than impose those issues on them, by leading them with questions about specific areas for change articulated through an analysis of government educational policy. In this way I hoped to avoid leading the interviewees, thereby finding out what drove them as school leaders and not specifically how they reacted to certain policy initiatives.

My pilot interview was with a headteacher who was also a friend, which led to a display of many of the skills Hook (1985, in Southworth and Connor, 1999) suggests we employ, such as humour, support and qualities such as rapport and trust, friendliness and understanding. However I think the difficulty of maintaining formality and the temptation of guessing what I thought he meant undermined any advantages of in depth knowledge that I had as a researcher in these circumstances and I ran the risk of bias (Drever, 1995) and the disadvantages of over familiarity (Hockey, 1993).

I chose not to use the pilot interview in my analysis. Nevertheless I feel that this pilot was a worthwhile exercise because it allowed me to avoid a haphazard approach once the research had begun (Sampson, 2004). There were difficulties in taking notes while maintaining the flow of the dialogue and keeping the interviewee on task, a disadvantage associated with interviews (Drever, 1995). Therefore I chose to record data in the remaining interviews.

Drever (1995) recommended tape recording and I used the modern equivalent. The data collection was consistent in that each interview was recorded digitally and down loaded to a computer using 'Olympus Digital Wave Player'. I typed the transcript verbatim as soon as possible after the interview. I chose to do this because it gave me a deeper understanding of the nuances of expression in the way the heads expressed their views on the recording, which I might have missed at interview and wouldn't be available in reading a transcript typed by others. 
The questions were asked depending on the flow of the interviews. In keeping with my desire to let the heads speak for themselves and not to direct them or to stop them in mid flow I decided that if they were already providing information about the areas I required I would allow this to develop naturally as the interview progressed or in the form of individual prompts. This is one of the advantages of semi-structured interviews (Denscombe, 1998). In this way I both built up trust and allowed the interviewees to think in depth unimpeded by my constant intervention with questioning which I think could have created artificial barriers and direction.

This complicated the analysis as the interviews were being shaped by the interviewees and not by direct questioning. I haven't therefore analysed each question in turn but under the themes and issues as they were identified. This is a 'constant comparative analysis' as identified first by Glaser and Strauss (1967) because it involves taking each of the ideas or themes identified by the heads and comparing them with each other. I did this moving back and forth both within and between the interviews. I hoped this would allow me to collate important data and to construct common patterns and themes without being overly selective and losing objectivity (Bell, 1993).

After each interview using the processes of grounded theory I analysed the transcripts of interviews using open coding which enabled me to code as many times as each different incident warranted (Glaser, 1998). Thus each paragraph was interpreted as a coding aid (Miles and Huberman, 1994) and coded into as many different categories as necessary. I am aware that my process of recording and transcribing interviews is not one recommended by Glaser (1998) but is an accepted practice in interviews (Miles and Huberman, 1994; Drever, 1995) and I felt it added value to my understanding of the data allowing me to reflect.

In addition to open coding, I wrote notes of interpretation down the side of different paragraphs as suggested by Miles and Huberman (1994) and Denscombe (1998, p.130) based on Glaser's (1978) concept of memos. These were based on memories I had of the interview in terms of links to other interviews, gestures, tone and intonation of the interviewee and other observations. I also kept a research diary throughout the 
time of the research which was another form of data to which I could refer when constructing findings later.

I analysed each interview into as many codes as became necessary during the course of my interviews. After the first 11 interviews, when I was certain that no more codes would emerge in the first round, I grouped the codes as an inductive process, based on what had been told to me, into categories. For example within leadership I would have codes for leadership and attitude, leadership and performance management, leadership and external roles, leadership and accountability and so on.

To manage the data more effectively I pasted all the relevant data from the first round of interviews into categories around the coded data. I identified links with other sheets of categorised data. As each of these categories had its own page showing the links I was able to analyse across them by constantly comparing data to construct emerging theories (Glaser, 1998, 2002). I consistently moved from the data to the literature to enable me to understand my findings.

I noted which head made the comments and added any notes of interpretation I wished to record from the memos (Glaser, 1978, 1998) made earlier. This procedure helped me to build a more integrated approach to events and conceptual processes (Miles and Huberman, 1994, p.74). For examples see appendix 7. This also formed part of my triangulation of data. I am aware that my main source was semi-structured interviews and other data such as that obtained by questionnaire were not sought. Consequently I sought triangulation from the comparison of similar questions asked of the interviewees (Cohen and Manion, 1994) as well as a comparison of data from my other non headteacher interviews.

I was guided in looking at the data from the interviews as to how they would answer my research questions regarding how heads perceived their role was changing, why and how this would impact in the future. I then looked at the national educational agenda for change and how this was communicated to heads particularly through NCSL and the main themes which were shaping the changing role and how these two matched. 
Between September 2006 and April 2007 I reread all the data from my initial 11 interviews until I was sure that I had identified all the relevant areas mentioned by the heads. Having initially analysed the data I found I could make judgements on the themes forming. I became aware from the initial analysis that all those issues identified by the heads as impacting on their professional lives were to a greater or lesser degree described in relation to their impact on the standards attained by the children in their school and consequently the individual accountability of the headteacher.

My initial analysis led to 'fuller deeper waves of analysis' (Miles and Huberman, 1994, p.86) in the second round because it made me aware of something I hadn't anticipated. In addition to the emphasis on standards and accountability was the prominence in the first interviews of describing new roles, both internal and external, for some of these headteachers and the degree to which the standards achieved by the children in their school affected these roles as well as how they led and managed their schools because of them.

The pursuance of a wider external role has traditionally been an option and formed part of the professional lives of many heads so this was not an unexpected finding in my research. However I was surprised by the extent to which an external aspect formed part of the role of the headteachers in my sample. In addition new roles of school leadership such as the leadership of integrated Children's Centres became apparent. This impression was created during my interviewing and confirmed during my initial task of putting the data into themes. Interview question 3 (see appendix 4) made it apparent that for many headteachers the changing role of headship was likely to be manifested in part by the opportunities for new models and ways of leading schools and greater opportunities to widen their roles. For these reasons I decided to list the external roles of the headteachers 1-11 (see appendix 2).

This evidence was being gathered at a time when the role of system leaders and new models of headship began to gain momentum in the debate among headteachers. This is where my role as a headteacher and consultant leader and NLE developed and this insider knowledge also affected my decision. I was therefore aware of the debate among my peers as well as those in the interviews many of whom were actively pursuing a wider role. I decided to take this into account in the second round of 
interviews having reoriented my views following interim analysis (Miles and Huberman, 1994, p.86). While an investigation into the role of the headteacher was explicit in my research questions, the extent to which new roles were featured in the interim analysis led to the third research question and a focus of enquiry in the second round.

Following the interim analysis it became necessary to go and look at further coding within the themes to develop sub themes patterns and attitudes which would inform the detailed analysis and to consider the impact my analysis of the first round would have on constructing the research in the second round.

\section{NCSL as a factor in changes to the research}

Initially I had intended to include as part of my research a section about the role and influence of the NCSL on the professional lives of the heads in my sample. However I decided after my initial analysis that the inclusion of NCSL as a part of this research was not going to add to my understanding of the way the role of headteacher was developing. If I was to analyse according to my aim of letting the heads be the drivers of the research then to include questions about the NCSL was proving to be inappropriate. It was not arising naturally as part of the interviews and became separate from it. I decided therefore not to pursue this line of questioning in terms of the focus of the research or unless it came up as part of the answers to the questions about their issues put to my interviewees.

\section{The second round of interviews April 2007-February 2008}

My original intention in having a second round of interviews was to track the changes in their role identified by the headteachers from the first round. However as the research was unfolding it became apparent that to revisit all the original interviewees would not answer the question regarding the extended and new roles played by some heads which had arisen from my first analysis of data. I therefore had to decide both which heads to revisit and also who else to include in my second round of interviews. As all the heads had described the impact of standards and accountability to Ofsted on their role and actions as one of their main issues this didn't need to become a factor in making the decision as to who to revisit in the second round. The decision was based 
therefore around availability and the extent to which each headteacher pursued an external role or had expressed their intention of doing so during the first interview or who were undertaking new internal roles of school leadership such as co-locations or Children's Centres.

Most heads were involved to some degree outside their school as members of a consortium or other group. However for my purposes I have defined a significant external role as that of leading a group such as a forum or consortium or other network rather than just being a member of it. In addition, using Hopkins' (2006) and Hopkins and Higham's (2007) definition of 'system leaders', I have included those heads acting as a Consultant Leader or National Leader of Education or School Improvement Partner. I have also included those who work for the inspection services as an Ofsted inspector because it is an extensive role outside school (see Chapter 7 key finding 1).

From the chart of the cohort of the first 1-11 interviews I noted that Ht1 had retired although continued to work as a consultant, and Ht11 had moved on to the advisory service and so I decided that they would no longer be appropriate to revisit as they would not be able to answer my questions as practising headteachers. Two heads (4, 6) did not undertake system leadership as defined. Interviewees 3, 5, 7 and 8 were revisited in the second round and Hts 2, 9 and 10 would have been suitable but due to illness and unavailability during the interview period were not used. I wanted to see if these four headteachers had been able to continue to undertake work or to extend it and what motivated them and the barriers and opportunities which occurred from doing so.

I continued to use purposive sampling in keeping with the tenets of grounded theory (Robson, 1996, p.265) and in addition to the revisits I extended my sample by purposively seeking out effective headteachers who had a substantial external role for my second round of interviews. These interviewees included heads of federations and other executive heads such as NLEs unavailable when I drew up my initial schedule in 2005 as the first NLEs weren't deployed until November 2006.

I devised questions for the second round which would provide consistency by being the same for the revisits and the second round interviewees. However to ensure 
enough contextual information the new interviewees were asked the first question as were the earlier interviewees (see appendix 5).

Following the interviews between April 2007 and February 2008 I coded them according to the original chart of codes (see appendix 6). I found that the same codes could be used because I had coded so extensively in the first round. However some of them were little used in comparison such as networking and funding. I also subdivided leadership from the beginning to include specifically working as a system leader.

One of the first tasks was to chart the issues of all the interviews to determine if my original analysis of standards being the most important issue was still the same (see appendix 8) and to list the issues and the number of heads identifying each one (see appendix 9). In addition before analysing in depth I updated the interview chart to show the current external role undertaken by all the interviewees (see appendix 3 ).

In analysing the data for the second round I cut and pasted into themes and integrated all of this into the codes and themes already identified. It was immediately apparent that I had managed to collate a massive amount of data for some areas such as 'the changing role' or 'system leadership' or 'accountability'. I therefore reanalysed all the themes so that they were divided into sections such as motivation for each of the system leadership areas to make handling the data more manageable.

Data wasn't always obtained sequentially because in answering the questions the interviewees often linked themes, ideas and concepts themselves. One example of this was how accountability had been strengthened in some ways with the changes to the inspection schedule from 2005, which affected both how heads presented information in their school and managed their absence when pursuing new external roles. Accountability was mentioned in the question about issues impacting on the role of heads as well as answering the question about how issues had changed and also in probes about their new roles. I think this emphasises and helps to validate the point heads identified about the integral part accountability played in their leadership and management. 
I was able to use the patterns of evidence which formed through the themes becoming evident across the interviews. I triangulated these by cross referencing the reasons for the existence of new roles being given by different headteachers and compared with the reasons given by NCSL and the LAs. I chose not to use the evidence to provide a comparison study of national and local views but it was helpful to provide supporting evidence of the extent to which the heads were aware of the national educational agenda as it was being delivered by NCSL and through LAs brokering for NLEs or CLs as an example.

I undertook a final reading of the interviews and checked within and between interviews to ensure I had covered all the themes and patterns transpiring from the data. The main themes were:

- that new roles were becoming available for heads

- the impact of accountability was affecting their decisions to undertake roles and causing a degree of strategic and 'simulated' compliance (Thomson, 2008).

- Managing their roles and issues in turn impacted on leadership.

I have analysed each of these areas sequentially in separate Chapters $4,5,6$, followed by Chapter 7 which encompasses a construction of findings, conclusions and implications for the school system.

\section{The justification of interviews as a research method}

The structure of interviewing over a period of nearly three years allowed me to focus on individuals and to explore different people's perspectives (Hitchcock and Hughes, 1995). I had the time during the course of the research to make judgements over a long period and to return and review which enabled me to gather sufficient data to offer interpretations (Bassey, 1999) and therefore to construct findings. This was particularly important because my methods allowed me to analyse the rapidly moving and largely uncharted waters of change in terms of new roles for headteachers (Earley and Weindling, 2006; Harris et al. 2006; Chapman et al. 2008). 
The interviews were semi-structured where the questions were known to me and accompanied by a checklist but were still "flexible" (Drever, 1995). Not using a totally free and unstructured interview technique enabled me to develop the findings from the interview within a conceptual framework bound by my research questions.

Using interviews allowed me to work as a 'traveller' (Kvale, 1996, p.3) in that I have asked questions which have allowed interviewees to 'tell their own stories of their lived world' to see at first hand the feelings of the interviewee and this together with open questioning enabled me to discover insights (Southworth and Connor, 1999) I might otherwise have missed in using questionnaires or surveys. In addition to which, the interviewees may be more willing to share face to face than they would be to write revealing answers in a questionnaire (Corbin and Strauss, 1990). The use of interviews further enabled me to make judgements and assumptions which were probed or questioned and allowed me to ask supplementary questions as necessary. This allowed me to use prompts to open up dialogue and probes to focus on a particular point for expansion as I felt necessary (Drever, 1995).

I rejected the use of surveys because they were unsuitable for this research as they aim to provide a general picture of people's circumstances and opinions, across a defined 'population' and wouldn't have allowed me to explore individual viewpoints in depth (Drever, 1995, p.5). The great strength of being able to probe and question was that the interviews developed and allowed me to change the focus in the second round of interviews due to an analysis of the issues constructed from the first round. I wouldn't have been able to do this with a less flexible approach or one with fixed questions.

Questionnaires may have been useful initially to establish a suitable range of headteachers. However I felt that I had reasonable access to headteachers and I wasn't looking for a random sample or a range across the full scope of headship. Those interviewees who were not heads wouldn't have been accessed by questionnaire as their role was specific and their identities known to me. As my questions were open, general and not leading I didn't need to use a questionnaire to help shape the questions in the interviews (Drever, 1995). 
My interviews were between one and three hours with the exception of two headteachers $(19,21)$ which were conducted on the telephone for one and half hours and two hours respectively. This occurred because of the logistics of travel and availability of the subjects. With these exceptions the interviews were conducted face to face in a familiar environment for the interviewees at a location chosen by them, usually their office thus enabling them to be relaxed as identified as good practice (Drever, 1995).

Advantages of telephone interviews are that they are more convenient than travelling to face to face interviews and quicker (Bryman, 1989). The disadvantages of telephone interviews have been argued by (Drever, 1995) to include that observational data are harder to gather as the interviewees cannot be seen. This is a disadvantage given that he argues that ' $50 \%$ of the information given is non verbal' (p.15) Thus it becomes more difficult to make the interviewee "feel that the information $\mathrm{s} / \mathrm{he}$ is giving is important and beneficial' (Hook, 1985, p.136). To offset this danger I engaged in 'paralinguistic utterances' (yes, ah, mmn OK) to offer encouragement during pauses but not to talk over the interviewee (Drever, 1995).

The reciprocity of headship, the desire of the interviewees to be heard and the importance of their story to the research evidence base meant that the advantages of undertaking these interviews greatly outweighed the disadvantages.

\section{Conforming to ethical standards}

In common with the recommendations of Drever (1995) I ensured potential interviewees knew either by telephone or letter the aims behind my research and what the interview process would entail. I explained why I had chosen to contact them and that I wanted to complete the research as my own investigation into the views of headteachers and others as to the effects of the national agenda for change.

To ensure ethical access to the data from NCSL I contacted Steve Munby and Geoff Southworth the then Chief Executive and Deputy Chief Executive Officers respectively regarding general access to NCSL staff and access to the website respectively. Permissions and protocols were agreed in that the website was a public arena and subject to normal copyright. Restricting the NCSL aspect of the study 
during the course of the research meant that no staff members other than Steve Munby were formally interviewed. I contacted the LA officers by mail and outlined my research to them requesting an interview which they granted. Headteachers were approached in person by telephone with a follow up email confirmation.

All interviewees were offered similar protocols regarding confidentiality and access to data. I sent the transcripts to everyone for verification and followed up each interview with personal contact by email/telephone depending on accessibility and offered the interviewees the opportunity to change any aspect if they were misrepresented. Only one headteacher made changes (20) and the change was made to clarify her meaning in one sentence.

I assured them that I would not discuss their comments or data outside the interview and that they would be anonymous within it as I would change all recognisable names. Steve Munby remains the exception as he is uniquely identifiable by his position, but I did not discuss the contents of the interview outside this research which was agreed between us. Context was accurately described in terms of urban challenging environments but not contextual information such as area or specific context which could give away the name of the LA, the school or its headteacher. As headteachers are independent regarding the decision as whether or not to give me their opinions, I didn't feel it necessary to contact their LAs or Governing Bodies.

\section{Qualitative analysis: Grounded theory}

A definition of a grounded theory study is that it 'seeks to generate a theory which relates to the particular situation forming the focus of the study' and this theory is 'grounded' in the data produced by the research and the observations made of it (Robson, 1996, pp.190-191). Glaser's (1998) view of grounded theory is that the researcher should have no preconceptions of what $\mathrm{s} /$ he will find and that the findings will become apparent through coding the data and subsequent analysis.

My research draws on grounded theory in that I have let the data determine the outcome and have not pre-empted it without being circumscribed by that methodological approach. Robson (1996) doesn't believe it is possible to undertake qualitative research without some pre-existing theoretical ideas and assumptions. 
Several writers (Hockey, 1993; Merton, 1972, in Hellawell, 2006, p.484; Cassell and Symons, 1994 in Sampson, 2004; Pollard and Tann, 1993; Charmaz, 2006) do not believe that qualitative research can avoid a degree of subjectivity but this can be minimised.

I minimised the subjectivity inevitable in this type of work by ensuring that the questions I asked were open ended and in no way led the interviewees to say what they might have thought I wanted them to. However unlike Glaser's (1998) view it cannot be said that I had no previous knowledge of the area with which I was concerned and must have some preconceptions as a practising headteacher. In that sense I am an insider researcher (Hockey, 1993).

\section{My position as an insider researcher}

I have sought to be 'reflexive' in responding to what I bring to the research (Hellawell, 2006) and I am aware of constraints which might influence the quality of my findings (Denscombe, 1998). One such constraint is my position as a headteacher and insider researcher.

As a headteacher I was an insider researcher regarding both types of interview and with the research areas themselves. It is appropriate to locate myself along a researcher continuum (Le Gallais, 2003; Mercer, 2007). In all cases I was an insider but to a different degree. There were two headteachers who were close colleagues in the same authority and so I was towards the insider end of the continuum, but less so with those whom I had not previously met. With regards to the Chief Executive of NCSL I have not worked directly with him and so this interview falls more towards the middle of the continuum. I work for the LA as a headteacher and these interviews fall into the same category as peer headteachers. I wasn't an outsider on the continuum at any time.

The advantages and disadvantages of insider research have been described by several writers (Hockey, 1993; Sampson, 2004; Hellawell, 2006; Mercer, 2007; Le Gallais, $2003,2008)$ and it was necessary to consider both dangers and benefits when conducting my research. Entering a research setting as an outsider has the potential advantage of being more objective and seeing things more clearly with a stranger's 
insight (Schutz, 1976 in Le Gallais, 2008). However this option wasn't open to me and $I$ had to accept the limitations of my insider position.

Notwithstanding the potential dangers of my own position (Drever, 1995) and acknowledging that headteachers may have the desire to open up to any researcher and the confidence to do so, my lived experience gave me several advantages. One advantage is that $I$ have a deeper knowledge of the field than an outsider would have (Hockey, 1993). My insider knowledge allowed me a greater understanding of the questions to ask and the probes to make. Headteachers were aware of my role and the depth of understanding I could bring to the interviews which gave them depth and complexity. I was also able to empathise as well as to inspire trust and this empowered the interviewees, especially the headteachers to open up. This enriched my understanding (Strauss et al. 1985) by enabling me to judge the validity of what I was told particularly with regard to system leadership where literature is sparse (Chapman et al. 2008).

However accompanying this advantage are certain disadvantages such as the potential element of collusion or allowing special pleading within interviews (Hockey, 1993; Sampson, 2004) and preconceptions, seen as a disadvantage if working within a grounded theory approach (Glaser, 1998). I believe that my being an insider disturbed the purity of grounded theory according to Glaser (1998) but others have also deviated from Glaser's somewhat purist standpoint. Charmaz (2006) argues that views held by the observer in research shapes what is observed. Therefore facts or information obtained in interviews by the researcher will be influenced by the values they hold. This suggests that the impact of the researcher is inevitable. Not only will prior knowledge impact on the research but not everyone agrees with Glaser (1998) about the value of researching without prior knowledge. Jones and Noble (2007) cite Strauss et al.(1985) who stressed that they found the value of data collection and analysis were deepened by the personal experiences they brought to bear in the area of analysis.

Using data generated concepts has been identified by Bryman $(1989, \mathrm{p} .135)$ as one of the most 'significant perspectives' of qualitative research. I haven't sought to work to a theory I wished to prove by anticipating what the interviewees would think and 
structure questions accordingly. However in contrast to Glaser (2001 in Jones and Noble 2007) I have sought to construct findings which are more than 'illustrations'.

I was aware that my knowledge of the area gave me a deeper understanding of the issues and like Strauss et al. (1985) I think there was an enrichment of the analysis because of my previous experience. Kvale (1996, p.12) further argues that to be successful with non-structured or semi-structured interviews requires a high level of knowledge on the part of the interviewer of the topic because of the methodological considerations which have to made 'on the spot' and Drever (1995) similarly refers to the need for skill on the part of the researcher as an interviewer. As my interview questions were open I believe that my prior knowledge enabled me to probe and prompt with more understanding due to my position.

It is impossible for a headteacher to be an outsider in the focus of my study and if this were to be the only valuable form of research methodology, then the views and opinions of the heads as identified to me couldn't be used. Perhaps my views can be best summed up by Hammersley (1993 in Hellawell, 2006) who suggested that there was no overwhelming evidence of the best approach between that of insider/outsider, as each has its advantages and can be seen to be contingent on the focus of the research. If this is the case then I believe that my study has validity within the debate of new patterns of school leadership despite being an insider.

\section{Ensuring the accuracy and honesty of the data analysis}

I was aware that:

'Fieldwork methods and fieldwork relations will shape the nature and content of members' responses' (Bloor, 2001, p.392 in Sampson, 2004, p.396).

I realise that the integrity of the data should be made clear (Denscombe, 1998) and have therefore ensured a degree of detachment (Hellawell, 2006) or 'distancing' (Drever, 1995) of myself from those researched by treating the interviews as having a formality with a specific purpose and not as a conversation between colleagues (Drever, 1995; Denscombe, 1998). In doing so I have sought to maintain the integrity of the data by recognising that I am likely to be more vulnerable to the pressures from within myself to understand and empathise and in doing so may, as argued by 
Hockey (1993), miss the reality and allow personal bias and 'insider perception' to cloud my judgements. I was however careful and conscious not to reveal my own prejudices by showing agreement by words (Drever, 1995) or by body language.

I was aware that being an insider might also cause an assumption of reciprocity of perspective in all heads but especially in those who were known to me or who knew of me. I discovered that my credentials had in some cases been checked out by reference to my school's Ofsted and I was aware that there were issues in accessing heads who may have agreed to talk to me precisely because of reciprocity. There seems to be an inevitable shared understanding and acceptance given by virtue of holding the same job. A difficulty of which I was mindful was that 'over familiarity' (Hockey, 1993) as an insider researcher might cause the heads to tell me what they thought I wanted to know or create assumptions which caused them to omit explanations they might otherwise have made, thinking I knew the answers. MacBeath (2008) described how the heads in his study talked to the interviewer in a 'restricted code' which he saw as assuming a 'common linguistic reference point' between them. My interviewee headteachers did this as they knew there was commonality between us therefore I frequently sought clarification 'for the tape' and ensured reflexivity and triangulation with other data sources and so found the other interviews outside headship of value.

I made it clear in my explanation to heads that it was their views I sought and was careful not to lead. One head (4) answered in response to this assurance 'Why would you think I wouldn't feel I could say what I believe in?' (4) Another was keen to stress her own 'integrity' and 'self worth' (16). I believe there was an equal power relationship, at least within the headship interviews due to their position within the field as headteachers with a reputation for effectiveness. The degree of power in relationships regarding the LA and NCSL interviews were balanced more in the favour of the interviewees because I had less insider knowledge of the areas under discussion.

Another way I tried to ensure the integrity of my data analysis was to use my supervisors' expertise to validate the process. I shared with them several of the raw data interviews from both rounds and in addition the first open coding at the 
beginning of the analysis process to ensure that I was doing justice to the research. Finally, an example of my coding process was shared with them (see appendix 7).

I believe that the study is authentic at the time I wrote it and the findings constructed represent the views and opinions, concerns and feelings of the interviewees. I am aware that this study cannot be replicated by others due to its specific location in time and place and that the roles and lives of the interviewees will have moved on in the three years of my research. Another researcher will not be able to produce the same study but nevertheless while recognizing this as a limitation of the research it is inevitable due to the character of qualitative research.

\section{How the research could have been improved}

Other leaders within schools could have made a valuable contribution to the understanding of how the changing role of headteachers impacts in both client and base schools. I would have liked to have pursued the views of the staff in my sample schools as to the impact of the headteachers' new roles which would have added valuable comparative data. I regret that this was beyond the scope of this study because of the constraints of time and other resources. 


\section{CHAPTER FOUR: New roles for headteachers}

\section{Changing roles}

That schools have had to deal with relentless change (Hargreaves, 2005b), over the last twenty years is indisputable and has been well covered in the literature both in terms of policy (Ball, 1990, 1994, 1997, 1998; Bell,1999; Tomlinson, 2001; Bell and Rowley, 2002; Whitty, 2002, 2005), and its impact on the role of the headteacher (Hellawell, 1991; Mortimore and Mortimore, 1991; Ribbins, 1993; Southworth, 1993, 1995a, 1995b, 1999, 2004, 2008; Webb and Vuillamy, 1996a, 1996b,1996c,1996d,1999, 2002, 2006; Hall and Southworth, 1997; Woods et al. 1997; Day et al. 2000; Bottery, 2004, 2007a, 2007b). Change as part of the role of heads has been recognised by the interviewees. Below is a typical example:

'The expectations for a school, never mind a head, are there will be another lot of legislation soon just as you are getting your head around the last lot. There will be another 'Excellence and Enjoyment' or another 'Every Child Matters' or maybe another National Curriculum revamp, and it is all a bit of a shifting carpet, and you have to try to keep your balance as head. '(16)

The reasons why primary heads have reacted in a particular way to current changes are less well known. Bush (2008, p.277) echoing an argument by McEwan et al. (2002) attests that leadership is increasingly linked with the personal and professional values of the leaders themselves, but that predominantly headteachers have what is to be valued 'imposed' on them by the policies of the government. This supports an earlier view of the attitude of government towards 'vision' that you can have 'any vision you like so long as it fits with ours.' (Glatter, 2006, p.71).

A question to which I wanted to find the answer, as some heads arguably enjoy more 'earned autonomy' (Morris, 2001), is to what extent have they used the imposed changes by government, and shaped them to change their own roles and to the benefit of their own schools in ways identified by some writers (Chapman, 2002; Hargreaves, 2003; Mulford, 2003; Hopkins, 2006) and what have been the barriers to them achieving this. The dilemma is identified by this quote:

Oh yes, my role has changed since I first became head. It's difficult to know what's driving me now. Whether I am doing things the way I would do them 
anyway, or whether I am being driven by external forces. It's difficult to say if it is the government or me. (18)

Although it affected them personally to varying degrees, all the heads felt school leadership was changing due in part to the increase in workload which was seen to have been continuous throughout their headship. The role was seen to be increasingly undoable in its traditional form. The views of all the heads is illustrated typically in this example.

'I suppose for me as a head one of the big issues is manageability of the role. It just grows and grows and grows...' (15)

Another reason cited was the recognition by heads $(3,5,8,9,10,12-21)$ of the future lack of school leaders. During the period of the interviews 2005-2008 there was an increase in the publicity given to the need to plan for succession in the TES (Barker, 2007, 2008) and at Conferences led by the SSAT and NCSL. Much of the work being undertaken by NCSL was based on the need to secure enough effective school leaders for the future as one of its corporate goals from 2005 (NCSL, 2005b) and the use of part of its website from 2006 was devoted to 'Growing Tomorrow's Leaders Today'. This together with the arguments for system leadership outlined for example by Caldwell (2006a) and Hopkins and Higham (2007) has in part led to opportunities to innovate practice and the availability of new opportunities such as leadership of federations and NLEs. In addition, the role of ECM was highlighted by all heads as bringing with its introduction, new roles for them and new ways of working and relationships with others as well as potential changes to the curriculum.

\section{Headteachers' vision of the development of school leadership}

Gunter $(1997,2008)$ claims that 'visioning' the future distracts from what is currently happening, nevertheless all the heads speculated about how future models of school leadership would develop when asked about their own role change. There was some difference in the extent to which the interviewees could visualise the future roles of heads as well as a range in terms of the amount of change. The degree of visualisation of the future of school leadership differed over the time of the interviews with heads less likely in September 2005 to discuss the future of school leadership in terms of new roles for themselves and more likely to do so in the second round. This may be partly as a result of the nature of the sample as the second round involved a purposive 
selection of those who pursued, or had indicated that they would pursue, an extensive external role from the first round. In addition it may also be partly to do with the speed and pace of change in the area of the development of new models of leadership (Chapman et al. 2008).

At the beginning of the interview cycle one head acknowledged that 'as a head you have to accept that these days there is a lot you are not going to know' (5). Another speculated:

'There could be different models, but I think that would be really difficult to monitor in practice. ' (3)

In thinking this way she is echoing the view of Steve Munby who thought in relation to future school leadership:

'I think there will be no one model. ' (Munby, 2005, interview with the writer)

Even later in the interview cycle some heads while feeling that some change was inevitable still weren't quite sure what:

'I don't think the traditional model of one head-one school will be in operation forever because it won't work like that I don't think. '(17)

And even if new models were known in principle, defining terms was often confusing:

'Well I don't really know now what an executive head is... ' (8)

One aspect of the future discussed by five heads $(3,14-17)$ is the role of the government in the change process.

'I can't imagine it would be an easy thing for schools to develop or change just as they want to do unless it fits in with the government's ideas' (3)

'I think there will be a lot more part time work but it will be to the agenda which suits the Government.' (17)

That educational policy has unintended consequences and is shaped by agents of change (Clarke and Newman, 1997; Levin, 2003a) has been noted by the interviewees: 
'I am sure they [government] want the best ... but I wonder how many lessons are learned from things that they put in that go wrong and especially those which are preventable.' (14)

And echoing the argument of Clarke and Newman (1997) where agency shapes policy, with regard to the procedures for remodelling the workforce:

'I mean it is dead easy to sit and work out this fabulous plan, and we can all do it sitting at home, and there it looks marvellous, and you go in on Monday morning and it doesn't work because you have missed something or something happens. Well then you can just multiply that up in governmental terms and you get a monumental mess which they just didn't anticipate, that doesn't work in practice. ' (16)

Or, unlike Ht 3, one head believed the system would 'evolve' with heads acting as agents of change, and clearing up the messy situation on the ground (Hopkins and Higham, 2007) if only through necessity:

'I think what will happen is that heads doing extended provision will lead it. They will find a solution and that will then become a pattern of practice...I think it's quite shocking how little real thought is given to how education policy will work' (15)

The pivotal role of the headteacher in future school leadership

The role of a single headteacher who leads on most if not all issues in school has been increasingly perceived as unsustainable (Hall and Southworth, 1997; Harris et al. 2003) and undesirable (West Burnham, 2005) or 'untenable' (Southworth, 2008, p.424). The pivotal role of the headteacher in the future of school leadership was discussed at length by all the headteachers with reference to a variety of contexts. This has led to the identification of several issues:

- Whether a single headteacher in every school is necessary.

- Whether or not a school leader needs to have qualified teacher status (QTS).

- If school leaders are to lead more than one institution should they also have QTS and if not who should?

I asked a general question about whether school leaders should have had a background in teaching. Nine heads $(3,5,9,12,13,15,19,20,21)$ were prepared to 
various degrees to accept that someone who was not a qualified teacher could lead a school. One head was certain of this:

'I don't believe you have to have been a teacher to be a headteacher. I have always thought that.' (20)

Two heads were cautious, but 'open' to the idea:

'I have got quite an open mind over people coming in who are not teachers but other professionals. I think that it's not impossible. '(13)

Ht (19) who led a federation wasn't convinced and thought there was a concern that only those with QTS would have the 'vision' to lead a school but wasn't willing to suggest this was essential and was prepared to be 'open minded to it'.

Four heads $(3,9,12,21)$ were in general agreement, but with the proviso that such a leader had the 'right personality to lead and motivate with vision' (9) and that:

'Parents need to be assured their children's education is going to be the best, but who organises it doesn't have to be a teacher any more than a football manager has to be the best footballer. ' (21)

A subset of two $(5,15)$ emerged from those who were prepared to consider a school leader who was not a teacher. These heads changed their views from for, or against, as they began to consider the issue during the course of the interview.

'A few years ago I would have said 100\% bring somebody in from outside teaching... Then if you start to look at FMSIS you couldn't do that unless you were a teacher... So I don't know now.' (5)

Later he became more certain in his views in that:

'...first and foremost however much you delegate, you have to know how to say that is good teaching, and more importantly that is good learning, and why. To do that, you have to have an educational background.' (5)

Ht 15's views went the other way and she started by being certain that:

'...the school is shaped by the headteacher and I believe it more and more and more' (15) 
Later she wasn't sure it mattered that the person 'at the top', was a headteacher providing someone with an educational background was leading the learning:

'Whatever happens in the future you will still have a lead educational professional whatever they are called... deputy, head or lead learner. ' (15)

All the heads in the above set could foresee the school leader as someone without a teaching background despite some strong reservations about it. In contrast three heads $(14,17,18)$ were definitely against the idea of school leaders being other than qualified teachers. Ht 18 argued 'I don't think standards would be good enough' without 'professional teacher training'. Ht 14 thought such training was 'fundamental to whoever runs a school.' Another argued:

'I think you can delegate many of the other roles but you have to know about your staff and how they deliver, what the content is, and how you can make it better. I can't see that if you had someone who came without a teaching background they could manage that. '(17)

The 'balance' between the head's role of lead professional and chief executive has seen a sharp shift in favour of the latter during the reforms of the 1990s concerned with site based management (Bell and Rowley, 2002; Bush, 2008). One head (8) however while agreeing that schools in general were 'becoming more like a business now' with the change in the role with the balance towards chief executive becoming 'inevitable', added another dimension to the debate with a comment about the role of the leader of more than one school:

'I mean with executive heads you still need people in schools who are in charge... and so deputies are still doing the traditional head's role. '(8)

The consensus from all responses is that in the future there needs to be a lead learner with QTS but the contention is whether or not the leader of the traditional school or extended model has to have QTS and on that the debate lies.

\section{Headteachers - lead learners or chief executives?}

Other comments centred on the variation within the role of headteacher, according to the extent to which they should adopt the role of lead learner, chief executive, or to some degree a combination of the two. This is a debate that has been identified by Coulson (1976); Hughes (1988); Hellawell (1991); Boyle and Woods (1996); Hall 
and Southworth (1997) and Bell and Rowley (2002). Three heads of two and three form entry urban schools $(5,8,18)$ thought it important that headteachers maintained their lead learner role in school to some degree at least as illustrated typically by this comment:

'I hope heads don't lose touch with what is going on in the classrooms... I think it would be really sad if the job went that way and heads didn't get involved with the learning and the children.' (18)

Ht 5 who was head of a three form entry urban school thought that size of school could be a determining factor in the extent to which the head needed to be able to do both roles.

I mean most of us are doing that now and are divorcing admin from teaching and learning. ... but it ain't going to work in a one form entry school in the middle of Wiltshire.' (5)

One head reinforced the views of Leithwood (2001) in saying that with all the different roles heads undertook, they were being 'pulled in all directions' (8). I asked the interviewees why they thought new roles were developing.

New roles developing to spread 'best practice'

There is an encouragement for heads to lead 'outside their own institution' (NCSL 2005a, 2005b, 2005c, 2005d, 2007a, 2007b) as part of the promotion of a proliferation of ideas or as part of a 'critical mass' of school leaders who are used to spread best practice (Fullan, 2005). Three heads commented on this as a reason for encouragement to work with other schools $(7,13,18)$. For example:

I suppose someone must have thought that a lot of schools are doing great things and why aren't we sharing this?' (18)

Another head saw the reason as a combination of factors.

I think there are two aspects to that. I think there is the positive one, as I think we should be proactive and work outside our own school. I think we as heads have a responsibility to our children as a whole community so we should be working together on that aspect of it. ... I think it is a negative aspect in terms of those of us who survive headship being asked to help, or plug holes in dykes of schools where others haven't been so lucky, for one reason or another. (7) 
New roles as a solution to the potential lack of school leaders in the future

I wanted to find out to what extent the problems outlined in the literature around the need for the system to change to accommodate the dearth of school leaders (Hargreaves, 2003; Mulford, 2003; NCSL, 2005d, 2006b) was understood by my interviewees.

Twelve heads $(3,7,8,9,12-17,19,21)$ identified a problem for the system in terms of the imminent retirement of many current headteachers. Some typical examples were:

'I think they are panicking and witless about what is going to happen in the future with headteachers' (19)

'Because they haven't got enough heads coming through have they? That's the bottom line.' (16)

'I mean I am 54 and a lot of my friends from college who are teachers have either gone part-time or thinking of it.' (13)

A subset of nine heads $(3,7,8,9,12,14,17,19,21)$ thought that the crisis was more than just people retiring in that the job of headship itself was unattractive and either causing people to leave as identified in this example:

'I don't think it is just the problem that people are retiring... I just don't think heads are happy and they want to just go and I think the government and LEA need to acknowledge that.' (8)

Or, failing to attract successors to leadership as illustrated here:

'Well think about it. Why on earth would you want to go and put yourself into a situation that you know is going to be incredibly stressful?'(14)

'I think they have to be more proactive in looking at ways of ensuring succession. My three assistant heads don't want to be heads. So they will have to consider where they are going to come from.' (7)

'I think it will have to change because they aren't getting people wanting to do the job anyway.' (9)

I asked heads why they thought the job was being seen as unattractive for successors. One suggestion included poor pay differentials between the head and other members 
of the leadership team (7). Ht 5 and 21 also agreed with $\mathrm{Ht} 7$ but qualified this by seeing it as being a problem for heads of small schools. Ht 19 disagreed that money was a factor:

'It's not made attractive enough and I don't mean salary because the money is not the main factor. ' (19)

There is evidence to show that the situation may be determined by several factors in different contexts and not just a question of budgetary considerations. Unsociable working hours was another reason for lack of interest in leadership identified by two heads $(7,17)$ :

'...they think 'do I want to come in at 7.15am and go home at 7.15 '? (7)

Or:

'...you hear a lot of headteachers saying we work the whole time and are at school at the crack of dawn, and of course we do!' (17)

Ht 3 thought similarly to Ht 7 and 17 in workload itself being a disincentive to recruitment but expanded her reasoning to include aversion to the type of work:

'I have got people here who could definitely do it [workload] but I think what happens is they look at what I have to do and say "Well I don't want to do what she does. "Frankly, I don't blame them. '(3)

Two heads $(5,12)$ put the blame for the prospective dearth of school leaders firmly on the mishandling of the system by the government which had lost the trust and contributed to the low morale of the profession echoing the views of Bottery (2003):

'But we could have had enough school leaders. ... There is a lot of talent around, and there is a lot of talent coming through, so what is the reason they aren't interested? Have we put people off leadership by some of the things we have demanded of headteachers or some of the policy decisions that have been made?' (12)

'The headship is up for 'St Edgars'. [One of the biggest schools in the LA] They have had one applicant for the job. Yet NPQH courses are stacked out. Something odd there isn't there? They [government] want to be asking, "Why is it that there are so few applicants for headships?" It's all down to pressure and workloads' (5)

Another reason given was relationships with the community. A Mori survey commissioned by NCSL (2008) found that $49 \%$ of British adults thought that 
headteachers 'were doing a better job than 10 years ago'. However the views of these three heads $(3,5,17)$ disagreed:

'I think for many it is the lack of respect within the community which is an issue. The fact that heads are made a scapegoat for every issue is a factor which puts people off doing it.' (17)

'It's something to do with public perception of the role and how the government through the media, encourages, or influences people to think.'

There was a view articulated by heads $(8,11,12)$ who had experience of international placements that heads were more valued in other countries. It was believed this was due to better pay and less accountability.

'It was fascinating in other countries because people really valued heads.' ... Heads and teachers had much more status in terms of respect, but that has been a media issue around education over here for many, many years actually. (12)

By holding this view Hts 3 and 12 echoed Ball (1990) in his views of a 'discourse of derision' being perpetrated against the profession by government through the media.

However there was a contrasting view from one head, who, echoing a view of headship supported by Etzioni (1969) thought that the profession had become more 'semi professional'. He thought this made it less attractive to those wishing to pursue a professional career and was a situation that the profession had partly brought on itself because:

'We have broken down the barriers and made ourselves accessible... we have become like glorified operators in a factory. We are not seen to be professional, therefore we are not trusted, and therefore we need parents to come in and tell us how to run the place and that's not the answer. '(5)

Five heads $(5,8,9,12,14)$ put some of the blame for lack of interest in headship on the system of accountability and the pressure to perform. The following example is interesting because the potential flaw in the system is identified by a head who is herself a current practising Ofsted inspector:

'But with the Ofsted framework as it is, are we attracting young teachers into the inner city schools with the challenges of the accountability framework? Would you want to be associated with a school when your name is on a report in the public domain and will affect your future career?' (12) 
Two heads $(8,9)$ distinguished between a general lack of enthusiasm for the role and a disinclination for headship in challenging situations for example:

'They can't get heads for schools like ours.' (8)

The implications of not having enough school leaders were discussed by five heads $(7,9,11,17,21)$. One solution could be to encourage heads to lead more than one school:

'I think the future of headship is going to be that you are not just head of one school. I think from a sustainability point of view there won't be enough people who want to become headteachers because the role doesn't appeal to many staff.' (17)

Finding leaders to lead across schools is potentially difficult as highlighted by $\mathrm{Ht} 7$ who thinks:

'... and they will struggle to fill these roles of one head for several schools, it's a very different way of working' (7)

Both Hts 7 and 9 commented that the reason for heads of single institutions being reluctant to take on the role of executive head is because they would lose contact with the children:

'I would like that role as long as I had direct contact with the children and they related to me as their head as well. '(9)

If the system does manage to attract enough leaders another potential difficulty highlighted by three heads $(9,11,21)$ was the quality of their leadership:

'It's not only a question of not getting enough headteachers, it is also a question of - what quality are we getting?' (11)

'I think the danger of relying on having heads to work in lots of schools in federations is who you attract... I think there is a danger that in a scarcity market out there, they will not get people for the most professional reasons.' (21)

Changing the role of headteacher as a way of addressing its demands 
Eight heads $(4,8,10,13,14,17,18,19,20)$ didn't find their own role undoable but believed that heads in other situations might, with the exception of $\mathrm{Ht} 4$ who didn't know if others would find the job undoable as demands increased and responded:

'Yes, well, I don't know. I suppose you mean heads in the future can't do everything? Well to be honest I am not rushed off my feet. ' (4)

Other heads in this set offered similar views on the general 'undoability' of headship as this example:

'I am not finding it undoable, I absolutely love it... I don't know about the future for the small school head who has got to do some of the things which we do with a much smaller staff to go around and budget to use. They are going to have to think about either networking or sharing the load somehow.' (10)

There is a common thread for this set of heads in that they all lead larger than average schools and so will benefit from a bigger budget and the opportunity to afford more or higher paid senior staff to be more strategic. I will develop this further in Chapter 6 . However of note at this point is the view from the head of a small school that the role of heads of small schools has to change because they are at a disadvantage because:

'As a head I still have to have responsibilities with areas, as we just don't have enough people.' (9)

The importance of being an experienced practitioner was highlighted by the heads in this set as a way of managing the demands of headship. For example:

'I think it is undoable when we first start out as heads because it is just enormous. I think the longer you do it, and the more confident you get, the more you can sift out the things you don't need to do. ' (17)

'I think the first year of being a new head is hard and it's like being a NQT again.' (19)

One head was convinced the role was undoable in its present form in any context:

'I think the role is unmanageable anyway for heads and I think that will remain the case until someone breaks the role down.' (15)

The issue of how heads use staffing to manage their role especially in terms of their new roles is an area to which I will return in Chapter 6. I will now consider the type of 
new role school leaders are undertaking, some of which are internal and some external.

The development of new internal roles for headteachers

Every Child Matters (2003a) from which followed the Children's Act (2004e) has provided opportunities for new roles for school leaders. At the beginning of the interview cycle in September 2005 ECM was identified as an important future issue for heads by some commentators:

'Picking up the community regeneration agenda, multi-agency. How do school leaders make sense of that? I think that's a major challenge.' (Munby, 2005, interview with the writer)

Heads interviewed in the autumn of 2005 agreed with Steve Munby and recognised the impact of government policy on their role believing 'the ECM agenda is going to be hugely important.' (1) and 'Oh yes absolutely! Well there again that [ECM] is an agenda we are aware of....' (2).

However there was a different level of understanding of how this was going to change roles:

'Well, gosh yes, that's a very big issue [ECM] and we don't know the answer to it ...' (1)

'I have already started to embed the ECM agenda into school.' (2)

I think the every child matters and extended schools agenda will impact ...I think that could be disastrous because I think we've got far too many responsibilities as it is... ' (3)

Another head later in the same term had an idea of impact in her context:

'We are in line for a children's centre and that will definitely have a big impact.' (8)

There is evidence from all the heads in the first round that they knew the ECM agenda would strongly impact on their role but in the early stages unless the heads had a children's centre there was less understanding of how this would be manifested. This is articulated by one head: 
'I think ECM is a classic example of people not knowing what is going to happen in schools... It is going to make so much difference for things like responsibilities and people don't really know what's coming.' (5)

His view is supported by the comments of these heads in the second round:

'Well ECM is an issue of course. One problem was not having that wider personal vision for it... (13)

'I have a funny view about all this multi-agency approach. ... I don't think there is a view of what it is going to look like at the moment.' (15)

While the method of implementation was generally disliked as it was 'imposed' and too 'quickly', (14) there was also acknowledgement from heads that:

'ECM is the best thing to come out of the department for education for the whole of the time I have been a head. ' (5)

I asked 'Why?'

'We have stopped talking about a child just in school and started to look at whole people and I think that is wonderful.' (5)

The benefit of ECM to the community is important in terms of how graciously the heads accepted, or even embraced further work, or new roles created because of its introduction. All the heads whose role had changed due to ECM with co-location (3) or existing $(2,8,13,19)$ or prospective children's centres $(4,5,16)$, while finding the disruption and even the initial imposition of the centre difficult, were all prepared to tolerate the situation because it was seen to benefit the community. This stoical attitude is illustrated by the comments below:

'It's almost like another school being amalgamated with us and all the emotional stress that goes with that and the amount of staff that are involved... It took so much energy last year - it was unbelievable.' (19)

'I never applied to become a children's centre but I got a letter saying "congratulations on your application"! My first reaction was like I am usually, which is to say 'great - something new, here's a challenge' that sort of thing and that's the way I work.' (13)

That the workload seems less stressful to heads that see a purpose to it, is also an idea supported by the comments from heads that have strived for a centre but not yet been able to achieve it $(4,5,16)$. All heads in this subset are frustrated at the delay or postponement. One headteacher commented how he was to be in line for a children's 
centre but that it was 'back on the drawing board again' and was frustrated because the LA 'had let the budget slip back and that budget was no longer available' (4). Another head (5) had gone to considerable lengths in terms of committing money and time, it was planned and agreed but by the time I revisited him two years later the money had not been found from the government to pay for it. The heads were angered by the inefficiency of the process summed up by this comment:

'They said to me in the middle of March - "Can you spend this money by the end of the year?" So I did. We have got all the furniture for it, but they haven't put a spade in the ground. In fact, they haven't even got planning permission yet, which is silly.' (16)

\section{Multi-agency work and an increase in heads' responsibilities}

One aspect of ECM is the change to heads' roles involved in children's centres and extended schools with more interaction with multi agencies. Seven heads $(3,4,5,7,8$, $13,19)$ complained about the bureaucracy and work overload involved in working with other agencies and no head commented positively on the future relationships. Examples of their pessimistic views below:

'Mind you if I have to work with social workers it will be a very short career!' (6)

'... but social services never really work together with anybody so how is that going to work? I have never known anyone as poor at communicating as they are, so what will happen there?' (11)

Sure Start was singled out for its ineffectiveness, as these examples illustrate:

'Sure Start is such a bloody bureaucracy... The task groups meet regularly but nobody actually does anything - it's just talk!' (5)

'Our children's centre has had to take over all the Sure Start work. ... The government wanted it in schools and integrated because they don't think Sure Start are doing it properly and it doesn't take rocket science to work that out.' (19)

The reason children's centres are placed with schools identified by Ht 19 was also recognised by Ht 5

'I think headteachers will be one of the main driving forces behind it [ECM]... which is why they put children's centres in schools.... Schools are going to be the centre for the local community. '(5) 
Another head generally positive in terms of the multi agency aspect of her role still anticipated difficulties due to the position of the education service:

'I think it will be a problem. I mean the job is already unmanageable now and if it grows any more then you will have to separate the educational leader from the extended school leader. ... I don't think we could do it all at the same time.' (15)

It was never the intention that heads would both manage children's centres and schools together. In my experience it was made clear by LAs that children's centres on school sites wouldn't be within the remit of the headteacher even if the governance lay with the school's governing body. There was the expectation that the children's centre would be managed but this person would not have to be a teacher let alone the headteacher. Four $(4,5,8,13)$ of the seven heads of actual or potential children's centres considered this, none of whom believed managing a children's centre had to be a teacher's role:

No not necessarily. I haven't thought about that but I suppose in terms of qualifications they can be from a wider sphere than education given the social and health involvement from Sure Start and all that stuff. (4)

However the situation is complicated by accountability. If a headteacher is accountable for the school to what extent are they also accountable for the children's centre? I will consider this in more detail in Chapter 5.

That some heads are more involved with agencies through the introduction of children's centres brought up the question of equity for one head:

'...my concern will be if that [a children's centre] isn't going to happen in every school then what about the school down the road? ... It will be interesting to see what happens to schools which haven't got extended facilities.' (15)

Some heads hoped that the ECM agenda and closer multi agency working would improve issues around 'the assessment for inclusion' (8) although the increased workload around this was also recognised by five heads $(5,7,8,10,14)$ exemplified here:

'I think the whole inclusion agenda has had a big impact on issues for heads. That's another lot of time consuming forms and I am lucky that I have a good 
person to lead on that ... the whole Crisping, the audit it's a massive agenda.' (14)

However the issue of small schools is again problematic as $\mathrm{Ht}(9)$ had to undertake the role of SENCO herself.

\section{Extended Schools}

Extended schools as part of the ECM agenda was raised by seven heads $(3,4,7,11$, $13,14,15)$ as likely to create new roles and more work for school leaders and therefore an issue to be managed:

'We have got an out of school hours club but it is actually run separate to school and that's how we want to stay at least for the time being - we've got enough.' (15)

'In principal I like the idea of extended schools... But the schools are driving the agenda and it will be the heads running it... ' (7)

'I am not worried at all but lots of heads I speak to are worried about opening longer and the extended schools agenda. (4)

One head wasn't sure of how this issue would develop and consequently his view of it:

'I am not really sure. I am split in terms of the extended partnerships issue....' (11)

Later in the interview cycle by 2007 there was some evidence that heads $(13,14)$ had delegated the work as soon as possible:

'Oh, and the meetings! You lose the will to live they are so boring, just excruciatingly boring. I mean the person who has the job of coordinating it all is just swamped with loads of paperwork.' (14)

While it was seen as a 'big issue' (4) in autumn 2005, by 2007-8, all the heads who had to manage multi agency working in children's centres or extended schools had managed it as an issue in schools by delegating the workload $(2,3,5,7-10,12,13,14$, 16-21) or because the none curricular elements impinged little on the school $(11,15)$.

Other new models of school leadership in a single institution 
Other models of school leadership such as co-headship have been identified by three heads $(1,15,18)$ to manage the crisis of succession.

'Shared headship is another way...It's a good idea. If you are moving towards retirement why should the school lose all that expertise?' (18)

'I think it's [co headship] perfectly possible-yes I do... I thought about suggesting it to Farah [AHT] but she wouldn't want to be head of a church school. ' (1)

Only one headteacher (15) in the sample was involved in co-headship for $50 \%$ of each week. However unlike the potential model described by Ht 18 this head chose coleadership with another as both wanted the role part-time to pursue an external role and for personal commitments and not as an exit strategy for retirement. Another new model of school leadership was the co-location of a special school on the site of $\mathrm{Ht}$ 3 's primary school. At the time of the first interview it was in the planning stage having been suggested by the head of a local special school with the aim of making the one organisation 'inclusive' and the primary head agreed that 'this would help our children socially'(3). By the time of the revisit for the second round of interviews in 2007 the building work was in progress and the school was 'undergoing a total rebuild' (3). There was some understanding of governance but the project was not due to be finished for one-two years. It impacted greatly on the role of the headteachers of both the primary school and the head of the special school who was retiring, but it was considered worth it at the time because of the benefits to the community.

\section{The development of new external roles for headteachers}

If my sample can be taken as typical of effective headteachers then there is strong evidence that where choice is part of the equation there is an increase in the leadership of the profession by the profession. This leadership is being expressed in terms of headteachers 'leading outside their own institution' in NCSL's Corporate Plan (2006a) and of caring as much about the children in the school down the road as those in their own school (Fullan, 2005). My research analysis is partly but not entirely linked to system leadership as defined by Hopkins (2006) as heads are choosing to undertake a variety of roles. Due to the extent and complexity of them it is not possible to describe the extent of everyone's role here (see appendix 3) but some indication of the range follows. 
The opportunities to work with other schools are regarded as important in Webb's (2005) research and Earley and Weindling (2006) describe the 'new' roles for heads as consultant leaders. Only two of the heads $(4,6)$ did not have a wider leadership role other than membership of the consortium. One of them however had briefly experienced a support role in another school but it was short lived with limited success as this quote illustrates:

'The LEA asked me to support... I've been there a couple of times and I've come back and said well... so the head's incompetent and that's my diagnosis ...' (4)

The external roles of the headteachers were many and varied but by far the most common was that of consultant leader. Out of 21 heads $15(1,2,3,5,7-17)$ were CLs having trained under the Primary Strategy Consultant Leader Programme rolled out from the National Strategies through NCSL and then the LAs. Five of these heads (1, $3,5,7,11$ ) had also undertaken national consultant leader training with NCSL and another worked for NCSL as a consultant leader in another authority (9). Two of these heads subsequently became NLEs $(14,17)$. Two other heads $(19,20)$ were also NLEs but by a different route. Other consultancy included one head (11) trained with London Challenge as part of his consultant leader role.

Twelve heads $(5,7,8,9,13-17,19,20,21)$ had also worked as seconded heads in other schools as part of an arrangement with their LA in addition to or instead of consultant leader work. For a subset of four, those who subsequently became NLEs, $(14,17,19,20)$ this work preceded their NLE work. In the case of the last three of the main set of these heads $(19,20,21)$ these roles turned into their becoming heads of a two school soft federation. In the case of one head (16), she became the substantive head of each of the schools to which she was seconded which was a total of twice in all.

Five of the heads $(12,13,14,17,18)$ were trained Ofsted inspectors although three of them $(13,14,17)$ were no longer practising. Other roles included leadership of the local headteachers' consortium $(3,5,7,13)$ and also for two of them $(3,5)$ leadership of the LA's forum and in addition one year's secondment to the LA for leading leadership strategy (11). Two of the heads $(5,15)$ had been external advisers for headteachers' performance management and one of these (15) was also a field worker 
for NCSL. One head (10) had a different type of role in that as well as consultant leader for a short while she moved swiftly on to work in an advisory role for the DfES for approximately two days a week. What is clear is that these heads support the assertion of Chapman et al. (2008) in that heads are undertaking a combination of roles.

\section{National Leaders of Education (NLEs)}

Heads were invited by NCSL to apply to become NLEs in the summer of 2006 . The role is part of the strategy to encourage 'system leadership' (NCSL, 2005d; Hopkins, 2006, 2007) and can be identified as similar to the 'critical mass' of school leaders (Fullan, 2005) and the 'transferred innovation' (Hargreaves 2003, original emphasis) used to describe the transfer of ideas from a successful or leading edge school to one seen to be failing. To spread best practice is seen as a necessary part of sustaining reform in the system (Hargreaves, 2003; Fullan, 2005; Hopkins, 2006, 2007). The role of NLE was identified by nine heads but only in the second round of interviews partly because recruitment didn't happen until 2006. Four of them $(14,17,19,20)$ were NLEs and four others $(3,7,8,16)$ were interested in undertaking the role in the future as illustrated typically below:

I like this new model that is about now where schools help - national leaders... That apparently is using your staff to support schools. I think it is a good idea but I missed the deadline for that but I will do it next time it is an option.' (3)

'Now I wouldn't mind doing the national leader work...' (16)

Ht 13 had just heard of it:

'There are a whole lot of outlets for heads now such as the consultant head and the new one, funny title - national leaders of education...' (13)

Two heads $(13,20)$ identified why they thought the role of NLE existed. This head had no doubts:

'I strongly believe that the NLE model came from the fact that the Department [DCSF] wanted to get around local authorities where local authorities are not effective and I have no doubt and there is no question about that in my mind about that. I think they have been extremely unhelpful in not being honest.' (20) 
Ht 13 felt that the LA 'had no plan' for what to do in a crisis where their schools are failing and was relying on NLEs to help them. She reiterates the idea of Ht 20 that because LAs haven't shown they can tackle the job heads are being brought in to do so. Although unlike Ht 20 she says:

'I don't like to criticise the LA because I have a lot of time for them, and it is one of the best I think, but they aren't prepared. How can you have a crisis in a school around its head or an inspection and the LA just not know it's going on?' (13)

The main difference between the role of NLE and that of consultant leader is the use of the NSS or national support school. As an NLE and CL myself I am aware that it was the practice for some heads to use staff in this collaborative fashion in the past, but now it is an expectation, as supported by this comment from a current NLE in response to my direct question to her:

'You are also a National Leader of Education. How does it compare with the work of a consultant leader?'

'I think there could be similarities... but your school becomes a national support school. So it's about using your staff as well to support which I think is a good model. ' (14)

\section{Leading a federation}

Sixteen heads identified leading a federation as a new role for school leadership $(4,5$, $7,8,9,11-21)$. However the degree of difference in terms of knowledge and understanding of the role and how it would operate was considerable. Only the three heads $(19,20,21)$ who were themselves heads of a federation of two schools had any real understanding of what such a role entailed. Two of them $(19,20)$ thought the model had merit for its own sake but one (21) was unsure of the model generally, thinking it worked well because of his particular circumstances:

'I am not so sure about federations generally, because this one is working for specific reasons such as using someone known and experienced like me in this community.' (21)

The point that his collaboration was for specific purposes is important. All the federations discussed in this research were the result of a 'stronger' school working to support a 'weaker' one. However four heads $(1,5,9,13)$ believed this shouldn't always be the case as typified by this example: 
'I suppose you would have a federated governing body for example and you would be looking at the good practice to share across schools and it shouldn't be one way either. At the moment it is, you are a strong school and the other is a weak one and I can see why it's like that, but shouldn't be always... they could come in at a more equal level. ' (13)

The view that federations are either inevitable or beneficial as a means of solving the problem of succession is not shared by all in this set. Two heads $(4,7)$ were against the idea:

'I don't believe in federations .... Again in my view schools are about communities and the headteacher is a key part of that community. ' (7)

I am not sure it works... I mean I am on the playground every morning and in the corridors. People identify with me and I am not sure you can do that... in fact I am sure you can't do that if you are head of federated schools. ' (4)

Another two heads $(11,12)$ were unsure. Ht 12 had seen federations working in Sweden where she explained that they had 'lead learners' however she was reluctant to praise them:

'I'm not saying it couldn't work here but you would have to win hearts and minds of the communities...' (12)

Other headteachers commented more favourably about the idea of them leading a federation. One head professed she would have 'gone down that way if nothing else had turned up. ' (18) Others suggested 'If I wanted a career move, I would really love that...' (13) and another:

'I still think soft federations have got tremendous potential. As a school right now we could easily support a one or even two form entry school with the sort of leadership people we 've got.' (5)

And one head liked the idea of leading several schools even if she wasn't really sure of how it would work:

'What I would love to see, and what I would like to be able to do, is to see, say, 3-4 schools with new heads in say, 3 of those schools and oversee and develop the leadership of those three schools...' (8) 
That leadership would need to change if heads were leading a federation of schools was identified by seven heads $(7,8,9,13,15,16,17)$. Leadership of a federation was seen to be different from a traditional model of head of a single institution and whether or not they were in favour of the model, there was some consensus as to what it would be like. Five heads $(8,9,13,15,16)$ identified the overall leadership of more than one school as a chief executive's role mainly because leadership would have to be more 'removed' and 'strategic' (15) as illustrated by these references:

'It's having 3 or 4 primary schools and you have a director headteacher over them all with a person who is head of teaching and learning and then you could have a business manager. '(9)

'You cannot be the headteacher of two schools in the traditional sense. So you would have to have a head type figure who took all the day to day decisions and then you would have the principal or executive who goes in and checks up on what they are doing. ' (16)

There was an assumption by the interviewees that schools would federate when there was a vacancy and not with existing heads in place. It didn't occur to any of them that a head from outside might in some way be imposed upon them. This is supported by the comment of Ht 3 who sees federation on her retirement as a solution to the colocated primary and all age special school she is helping to develop. An important point however is the role of governors:

'It is down to governors because if they don't [federate]either because they don't think it's a good idea or they don't appoint the right person then the whole concept of working as a new model will wither and die.' (3)

\section{The advantages and disadvantages of a federation of schools}

Establishing federations has been identified as being an important structural development for schools. It is seen as more difficult to recruit to small schools and particularly in the Catholic sector with its more stringent recruitment requirements (NCSL, 2006b). Five heads $(5,9,10,13,16)$ agreed with Steve Munby:

There will be a push based on just population trends to create federations of small primary schools possibly just under the leadership of one headteacher' (Munby, 2005 interview with the writer)

The issues are further developed by one headteacher: 
'I don't think long term small schools can survive in the same way, and I think soft federations are the answer. I think they will get to that point through failure and necessity. For example they aren't going to find enough headteachers for the one form entry Catholic schools. The incentive isn't there for deputies of large schools to go for headships of smaller schools.... I also think that people perceive smaller schools as a route to nowhere. '(5)

An argument supported by these comments from heads of three form entry schools. Ht 13 thought federating might be the answer for a 'group of small rural schools' and Ht 10 agreed saying 'I don't know about federating - possibly for small schools.'

Three heads in this set $(1,9,16)$ had worked in small schools and were aware of the problems they experience but only two considered federation:

'I don't think there is any doubt about it that with too few school leaders they will have to federate.' (16)

'I am quite into this idea of federations and quite like it and think that's the way things have got to go for small schools because of the workload.' (9)

Ht 1 in 2005, while not using the term federation, realised that the one form entry school wouldn't be 'viable in terms of management finance and standards'. She saw answers to economies of scale in terms of collaborative partnerships and that:

'... it isn't financially viable to keep the two local one form entry primary schools open so we are going to have to work together ' (1)

However the crisis of succession is seen to affect other than small schools.

'Say for example if you didn't have enough headteachers, you could put in a couple of really effective deputies. If it was a couple of very large schools you could have a couple of deputies in each school and an executive head. '(13)

\section{Headteacher's motivations for undertaking new roles}

Four of the heads $(8,13,15,19)$ combine a new model of leadership in school with an extensive external role. This matches the recent findings of Chapman et al. (2008) who found that school leaders were undertaking a 'combination' of roles. It is therefore difficult to determine any single motivation for either internal or external roles because for some heads the motivations are complicated and involve several reasons as illustrated by one head's answer to the question:

'What were the reasons for your taking on these roles?' 
What characterises new roles for heads is that they are mostly voluntary. Some, such as children's centre leadership can be imposed as they were for Hts 8 and 13.

However none of the other roles have been imposed on the heads but they have taken advantage of opportunities made available to them through government policy particularly ECM and the encouragement given through interaction with NCSL, TDA, DCSF and LAs. The one reason common to all the heads follows the argument of Earley and Weindling (2006, p.38) in that as they are experienced heads, 'Professional revitalisation or refreshment is essential.' In seeking to analyse why heads undertake different roles I have taken the main reasons they gave for their new roles as the basis of my subheadings. Nevertheless it was apparent that many heads had a variety of motives for choosing the roles undertaken by them.

\section{Financial considerations}

Reasons differed as did the heads attitude to the motivation of other heads. So for example two heads $(5,7)$ chose to work in consultancy as a potential income stream either after retirement (5) or as a safety net 'if it goes wrong here' (7). This was a course which drew short shrift from one head:

'I was an NPQH tutor, and I stopped doing it mainly because there were a lot of the tutors who I knew were failed heads. They had come out of headship and thought, "How am I going to earn, or top up my pension?" and they were diabolical headteachers, but there they were leading NPQH. I don't think that is right.' (11)

Other reasons included practicalities:

'Well we set up the job share because we had children-it's as simple as that.' (15)

For some heads $(19,20)$ the external work was financially very rewarding and they were paid six figure sums for being heads of a federation but for others who were seconded to other schools $(13,16)$ or a federation head $(21)$ the rewards were not great in comparison for the work involved as typified by this comment from a seconded head who was leading two schools for a year: 
'I got two points. I mean two points for two or three days a week. You wouldn't notice, and yet if they had to bring people in it would cost lots more.' (13)

While it isn't anyone's primary motive for an external role, four heads $(5,8,9,16)$ noted that it was financially advantageous for the school particularly to supplement the budget:

'I did PSCL which was one day a week and two days a week for the LEA in 'Blake school' and others, at $£ 300$ per day to get rid of a deficit. In doing that I earned $\$ 17000$ to pay off my school's deficit.' (16)

\section{Professional challenge and development}

While not wanting to leave their schools permanently, fifteen heads $(1,2,5,7,8,9$, $12-17,19,20,21)$ identified their need for challenge. Below are examples from a variety of contexts:

'One of the things for me now is getting out. ... [but] 'I don't have to leave here to do it as a PSCL.... I couldn't be an adviser...' (2)

'I love doing it because it gives me another perspective as to what is happening nationally apart from any reading.... I would just be stifled otherwise. I wouldn't be able to stand it.' (8)

'I wanted a challenge I suppose. I think having both schools has put me out of my comfort zone and this is good for us because you can become complacent.' (21)

'You pick up such a lot just by visiting, talking and looking at people's documentation...It is developing skills, ... so that was a good experience for me.' (15)

In this set there was a subset of three heads for whom working internationally was a stimulating exercise, which offered personal growth and development. Hts 5, 8, and 12 had undertaken seconded international work. The motivation for this is summed up by this headteacher's quote:

'After a long period at 'Woodlands' it was hugely refreshing to step out of your own environment and do something very different, and to think of things in a very different way for a year.' (12)

\section{Moral Purpose}


Leading with moral purpose is a motivation strongly encouraged by writers (Fullan, 2005; Hopkins, 2006, 2007) and NCSL with its strapline from 2008 being 'inspiring leaders; improving children's lives'. This is particularly prevalent among those 17 heads defined as system leaders (Hopkins, 2006). This is illustrated by these responses:

I think that if we don't become involved in terms of moral purpose, then our job becomes just one of carrying out government instructions and I don 't think we can do that either.' (3)

'The opportunities of working with other schools are the chances to develop your skills as a head and help colleagues. Not by saying that you are better than them but that a problem shared is a problem halved. '(16)

Two heads $(5,14$,$) compared the role of CL/NLE favourably to that of a SIP because:$

'NLE is about supporting rather than, you know, what a SIP's role seems to be, which just seems to be challenging only and just data driven.' (14)

The judgemental role of Ofsted was also difficult for three $(13,14,17)$ out of the five heads who had trained to reconcile:

'No I didn't like the Ofsted role. I did a few inspections and I didn't like it at all. I found the whole punitive aspect of the role difficult.' (17)

One head didn't wish to try it as he felt they didn't 'give support to schools' adding:

'No I wouldn't do it because I don't like the relationship between Ofsted inspectors and schools. '(5)

Another head explaining how he didn't want a different role or external role echoed the above view rather more forcefully:

'In some places you need Ofsted training... but be an Ofsted inspector? Oh forget it. It's my equivalent to 30 pieces of silver. Judas! Judas! I have held that view for a long time about people who do it and I am not going to change it.' (6)

This view of Ofsted contrasts with that of $\mathrm{Ht} 18$ who 'waves the flag' for them while realising she is a 'little lone voice' and the pragmatic approach of $\mathrm{Ht} 12$ who does it because she gains useful information to improve her school. 
The need by heads to support and not to be purely judgemental was also recognised by CLs in Earley and Weindling's (2006) study of London Challenge consultants. There is also a high level of personal satisfaction in succeeding in other schools articulated by 10 heads $(3,5,7,9,13,15,17,19,10,21)$ and typified below:

'I know when I went in there it would have definitely been special measures, so it has shifted and that is a great sense of achievement.... I suppose we found there was a 'kudos' or a status which goes with the work-I must be honest.' (13)

'You start to see a change and that's what keeps you going' (5)

\section{How headteachers new roles developed}

The opportunity to work outside their school presented itself in different ways. For roles such as working with the DCSF (10) or for all the work through NCSL including $\operatorname{NLE}(14,17,19,20)$ and facilitation (15) the heads applied to advertisements and were successful. For example:

'...the opportunities are there working with NCSL and they come up and I apply for them.' (15)

One exception was Ht 9 who was recommended to the NCSL by her LA for a specific project as consultant leader. Other heads generally worked as CLs for their own LA. In these instances the process of becoming a CL was by invitation for ten heads $(1,3$, $4,9,10,11,13,14,16,17)$ in the early stages of the programme and then an expression of interest to the LA or application for five others $(2,5,7,8,15)$. The decision rested with the individual LAs and how they wished to organise the process.

\section{Reasons for giving up new roles}

Some heads had to make decisions based on prioritising the work because they didn't have enough time to do both:

'I did the primary national consultancy for a year but then I did the [DfES work] and I couldn't do the two. I haven't got the time to do consultancy as well as what I am doing. ' (10)

Or were given or found new opportunities (15) or because it was having a detrimental impact on their life working in more than one school: 
'Well I won't do that anymore now. You see I was working seven days a week then... and your own school doesn't go away does it? (16)

Another gave up because the work wasn't as stimulating as he had expected it to be and he found he missed his school:

'Ironically when I went out for a year the things I had begun to hate before ... such as lunchtimes and so on - they became the things that I missed.' (11)

The opportunities to move on having proved success in one sphere are highlighted by Ht 19:

'One approach asked me to apply for secondment to set up a 'county challenge' as part of a core group to be the primary head on it... I wasn't interested in that because it would have been too far from home ... and only at the base school salary. '(19)

\section{What next for system leaders?}

There is some evidence to substantiate the views of Gronn (2003) that leadership can become a treadmill and my research extends this to an illustration of how system leadership can become a trap because of the drive of personal challenge. This was identified by all in the category with two examples below from heads in different contexts, roles and LAs:

'I feel in some ways in the last 4-5 years I have had so many opportunities I really want to try, it's like being let loose in a sweety shop. But there are so many, and I am so greedy to try all the new ones, that I have to learn to say no to some of them, but it is difficult. There is a limit not so much to what you can do, but to what you can do simultaneously. '(19)

'I have got to the point when I am sitting here and thinking I am bored and that is no good for anybody. What happens next now? Do I take a third school? Do I leave altogether and take two new schools?' (20)

Another found she enjoyed her secondment and found new challenges outside headship:

I enjoyed the two terms secondment last year which gave me a bit of a taster for it [Ofsted] and so I thought yeah I can do this and I think I will enjoy the change.' (18)

Or for two heads $(16,20)$ the difficulty they envisaged of returning to a previous role: 
I think that there will be a problem for people working with people who are working in more than one school because I will tell you now I can't come back to this school full time.' (20)

One head working with her LA on the identification of new models believed they hadn't necessarily caught up with offering heads opportunities and understanding of what could come next:

'We should be asking "Where are the models and what do they look like?" ... and they [the LA] should say "Lets look nationally and internationally and go and see some new models and come back and decide what does it mean for Mid City and how can we learn from it?"' (13)

Retirement wasn't an option for the thirteen heads who had worked in an extended role in their fifties $(1,3,5,7,10,11,13,14,16,17,19,20,21)$. Only one head retired during this research (1) and she worked extensively afterwards as a consultant for two LAs. She was under the impression in common with the findings of Earley and Weindling (2006), that once she left headship she would lose her credibility to give advice to heads as a consultant. However later when I sought to interview her for the second round to find she had retired she commented that she found that consultancy work was still plentiful concurring with Gunter and Forrester (2008).

Other heads in this set wanted to find other work possibly 'part-time' $(13,14)$ :

'I can't ever see myself wanting to stop work at that age but I would put 60 as the time when I would want to stop full-time work.' (14)

Only one head (11) said 'I don't know' when asked where his future lay and only one who was uninterested in an external role was actively talking about his future in terms of when he could afford to retire:

'When I do the sums I could be out in 3. I won't have to work past 55 and if the arrangements stay the same I will take an actuarially reduced pension.' (6)

One head thinks in common with Munby (2005 interview with the writer) that the system will be varied and system leadership will not suit all. 
'My instinct is that it [headship] won't really be any different for most of us.' (15)

Three heads $(3,16,19)$ could see some new opportunities in cross phase leadership:

'I think there are more opportunities for heads now. There is a greater recognition of different skills heads have. I mean there hadn't used to be anything cross phase and I mean through schools are popping up all over the place.' (19)

There were two main issues common to all heads in managing new roles. One was the impact of standards of attainment and their accountability for the performance of their school or schools considered in Chapter 5 . The second was how heads built capacity in their schools and managed changing relationships which is considered in Chapter 6. 


\section{CHAPTER FIVE: Standards, accountability and the role of the primary headteacher}

Many new roles were developed for the heads in this research because of a form of credibility they had attained or 'earned autonomy' (Morris 2001). Glatter (2003) identified a trade-off between increased autonomy and accountability the former being granted through successive or sustained inspections. Pivotal to the success of these were high standards achieved and/or attained. It is not surprising therefore, that most of the issues impacting on the role of the heads as they identified them, were described either in relation to their impact on, or how they were affected by the relentless drive for standards and in order for the heads to satisfy the various forms of accountability for which they were subject. This chapter considers the impact on the role of primary headteachers of standards and accountability for performance of themselves and of their schools.

\section{The relentless drive for standards}

The Labour Party saw the way of achieving improvements in education was to concentrate on 'standards' not 'structures' (The Labour Party, 1997). There is debate regarding the extent to which they also concentrated heavily on structures (Bottery 2007a) nevertheless the emphasis on standards has had a major impact on the role of headteachers in my research. Managing standards of performance was an issue for all 21 of the headteachers in the 25 interviews in both rounds. It was also the main issue for 11 of the 21 individual heads interviewed $(1,3,6,8,9,10,13,14,17,18,20)$. (See appendices 8 and 9.)

There was no distinction as far as the importance of standards was concerned in terms of the timing of the interviews as this range from 2005-2008 illustrates:

'And we have to be careful how we bring changes into the roles in the school that standards don't fall because they are the bottom line.' (1)

'So the first thing you have to achieve is high academic standards both at Key Stage 1 and Key Stage 2. '(3) 
'Standards are definitely our biggest pressure because of Ofsted. I don't think there is anything else. ECM is a big issue for us now but not like standards.' (9)

'Yes, so it is the standards which is the main issue for us.' (10)

2007

'Mostly the worry about standards...' (13)

'Well it has to be standards. That has to be number one. It occupies most of my time and role as a head. ' (18)

'With the present system the end of key stage results have to be the highest on the agenda for accountability and of course Ofsted. '(14)

2008

'The pressures of getting our sort of children to the expected levels are phenomenal.' (19)

'Standards is the main issue and is the absolute driver behind everything for us'. (20)

'The pressure for me is the Sats and there's no denying we have to make sure that those are good. It's every year and year on year. If I wake up thinking about anything then it 's that.' (21)

I have chosen these examples because they illustrate that the pressure to raise standards from the point of view of achieving the highest possible Sats scores is felt by heads in different contexts. Some heads $(1,9,13,18,19$ and 20$)$ are from areas of urban deprivation, $\mathrm{Ht} 21$ is from rural deprivation but the others $(3,10$ and 14) are from affluent areas and yet the pressure is great in all contexts and across the years.

Standards as it directly impacts through inspection has been analysed later in this chapter in the section on accountability and the pressure to perform. Here I consider how standards impact on the role of the headteacher regarding the curriculum and inclusion.

The curriculum and standards

Elkins and Elliott (2004, p, 22) identified the prescriptive nature of the national curriculum and national system of testing and how it had 'regulated what is taught and how it is assessed.' There is strong evidence from the majority of the heads' responses that their perceived need to maximise test results had impacted on their leadership of 
the structure and delivery of the curriculum. A typical example being:

'I know how to organise the teaching and learning for them [the children] to get optimum standards. ' (13)

'Standards' was seen to be the 'main driver' (20) for many schools and to retain or gain high standards particularly for schools in challenging circumstances:

'Particularly because... [ the client] school was in a category only one aspect really mattered and that is literacy, numeracy and science and so we worked heavily on that. ' (19)

The National Strategies for Literacy and Numeracy have had considerable impact on the curriculum since they were introduced. There has been criticism of them and their impact on pedagogy, creativity and the wider curriculum (Docking, 2000; Alexander, 2004; Brehony, 2005; Webb, 2005) and there is some sympathy with this view from everyone as illustrated below:

'If you think about when the literacy strategy came in I mean I would jokingly say well after 10 minutes you can scratch your nose and after half an hour you can wipe your bum and you know it was like that.'

Nevertheless it was also acknowledged by some heads $(2,15)$ that the National Strategies helped them to raise standards perhaps precisely because it offered a 'lifebelt' (4) because teachers knew what they had to teach to cover what would be tested:

'The great thing about the Strategy is that it gives you a systematic approach to teaching literacy and numeracy which we didn't have. Pre National Curriculum we had nothing. ' (15)

'I felt it gave me the legislation to push through that whole agenda in the primary strategy.' (2)

However she later qualified this with how she also felt 'constrained' by the strategies and felt that 'primary schools have more to think about than literacy and numeracy' (2). So it could be argued that heads maybe being pragmatic by using the Strategies to be 'safe and secure' (4) in their practice. 
The Strategies were never mandatory but they constrained the actions of the profession (Whitty, 2005) because many heads didn't realise that especially as their use was heavily encouraged by the LAs and Ofsted. After they had been in place for some years, schools had to be strongly encouraged to teach creatively and to 'personalise' learning (Miliband, 2004) after the government had become worried that standards had plateaued in their second term (Hargreaves, 2003; Hopkins, 2006). The plateauing of standards being a reason for change was recognised by the heads in this research. I asked them why they thought the encouragement to be more creative was a message being heard from the government and policy advisers. Their opinion can be summed up by this example:

'Because it hasn't worked. No good hitting a plateau. We know it's about standards and that's all they care about. (2)

However a tension between standards and creativity in the curriculum identified in the literature (Webb, 2005; Brehony, 2005; MacBeath, 2008) has also been highlighted by five heads $(2,5,9,12,16)$ as illustrated below:

'They want even more from us and all right you pick up Excellence and Enjoyment... yes, there is a lot on enjoyment but there is a hell of a lot on standards ...' (5)

I think the emphasis on standards has improved teaching across the board and I wouldn't argue with that but why do they have to go to such extremes as now? It hasn't stopped...they won't let the standards agenda drop at all, and it's still the dominant aspect of inspection and so I don't think it fits with the excellence and creativity at all as part of the jig-saw puzzle. (12)

The fear of promoting creativity to the detriment of results was still a fear for many as illustrated:

'When we do the dance festival I think, oh if we don't do very well at Sats then people will say "Oh it's because they took two weeks of the children's time..." It's like a standards market now. ' (9)

Nevertheless ten heads $(2,4-9,11-13,21)$ discussed the importance of ensuring that the curriculum was interesting for children as well as raising standards:

'Particularly here, we think in an area of deprivation it is the broad and balanced which is equally important.'(4) 
However important creating an interesting and creative curriculum is for its own intrinsic value, or defining it to fit their own values as a form of 'principled pragmatism' (Moore et al. 2002), all the headteachers remembered the importance of standards and ensuring the quality of teaching and learning to facilitate that as exemplified here:

'Then what we do with absolute concentration and I think this comes very clearly from me, is that the quality of teaching is our first item. ' (20)

\section{Teaching to the test}

One result of ensuring good levels of attainment and progress is 'teaching to the test' (Hargreaves, 2003). My research offers evidence to support this view as seven heads directly commented on the need to provide a curriculum which supported the tests or directly teach to them $(4,5,7,9,16,19,20)$ :

'I am not sure in recent years how much we have raised standards or just got better at teaching to the test. '(19)

'People definitely have to teach to the test of course they do. ... Most schools have to, so we can be sure of the results. '(16)

But also that it is being done with some reluctance:

'In the autumn you can be a bit broader in terms of what you teach whereas in the spring term to May you have to crank up the work for the tests more but we try to get a balance across an academic year.' (7)

'Our kids do English maths and science in Year 6... come May there will be kids in there crying because they can't cope with exams and the Government is making us to do this to 10 and 11 year olds. '(5)

However teaching test skills themselves isn't necessarily seen as poor practice by one head:

'I don't think teaching about how to do tests is a waste of time...I have helped with things like pick the easy marks. Don't do what you know is hard, pick the easy one. It's a life skill. Prioritising!' (6) 
There is a need for every year group to perform to achieve optimum standards for the school. To ensure this, data needs to be held and evaluated to identify any dips in performance for individual cohorts or children. 15 out of the 21 heads $(3,5,7,9-19$, 21) described the importance of a water tight tracking system and assessment program (14) and analysing the data produced to enable them to show the children's progress and gain a good result from Ofsted. Performativity regarding pupil progress and the need to perform to ensure their place in the league tables (Elliott, 2001) was an issue throughout the research period. Examples include:

'You live it, sleep it and breathe it as a head don't you? ... In the early days there was very little understanding of the importance of progress year on year. It was felt to rest pretty much with Year 2 and Year 6 and so that had to be addressed.' (18)

'We had a dip in Maths to 70\% which is poor for us and it brought down our Panda grades and hit us with value added. So we had to do something and we looked at the kids and asked could we get 10\% and so we targeted them and went to $80 \%$ level 4 and $40 \%$ level 5. ' (7)

The curriculum also has to be adapted to ensure that it targets improvement as identified here:

'We are also looking at the curriculum with regard to making it more focused particularly on maths and analysing where the children are falling down.' (10)

Even when the curriculum is suitable and in place for maximising results there is still the need to review it according to changes in the Sats:

'Standards started to dramatically go up and then over the last couple of years the writing Sats changed and that's where they found it hard and its getting the ideas together to how we can improve it and so within the school now our big issue is writing. '(8)

There is evidence to support the notion that heads will take on work which could be delegated to others but is so important they have to manage it rather than leave it to chance. One example of this is to manage the assessment process as it impacts so strongly on standards and the school's self evaluation systems which both in turn impact on inspection. For example: 
'I coordinate the assessment. I spend a lot of time on it because I want it done properly and I like to be able to track every child and look and see the trends.' (18)

The 5 outcomes of ECM, standards and the curriculum

While acknowledging it was an issue to be managed, there was a general consensus among the heads during the course of the interview cycle that the 5 outcomes were already embedded into their schools and wouldn't require much change to the curriculum or impact detrimentally on standards. This view is exemplified below:

'Once I realised that it was pretty much the same, just in 5 categories, I didn't worry about it. ' (17)

'We have got the ECM agenda. We have got to see how it can work concurrently alongside what we are already doing in the curriculum. We are already doing a lot but it's just recognising it. '(10)

One head resented the imposition:

'I don't like it [ECM] actually, not the sentiment behind it - but I think it's forced. ... I resent the fact that the ECM agenda has led the way the SEF is organised.' (14)

However while it imposed an additional administrative burden in terms of the SEF the 5 outcomes had little impact developing new roles for heads as they delegated the actual tasks of developing the curriculum to members of staff which I will consider in Chapter 6.

Tensions in the government's agenda between standards and inclusion

It has been argued that change can have 'unintended consequences' as it is shaped by those who implement it (Clarke and Newman, 1997; Levin, 2003a) and that an essential role for leadership to be successful must be to make sense of the tensions and contradictions of the policy environment (Simkins, 2003, 2005). One of the potential problems is that government policy is made by several different groups who may be competing (Levin, 2003a). Adams and Kirst (1999, cited in Leithwood, 2001) recognise a dilemma for schools regarding tensions between maximising results and 
inclusion of all children regardless of need. My research supports this finding.

Seventeen heads $(1-11,14-17,19,21)$ identified this tension as exemplified below:

'Inclusion is the one [issue] that is seriously in danger of disturbing the standards agenda... Ofsted acknowledged that. They said we had a difficult balance to maintain between inclusion and achievement. '(6)

'The trouble is that the government want it all and don't know how to get it. They want all these miraculous results. They want all children to be average and so they don't understand what averages are therefore. You can't have everybody average can you!'(16)

'But you know they want 100\% at L4+. Well for God's sake you'll never get that will you? I mean that's the problem - the pressure to do that. But what about SEN?' (2)

A tension was described between raising standards and inclusion highlighting difficulties associated with special educational needs and deprivation. The problem described by several urban heads $(1,2,4,8,9,12$, ) was outlined by one of them in the example below:

'The challenge is in inner ring schools where you have got both agendas of ECM and standards pushing at both levels - that's where it is hard. ' (9)

This headteacher saw it as being particularly an urban issue but other heads in more affluent or mixed areas also identified the tension $(10,11,14,17)$ :

'So it's a changing clientele ... when Ofsted and people like that come in they must realise its not totally a well to do area any more it has changed considerably since I have been here and it is changing rapidly now. '(10)

Another aspect of the tension with inclusion, and standards was highlighted specifically by seven heads $(2,4,6,10,11,12,20)$ around the behaviour of children:

'Because we have got some very difficult kids we work on it. This is what is so difficult when people like Ofsted come in. They see these well behaved kids and they think they should be achieving even more - they don't realise how difficult it is to get them to this point. I find it's a massive pressure. '(11)

\section{Accountability of the headteacher}


I asked heads a general question in terms of where they felt their accountability lay. While most of them later in the interview discussed their role in terms of the entitlement of the children and the need to perform to ensure the governors and community were satisfied, one head immediately and firmly placed his accountability outside the realms of inspection.

'Definitely still to the children as far as I am concerned.' (7)

Eight heads $(1,4,5,7,8,9,11,21)$ highlighted that accountability was so strong in this country because of a lack of trust in the profession:

'It is certainly about lack of trust. Certainly we are the least trusted of all professions. The fact is that Harold Shipman can do away with 300 people and we have to check that someone hasn't bought their wife a dishwasher out of petty cash.' (5)

Over the last twenty years accountability has been strengthened and 'Being held to account' (Leithwood et al.1999; Ranson, 2003) is now the dominant mechanism of accountability. The importance to which this form of accountability impacts on the role of the headteachers in my research is supported by the number of them who cite it as an issue. Accountability to Ofsted was the main issue for 5 of the heads ( 7 in both rounds, 11,12,17,19) and described as one of their issues by all heads interviewed apart from Ht 4. One head put standards and accountability jointly as her main issue:

'Yes I think the standards agenda has a major impact on my role as head...that coupled with or as part of accountability through Ofsted which I have found to be very negative.' (17)

\section{The perceived need for external accountability}

Whether or not it was manifested through inspection by Ofsted, six heads commented that some form of external accountability for schools was necessary $(5,12,13,15,16$, 17). Accountability was welcomed by one head as 'a good thing' (15). Her reasoning for this view was:

'I started 20 years ago and there were a lot of children who left the school not having the basic skills ... you would hear people say 'these children can't achieve'... but because we have had that attainment accountability, it made you shift those kids.' (15) 
Similarly, if not welcomed, being held to account was seen as necessary for the good of the system, as these typical quotes suggest:

'There have to be ways of judging schools. I don't think you can go back to how it used to be. '(16)

'Well I don't welcome it but the bottom line is that not everybody does the same high quality job do they?' (5)

In saying things can't return to 'how it used to be' before Ofsted in the early 1990s these heads gave the impression that because there was no nationally imposed accountability there was no effective accountability for teaching and learning. This is reminiscent of Barber (2002a, 2005) in identifying the 1970s as 'uninformed professionalism' and of the government having 'won hearts and minds' (Clarke and Newman, 1997). However it could be argued that the crucial point is less about the need for accountability itself and more about fairness and consistency of the process of accountability for the performance of schools both at individual school and system level. One head (12) while agreeing with the concept of being accountable 'I think there should be accountability. I feel very strongly that people should be held responsible. ' was concerned that it was the 'right type' and that perhaps the system had 'gone too far' with the degree of public personal accountability for the head.

\section{Ofsted and 'The New Relationship with Schools'}

John Dunford of SHA now ASCL (TES, 2003) suggested that heads were subject to accountability from 21 organisations including governors, LAs and various government agencies. The new relationship with schools was a response to the undifferentiated external pressure on schools of the previous accountability system (Hopkins, 2006, 2007). The Section 5 inspection framework was set up with the aim:

'to help schools raise standards' [through] 'delivering an intelligent accountability framework, a simplified school improvement process and improved data information system.' (DfES/Ofsted, 2004, p.1).

As well as fulfilling its role of raising standards of performance in schools the accountability system must also 'build capacity and confidence for professional accountability.' (Hopkins, 2006, p.10). This was referred to as creating 'informed professionalism' by Michael Barber (2002a, 2005). I wanted to discover the heads response to the implementation of the new framework and if indeed it was offering 
them in their view an element of 'earned autonomy' to have some control over the development of their roles.

The first interview coincided with the introduction of the Section 5 inspection schedule in September 2005, meaning that for some heads, their most recent inspection was under the Section 10 framework. Nevertheless they were all aware of the need to prepare for their next Ofsted, and so described their issues in terms of it. Only one head in my sample felt unsure of what to do next although clearly like everyone else saw it as a process to be managed.

'I think part of it will be learning how to manage Ofsted... I haven't worked out how I am going to do it yet with the new one.' (6)

Headteachers identified the Section 5 framework for inspection as mainly resulting in:

- A rise in the importance of data in determining the outcome of inspections.

- A need for robust school self evaluation.

- The forming of new or changing relationships, e.g the introduction of the SIP role and reduction in their interaction with the LA.

The increased importance of data in determining the outcome of inspections

The most effective way the education system is regulated is through the system of monitoring which is mainly achieved currently by inspection. The amount of data held on schools has increased massively throughout the years (Ball, 2003) as the government encouraged informed professionalism where 'teachers are driven by data and what the data tells them.' (Barber, 2002a, p.187). When describing the impact of inspection on their roles eighteen heads described the importance of data to the inspection process. The three who didn't $(1,2,4)$ were interviewed early in the cycle of interviews and one reason for their failing to appear concerned about gathering data as opposed to their concern over standards may be that the significance of knowing the data in detail for their school in order to help them prove their worth in inspection had not yet become apparent to them. Of the 18 heads in this set only Ht 11 professed not to be led by data, proclaiming 'I am not data driven. I am not obsessed with targets and never have been.' Although later he talked about 'We now have much more accurate data. ' (11) While maybe not obsessed, he still ensures that he doesn't 
make the mistakes in headship of not having data to talk from. Evidence of the importance of data in inspection is highlighted by all of the interviewees:

'Oh yes absolutely certain inspection is data led.' (16)

'I think in reality and in talking to other heads that's what they base the preinspection on and data determines what they think when they come in. '(14)

The ability to be able to interpret data is seen by headteachers as being an important skill for them to master. The following quote by a practising Ofsted inspector typifies their response:

'The problem is that Section 5 inspections are so driven by data that you are making a mistake as a head if you don't really know it well...' (18)

And another who is trained but doesn't practice:

'I think you need to be good at data analysis as a head and you have got to have a rigorous system at your own school and you can identify where the gaps are and where you need to make the improvements and know what you are going to do about it.'(17)

While data has always been important as a measure of a school's performance there is evidence from 2005-2008 to support the view that with the onset of shorter inspections there was little time for inspectors to concentrate on issues other than standards. This appears to exacerbate the pressure to show results:

'Let's put it this way when the data is high they [inspectors] have time to look at other aspects... But when the data is low they go for the jugular straight away. ' (19)

The Value Added (VA) and Contextual Value Added (CVA) factor

The impact of deprivation on the outcome of standards was recognised by the Labour government with the inclusion of a measurement of progress or a value added factor from KS1-KS2 as well as attainment data. The importance of favourable VA to gaining a good inspection was articulated by all headteachers except four $(1,2,4,6)$ who were interviewed early in the Section 5 cycle. Both Section 10 and Section 5 frameworks for inspection are differentiated in that both attainment and achievement are measured. However my research indicates that the use of VA as a measure of 
improvement has meant that progress has overtaken attainment in inspection depending on the deprivation factors in the school.

A value added score of 100 is considered to be satisfactory by Ofsted in that children have made the expected level of progress between KS1 and KS2. A further measurement of CVA adds contextual information to the single value added score based on attainment. Implications for this have been considered by heads in that good attainment at L4+ at the end of Key Stage 2 doesn't necessarily give a good score for progress which is dependent on the value added from Key Stage 1-2. This can mean that a school which would have done well in past inspections based purely on standards of attainment may now be considered to be 'coasting' or performing inadequately. Conversely, a poor attainment score can still result in being judged as 'good' or 'outstanding' by Ofsted, if the school can demonstrate that they have made good progress from the baseline of Key Stage 1 and on entry to school in Reception. Satisfactory CVA seldom leads to an 'outstanding' inspection, (although as I will illustrate later the outcome of inspection to some extent depends on the attitude and skills of the individual team) but satisfactory or even low attainment is still compatible with good CVA and therefore a 'good' inspection. Heads felt they needed to understand the implications of the VA system on their intake as illustrated in detail here:

'For example if you have Chinese children they count heavily against you and then as you go down the list you get to the zero effect which is something like a non FSM, non SEN white boy, or something like that, which has a zero effect on the results. As you look down the other end it is a real hit and miss as to whether your school happens to contain people on free school meals, what background they are from... So if you have boys from Pakistan, free school meals and school action plus you are well on the way! They are going to count really positively in your $C V A^{\prime}$. (18)

Taking findings from both rounds there is some correlation between those heads that benefit from having the majority of children who count positively for CVA liking the system and those who don't, disliking it. Of those 13 heads who commented on CVA $(5-9,12,13,15,16,18-21)$ who were in areas of deprivation, all of them with the exception of Hts 7, 16 and 21 commented favourably:

'At the last inspection ... the achievement came out as very good. So although attainment was a (grade) 5, achievement was a (grade) 2 which is great. But we are on a continual knife edge. ' (13) 
'I think it is a much fairer system for schools like ours which have real difficulties struggling with the attainment only system....

Not all the heads in this sub set agreed that CVA was fair. One head coming from an area of rural deprivation and might be expected to like the system of CVA as he is likely to gain from the value added to be given for SEN, when asked was emphatic that he didn't:

'No I don't! I think it is blinkered to be quite honest.' (21)

All of the headteachers who gained in the past, in a system which judged a school's performance on mainly attainment, disliked the emphasis on VA $(3,11,14,17)$ :

'Most of the schools it seems to me which are outstanding are inner city schools with over 101 CVA. The way it is calculated helps them.' (17)

There was a degree of cynicism that the introduction of VA might be because the government needed to find ways of encouraging practitioners to apply for challenging contexts and were reluctant to apply to schools where attainment was difficult to achieve and so therefore another measure or CVA was added. The difficulty for heads however is that it is an inaccurate measurement and based on criteria such as FSM which isn't robust as it relies on both accurate reporting of statistics by schools and for parents to apply for it which they don't always do as illustrated by this comment:

'A lot would be eligible for FSM but don't apply and so on the benchmarking we got crucified on the PANDA' (6)

One head explained the dilemma facing the accountability system very clearly:

'Well it is certainly very much better for schools like ours but I think from the point of view of fairness one or two things would upset me if I was in a middle class school. One is that they have taken L6s out of it and so the value added for high performing schools is very difficult and the other one which is to our advantage is that in second language schools there isn't a normal curve of progression and so you can't expect from year 2 to year 6 to look like it would be if it was a white school-progression wise, which had already got a level of English in Year 2. (19)

Most heads acknowledged that 'you cannot compare KS1 assessments with KS2 assessments' (7) because of differences in the testing criteria. Once gaining their 
school's successful performance there was evidence of pressure expressed by heads from all contexts $(5,8,9,13,14,17,19,20,21)$ to maintain it as ' $g u t s$ are on the table day in, and day out, and everybody is held accountable for it. ' (20). The implications of this for future leadership are that head teachers may look more favourably at challenging circumstances because they may be 'winners' for CVA:

'So I was either looking at special measures or I was looking at a good to outstanding school. I didn't want to go for the 'swimming like crazy to keep satisfactory in your grasp' type of school. ' (18)

There was some evidence that the league tables were still identified as a pressure because they are public even if the problem of accountability for heads in challenging circumstances has been alleviated to some extent by the CVA system:

'In the end though the league tables don't help - its all about the comparison, and there is always somebody who is better, but of course half the schools are always going to be in the bottom half of the table no matter how good we all get, and its so depressing and demoralising for staff.' (13)

\section{The accuracy of data and inspection judgements}

Whether or not the value added system is fairer in principle or not than the one preceding it, for VA and CVA to truly benefit as a measure of a child's and its schools performance then there has to be an accurate method of calculating it. Chapman (2001) argued that the accuracy and relevance of data and the skill of inspectors in gathering and prioritising information during the inspection was essential if inspection was to improve schools. However Gorard (2006) in common with the heads of this research cast considerable doubt as to the accuracy of value added data. The questions around the accuracy of data were only part of the interviews from round one beginning with (5). Before that it had not been part of the discussion generated by the heads. However from the end of autumn 2005 particularly as a result of my research of the literature together with my own experience, I realised how important this would be to the research and started to ask supplementary questions such as 'What is your opinion of the accuracy of the data used to judge your school?' Typical responses were:

'I don't think it [CVA] is accurate enough but I think it never could be really because there are so many variables in it.' (19) 
The data collected for judgements was also considered to be inaccurate because of the quality of the Sats markers by four heads $(5,8,9,15)$ :

'Our English results were appalling and badly marked. The marking was done appallingly and we sent them all back and they just wouldn't entertain them but if you looked every child was given the same marks for the first section and that is ridiculous.' (8)

Two heads $(7,19)$ highlighted the validity of the data used such as FFT or QCA optional tests:

'Well last year we were only going to get $44 \%$ on Fischer and we got $78 \%$. The reason for that is that it doesn't allow for children's English which really kicks in, in Years 5 and 6. Fisher skews in the same way that the optional tests skew the other way and give you false reports. '(7)

It has been made quite clear to inspectors that they should only use CVA as one of a range of indicators for judgement (Bell, 2003) but it is down to the individual teams as to the extent to which they adhere to this advice. The importance of the quality of individual inspectors was highlighted as an issue by eight heads $(8,10,12-17)$ with the inability by inspectors to heed the advice of using data as a broad brush stroke thing really and not an exact measure. '(18), or to be able to read data at a sufficiently sophisticated level identified as being frustrating:

'I think for me there is a recent frustration in that I can understand and interpret the data for my school... but when you have people who are coming to inspect your school and who can't really understand what you are putting in front of them then I find it very frustrating.' (15)

However some heads had cause to thank the individual competence of their teams. An example of this below:

'So he [the lead inspector] said "Well, I think you need to know from the beginning that we understand schools like yours which get high standards at the end of KSI but find it difficult to demonstrate progress at the end of KS2." ' (3)

One headteacher also had a more positive view of the quality of the judgements. She made the point 'Thank God it was an HMT' (8), because the inspection report reader 
would be less likely to challenge the judgements of HMI and her latest CVA results had set her up for difficulties. Another aspect which impacted on the fairness of using data and value added to judge progress was the attention drawn by several heads to the opportunity and importance of manipulating the data to their advantage:

'I mean here we go again with it... 40\% SEN in some schools and 90\% Sats results. Rubbish! Like I said, I understand if you've got the government on your case heads get pressurised.' (2)

'But it's also about value added so if the results are too high in KS1 then God help you!' (9)

'We have overachieved in KSI to be brutally frank and it requires delicate conversations with year 2...You have to be really solid now in your judgements because of the impact on your value added. '(7).

Interestingly in the second round this head teacher was describing the perils of still being:

'crap for value added because our KS1 results historically have been too good'... we always pushed in year 2 to get good results for the children to get the best they possibly can, and what's wrong with that?' (7)

Some heads are hostages to fortune as they are not in control of the KS1 results. Two heads $(10,14)$ were in this category in my research but their view supports the general view that it is difficult for heads in junior schools to prove progress:

'We are basically high achieving but we are a separate infant and junior school and so of course we have to very carefully watch the value added coming up from KS1 to KS2' (10)

Seven heads $(2,7,9-12,14$,$) made the point that it isn't so much that the KS1 tests$ weren't accurate in the past because of cheating or manipulation just that the 'goal posts were different' (11) A child was awarded a level 3 even though it was just on the cusp of that level or a $3 \mathrm{C}$, and now heads need to ensure the child is 'securely Level $3 B$ across the board' (12) in order for them to show the value added in Year 6. Below are examples from different contexts:

'Five years ago I would say go for it if there is a chance they can get a 3 but now it's around performance management and totality of performance. Is that child a $2 B$ in your test and classroom assessment? Does a work sample reflect 
that? If so then they are a $2 B$. So what it gives you of course is a declining trend in KSI which is what we have now. ' (7)

'With regard to standards we are finding that in fact a level 3 at KS1 is nothing like a Level 3 at KS2 and we find that quite difficult to build on and justify.' (10)

$\therefore$ and what a Level 3 looks like in KS1 is not what it looks like in KS2. That is just an inescapable fact of the whole methodology of assessment which is different.' (14)

One head has countered the value added problem by resorting to 'brave' and 'drastic action' (12). She goes on to explain:

'We opted to use our teacher assessment results because they were based on the evidence of the children having achieved that level. Our scores were massively deflated...' (12).

However when the school was inspected again they were judged as good partly because while the attainment at the end of KS2 was below national expectations the progress of the children from KS1 to KS2 was good.

Four heads $(9,11,12,18)$ identified that the need to prove progress has meant a renewed emphasis on the accuracy of judgements determining baseline on entry to school.

'I feel I have got a more secure baseline to go from now and so that has helped people make better judgements and we have given them the tools and the training to make better judgements... and of course it has been really important to do this to secure standards and progress. '(18)

'I am determined to make sure that our baseline is accurate and that KSI is accurate because low and behold we are in trouble if at KS2 if they aren't right.' (9)

Given the perceived failings of using VA it may not be fair to judge managing the data as a form of cheating in the way (15) seems to be suggesting:

'As we get to know the system better people will know how to work it and we will end up with lower results at the end of KS1 and so VA will be higher at the end of KS2.' (15) 
13 out of 21 heads $(3,6-15,17,21)$ expressed concern about the impact on Ofsted of their key stage results but they are experienced heads and could argue their data and decisions.

'They [Ofsted] did look very carefully. We were inspected in January this year but we evidenced our argument with-come and look at the progress the children have made so far within a term.' (12)

These interviews support the point that it is important that heads take control of the inspection and managing the process. At the beginning of the cycle in 2005 one head described how he was unsure of how to manage the process (6) but by the end of 2007 another stated:

'I think I understood their agenda. What had happened was that as soon as I realised what CVA was going to do I had worked it out and sorted it... It's knowing what to say and how to contextualise.' (3)

The increased importance of self evaluation systems

One aspect of the New Relationship with Schools (DfES/Ofsted, 2004) was the introduction of the Section 5 framework and the introduction of the SEF. While not statutory there is an expectation by Ofsted that schools will complete a self evaluation form (SEF), submitted online, which will be used to inform judgements made about the school. All the heads commented on the need to undertake their school's self evaluation and typically:

'There is a far tighter self-evaluation there has to be. Your own data analysis and the way we do our SDP review is wholly set by the self evaluation agenda.' (7)

The reasons were either because the SEF had just been introduced $(1,2,3,4)$ ' and I want to get the whole self-evaluation issue sorted' (2) or because they were using it (5-21). There was some difference in heads' attitudes to the new relationship. Two heads $(4,15)$ welcomed the shorter inspection and weren't worried by the need to be in a state of readiness:

'I think it is much better now than it was when you had a year to prepare...' (15) 
'Well in theory it should keep us in a state of readiness for inspection I have no problem with that...It's all on the SEF.' (4)

In contrast to these very definite views above, another head was warier about the need to be ever ready and viewed Ofsted in a way similar to that described by Troman (1996) as an 'absent presence':

'I think what the real pressure is with Ofsted is that you don't know when they are going to come. We are all on pins waiting for it... it's more of a shadow.' (10)

She continued that while in favour of the system having had some input into it nevertheless disapproved over the way it had been introduced in September 2005 along with both remodelling and ECM. The comment about the timing was echoed by seven other heads $(2,5,7,8,9,12,13)$. While the shorter inspection was generally welcomed this was qualified by some heads because of work intensification:

'you will have to prove yourself to even greater lengths now through records because they are only coming in for one day.' (18)

'Previously with the old system you had a bit of time to breathe but the process of self-evaluation means that you cannot stop. ' (7)

Attitudes regarding the usefulness of the organisation and structure of the SEF as a document were also mixed. The bureaucracy surrounding the SEF was seen by 4 heads $(6,11,14,17)$ as a burden:

'An obvious external pressure is the self-evaluation process. Having had a year out I am finding that quite difficult to do accurately. '(11)

However later in the interview he made an interesting comment which links with Ball's (2001) concept of 'fabrication' in that he believes that heads use the SEF strategically to show their schools as they wish them to be seen.

'They know that whatever they put in the SEF, what is really needed, and what is good in their own schools'. (11)

Some heads were more positive possibly enjoying the structure and security it brings with it: 
'Last year our results were better than this year but were still down and the SEF actually says that it was due to the large cohort of SEN children. I put that in and I would hope that if Ofsted does what it says it is going to do and takes account of the school's self-evaluation and where the school sees it is going I would hope that they would be fair about that. '(10)

'I think the SEF is excellent. I think the SEF is an important document. I have spent hours on it and I am on my fourth version of it... It keeps me focused on what I have got to do and I keep going back to it. ' (7)

One headteacher (14) disagreed with the value of having to continually update it and called it 'that bloomin SEF' due to the times it had to be changed and another (6) also admitted to 'having known people work hundreds of hours on it' but this was not for him.

Managing the process of inspection has always been part of school leadership since the inception of Ofsted (DfE, 1992b). There is strong evidence from this research that the new framework with its emphasis on school self evaluation has increased the need to refine the data and the system of gathering it in order to present a coherent picture to inspectors:

'Our VA wasn't 100 when we were inspected and we got questions but what is important is the way in which you present the information to them. I presented the information to the inspectors in a way which enabled me to show good progress across the school. ' (12)

When judging the leadership of the headteacher, it is important that the quality of teaching judgements made by the inspectors agree with those of the school. Two heads specifically mentioned that they had taken up the offer of inspectors to jointly observe with them as a validation of judgements made in the SEF.

'I observed a lesson with the HMI and the first thing he said was "well what did you think? What feedback would you give that teacher?'... So it was reassuring that I picked the same strengths and weaknesses as he did.' (11)

'...we observed a lesson which was a difficult lesson to call and as far as he was concerned I got it spot on and he actually said to the teacher 'your headteacher is absolutely right in her judgement.' (3)

Stress and inspection 
Inspection was stressful when judged to be unfair. One example of this was when a head believed that inspectors concentrated on following a government agenda and were more concerned with finding evidence to justify it rather than concentrating on the issues for their individual school:

'I think Ofsted responds to government papers or the agenda that's on offer. When our team came out they were responding to the Rose Report about early reading and early phonetic development and I think they felt that that is what they needed to respond to and they had been told to look at that. I have heard from another colleague who had the same team and who said "you have exactly the same key issues as we did." '(17)

Assuming the individual teams are fair preparing for a good inspection will still have some degree of stress attached to it as all heads are aware of its importance to the reputation of both the school and themselves. However the degree of worry this caused them in their professional lives was varied. Six heads $(4,15,16,19,20,21)$ specifically stated that while they prepared for it they were not worried by Ofsted. This is supported by the comments of Ht 4 who suggested that he always looked at external pressure from the government's agenda in terms of 'Well I don't actually care'. I believe there was a measure of security for him in having moved his school from special measures and claiming that it 'couldn't have got any worse' (4). One head in this set commented 'No, we are not worried by accountability to Ofsted' (20) and another suggested that while she had to manage it she found that:

'Ofsted is reassuring and I suppose having done it a few times I feel better about it.' (15)

A common factor to all the heads in the above set is that they had recently moved their school $(4,15,20)$ or a client school (19) from special measures to satisfactory or better or were in the latter stages of doing so $(16,21)$ and secure that Ofsted would validate the improvements made. These heads still had a degree of concern about needing to ensure the school was secure but there was less of a direct pressure on them and a security and self-belief to be gained from the experience of being validated already as successful leaders together with tangible results which they could prove to Ofsted. It has to be remembered that schools are monitored regularly in this position and so there is a strong element of the known position for these heads due to the interim HMI monitoring reports. This concurs with the findings of MacBeath 
(2008) who found that the leads for improvement given by inspectors were largely acted upon.

Caution needs to be applied in the assumption that the pressure to perform might be less due to the relative position of the school. Four heads $(2,8,9)$ and $(6)$ as an acting head, had been appointed to schools in special measures but had since seen their leadership validated by Ofsted. However they were under stress to perform possibly because their school's inspection was some years before in the previous cycle, and so were consequently under pressure to perform and mindful of how stressed they felt when moving to their schools as inexperienced heads. Ht 6 sums this up possibly for all:

'I said to the staff, I have been in special measures, you haven't and you never want to go there' (6)

There was therefore a heightened awareness and fear of what it would be like to fail. However I believe another factor here is the way in which the individual manages pressure even if their school is performing. The level of professional pressure six heads $(4,15,16,19,20,21)$ felt under was relatively minor as already identified, but they were also motivated by the pressure they felt under with regard to their professional pride. It may not have highly stressed them and they may even have gained a 'buzz' out of it, but they were pressurised to perform nevertheless, and in common with all heads it didn't diminish the focussed and relentless pressure they imposed on the school. This pressure can be supported with an illustration by Ht 20 who ensured high standards by ensuring she 'gets the right people' and in doing so, 'doesn't get taxed by staffing issues' because they are as driven by raising standards as I am.'

Expectations of the levels to be achieved are a powerful indicator of how stressed or under pressure heads are and the unexpected can seriously worry them. If heads are in post for a long time they believe they will be blamed for any failure. The result of this means that for most of the heads who had been in post for more than five years and who were likely to be subject to an inspection soon, there was some degree of worry over sustaining success. This included Hts 1, 2, 3, 6-14, 17, 18 which was 14 out of the 21 individual heads interviewed. For them the individual sense of responsibility 
was greatest as the failure of the school would be a direct assessment of their leadership:

'I can remember thinking I am going to be judged on these results and I felt awful.' (8)

As well as the differentiation of levels of stress caused by personal responsibility for the school's success there was also some differentiation according to the level of pressure there was perceived to be to secure an expected level of standards. For some heads the results currently being attained by the pupils in their school gave them some level of security providing they believed they could be maintained. This may have been due to the standards of attainment for four heads $(10,11,14,17)$ which were high or if not the level of CVA or VA mitigated the results for five others $(5,13,19$, $20,21)$. One complicating factor was timing. Six heads $(6,8,9,10,13,14)$ identified the importance of the inspection to be timed in the favour of the school's results because if the inspectors came at the wrong time there were fears low results would impact unfavourably on their inspection. One school experienced a 'dip in performance' causing concern between inspections and so 'it was a worry and everything we did was geared towards improving and getting back up. So yes it is a pressure. (14). For another head because:

3 years ago we had 12 children come from Jamaica in Yr 6 and I would say that 8 of them had never been to school. It was terrible because they had to be included in the results... It was a real, real bad year. (9)

There was a different reason for the pressure felt by one head (10) who had a high profile external role and knew that a poor inspection would affect her opportunity to continue as the governors might withdraw support. In another context two outstanding heads had made so much progress they had the worry of sustaining it for the next inspection.

'I ended up feeling where the heck do you go next because there is only one way and it's down at that point... So my main problem has been securing that continuing outstanding. It put a lot of pressure on me. '(19)

'I suppose it's keeping the momentum going after an 'outstanding' Ofsted... is the big one [issue] for me.' (8) 
For some heads there was a degree of anger and frustration at the vulnerable position they were placed in with the public nature of accountability. The pressure of personal responsibility for the heads is linked to the fact of the public nature of inspection as it is their name on the front of the Ofsted report. This was mentioned by six heads either as a concern $(8,9,13,14,17)$ or frustration at the unfairness of it (12). One head linked her public accountability to that of a GP in that 'I couldn't pull off a report that says whether my GP is a good GP or not' (12) and another gave an example of the implications of integrating the inspection report for the children's centre into the school's is that it causes concern because 'that's what I worry about with my name on the front of it.' (13).

The new relationship with schools and new accountability partnerships: SIPs and LAs

The 'single conversation', as part of 'intelligent accountability' (DfES/Ofsted 2004), was meant to reduce the impact of inspection on schools (Hopkins, 2005, 2008). My research shows that there are mixed reactions to both the intention and outcomes of the new partnerships created as a result of the 'new relationship' (DfES/Ofsted, 2004). A new system leadership role (Hopkins 2006; 2007) has developed in the use of SIPS in the process of school accountability. Little was known of SIPs in September 2005 when I began these interviews. Ht 1 had 'no idea how they would develop'. The system was largely in place by early 2008 but LAs had adopted SIPs at different times and this affected the amount of personal knowledge heads had of it. In contrast to my first interview, one head (10) was directly involved with the development of SIPs at government level and could reasonably therefore be expected to understand and support it and gave her reasoning in some detail as:

'I think one of the positives is that they will be quality assured. They are hoping to bring in a national system of quality assurance so that every local authority in the country will have a good level of SIP. At the moment it is variable throughout the country and some local authorities are brilliant and others are not.' (10)

So while the above may be the intention, there were mixed views amongst the other heads and a degree of the unknown in those early days when I asked heads how the relationship with SIPs would work. Opinions varied: 
'I don't think I can answer that or comment really because I haven't looked at the training for the SIP nor have I seen a package for what they will be doing in schools so I would reserve judgement on that. (14)

'The link advisers role is to offer advice and I think what is happening is that the SIP is taking on the monitoring part of the link adviser's role and the link adviser will be able to do the advice part.' (17)

However one head saw a difficulty in this in that the LA would lose its knowledge of the schools if this happened:

'I know we all criticise the LEA and some of the advisers but at least there was some level of continuity in that they could identify that there would be a problem at a particular school coming up. How is a school improvement partner going to do that?' (16)

Heads who had considered the role were concerned about the quality of the individual SIP and were typically:

'very dubious about the relationship with SIPs. I think it will very much depend on the kind of person who has the role.' (17).

There was also identified a potential difficulty over the definition of their role in terms of 'partner' or 'assessor'. One head however, having now trained as a SIP, had no doubts as to the relationship being definitely more along the lines of inspection. He commented on his training:

'It was a model for challenge, no support whatsoever and they didn't want to talk about support. Everything is down to standards, standards and more standards. So I think SIPs are going to be a bit of an issue. ' (5)

Many LAs have trained their own advisers as SIPs. Three heads $(4,5,18)$ mentioned this with two of them seeing a potential conflict of role:

'If I want to have a private and confidential conversation with my school improvement adviser about an issue I have got in school then he is bound to be influenced by what I have said when he comes in with his SIP hat on! It has to affect his judgement doesn't it? I mean it's not rocket science is it!' (18)

'In ... [another LA] all the advisers are now SIPs. There is nobody back at the ranch to give you support and so-you need EAL support? Well tough, there is nobody there!' (5) 
Or because, in the case of $\mathrm{Ht}$ (4) who commented that he wasn't impressed by the quality of LA advisers and saw their being 'rebadged' as SIPs as a retrograde step. One head identified a potential problem of future capacity regarding the number of SIPs available and their workload:

'Then you have got someone like Carole who is a SIP for ten schools in Midshires and she doesn't know whether she is coming or going. '(5)

\section{$\underline{\text { Relationship between SIPs and Ofsted }}$}

The relationship between Ofsted and the SIP process was largely unknown and was highlighted by one head:

'I wonder what the relationship is going to be between the Ofsted team and the SIP? Is there going to be some prior consultation before the inspection?' (7)

Four headteachers $(1,5,17,18)$ saw them working less as a 'sounding board' (4) and more working 'hand in glove' (17) with Ofsted and the LA and as a consequence the relationship between SIPs and schools would be more 'inspectoral' than a partnership (17). One head (5) himself a SIP, brought up the issue of accountability if the SIP was incompetent:

'SIPs aren't accountable they can say "well so what! I will go to another authority!"

\section{New roles and new accountabilities}

Another context to consider in terms of the stress identified by heads to secure a good inspection comes from the set of heads that were working as system leaders in a school in special measures $(13,14,16,17,19,20,21)$ or considered by the LA as being vulnerable to failing in the next inspection. $\mathrm{Ht} 13$, was seconded for part of the week by the LA, Ht 16 had a full time secondment, Hts 14, and 17 were working as NLEs in other schools while maintaining headship of their own school and Hts 19, 20 and 21 were heads of federations and in the case of Hts 19 and 20 doing this as NLE work. Their attitude to pressure was again differentiated between how they felt as heads and also because inspection affected their reputation not just in their school but in the client school also. Six heads were leading both outside their own school and 
maintaining their substantive headship $(13,14,17,19,20,21)$. Two examples illustrate their concern:

'Well I think you do feel occasionally, you have reached a height that some people would love to see you fall, not that anyone has said it to my face. But of course it would be wonderful gossip for at least a week. '(19)

'It worried me in fact it was the main thing which worried me about taking on the role of National Leader of Education about how much would I be to blame about a school being in difficulties. '(17)

The existence of an acting head in the client school complicated the role of system leaders and affected their level of control and in their eyes opportunity to improve the school. For this reason Ht 16 having experienced working in this way as a PCL wasn't prepared to do so again and would only accept full secondment. Ht 5, while not working as a system leader at the time of his interview, had done so as a full secondment but would work either way. In another example the head was a NLE who had worked in one school as its executive head and is talking below about the contrast with her current status as consultant head:

'I think the difference between that [consultant head] and when I was seconded, is that of being in charge. Well, not completely in charge, but being able to have a clear role. '(14)

Consultant leaders work to the agenda of the recipient head and the intervention should over time lead to improvement (Berwick, 2004, in Earley and Weindling, 2006). However lack of direct power to make changes can be one of the disadvantages of the role as a consultant head. Evidence to support the importantce of clarity of role and autonomy identified by $\mathrm{Ht} 14$ from this consultant leader:

'Our brief was to support in raising SATs results but it's too short term. I would like to have the opportunity to do more focussed work and stay for a couple of weeks and stay there and follow through instead of revisiting conversations because you were coming back and forth. ' (9)

One subset within this set of system leaders is that heads of a federation were less likely to be concerned by accountability to Ofsted than system leaders who weren't possibly because of the level of control they exercised. One head working in a federation was less worried than many about inspection despite the second school being in a category, 'because of the way it [inspection] works with the value added 
but nevertheless she acknowledges that 'standards is still a pressure every year.'(19). Ht 20 was 'gung ho', for inspection in her situation as 'people need it.' They needed it because success would validate the reputation of the leadership of the school. At the moment their reputation was based on success in the base school. It would be much enhanced if the inspection was also good for the client school. Ht 21 was similarly unconcerned by an impending inspection as he had been awarded 'two outstandings and a good from the SIP' in his client school and so was ready for them because he was confident he could show progress. When client schools have a successful inspection, there is a lot of ' $k u d o s$ ' (13) to be gained for system leaders because of an enhancement of their reputation.

In view of the high profile the role of system leader currently has with the government I asked the following question in the second round of those involved in leading outside their school:

'Do you think in terms of NLE/NSS schools the Government or DCSF, NCSL etc is monitoring what happens to support schools?'

The replies varied from not having thought about it:

'Oh God! I'm glad you asked that! I don't know!... 'I think they are monitoring how successful NLEs are. I don't know. '(14)

To one head who had some understanding:

'They seem to be monitoring Ofsted. If you look at what they say about NLE schools they are looking at Ofsted and the Sats results and VA. They [NCSL] are having a meeting at the end of January to decide if any need to be deselected or whatever they call it.' (19)

Apart from any monitoring which may be being undertaken by Ofsted itself, NCSL is monitoring the performance of NLE/NSS both in terms of that of the support school and the client school through Ofsted reports, individual NLE's reports and independent reviews (Matthews, 2007; Hill and Matthews 2008).

It might be a concern as to whether inspection would be complicated in heads first schools in view of their system leadership roles but there was little evidence to suggest this. Only one head (19) commented at all, and said that 'the team didn't 
understand the leadership role across the two schools. ' (19). It would appear that the inspection process isn't 'intelligent' enough yet to be able to differentiate according to the needs of system leadership. I believe it would be more efficient to inspect all schools in a federation at the same time instead of at different times, but accept the difficulties in terms of practicalities of schools being in the middle of a cycle even if the will or awareness from Ofsted was there and understood.

\section{New roles and single institutions}

The new roles have meant that there are changes to headteachers roles within school but they are sometimes unsure of what it will mean for their accountability. Five heads $(4,5,8,13,19)$ commented on the impact of governance and inspection on their roles with Children's Centres. Ht 19's governors were 'all for it' in terms of having a Sure Start children's centre moved to within their remit. The reason given for this was that it would 'increase their empire'. Other than this she made no allusion to the effect the change in governance would have on her role and it seemed that so long as it was well managed by the centre leader it would have little personal impact on the management role of Ht 19. The other heads in this set had more to say particularly in the early stages of interview when the accountability of heads with the set up of children's centres on their sites was less well known:

'What exactly are you accountable for? I think those lines of demarcation are going to become really faint, unclear and grey. You are going to be a bit unsure about which part you are accountable for and which part the PCT people are accountable for. ' (5)

'From a building and site management side of things the site manager is responsible. Because I am overseeing the site manager in school then that is part of my remit....It is all one building and so we are responsible for it but they are not my staff who are actually working in the children's centre part, and they are not accountable to me. So it is a grey area isn't it? (8)

'I am worried about Ofsted with the children's centre. I am really quite concerned and I asked Christine Gilbert about that at the heads' conference and she said that she was sure that inspectors would be sensitive to the fact that children's centres were just developing but I am not sure about that. I think they look at provision now, and I don't think they give two hoots about it developing.' (13)

Ht 8 is on the steering group of the children's centre and the centre is governed by the school's governing body. While they are responsible, she is quite clear she is not, as 
she doesn't line manage. Other heads $(2,4,13,19)$ do see themselves as having responsibility and accountability despite having children's centre managers:

'I knew I would have to run it anyway. In other words it would be on my desk anyway I might as well run it through governors. ' (4)

It is by no means clear as to how the situation will develop. It is a consideration for future research as to date none of the heads in my sample have been inspected with the child care as part of the remit of the inspectors. I suspect that when they are, the expectations of Ofsted will steer them in the direction of their responsibilities.

\section{Work intensification and new roles for headteachers}

The management of bureaucracy and workload wasn't an issue caused only by the operation of new roles for heads at the time of this research. Webb (1999a) identified stress as being part of the intensified workload of the managerial headteacher. Some of the work overload identified by the heads in my research was due to government initiatives and had been specifically mentioned as a main issue for five of the headteachers:

'I think the bureaucracy has definitely got worse. I think it's because it's all about accountability to government. You have to account for this, or you've got to prove this, you have got to prove that.' (5)

'I definitely think it's got worse...[and] I mean I was a head pre labour. ' (4)

'Over the last 10 years has been workload and this has just got worse and worse and worse.' (9)

While largely managing the roles and being open to doing them in the first place, nevertheless thirteen heads $(3,5,7,8,9,11,13,14,16,17,19,20,21)$ identified an intensification of work with new roles. They stressed the need to keep a balance of priorities which one of them referred to as 'keeping all the balls in the air' (3) and the work intensification caused by doing so. The example below serves to illustrate this general feeling:

'I have to think how much capacity have I got to do this and not be dead at the end of it! If you constantly, every year, take on a new school with massive problems think of how draining that is. ... '(19) 
'I am honestly not sure that government people have got the full picture of what it takes to do consultancy on top of your own job.'(8)

Two heads $(13,14)$ were involved and another $(8)$ had been involved in co-leading in another school. However they had different experiences of co-leadership. Ht 8 found it harder to work with another and commented:

'I must say that was the hardest thing I have done and I felt ill at the end of that term it was such hard work.' (8)

However the other two heads $(13,14)$ working in a similarly challenging situation found in one case working with someone she 'could talk to' (13) and in the other having the opportunity to 'bounce ideas off each other' (14) made up for the inconvenience of increased communication needs. Further support for the intensified workload for heads managing more than one role at a time is offered here:

'...I had two days a week released here from my headship ... to try and help set up the other school. So I was unpopular in my own school because I was away so much, and I was unpopular here, because I wasn't here the whole time.' (11)

While not suggesting it caused a particular impairment for the heads in my sample undertaking their roles, three heads described the role of alcohol in de-stressing due to work intensification $(5,13,19)$. The first in relation to others he knew 'drinking two bottles a night' to cope (5) the latter who had herself found that she went home and the first thing she did was to 'open a bottle of wine' and stopped altogether as she felt better for doing so and Ht 13 who described it thus:

'I manage my stress $O K$ but I don't look after myself and I don't get enough exercise and I drink too much wine in the evening!! So yes, I think things like that I am aware of and ask am I going to be able to sustain the pace?' (13)

Seven heads $(3,4,5,10,12,13,19)$ explained that one way of managing work overload is to prioritise which roles to take up or leave:

'One of the reasons I gave up writing educational materials was that while I absolutely love it and find it very rewarding it wasn't bringing a huge amount into school in my role of headship. Something had to go and so that went.' (12) 


\section{Earned autonomy: Myth or reality?}

Morris (2001) called for a system where there would be a degree of 'earned autonomy'. I wanted to pursue this idea in my research as arguably being judged as very good or outstanding at Ofsted meant that these heads could justifiably be considered to be in the category of having the 'required knowledge and skills' to be granted some form of earned autonomy (Barber, 2005). I asked the interviewees, either directly, or through probing supplementary questions, if they thought the system of intelligent accountability was creating any form of earned autonomy for heads. Only one head saw earned autonomy as part of the government's agenda:

'We are being pushed down the route of earning autonomy and the government is pushing the subliminal message that if you are doing a reasonable job we are going to leave you alone. '(18)

Three heads felt that the inspection would change in the future due to the increased likelihood of lighter tariffs which would be used more for heads who had been validated through inspection. They had some knowledge of this as a form of inspection because they had experienced it as a head (19) or knew of it as an inspector $(12,18)$ :

I think lighter tariffs will be used much more frequently which isn't always as easy as it might seem. It sounds great but you have to have your data and evidence just right to show them to get through that and come out of it well. It is a pretty pacy day. ' (19)

'I know the way that Ofsted is going is to do more reduced tariff inspections.

... They are looking eventually at just having overall effectiveness as a report.' (18)

(Elkins and Elliott, 2004) argued that a degree of successful external accountability facilitated an independence within the framework of school leadership. Some of the headteachers believed there was a degree of autonomy earned through a good inspection result.

'Yes I think it does actually. It's not something I want especially that people accept things just because I have said it. I wouldn't feel comfortable with that.' (21)

'Yes it [success] does give you independence' (19) 
Ht 7 hadn't got much 'faith in the reasons behind' heads being granted earned autonomy:

'It isn't really about being professional in your job you only get autonomy if you are achieving the results in the tests. ' (7)

Three heads $(3,5,12)$ are sceptical as to the degree of autonomy heads have in any circumstances:

'You may feel that you have more autonomy but I'm not sure if you have.' (12)

'I don't think heads are all that autonomous...In terms of the national agenda then I think many heads allow the external agenda to dictate what they do and don't use it to work best for their schools. ' (3)

'I think there is autonomy but within very well defined parameters of accountability and you had better not step outside those or you will be in all sorts of trouble. ' (5)

Four heads $(4,6,15,16)$ had put themselves into situations where their previously high reputations were under threat because the school they moved to was in a category. They were aware that this would impact on their future reputation.

'My school was in top 10 most improved schools in the country and then I moved on to be an adviser and carved out a pretty reasonable reputation and I put it all at risk coming back here because if I hadn't been able to do it...that would have counted for nothing. ' (4)

One head felt validation gave her confidence:

'Yes I do feel I can work outside the school more easily now and I think it is borne out of a greater confidence.' (10)

However to some extent it depends on the individual because another head didn't feel a degree of confidence or earned autonomy from success at Ofsted commenting:

'No... I think it comes with experience and reflection. I really don't think the confidence to act has anything to do with Ofsted. '(15)

Success gives heads the independence which is absolutely crucial in a period of rapid change. 
'Oh yes I couldn't do what I do if people I worked with were interfering... I was talking to someone who was doing a strategy survey inspection... He said that everywhere he went people in schools were gridlocked into systems they had to use but were going nowhere and people didn't have any ownership of them... and people in these schools had no opportunity to do what they think is best.' (19)

Ht 19 was talking about the imposition of the ISP programme which she believes 'doesn't work' whereas another head had discovered its use in a school she worked in and had adopted parts of it for her own school because 'There are elements of ISP I really liked.' (13). The significance of this is not that these two heads disagreed over the virtues of ISP, but that they had the freedom and autonomy to make the decisions as to what was best for their schools, unlike the schools in a category, which had the programme imposed on them, usually by the LA.

Another head (20) described autonomy she had as a head to shape her school as she wished but believed it was more to do with her own style than a degree of granted autonomy. It was more 'taken' than earned as she knew she was almost indispensable to the LA. This degree of assumed power was evident from another head of a federation with a very different style. When asked:

'How much do you feel you can shape national issues or initiatives?'

He replied:

'To be honest I have always done what I thought was right and in the best interests of the school. I have always worked like that. ... and if they all want to argue it when they come, that's up to them.' (21)

One head saw the problem of isolation in being left alone:

'I think you can end up with more autonomy these days. But I think you also have the responsibility that goes with that so it's a double edged sword really. It is a very powerful job with autonomy I suppose but you can't hide behind anything. The buck stops with you and you are out there on your own.' (18)

Ultimately heads may be on their own as suggested by $\mathrm{Ht} 18$ but in terms of managing their roles they rely heavily on others particularly staff. Chapter 6 considers how heads build capacity in schools to manage their roles. 


\section{CHAPTER SIX: New roles and strategic leadership}

Leading strategically is linked to leading successfully (Leithwood et al. 1999b; Barnett, 2001; Davis and Davis, 2004; PwC, 2007). The need to manage reforms with respect to their number and work intensification for headteachers has led to calls for heads to distribute leadership (Spillane et al, 2001; Spillane et al. 2005; Spillane, 2006; Harris, 2004, 2007, 2008; Caldwell, 2006a, 2006b; Hargreaves and Fink, 2006, Hopkins, 2007) as 'leadership' is used as an 'indispensable coping strategy' (Oduro, 2004, p.3 original emphasis).This chapter considers the impact new roles for headteachers has had on the roles of others in school and the community with particular reference to staff.

\section{Governors}

The role of the governing body is perhaps most interesting due largely to its omission from much of the interviews especially as they have to give permission for heads to become system leaders. Few heads mentioned their governors voluntarily. Mostly I found out about their influence on the role of the headteachers through probes or prompts to other questions.

Jones (1999b) saw the general relationship between heads and governors as 'good'. However my research may be more in line with the findings of Radnor et al. (1997) who argued that as well as offering support for headteachers some governors were a 'threat' or a 'hindrance' and Levacic (1995) who recognised that their intervention in school could cause 'conflict' between themselves and headteachers. This is supported in my research in that the governing body was an issue which impacted adversely on the leadership and management for three heads $(4,5,11)$ all of whom managed them. However they found the effort of having to constantly work with governors was a time-consuming and frustrating issue and saw the governors as not being up to the job. One head put as his main issue 'Bureaucracy as far as the governing body is concerned' (5) and echoed the view of Ht 4 in that having a large school in the 'big company bracket' (4), meant some governors were 'out of their depth trying to cover the issues' (4). This led to a greater workload for the heads because of: 
'the amount of time that I have to spend engaging with governors and other stakeholders. You are doing it, then you are writing it up and then you are evaluating it' (11)

While largely supportive of the roles and actions of headteachers, some governors were still questioning. Two heads $(10,20)$ had to convince their governors that the school would be secure with the developing role of the headteacher:

'Governors here are now very supportive. I think initially they were worried that I wasn't going to be here as much but now they are much better.' (10)

In only one case did the governors' opposition initially serve to constrain the head's actions as a system leader when the reluctance of the deputy to step up left the governors 'unconvinced it was the best thing for the school' (20) although once the deputy left after a period of secondment, it ceased to be an issue. Heads were however appreciative of the support they received for system leadership:

'I would never say anything against my governing body because they have always supported me' (18)

One chair of governors in the school led by Ht 13, thought that she should undertake more work to help local schools but this degree of moral purpose was unusual and in all the other cases the reason for the governor's support lay in those similar to that highlighted by one head as their fear of losing an effective school leader:

'Yes ... and you know governors were scared! I said to them "Well think if I wasn't here ..." They said "Are you leaving?" And I said "No, no I am not. But you have to think, well if I was..." ' (2)

Of the eleven heads $(5,7,8,9,13,14,16,17,19,2021)$ who worked as system leaders only two of them $(13,21)$ commented on their relationship with the governing body of their client schools. The first of these Ht 13, in terms of the fact that they were very grateful to her for leading their school to a satisfactory inspection when special measures had been forecast prior to her arrival. Ht 21 commented on the governors of his second school when I asked:

'What was the process of becoming the head?'

'I went to see the governors, just for 5 minutes really, and they interviewed me and offered me the job and we went on from there. '(21) 
It might appear that the governors showed a lack of interest in the appointment of this head but they are likely to have been under some pressure to accept the LA's support in the form of these heads as all ten of the schools were seen to be failing leaving governors with little choice but to accept them as they would be perceived to be part of the failure if it was aligned to leadership. This doesn't mean that the package of support isn't welcomed and certainly in the case of Ht 21 as he was known and respected in his community and the governing body of his client school were glad of his help.

\section{Workforce reform}

\section{Background}

Ten heads described some of the staffing issues and difficulties they had previously managed over the quality of teaching and learning $(2,4,6-9,15,16,19,20)$ but none of them had a serious current problem. Two heads $(15,16)$ had the weakest teams and were still working through some issues regarding the quality of staff but they had very recently taken their schools out of special measures (15) or were close to doing so (16). Clearly a strong and supportive staff will have had a large contribution to make to that success. All the other heads had strong teams as typically illustrated by one head below:

'...so the challenge has been moving it on from special measures. It is a very effective school now, but the challenge has been moving it on and continuing to move it... '(8)

Therefore, while acknowledging they existed, it is outside the scope of this research to analyse past issues of staffing and I will instead consider staffing issues relating to building capacity for new roles.

\section{Performance Management}

(Rutherford, 2004) identified that by 2003, the government's emphasis had moved from performance management to concentrate on remodelling the workforce and there is evidence to support that this is reflected in the analysis of my data. A typical example of this is illustrated by this headteacher's view: 
'Performance management and quality monitoring is fine and we monitor three times a year. Now it's just a job you do. I don't mean it to sound dreadful and it's not about the people side of it, but for me it's now just another evidence file you have to fill.' (18)

While disliking the bureaucracy, performance management was used by all the heads to recognise a successful performance or for professional development. It was used to enhance leadership which heads saw with their current staff as being more celebratory than an appraisal of performance:

'...we see performance management as a positive process to enable people to develop.' (7)

'Performance management should be seen as a teacher's right rather than as something negative. It should be something very positive. '(15)

No head was using performance management for the purposes of identifying or working through capability issues explained by this example:

'If you have a worry about that member of staff's performance either in teaching or whatever it is, then you don't wait for performance management to say it, you should have been saying it all the way along. ' (12)

None of the heads felt that staff shouldn't be in the situation of being held to account for standards echoing this head with:

'It puts them [staff] under a lot of pressure but it's for the children'. (13)

One head sought out staff deliberately who she felt could manage the pressure:

They [SLT] wouldn't work in this school for me if they weren't driven by exactly the same message to ensure standards. ' (20)

Staff may have also been driven to succeed and to perform to high standards by personal survival in the performance management process too of course.

Workforce reform: Planning, Preparation and Assessment (PPA)

Nine heads $(4,6,7,8,11,13-16$, specifically mentioned PPA. For some heads who didn't mention PPA it was possibly too early in the cycle of interviews for it to have 
really impacted in the school $(1,2,3)$. However Hts 3 and 5 didn't mention it in the revisit either. I would speculate that the heads interviewed later in round 2 who didn't mention PPA didn't do so because it had little impact on their role as heads and any issues had already been worked through. It was an issue for the nine heads in this set in terms of cost for three of them $(6,7,16)$ ' $P P A$ will have us in the red within 18 months. '(6) and for all of them '...there is the problem with the cover for PPA...' (13), with some resentment felt over the lack of appreciation from staff for the amount of 'non contact time, PPA and leadership time we never had' (8) and the impact on standards with inadequate cover systems explained in this example:

'I was lucky in that we had got the specialists to do this so it worked. ... So I didn't have to fill up PPA time with teaching assistants or supply and the children still got quality teaching. ' (14)

For one head it was her main issue because:

'I waste more time, or somebody does, sorting out PPA time and effective cover, than anything else put together. '(16)

However in contrast, $\mathrm{Ht} 4$, also in a large urban primary, really welcomed PPA and had 'no problems with it'.

Five heads $(6,7,14,15,16)$ believed that there was a danger of standards falling with PPA because:

'If you reduce the number or quality of adults with the kids how can you improve standards?' (6)

Reasons given for the likely reduction in the children's quality of learning, were unqualified staff, such as sports coaches $(14,15)$ who may be drafted in, and can't manage behaviour (14) or the use of TAs which was limited in terms of time they could be expected to cover and their quality $(6,16)$. Worst of all solutions was seen to be the use of supply teachers $(6,7,13,14,15,16)$ typically referred to as 'child minding' (6). One head used her internal staff to cover as an exercise in damage limitation as they were 'basically too 'knackered' to stay in the classroom anymore...' (16). 
This was the most significant aspect of the current government policy initiatives which the heads had to manage in terms of the intensification of their work and also because of the impact the reform had on the school. This impact was manifested both through the imposition of the process of restructuring itself and also because of the way in which it was used strategically by heads to build leadership capacity in the school.

'I don't like all of it [workforce reform] - obviously there is the problem with the cover for PPA, but apart from that the opportunity to be able to be more strategic is really good' (13)

There was considerable cynicism from most of the heads $(2,5-8,12,13,18-21)$ as to the motives for the reform being mainly due to the government having to put right past policy mistakes (Hay, 1996, Clarke and Newman 1997) rather than as a valuable policy in its own right, as illustrated by this example:

'Really to me, the remodelling agenda is simple. The government cocked up the salary structure to the point where they couldn't afford it, and are now trying to reduce the bill.' (6)

Five heads $(1,2,6,7,16)$ also disliked the imposition of workforce reform as this headteacher typically explained:

'I don't see why we were forced to restructure. Why make it statutory? To make it a wholly teacher association driven agenda under the auspices of the DfES has caused a lot of unnecessary hard work. ' (7)

Another head felt that as she had recently remodelled due to amalgamation, it was wasting her time to do so again:

'I put the remodelling aside. I didn't want to get my head around it... because we are doing nicely. ' (2)

While being cynical about why it was introduced, and having different experiences and needs over why and how they should remodel, most heads were nevertheless generally positive about the way they were able to use the process: 
'TLRs were quite positive because it gave us the chance to rethink leadership and how we would want it to be restructured in a brave new world. '(12)

Ht 2 who initially didn't want to remodel nevertheless felt that she would 'kick herself if she didn't 'realise it is an opportunity for development for the future' and so made the best of things. Another example of changing views from $\mathrm{Ht} 7$ who said he found the sudden need to change 'destabilising' but by the second interview contradicted this view when talking about the TLR structure which having worked through, he now found useful to enhance his extended role.

When the need to remodel the staffing structure was introduced to schools in September 2005, it was not a new idea for them. However the problem for heads in managing the process was that there was so much disagreement between the policy makers TDA and RIG that by the time there was a model of guidance for the issue, it left very little time from September for the negotiation of the new structure and its agreement by December, to take place. Therefore the implementation of the procedure for remodelling caused most heads considerable work and stress. Sixteen heads $(1,2$, $3,5,6,7,8,9,10,12,13,14,15,16,17,18)$ commented on the process. At the beginning of the interview cycle in September 2005 one head described the process as likely to be rushed and that there were 'huge time and personnel issues involved in all this.' (1). Later in the cycle remodelling was judged to have been 'very difficult' (18) and 'very rushed' (12) as typically reflected in these examples:

'the hardest term I have ever known and I think that has been because of the SEF and the TLRs and the whole restructuring...' (8)

'I think the whole bureaucracy around it was ridiculous really. All the work around the negotiations ...' (17)

Much of the reason it couldn't always be sorted quickly was because of the role of the governing body and the associations. The structure had to be ratified by the governing body by December 2005 with an implementation plan to be in place by December 2008. Problems of gaining ratification were mentioned as described here:

'...you have to go to your governing body in September, then you have got to go back in December, then have it done for December $31^{\text {st }}$, having gone back all the time...' (5) 
It was also a 'big issue' (9) for the governors but not for any of the heads in terms of difficulty in gaining their agreement, although one head had to use some persuasion:

'One of the governors put forward a different structure but we are using the one I did...' (9)

One head identified that this work overload in autumn 2005 had since been recognised by the DfES:

'I think the DfES has recognised it, and we had a workshop about it... and looked at seeing how, if that was ever going to happen again, they would have to look at the different things that were coming through and how they would impact, because they are well aware that it was an appalling term. '(10)

Hyman (2005, p.203) noted from his experiences working at Islington Green prior to it becoming an academy that 'good' heads were taking policy and shaping it to suit the needs of their school. Most heads reflected a similar attitude and by the end of the interview cycle in 2008 their typical view can be exemplified as follows:

'I suppose we restructured when we had to in 2005, but to keep the peace. Then about two days later I changed the structure, because once you had done it, you could undo it. You had to do it to a date, but then you could change as you liked. ' (19)

The role of the LA and the unions in remodelling the workforce

The role of the LA was hardly discussed by the heads in relation to the process of restructuring. One head commented on how little the LA had helped her in the process of training for the impact of remodelling with 'the huge personnel issues involved' (1) and felt unprepared. To some extent this may have been unfair as the rules around workforce reform seemed to change daily and the comment was made at the beginning of September 2005. During the rest of the interviews the LA wasn't mentioned in this context. Either the LA really had no part to play or it wasn't significant enough for the heads to mention it both of which are indicative of their diminished role in the organisation of these schools.

The unions impacted more than the LA on the procedures to remodel the workforce. However the unions didn't speak with one accord which was frustrating for the heads 
as they weren't sure how to react with differing views and reactions from the unions and associations:

'We are doing this [remodelling] with the NUT saying we are not playing, the NAHT saying we don't want to know about it. I had a stroppy letter from the GMB the other day - well, we haven't even got anybody in them!' (5)

Nine heads $(5,6,7,8,9,14,15,16,18)$ identified the actual or potential involvement of the unions. The agenda was complicated because in the new staffing structure it wasn't possible to give one management point. The impact of this was that staff would either have to be slotted in at a higher rate which may not be appropriate due to coverage of responsibility or finance, and if not, the staff would lose their allowance. This dilemma affected six heads $(7,8,9,15,16,18)$. They found that staff either accepted the situation as in one case:

'It means that over the next 3 years two people will lose one point. People have been fine about it, they have taken it very well and there haven't been any problems.' (9)

Or, the decision involved the threat of, or recourse to, union involvement $(7,8,15,16$, 18):

'The big problem was that the unions wanted everyone who had a management point to have a TLR. Well that didn't make sense, and we couldn't afford it.' (18)

And similarly:

'We don't know if we are going to get huge union intervention in next term ... Because we had 11 post holders and we only needed 4. So we have had to reduce and re-advertise and while most of the unions are on board with usthe ... aren't.' (15)

Like Ht 15 another head who had also taken on a school in special measures had a difficult, but different set of circumstances to manage and had to consider the staffing structure:

'Seriously, when I came here there was big union action. Everybody who'd had points previously had somehow not got a job in the new structure... '(16) 
One head acknowledged the problem:

'I didn't have massive issues within school... as I wasn't trying to move people out of positions of power, which has made it very difficult for some heads hasn't it?' (14)

The potential of being constrained by fear in the process of remodelling was suggested by senior officer from an LA:

'I think a bigger one, the one that we've certainly talked about within the organisation, is the thought of a missed opportunity really around TLR to remodel. So there will also be another pressure coming out of "phew we did it... got it through the governing body, everyone is happy and we haven't got anybody walking out on strike, " but in 6 months time I think people may see it as a lost opportunity. ' (Senior LA Officer )

This possibility was recognised by three heads $(2,8,9)$ two of whom commented

'I have spoken to people and they have gone for the very easy option and it's tempting because you think... oh gosh the hassle that is involved but then you have to think of the children and the school. It is an opportunity. '(8)

'...restructuring...was quite a big issue in school, although people were alright, because we decided not to just keep the same. I know some people may have, but I think it is a mistake. ' (9)

There is some evidence later in the interviews that $\mathrm{Ht} 9$ was right, as $\mathrm{Ht} 7$ in the revisit, two years after his initial comments about the possible difficulties encountered with union action, described how he eventually remodelled:

'I ended up saying let's get on with life really and amending what I did because the first format I wouldn't have got through governors or staff. I would have had the NAS crawling all over it as people would have lost out a lot. So in the end I went back and thought it through and came up with the middle ground. ' (7)

\section{The financial implications of workforce reform}

Some heads while concerned about the cost of TLRs, saw the benefit as described below:

'We have pitched them on TLR2 and it is a significant budget worry... whether we will be able to afford them in 6 years when they are on UPS 3 as well, I don't know.' (7) 
One head felt it important to stress to staff that it wasn't a transfer of role, and that there was an element of accountability in the new TLRs:

'I'm giving them [staff] the message that you are being paid a lot of extra money to do certain things ... you are going to have to ensure that other people are doing them too and you are holding them to account. '(11)

\section{$\underline{\text { School organisation }}$}

The staffing structures which were implemented in schools as a result of the workforce reform requirement to restructure were varied and in some way context specific. Decisions were made as to whether to cover the curriculum and management areas in phases and broad areas $(2,5,8,13,15,18)$, for example:

'We have four on the leadership team and that includes the SBM. We have TLRs for areas but I have moved away from posts for individual curriculum areas. ' (18)

'The senior team has been restructured and so we have a phase leader for each part of school and they are responsible for generic areas rather than curriculum areas. ' (15)

Or to maintain a variation of the subject specific model, at least for some of the subjects, with some subject areas such as English and/or maths lying with assistant heads $(3,6,7,9,11,12,14,19,21)$ :

'We use subject areas because one thing about our school development priorities is that literacy and numeracy always feature because of the standards. ' (7)

There were variations within this model, because Ht 12 chose to include the core areas of maths and English at the level of assistant headship or 'Director' (12) but:

'At the next level we have senior year group leaders who manage the curriculum and pupil progress teaching and learning across two year groups. I then have year group leaders who manage the curriculum, standards, achievement and assessment within their year group. ' (12)

Size of school was part of the reason for the decision of how to organise the staffing structure for some of the heads but they didn't always come to the same conclusion about the impact of it. Two heads $(7,15)$ were in two form entry schools and chose 
different structures and another two heads $(13,14)$ were in three form entry schools and their decision was partly based on size of school, but as these two quotes illustrate, they didn't come to the same conclusion about how to remodel:

'I have felt in the past that three form is just too big and because of this we have changed our staffing structure... well we have moved from subject leadership to phase leadership and that's been so successful. ... I felt that the subject leadership just did not work.' (13)

'I thought about phases but because we are three form entry and the year group structure is very strong here I want to preserve that - so didn't use them.' (14)

Other reasons included school contextual factors such as the priorities of the school (7) or the inclination of the leadership (5) or historical reasons because 'We have always had year group leaders at Woodlands. ' (12). One head interviewed later in the cycle changed her structure during the ensuing two years from initially having agreed 'three teams of people, each run by an assistant head with an advanced skills teacher attached to each team and a spread of abilities and year groups working for the teams plus the teaching assistants.' but because it didn't work 'now we are back with a more traditional year group set up... [which] I think suits the staff. (17)

\section{Role of the Teaching Assistant (TA)}

Only four heads $(4,5,16,17)$ mentioned the role of TAs in describing how they restructured and the role had little impact on the process and none of the heads had HLTAs. The reasons for this were given as the limitations of the role of TA:

'You could have an NQT for the same money and they can teach' (5)

'I think all the HLTA hasn't really worked has it? But I think the idea was to address the problem of running out of teachers. The problem is they are not capable of doing all they have to do for Ofsted etc if they are taking classes. They are not trained to do it. '(16)

Or the bureaucracy involved with managing the role and RIG involvement:

'We haven't got HLTAs either because I think that's a minefield as well to be honest, you know with the bureaucracy.' (4) 
He was referring to the restrictions imposed by RIG on what level and type of responsibility could be given to TAs. This has restricted the ways in which TAs have been used in schools. NQTs have been chosen instead of TAs because initially the cost of an NQT is about the same as an experienced TA. Although NQTs cost more as they gain experience as teachers, they are able to take on more responsibility, and as they leave for promotion the cycle just starts again.

\section{Using workforce reform to build capacity to sustain heads' new roles}

\section{Managing ECM}

One factor which was important in the decisions taken over staffing was the requirement to consider the needs of the ECM agenda. This was in terms of new roles for heads with the imposition of children's centres on site and the extended schools agenda, as well as integrating the 5 outcomes into the curriculum, at the same time as remodelling the workforce. To consider how these areas could be worked together to benefit their facilitation seems a reasonable course. One head felt that the way policy was introduced was unhelpful as illustrated here:

\section{'I also think that what should have been given to heads before the} restructuring were the ECM agenda and the implications of extended schools. All that should have been known to heads before they had to restructure. That way you could have looked at the whole picture when considering how to restructure staff.' (10)

However my research shows that nine heads $(1,2,3,5,7-10,12,15)$ had anticipated the agenda and recognised both ECM and remodelling as issues to be worked together. Examples of the strategic vision of these heads from both early in the cycle $(1,2)$ and small schools $(1,9)$ and two form $(8)$ and three form entry $(2)$ :

'...you ask what do you think your vision is in your community and how would you move forward with ECM and remodelling linked to your vision?' (1)

'We have got 3 TLRs. One is for someone to look after the English and Maths and the standards for those, someone to look at the ECM agenda. ' (9)

'...we are going to introduce 2 assistant heads, keep the phase leaders and introduce a couple of TLR 2 points for some weighty issues for the whole 
ECM. You know emotional well being and that whole agenda down there... I want someone to coordinate the outreach... '(2)

'What I have tried to look at, is someone for the extended curriculum, and someone for the ECM agenda... '(8)

In the revisit two years later this head was able to confirm:

\section{'I remodelled towards the ECM model.' (8)}

Some heads had used TLRs for the purpose of integrating ECM into school $(2,5,8,9$, $15)$ and others used assistant headships (3, 7, 10, 12). In one large school a head (5) went so far as to offer TLR 1 for ECM on its own, which is indicative of how a large primary can afford to manage the agenda through recruitment and retention. For those offering assistant headships, ECM was usually integrated into a larger portfolio:

'I put things like health and healthy schools and modern foreign languages in one AHT's role and I put behaviour, inclusion, those sorts of things in the other.' (3)

One head didn't restructure in this respect because they already had inclusion leaders who took up the ECM agenda, or who could transfer with little change (10).

Eight heads $(2,3,4,5,8,13,16,19)$ either had or in the case of $(4,5,16)$ thought they were going to have, and had planned for, a Children's Centre. All saw this as an opportunity for new roles to be created.

'I am hoping to appoint my children's centre manager from January. They wouldn't have anything to do because it's not even built yet but I will find them something to do. '(4)

We appointed to the children's centre in January [2007] and we have no building yet! (13)

Not only did a children's centre result in the employment of a manager for the children's centre $(2,8,13,19)$ but also roles for others in school to manage the increased administration to cope with it such as the 'appointment of a new office manager to cope with the business side of it' (8) 
Only one head (6) specifically said he hadn't considered the connection between the remodelling and ECM agenda.

\section{New external roles for heads}

One worry for all the heads engaged in new roles, was the need to secure their own school's stability if they were used extensively in non traditional ways. Fifteen heads $(3,5,7-10,12,13,14,16-21)$ identified a need to ensure the school was secure when either they or other members of supporting staff were absent.

'I think you have to make sure your own school is secure, when you come out.' (10)

When heads have worked in other roles sometimes this concern is reinforced by events:

'...something that I have noticed, and that I will have to watch, is that being out, I have lost some control here. '(14)

'The barriers to going out are that you have to have eyes in the back of your head because you can't let go of your own school. ... No matter how good your deputy is, it is not their school. ' (16)

And is something the LA needs to be aware of:

'... the LA had just sat back and thought, "Oh well Irene has got an outstanding school", and left me to it. But I said, "If you are not careful, if you are stretching a NSS or any other support school working along those lines, then you are risking the situation when it is the base school that is the one being bled." '(19)

Five heads $(7,8,9,19,20)$ who were leading outside schools in particularly challenging urban environments, identified the need to build capacity to sustain their absence as crucial in their circumstances. Sometimes as illustrated in this example it can impact on the work they do:

'I am doing one [consultancy visit] tomorrow morning. I am going to have to phone George [the head] up and say I am going to be late in coming because I am going to have to be here again tomorrow morning because it is not fair to leave even experienced colleagues, which I have got here, to face this as it 
rumbles on. It can get very unpleasant when you are banning people from the site. '(7)

One head (8) is concerned that the system recognises this, and asks if 'people like Steve Munby' understand when looking for system leaders that for them it is hard with the 'shootings' and 'stabbings' but that such heads have 'so much to give. '1 That there is an awareness of the difficulties heads have with managing their schools and the opportunities is supported by this example:

'...how do school leaders take responsibility not for just their own school but for wider system issues... how can we help them do that? That's about their skill set and also about how they can create capacity within their own schools to enable them to do that.' (Munby, 2005, interview with the writer)

Six heads identified new roles for staff working as part of a support school in other schools $(13,14,17,19,20,21)$. One head had structured differently in both schools according to need. A 'floating' deputy worked between both schools in the federation in addition to a deputy in each of the schools:

'I have got faculties in the base school and supposedly ordinary coordinators in the other schools but they are in very early stages.... I have now got two deputies in this school and one which we call the national support school deputy who goes with me on other jobs.' (19)

One distinction that has to be made as a result of these responses is the extent to which building capacity through workforce reform has been used by heads as a tool to facilitate succession planning and new roles, or just to manage the current undoability of modern headship. The analysis is complicated in that it is difficult to distinguish their motives in staffing decisions taken, because many of the heads were simultaneously undertaking workforce reform to enable them to lead as they wished to in their substantive role with the increase in bureaucracy, as well as remodelling to build capacity for system leadership. Six heads $(2,3,5,8,13,19)$ had an internal new role and an external one. I asked all those with new roles if they consciously used the remodelling task of reviewing the staffing structure initially with a view of how it would help them with an external role. The various viewpoints are represented these

\footnotetext{
${ }^{1} \mathrm{Ht} 8$ became a NLE after the end of the interview cycle.
} 
examples:

'No. I haven't changed it because of going out but to manage my role in school more' (8)

'Oh yes definitely. It is definitely true for me... it is easier now to work outside school.' (5)

'No. Well maybe partly about going out but partly about leadership succession here.' (17)

'No, I didn't even look at it'. (19)

For Ht 19 changing staffs' roles to manage her leadership of two schools which she had done since the end of 2005 was seen as part of managing the workforce but not part of the need to undertake statutory workforce reform. It is however indicative of how heads have used the legislation to enable capacity building to secure their schools. Harris et al. (2006, p.404) identified executive headship as playing a 'powerful role' in bringing 'leadership and teaching capacity' into schools in challenging circumstances. I would extend this to include the role of NLEs and some consultant leaders who have also used their own staff in other schools such as ASTs. Ten heads $(5,7,8,9,13,14,17,19,20,21)$ identified potential problems for those who are leading extensively outside school as a system leader being the need to ensure there is enough capacity in the 'base school' to allow for the 'injection of capacity' (19) into the supported or client school. This is the case for all those involved in consultant leadership but magnified for executive heads. Further support is provided for this argument below:

'What I want to do next is to make sure that the systems at this school are more effective than they are at the moment because almost inevitably by taking people out to work somewhere else you endanger your own establishment. ... I need to revisit the staffing structure to see how robust it is to enable me to carry on going out. ' (17)

'As far as the external stuff is concerned if I hadn't changed the internal systems I couldn't have maintained the standards or the role because I would be dead!' (19)

The changing role of deputy and assistant headteachers 
Gunter (2008) and Southworth (2008) argued that there has been an increase in the number and use of assistant headteachers and deputy headteachers in schools. My research would support this view. The importance of the role of deputy and assistant heads in building capacity for new roles, although not necessarily external ones, was recognised explicitly by seven heads $(2,3,5,7,8,10,16,18)$. All the heads in the research had a deputy except Hts 7 , and 20 (who had three and five AHTs respectively) instead. An exception was $\mathrm{Ht} 17$ who had three assistant heads but was going to advertise for a deputy in the next term.

Typical answers in support of the deputy's role for building capacity for system leadership were:

'I have had a really good deputy up to now who can manage in my absence... It 's about capacity which changes of course. ' (3)

'I know when I am out the place is being run extremely well which is important. Mainly because I have got a brilliant deputy and she is superb. '

'So recently I have had a new deputy head but she was my assistant head who I have trained up. I think you have got to make sure that the school has got the capacity for you to go and do work outside haven 't you?' (10)

Although Ht 20 didn't see the need for a deputy she did release one AHT to manage each school at the times she wasn't going to be there. So in terms of delegated role, at least on a day to day management basis, the role of the AHT in this sense was the same as the deputies in other circumstances. Her decision may have been made because two years ago when she first wished to move to system leadership she was blocked by a deputy who didn't wish to step up. With five potential leaders she was no longer going to be faced with this problem.

Ht 7 created assistant heads because he wanted to widen the distribution of leadership and not to have to rely on a deputy.

'I think that a learning experience I am going through now with the assistant heads and going out is to make this school less dependent on me both for my own sanity and for the health of the school. ' (7) 
However it has been achieved 'Succession planning is important to ensure standards don't drop in your own school' (19), and most heads identified the need to build up a constant stream of candidates to continue to build capacity in schools.

\section{The increase in the use of non teaching support staff}

My research supports Gunter (2008) and Southworth (2008) in that the increased numbers of support staff is a developing area in schools. Ten heads $(2,4,5,8,9,13$, $17,18,20,21)$ identified an increase in the use of support staff which has increased their overall staffing levels:

'Well on the whole site I have probably got 58 staff something like that now, and only 15 are teachers... I mean in my first headship[in 1995] you had a couple of nursery nurses in the nursery and a teaching assistant further up and that was it, whereas now, they are everywhere. '(4)

'I think the other main issue to deal with which has changed is the management of people. We have over 120 people who work here and that's grown in numbers and type of personnel. '(13)

Southworth (2008) highlighted the importance of the SBM or SBD in supporting heads to manage their role in school or across schools. For six heads $(2,5,8,13,18$, 19) the SBM has become a key member of staff and for two $(5,18)$, members of the SLT as one of them typically explained:

'The most important post I put in is my school business manager. She looks after things like health and safety, attendance and she line manages anybody who isn't class based, such as the caretaker, the cleaners, and the technician and she is on my SLT. It just takes such a weight off me, and I couldn't imagine doing another headship without another one. ' (18)

Four of these heads identified the direct impact support staffs have had on the opportunities heads have to lead outside school $(8,13,17,20)$.

'I also have a very effective office manager and she has probably been more key to me being able to go out of school than anybody else.... '(17)

One head identified how support staffs were used across her two schools: 
'I employ a professional assistant and somebody who was in banking two days a week and works with me wherever I want them to and just does exactly what I need them to do. My PA works across both schools... '(20)

An important consideration regarding the above is that all of those with increased support teams are in medium or large urban primary schools and can afford it. This is also illustrated by how one head has a long term 'vision' for more to enable her to be more 'strategic':

'What I really want are two more - I want a data manager as at the moment I am spending hours on the computer, ... I would also like an inclusion manager who takes on child protection, attendance, all those issues and you just don't need a teacher to do that but it needs a key professional. '(13)

Building capacity through distributed leadership

One head described the demands of system leadership as:

'... you are taking key staff out of your base school and of course you are only there half the time and so it is looking at a completely different approach to leadership to what I had to do before.' (19)

Another means of securing the school in the absence of the head was to build capacity by distributing leadership. Harris (2004, p.16) argued that for successful distributed leadership to impact in schools it must be encouraged and 'generated' by headteachers and that it is a 'collegiate' form of leadership (Harris et al. 2006).

This study strongly supports that the intention to distribute leadership was present and was seen by all the heads except Ht 6 who used his deputy to assist him but not as a strategy to manage new roles. Distributed leadership was identified as necessary to build an effective team to manage the extended and changed role of the head. The most straightforward answer to how this could be accomplished came from Ht 21 when he said, 'I think you have to plan well ahead and delegate well.'

The intention to distribute leadership doesn't in itself guarantee that heads were successful in doing so, just that they believed they were. Ht 4 firmly believed he was distributing leadership: 
'...one of the strengths of the school now is distributed leadership... makes me uncomfortable now but I delegate decisions as against jobs to do. That's the subtle difference.

Although his comments shortly afterwards brought the reality of this in doubt when he discussed the parameters under which a member of staff worked:

'Actually I had to rein in my maths coordinator the other day... she said well I want it to be like this and I said well with all due respect we will go with this consensus and then she thought well ok...(4)

A different example from this head who is describing how due to the increase in her workload partly from government initiatives and partly her extended role, she is now more strategic in that she monitors teaching and learning more through reports from her leadership team than visits:

'I suppose that I am still doing some of the observations and keeping my hand in, but more and more I am just getting impact reports over what is happening and monitoring from the different areas and so what I am getting is an overview of what is happening. ' (8)

Another in common with $\mathrm{Ht} 8$ is more strategic but comments on the detrimental effect this has had on her relationships:

'...I miss the interaction with the staff about teaching and learning. More of my conversations now are about the results and analysis and data and tracking than about the nitty gritty of teaching and learning and the exciting part about how you get children to learn.... That's the worst.' (14)

Another head commented that because of the 'danger when you are sent to work in another school' she secured her absence by distributing leadership:

'... and the staffing structure is developing along the lines of delegation much, much better than it used to be. ...It's to do with the accountability. ... They have actually got a lot of autonomy as long as there is good continuity and progression and the children are showing the results. '(13)

An aspect of distributing leadership is the degree of 'letting go' (17) to be undertaken by the headteacher. However it was recognised by six heads $(2,9,11,13,16,17)$ that this 'letting go' by them might not be easy, as identified typically by Hts 2, 16, 17 in these examples: 
'You kind of think that nobody else but you can do it, but they can actually, and it's about letting them do that' (17)

'You have to let go of it [the school] and that is a very hard thing to do.' (16)

The issue of delegation or distributing leadership was complicated by the opportunity to do so and the problem of leading small schools was identified again by two heads:

'It's difficult because they talk about leadership giving lots of people responsibility but when you are in a small school there are only a few people you would give responsibility to, and so you have to do far more as a head.' (9)

'The issue is overload and not enough staff in a one form entry primary school to delegate' (1)

These views echo Southworth's (2008) however one head of a large school didn't see size of school as a problem and only saw bureaucracy in terms of numbers of children and not policy initiatives:

'The plus side for a smaller school is that they are dealing with fewer pupils... So yes, harder, in terms of there are fewer staff to do the work, but then there wouldn't be as many children generating the work. '(14)

Eight heads $(3,7,10,12,16,18,19,21)$ identified lines of communication and understanding of role as important aspects of distributing leadership. These have often to be learned quickly, as circumstances can move fast when heads are called into other schools:

'Well, I think that if working in a role outside school is to work, there has to be a really clear definition and understanding of what the role of the next person in line is. ' (3)

'Are they just expected to just mind the school or is development expected to take place?' (12)

'You've got to make sure that you are briefing the staff and to make sure that you have got your succession planning there.' (10)

One head in agreeing gave an example of how he had failed initially to secure this:

'... we hadn't made it totally clear who was in charge. We have to have a named person to make decisions when I am out and we forgot. Systems become more important and people have to know. ' (7) 
Another head described the importance of the staff agreeing to system leadership:

'You as a head make conscious choices but everybody has got to be involved with that choice.' (12)

Benefits for staff of increased CPD opportunities working across schools were identified by six heads $(13,14,17,19,20,21)$ who used their staff in other schools.

'I have got people here who really excel at some parts of the job and we want to promote that and give them the chance. ' $(21)$

Harris et al. (2006, p.402) have identified the need for the 'integration of external consultants or managers' from the base school with those in the client school as vital for success and this view is supported in my research as exemplified by these comments:

'I needed a year 5 teacher over there because something dire had happened in the spring term and we could afford to manage it here so I brought someone over from here because that was more important at the time.' (20)

An example is we have got our curriculum coordinators sorted out across both schools... and now we have got a situation where we hold joint staff and governors meetings.' (21)

These heads gave the impression that the chance to take on more responsibility for staff was one they could refuse. However this need not necessarily be the case as my research supports the view of Hatcher (2005) in that the power to undertake new responsibilities lies with the head, providing they can convince their governing body to allow them to undertake different roles. This in turn can put some pressure on staff to step up. How much there is a level of choice for staff in the decision to undertake other leadership roles is difficult to determine and perhaps unsurprisingly, none of the 21 heads suggested that they had worked in any form of new model of leadership against the wishes of the staff. However the comments of two heads $(18,19)$ suggest that some persuasion had been necessary in their schools. Ht 18 commented that she had given staff 'responsibilities which had taken them out of their comfort zone' and an example from another head: 
'...we were offering autonomy but with responsibility and accountability and it was quite frightening for people at the beginning. But it has actually improved the school massively. '(19)

A distinction needs to be drawn between those heads who were leaders to whatever extent outside school, who maintained headship of their own school (1, 2, 3, 7-10, 13, $14,15,17,19,20,21)$ and those heads $(5,11,12,16,18)$ who were seconded full time. All in the latter set felt the responsibility of leadership to be far greater for those stepping up under such circumstances than for those leading with the head still in place, if less often, in school. They all found this difficult as this example illustrates:

'It is different in some ways if you are going on a full time secondment. You then have to be prepared to let the person you leave behind to do the job. Even if they make decisions you disagree with you have to let them do the job. '(16)

In the experience of one head the school was maintained but she felt it didn't move forward.

'Before I went off on secondment in the autumn and spring term everything was in place - the improvement plan the assessments were all in place the SEF everything was in place and ready. My argument was that the SLT just had to follow it! But it didn't quite work out like that and when I came back into school in the summer term this year - it was a nightmare!' (18)

However a question which might be asked is - to what extent was it a lack of interest rather than concern by staff not to overstep the mark in the absence of the head? This supports the argument that with either a full-time or a partial external role, communication of the distributed role is essential. Another seconded head supported Ht 16's view of the difficulties in seconded heads coming back because the roles in school will have changed:

'Well I had a secondment last year and so I am back in trying to get a pulse on everything that is happening in school which is quite surprisingly difficult having had a year out.' (11)

Ht 16 professed that once having been on secondment because she had lost the sense of ownership she decided that she would never 'go back afterwards' 
A consideration in the distribution of leadership and system leadership is overstretching capacity. This can occur either because the needs of the base school were underestimated as identified by two heads:

'I drive all the assessment and I do all the analysis and it left a big gap. That was a mistake really because there wasn't anybody on the team who felt really comfortable doing that particular role. '(18)

'... some people's response to being delegated responsibility is to turn into megalomaniacs and you don't always catch it for a long time if you are out.' (16)

Or as identified by three heads $(7,17,18)$ because the capacity of the system leader was stretched. Ht 7 identified that this was because:

'I have to be in meetings all the time. OK some are partly self imposed because I chose to do the PSCL work but ...I am not even getting the time to walk around classes as you would normally do.' (7)

However heads felt that with the right distributed leadership system in place their own schools hadn't been allowed to suffer unduly or in one case that any loss of effectiveness was considered to be worth the cost:

'I would say I have probably taken my eye off the ball in this school. However my focus has to be to support this other school because I feel so desperately sorry for the children there. ' (17)

One head who felt that the structure left in the base school had to be 'very very strong' continued with her views on system leadership:

'I think it is worth it for the children, and for the staff, if it allows them to have other experiences such as working with other teams from other schools or whatever, then I think it can be hugely beneficial. ' (12)

If not, she felt that heads had a 'duty' not to go. Benefits of increased leadership capacity being brought back into the base school were identified by twelve heads (1, $5,8,12-15,17-21)$. An example is skills that were gained through knowledge of inspection $(12,18)$ :

'I have a senior leadership team who are hugely confident in observing lessons and are actually very confident at making judgements because I had 
done inspection and the people I had brought in because of that. I think that has really been very, very beneficial. '(12)

Or by adding capacity to both schools:

'...well if we could carry on with this school for the rest of the year then the main advantage is that you would have massive capacity to improve because you have got a large staff which have had a lot of training and who are up for change.' (19)

'I think the idea of heads leading more than one school has enormous potential for securing schools because I am able to keep people here by letting them do work over there. I can grow all sorts of new jobs for people because of them working elsewhere and eventually it will happen the other way around.' (20)

And for five other heads in this set, knowledge and skills were gained from experience of different leadership programmes such as the ISP (13) succession planning and aspiring leaders (15) 'using my knowledge of adult learning styles as well for the school.' (1) 'I have brought things I have learned from the consultant leadership programme and changed things and the school has definitely moved on'

One head articulated general benefits around using school improvement ideas from other schools:

'You start reading other people's improvement plans and philosophy and the vast majority of them give you a tour of the school and you come away thinking oh that's a good idea and you bring it back.' (5)

Although in contrast, as well as gaining some skills in distributing aspects of their job to others, was also argued by the same head that some of his skills had been lost:

'I have got a link advisers visit in the autumn and I can't now do it on my own without the leadership team because I don't have a clue now about all the data and some things now I don't even read. ' (5)

The impact of system leadership is changing the role of heads but while some skills are lost other skills and experiences are gained. However what is crucial is the trust which is built up in the relationships headteachers experience with staff and in particular the SLT. 
The Price Waterhouse Coopers Report (2007) was critical of the profession for maintaining an 'operational' rather than pursuing a more 'strategic' role. A dilemma identified by six heads $(9,13,14,17,20,21)$ was that although they recognised the need to be strategic they still felt that they needed to prove they were credible as teachers and could cover their roles if necessary. Ht 20 had to plan in the absence of a Foundation Stage manager and was pleased to be able to prove she could as 'it surprised a few people', and another example below:

'I have just done the R.E. because people were very busy. ... and also as head I think you need to be seen to do it. If you delegate everything there will be people in school who are thinking, well what does she do?' (13)

This would not be a dilemma if the leader of a school did not have QTS (see Chapter 4).

\section{New roles and client schools}

Harris et al. (2006) noted in their study that the executive head used the staff in the client school as part of the process for improvement even if it altered the pace of working. This was recognised by heads in this study who were or had recently been involved in long term working in other schools $(5,8,9,13,14,16,17,19,20,21)$. All the headteachers described how they took time to build relationships with staff in client schools as they recognised the difficulty supported schools would have with someone new coming to lead them. Often members of staff in the client school felt vulnerable to change, as identified by these heads:

'You can imagine for staff to be told that their work has declined over a number of years is very depressing isn't it? Really I had to try to keep them buoyant but at the same time - be firm.' (13)

'Yes in the beginning it was difficult. We will have had St Borth's school for two years soon and it's alright now but at first they thought it was like a takeover and you can't blame them really. ' (19)

'It was difficult initially from the point of view that the people at Manor school were feeling worried and felt that here were people coming in to tell them what to do and I had to manage it fairly sensitively. ' (21)

Another federated head made the point that each situation between schools is different and so 'I think the success heavily relies on individuals' (20). All the heads that had 
some form of secondment with two schools $(13,14,17,19,2021)$ tried to ensure continuity of entitlement and sometimes structures between the two schools. This was irrespective of context, but there was some difference in the degree of success:

'We were able to include them on the performance training day that we had, so their leadership team got the training that our leadership teams did... but it's only going so far and it's frustrating. I mean we were going to have a leadership team meeting... But we organised it and when we got there, someone wasn't there and had forgotten, and that's frustrating. '(14)

'I run the two schools a bit like a split site might be. So innovations at the two schools tend to be paralleled but the school which is the weaker school gets a simpler version of it. '(19)

None of the federated schools had the same governing bodies and the link between the schools was clearly through the role of the heads such as joint governors meetings in the case of Ht 21 . Otherwise the heads managed the governors separately.

Apart from the feelings of the staff of the client school, heads involved in consultancy described how they felt in undertaking the role. Most heads undertook new work with some trepidation as described here:

'I felt scared, because who I am in my school is different to who I am in the $L A$, and who I am in another LA is different again. They don't know you, they don't know if you are any good, they don't know if your school's any good and they take you at face value.' (9)

\section{An absent presence}

The importance of headteachers as a presence in their schools can be identified in this research. All heads interviewed practised 'environmental scanning' (Preedy et al. 2003, p.3) which entailed them identifying the needs of their stakeholders to some extent. As well as the needs of staff, all headteachers acknowledged the importance of building relationships with the community and parents, identified as a 'key role' for 'educational leaders' (Preedy et al. 2003, p.3). All the heads often mentioned all the stakeholders together (governors, parents, staff, and children) in terms of how they found ways of marketing or managing their absence. Fifteen heads $(1,3,5,8-20,21)$ directly discussed the need to be visible, and that if they weren't there then their influence had to last during their absence. Preedy et al. (2003) and Crawford (2007) 
argued that the headteacher is possibly considered the key person in the school as they are perceived to be responsible for children's progress. Some heads believed that the position (11) or presence $(2,7,8,9,18,20,21)$ of the headteacher gave parents security:

'whether the head is a charismatic leader or not they have the status of headteacher' (11)

'I would come back here and although the parents are mostly OK they didn't like me to be out for two and half days and you get a few ripples here and there.' (8)

Four headteachers $(3,7,13,17)$ believed that no matter how much leadership is distributed sometimes staff just wanted personal contact from the headteacher. It didn't matter whether heads were undertaking new internal roles as the head of a colocation illustrates:

'But what you have to realise is that when you are taking time to establish... different type of work what are all the things you are not doing, you should be? It's the things in school which can then slip and people who should have been stroked haven't been because you haven't had time and somebody else has forgotten to stroke them in your absence. ' (3)

Or were undertaking leadership of more than one school:

'I think people should be able to come and see me personally shouldn't they? If they want leave of absence for something personal they don't want other people to know. ' (13)

'Staff are happy enough for me to go out to other schools but I always have to touch base most days because they don't like not to see me. (17)

The problem is not confined to heads in urban situations as above but also, as this further comment illustrates, it is an issue in rural contexts where the head is more familiar as a member of the community:

'No I don't think they [parents] were all that enthusiastic at first, but I make sure I am around for them as much as before if I can, and they see just as much of me really.' (21)

My research suggests that a form of 'permission' needs to be given by staff for heads to be able to play an extended role because a lot of trust resides in the relationship. 
Eight heads $(3,12,13,14,16,17,19,21)$ considered this aspect of their role to ensure that everyone gained from the head's absence and staff weren't left 'feeling dumped... '(12). Similarly:

... If you don't have relationships with your staff secure and in place and working well you can forget doing anything else at all. '(17)

Heads entrust their leadership and often reputation to the ability of staff to lead and manage in their absence:

'People have taken on more responsibility and they have said they feel trusted and have been given the chance to shine' (21)

One head identified a change of style in their leadership:

'... I couldn't lead personally as I did before because I would need duplicating if I did.' (19)

Another way the head's absence was made acceptable was for them to articulate the benefits:

'...the governors and staff realise that I bring some money into the school when I go out and I always push that.' (8)

Little was said about the change in relationships with the children. I think this is probably due to either the heads have already moved away from a hands on daily routine with children as none of them had a dedicated teaching responsibility although some $(1,4,6,9,21)$ taught sometimes through choice. They made sure they saw the children in school when they could and one head made the point that he 'rewarded' himself with 'time off from the computer by spending 10 minutes in every hour going around the classrooms'. (5) Only one comment was made which showed that her relationship with children may have been affected by her role outside school:

'I would have to madly rush around the classrooms here and say 'hello here I am' and the problem is illustrated by one child in Year one here who saw me coming up the corridor and looked up at me and said "What's your name?" I thought oh no!... That's upsetting as a head isn't it?' (13)

\section{Long term effects of system leadership on schools}


Three heads $(8,17,20)$ articulated the difficulties schools would have if system leaders left. Firstly it could be financial if the base school relies on the finance of the system leader to pay for other roles created in schools or other resources. Ht 8 identified finance being allocated to a 'new classroom' and another as follows:

'It does worry me that if this school doesn't come out of special measures then I won't go to another school which will have implications for the funding that I need to keep this school running how I want it to. ' (17)

Secondly the head may have involved so many staff across schools it may be difficult to unravel the roles if it becomes necessary to do so if the federation breaks up for any reason:

'My PA works across both schools and so how would anybody just untangle all that?' (20)

However the status which comes with being seen as a successful school for NLEs has also been identified:

I must admit that the NSS status seems to have brought us career staff... We really push that there are lots of leadership opportunities when we try to get staff.' (19)

There is some evidence from the responses of the heads as to the extent to which they consider the roles of system leadership to be sustainable. However as much of the work, particularly for NLEs or heads of federations is so new there is insufficient evidence for the likelihood of sustainability as much of the work is ongoing.

One factor to be considered for the sustainability of system leadership was the changes which occur to staffing in the base school. An illustration of this potential difficulty was offered by two heads $(14,19)$ :

'What I hadn't taken into consideration was that over the course of the year we have had a lot of new staff... I think we probably didn't put enough thought into inducting the more experienced teachers we appointed, and so I think a bit of the ethos in some of the ways I would want things done, has slipped.' (14)

'Twelve months ago I would have said yes there are problems with sustaining the model of NLE work but now I am going to say no because we have got 
through it to a new way of working which actually if anything is accelerating progress at [base] school again.... It is the succession planning which I think is the key thing now. '(19)

There were some key similarities and differences in the way that these school leaders managed their accountability and distributed leadership. The impact of their management and leadership of new roles on schools and implications for the wider system forms the basis of the next chapter. 


\section{CHAPTER SEVEN: Findings, conclusions and implications}

\section{Background to the findings}

From the beginning of the second term of the Labour government in 2001 it was argued that it needed to create the conditions for transformational and systemic change in schools (Chapman, 2002; Bentley, 2003; Hargreaves, 2003; Barber and Fullan, 2005; Fullan, 2005; Hopkins, 2006, 2007) to address the following issues:

- The creation of different organisations to cut across multi agency boundaries (Bentley, 2003) and promote social justice and children's well being through collaborative working (Barber, 2002a; Hargreaves, 2003; Hopkins, 2006).

- The need to raise 'standards' from a perceived 'plateau' (Barber, 2005; Fullan, 2005 ) to ensure a suitable workforce for the future.

- The management of succession to address both the retirement of the "baby boomer' generation and the perceived lack of interest from staff in wishing to step up to leadership which are significant challenges recognised by Hargreaves (2005a, 2005b) and Caldwell (2006b) and in the advice given to the Secretary of State by NCSL (2006b).

The use of schools in leading change has been judged as necessary as the 'top down', centralised one size fits all approach is inflexible and ineffective (Chapman, 2002). Therefore it is argued that there needs to be a degree of flexibility on the ground (Hopkins, 2006, 2007). Government has endeavoured to be an 'enabling state' (Hopkins and Higham, 2007, p.162) by producing conditions which have changed the roles of heads through opportunity and imposition. This in turn requires a level of trust to be built into the system as the speed at which the system needs to adapt locally and the specific nature of context makes micro-management of the system difficult. The trust cannot be universal. Gunter (2008) and Gunter and Forrester (2008) note that governments need to be informed by those it trusts to give it the information to produce the policies to suit its chosen direction. Therefore a 'critical mass' (Fullan, 2005) of level 5 leaders (Collins, 2001 in Fullan, 2005) or 'master strategists' 
(Caldwell, 2006b) have been identified who are able to help transform the system and demonstrate best practice to effect these improvements at ground level.

The creation of the conditions for system change has implications for the system not only to establish the type of change it wants but also for heads to have the motivation and ability to recognise the need for, manage, and embrace change. My aim wasn't explicitly to research the effectiveness of the roles themselves on the system but it will inevitably offer some conclusions about this and implications for further research regarding system wide impact of new roles for heads.

The main finding of this research is that headteachers were aware of the educational agenda for change and were taking advantage of the wide ranging new roles being offered to or imposed on effective school leaders which changed their roles significantly. These were either confined to changes to leadership of a single institution and/or heads were being used as system leaders at ground level to facilitate school improvement (Hopkins and Higham, 2007). As such they can be identified as 'policy entrepreneurs' (Kingdon, 2003 in Gunter, 2008 and Gunter and Forrester, 2008).

Gunter (2008, p.265) refers to the group of heads, who lead reforms 'locally and nationally' some of whom are implied in my research, as being 'pro government', but I think this is imbuing their motives with a consciousness which my research evidence suggests they don't have. The heads in my study were being pragmatic, reluctantly compliant, occasionally resistant or genuine believers with moral purpose, and often a combination of these, and believed they were working to improve children's lives. Their actions however, for whatever motive, have the consequences of implementing much of government policy.

New roles for headteachers have had an impact on the local and national system. As a result of these new roles a new definition of leadership needs to be considered. In particular, headship of extended schools, together with system leadership, have meant a change of role and relationships for heads with the government, NDGAs, LAs and other agencies and in collaborations with other schools. The introduction of these roles led to new roles for other staff and changed the way that heads interacted with them. They have led to higher levels of performativity for some heads and 
differentiated levels of stress in dealing with new roles. There are certain common identifiable characteristics and leadership practices among the headteachers which it can be argued facilitated their ability to react successfully to change. Finally there are issues identified by my findings which have implications for the government at local and national level.

The following key findings are a reflection of the consequences of the changing role of the headteacher as they reacted to government imposed change.

1. Headteachers were aware of the educational agenda for change and taking advantage of the wide ranging new roles being offered to or imposed on effective school leaders which changed their roles significantly with corresponding implications for the system.

2. There were changes to the role of governors as a result of changes to the role of headteachers.

3. New roles for headteachers led to new and changing relationships with Local Authorities.

4. There was an increase in the strategic role of the headteacher with the development of new roles for staff.

5. There were certain leadership styles and characteristics evident from an analysis of how the heads managed their new roles and built capacity in their school/schools.

6. The effects of accountability impacted strongly on the actions and reactions of headteachers.

7. There was evidence of earned autonomy with heads implementing government policy with a mixed picture of compliance, mediation and subversion.

\section{Key finding 1: The development of new internal and external roles for headteachers.}

The national educational agenda for change resulted in the creation of new and changing roles for headteachers which were both internal and external and often a combination of the two. The roles of headteachers were wide ranging and supporting the findings of the PwC report (2007) so were their external partnerships. New roles for heads have implications for the wider system and future government policy. 


\section{Headteachers' perceptions of change}

I wanted to discover why heads thought new roles were being made available to them. Reasons were identified as follows:

- Government's response to the undoability of traditional headship by providing ways of allowing heads to lead more strategically and manage workload.

- The introduction of new roles such as executive headship were judged to be a response, by stretching leadership, to the imminent retirement of the 'baby boomer' generation and lack of interest by suitable successors in headship.

- The impact of ECM in establishing new relationships and leadership and management practices.

- To spread best practice to other schools to raise standards and effectiveness in those schools through the process of collaboration.

While having an understanding of the issues behind the calls for changes in the system, with the exception of $\mathrm{Ht} 1$, heads did not specifically articulate a need within the 'standards' agenda to provide a suitable future workforce identified as an aim of Government policy (Blair, 1998 in Bottery, 2004).

While most of the heads identified the same reasons for change they didn't all agree that the issues they identified for others were still applicable to them. The timing of the interview was important in this finding. There was considerable concern over the undoability of the role and the amount of bureaucracy surrounding it in the first round of interviews. However while recognising the intensification of work as an issue, most of the heads had by the time of the second round of interviews, found ways of managing their role so that it wasn't undoable in their context. In common with the findings of Gunter (2008) they had already taken advantage of the opportunity to make changes through using the government's educational agenda such as workforce reform (see Chapter 6 and Key finding 4). 
There was considerable speculation by the heads throughout the interview cycle as to how their role would change. That there was more awareness of this post 2006 in the second round of interviews leads me to the conclusion that the publicity surrounding the agenda both in the TES and through the DCSF and NDGAs, arguably meant to 'design' future leadership (Gronn, 2003), was proving effective. There had been articles for a decade before about the impending recruitment crisis (TES editorial, 1997) and that heads might have to lead in more than one school (Cassidy, 1998). It was highlighted by Gronn (2003) but gathered momentum from 2005 coinciding with the renewed challenges of the NCSL. In addition LAs and NCSL were providing these heads with more opportunities such as PSCL and so experience was also alerting heads to the agenda for change regarding new system leadership roles and multi agency working and allowing them to be forewarned and proactive.

While not being entirely sure how future headship would develop the heads were sure that the role of the school leader would be pivotal, but not necessarily 'heroic' and singular. This echoes the view of Southworth and Du Quesnay (2005); Southworth, (2008) and West Burnham (2007) who argued that future school leadership would be ineffective if the headteacher were seen as a 'heroic' individual.

Whatever their opinion as to the desirability of it (some of whom agreed with Fink (2005) that it was misguided and others more open minded and sometimes changed during the interview) an analysis of the findings confirmed awareness by the heads of the messages coming from the government that the school leader of the future didn't have to be headteacher. That this debate was well known is an example of the success the government has had in paving the way for change and alerting all the heads to the prospect of it. Heads were made aware of the policy both by the publicity given to it by the release of information by government often to the newspapers, via their professional associations and through the professional development received through attendance at courses provided by, for example, the LAs and NCSL. Government is however only partially successful in designing leadership in this respect, as while heads were aware of the debate and had begun to internalise the argument against the necessity of a headteacher they had not all been converted to believing it was desirable, and so 'hearts and minds' (Clarke and Newman 1997) had not all been won.

Types of new roles 
There are three categories of roles heads were either pursuing, or had recently pursued, during the period of the research. In almost all cases the heads had a 'combination of roles' (Chapman et al. 2008). There was also a fourth group of heads who traditionally spent most of their time in school and did not have a new internal role created as a result of the national agenda such as leadership of a children's centre or extended school. This is because extended services had not impacted in their school, and may be located and accessed elsewhere, and the impact of ECM on the curriculum didn't affect the role of the head.

\section{Types of new headship roles}

\begin{tabular}{|c|c|c|c|}
\hline $\begin{array}{c}\text { Group 1 } \\
\text { Buccaneers }\end{array}$ & $\begin{array}{c}\text { Group 2 } \\
\text { Gurus }\end{array}$ & $\begin{array}{c}\text { Group 3 } \\
\text { Pioneers }\end{array}$ & $\begin{array}{c}\text { Group 4 } \\
\text { Heretics }\end{array}$ \\
\hline $1,2,3,4,5,7,8$ & $3,4,5,7,8,9,10$, & $2,3,4,5,8,13,15$, & 6 \\
$9,10,11,12,13$, & $11,12,13,14,15$, & 16,19 & \\
$14,15,16,17,19$, & 17,19 & & \\
20,21 & & & \\
\hline
\end{tabular}

Note: I have included Hts 4 and 16 in group three because they were planning for a children's centre which was postponed during the whole of my research period. However they subsequently opened after my research closed and I have included them because they were planning them. Similarly Ht 5 was planning for a children's centre and so it was part of his role at this time although the prospective children's centre had not been built by 2008. The presence of head's roles in more than one group reflects that they have more than one role.

Buccaneers are system leaders or 'educational change adventurers' (Hopkins and Higham, 2007, p.164). These roles were linked to those heads involved as system leaders with one or more schools to engage with them directly in school improvement. They were working at the edge of what was known as an 'adaptive challenge' (Heifetz 1994) and often at the margins of what was policy because they took action (such as with the allocation of staffing) that the system hadn't yet micro-managed. They were CLs, NLEs and executive heads and were linked to 'education failure' (Chapman et al. 2008), a finding also supported by Harris et al. (2006) and Hopkins and Higham (2007).

Gurus are system advisers. While these roles were also external to the school, I have not defined these heads as system leaders. In the case of SIPs this contrasts with the definition of system leadership given by Hopkins (2006) and Hopkins and Higham (2007). Those heads who pursued roles with other agencies, such as Ofsted, SIPs, LA adviser, DCSF, NCSL, QCA, British Council, Leadership within LA consortium, 
which while still involved in school improvement issues in education, were more detached from it as they were not directly involved in finding solutions for raising the level of provision in an individual school other than their own.

Pioneers were those heads who had a new role but located within an individual school such as the leadership of a co-located school or extended organisation with a children's centre or who were co-leaders.

Heretics were heads that had no substantial extended role as outlined above and rejected the new agenda although may have been involved as a member of a collaborative group such as the local consortium, however not in any leading role at the time of interview. Only Ht 6 fitted this category.

One feature of the descriptions heads gave of their extended roles is that many of the heads were discussing new roles such as Ht 5 in describing his work with the GTC in parts of the interview other than when the question was asked. This suggests to me either that heads had so many different roles they couldn't remember them all when first asked, or that they were so embedded as part of their lives they didn't see them as other than a part of their general routine. Substantial developments such as consultancy or federation headship loomed large in the interviews but networking roles and leading consortia were spoken of as an expected part of the job suggesting that heads had accepted the need for them to be so (Hannon, 2004).

The categorising of the heads' membership of these groups, while indicating the extent of their number engaged in a range and variety of the roles in this research, doesn't give an indication of the extent to which these roles were pursued. This ranged from none (6) or very little (4) to extensive and wide ranging in type $(3,5,7$, $8,9,13,14,15,17,19)$ and is analysed in Chapter 4 . This complicates grouping because sometimes heads had experience of a 'combination of roles' (Chapman et al. 2008), such as Ht 10 who had worked as a PSCL but wasn't active at the time of interview because of her time commitments and was only pursuing roles within group 2. Nevertheless, as my aim is to illustrate the range of roles heads undertook, I have included her role as a PSCL in the table above. 
I haven't included roles heads played historically before becoming headteachers. So even though Ht 20 was an LA adviser, it was before her role as a headteacher and not applicable for the purposes of my research, but is nevertheless an indication of the breadth of experience held by these heads.

\section{New external roles for heads}

A key feature of the extended roles for heads was the wide variety of roles some of the individual heads pursued. While some roles had only one head (5) undertaking them i.e. GTC or only two heads $(8,12)$ with the British Council, there were some roles which can be grouped around the concept of headteachers working outside their own institution for the benefit of others (NCSL, 2005a), Hopkins (2006) and Hargreaves, 2007a, 2007b) which involved the majority of heads.

While recognising that the evidence of the effectiveness of system leadership is sparse (Earley and Weindling, 2006; Harris et al. 2006; Hopkins and Higham, 2007; Chapman et al. 2008; Southworth, 2008) I have endeavoured to locate my findings of its effectiveness within the literature, in particular using the framework of questions from Hopkins and Higham (2007). In addition I have added another dimension to system leadership constructed from my analysis which is the importance and effectiveness of the system of accountability and inspection over and above that identified by Hopkins and Higham (2007) in both the way heads lead and the choice of who does so. Chapter 5 and Key finding 6 illustrates how it is only when the headteachers have secured their schools and their own leadership within the accountability framework that they can feel confident to pursue other roles.

System leadership is producing a 'new breed' of headteacher described by Gunter (2008) using Kingdon's (2003) term as 'policy entrepreneurs' or 'educational change adventurers' (Hopkins and Higham, 2007, p.164) who work externally to assist in the improvement of other schools. Hopkins and Higham (2007, p.152) describe system leadership as 'an emerging professional "movement", rather than an elite practice of a few 'superheads'. My findings would agree that the role is more widespread and embedded due to the role of support schools than that of 'superheads'. However it also identifies system leadership as less of a 'movement' and more of a strand in the professional repertoire of some headteachers. In addition it is something that they 
move into and out of depending on their circumstances such as Ht 10 who left PSCL work for a wider role with the DCSF. This finding supports the views of Steve Munby who commented that:

'I think that the notion of being a system leader is not for ever. It depends on the capacity in the school where you happen to be a school leader and that may go up and down. It is not like I am now a system leader and I am now going to do that and it doesn't matter what happens.' (Munby 2005, interview with the writer).

There is evidence in my research that an increasing number of heads became interested in a variety of opportunities relating to system leadership during the course of 2005-2008. My findings contrast with those of Hopkins and Higham (2007, p.152) who found only $13 \%$ of heads worked as system leaders. My research indicates that a high percentage of these heads $(95 \%)$, had at some time undertaken a form of system leadership in that they had been consultant leaders or worked as executive heads or part time seconded heads in other schools. I acknowledge the nature of my sample as a significant feature in the increased number of heads in my research who had been system leaders, but nevertheless it is indicative of increased interest in the field. My research concurs with Earley and Weindling (2006) and Harris et al. (2006) who found that system leadership was a growing phenomenon.

In my research system leadership is exclusively being used in situations of 'educational failure' (Chapman et al. 2008) a view endorsed by others (Earley and Weindling, 2006; Harris et al. 2006; Hopkins and Higham, 2007). In all cases those in my research who had been seconded to other schools (12 out of 21 heads sampled) and/or who had been CLs/NLEs (17 out of 21) had been required to lead in circumstances of educational failure. An important issue to consider is that while the system leaders may be successful in turning schools around this doesn't mean there is a corresponding likelihood of this improvement being sustained when they leave even though to ensure this should be an exit strategy for NLEs.

\section{School Improvement Partner (SIP)}

The use of the word solutions is important in defining group two. My findings indicate that SIPs are identifiers of problems $(5,14,17)$ and that if they work towards a solution then it is because of individual relationships made. The training of SIPs by 
NCSL, according to the two heads who had trained as SIPs, makes it quite clear that their role is to challenge schools and identify issues for improvement but not to work with those schools towards a solution $(5,15)$. Ht 10 had a contrasting view of the role of SIP to Hts 5, 14 and 17 and saw their role to form a 'partnership' with schools. In this she echoed the views of Hopkins and Higham (2007, p.163) who saw SIPs as 'change agents within the system whose remit is specifically school improvement'. The timing of the interviews is important in concluding whether SIPs will just monitor and check the improvement of schools rather than work towards a solution of issues with them. Most heads believed it was too early to tell and withheld judgement. However they speculated that the role of SIPs would be more that of an assessor and less that of a partner.

There was also some concern by many heads regarding professional relationships if SIPs were also LA advisers. Ht 18 exemplified this by saying that she wouldn't know which ' $h a t$ ' her adviser was wearing if he came sometimes as a SIP and others as a LA adviser. This view echoes the findings of Judd (2008, n.p) who identified concerns:

'...surfacing among some primary heads about the relationship between partners and the Local Authorities that appoint and manage them.'

I therefore draw the conclusion that because of the power dynamic within the relationship which is different to that of CLs and NLEs, and the operation of a predetermined agenda, SIPs are not in the same category as other system leaders as defined by Hopkins $(2006,2007)$ and Hopkins and Higham (2007). The role of SIP while being school improvement is not articulated by working with heads to find solutions in the way that other system leaders (CLs, NLEs, Executive heads) do. I accept that the power dynamic within the relationships some NLEs and executive heads have with schools may be firmly in the hands of the system leader, but they are still charged with working with schools to find a solution and are not there merely to identify their problems and walk away from them and assess the school's progress towards solutions at a later date. An implication for the government lies in quality assuring the effectiveness and impact of SIPs across the school system if they are not adequately monitored by LAs and local intelligence shared across authorities. 
The impact of the role is difficult to determine in such a short time from my research as it was unknown in the first round of interviews. However in the second round it was identified by 9 out of the 15 interviews (four of which were revisits) with four of the heads already undertaking the role. Subsequently I was informed that 4 other interviewees had been successful in their application to become an NLE. Although their appointment was after the period allotted for interviews, I include the information as an indication of the interest shown by heads in this opportunity and the success which NCSL has had in promoting it.

The heads saw the role in common with Chapman et al. (2008) as being part of the Government's strategy to combat the 'educational failure' of some schools, but in addition one of them went on to say that she also thought it was a measure introduced by the Government as a way of 'getting around Local Authorities where Local Authorities are not effective' (20).

This initiative is in its early days and is an aspect of leadership which will clearly benefit from further research. The role is monitored by NCSL for effectiveness according to the maintenance of an 'outstanding' rating by Ofsted for the NLE and the quality of Ofsted reports gained by the supported schools $(14,17)$. The key difference between consultant leadership which generally just involved the headteacher and that of NLE/NSS which used other teachers in the base school to support other schools was seen as a strength not only by those responsible for its design and implementation but also all those heads who were NLEs themselves. To date it is being viewed as effective in terms of outcomes (Munby, 2007, interview with the writer) and researched commissioned into its effectiveness by NCSL which has found NLEs supported by their schools to be a 'growing and powerful source for improvement in the school system.' (Hill and Matthews, 2008, p.16).

This was understood by the NLEs in my research. The degree of stress it put them under depended on the likelihood of them achieving good Ofsted outcomes. For some this caused no pressure or stress and one head (19) felt that possibly being an NLE offered a form of counter validation and security for achieving a good Ofsted. In contrast Ht 17 was concerned that the school in which she worked was not making the required progress and so was concerned for her reputation as a system leader and the 
potential lack of future resources for her school if she failed. The remit to act in client schools was not based on the role of NLE but on the individual circumstances of the schools in which they worked. The existence of an acting head was seen as a complication if they too wanted to lead $(14,17)$.

\section{Executive headteachers}

A feature of the federations was that while they were contextually different they were all created by the LAs to manage schools perceived as failing. In this they echo the findings of Harris et al. (2006), and Chapman et al. (2008). The key difference between the attitude of heads who were federation heads and those who were seconded but not in a hard or soft federation appears to have been 'ownership' and the power to act as the sole headteacher. Federation heads all treated the supported school as if it were an extension of their base school or part of a 'split site' (19) with roles which were created specifically as a result of the federation such as a deputy head across both schools (19), or for administrative support (20).

While trying to improve a 'weaker' school was the reason for federating in my sample, it was speculated upon by the heads that other reasons to do so might be economies of scale. They suggested that small schools might no longer be viable and that to federate with combined finances and staff operating across schools should also help to solve the problems of succession due to the dearth of future school leaders. These views concur with those of Steve Munby (2005, interview with the writer) and a LA senior advisor (2005, interview with the writer). This is further evidence of 'designer leadership' (Gronn, 2003) in that the Government's message promoted via NCSL about succession management and the survival of small schools being alleviated by federation is being communicated with some success.

\section{New internal roles for heads and ECM}

There was a tacit understanding that ECM would be 'hugely important' (1) in September 2005 but how this would manifest itself in changes to the head's role was not generally well understood. There was greater visualisation of the future by those who were going to be leaders of children's centres and seen as 'definitely have [ing] a big impact' (8) on their role, but otherwise ECM was anticipated to impact mainly on 
the curriculum and therefore on staff members other than headteachers (see Key findings 4 and 6).

NCSL has promoted the importance of high quality multi-agency relationships (Coleman, 2006) to ensure the successful leadership of extended schools. There was a mixed reaction to this and none of the heads anticipated high quality relationships with social workers, with the Sure Start initiative singled out as being particularly ineffective $(5,19)$. Heads complained that extensive interaction for them would be unwelcome and add to bureaucracy and workload.

Headteachers were of the view that the reason that children's services were coming into schools was less because schools are the universal service and more because they would be effective as the driving force behind their introduction. They had some justification in feeling this way, as Ht 19's LA changed their approach and integrated all their children's centres into schools. The main reason for the cynicism of the heads was not so much the extra work, which they had strategically managed successfully, but the unfairness of them having to sort out the problems caused by the inefficiency of others as they perceived it. Therefore there was a high degree of both resentment and cynicism about the extended schools' agenda and their role within it from most of the heads $(2-8,12,13,14,16,17,19)$ but this was tempered by their willingness to work towards it for the benefit of the community.

The accountability for the leadership of children's centres was not largely understood. The key is the role of the governing body. If the school's governing body was the main accountable body then this was separate to their role as governors of the school (DfES, 2007b). However in practical terms the existence of such a children's centre under the same governance as the school meant that the responsibility for the leadership of the organisation cascaded to the headteacher as the school leader. However the degree of direct accountability for this was unclear to all heads to whom it applied $(4,5,8,13,16,19)$, but was an issue for them as much of it was assumed and unformalised. They accepted accountability to various extents as part of their role with a mixture of resignation and for some enthusiasm because if they were going to be responsible for the centre they felt it was important to have overall control of its direction through the governing body. In this way they complied with the policy and mitigated the problem of having accountability but without the power to manage it. 
Apart from lack of role clarity the heads saw no problem with their accountability for a new and unfamiliar setting such as the children's centre because they were already accountable for those who were not teachers in school and viewed this as an extension of the same process. This evidence supports the findings of Gunter (2008) that there is a single undifferentiated group of staff emerging in schools. None of the heads anticipated there being any problem with the leader of a children's centre not having QTS, but most anticipated that headteachers would be in control of an overall organisation which included a school and children's centre within it. None of the heads saw the likelihood of such a combination having anyone without QTS in charge of teaching and learning but they acknowledged that providing there was a lead learner with control over the educational aspect of the organisation, it might be possible to have a chief executive overall.

Issues arising in using system leadership to build capacity in the system

The findings of Hopkins and Higham (2007, p.150) showed that there was no 'systematic knowledge as to how heads undertake leadership roles' and that 'replicating best practice from one school to another is not easily achieved' (Hopkins and Higham, 2007, p.164) and therefore not easily replicated across regions (Chapman et al. 2008). My research is indicating that there are some issues for the government in using system leadership to build capacity and sustainability into the system and they need to:

- Generate opportunities within the system for system leadership roles.

- Create the climate within the system which is conducive to attracting heads to new roles.

- Ensure that the 'right' heads are attracted with the combination of their perceived experience and suitable context with further implications for the system's knowledge of where the capacity exists.

- Educate governors in base and client schools of the benefits of new roles for their heads.

- Consider the implications for both the base and client schools if the system leader leaves and the successor can't or won't do the extra work.

- Consider the implications of having a level of frustrated system leaders if they cannot be further matched to opportunities in the system. 
- Appreciate and reduce the tension created by the New Relationship, flawed test data and inconsistent inspection judgements.

- Appreciate the need for a strong and secure base school to sustain the absence of system leaders and others involved in supporting schools.

- Generate opportunities for CPD for existing and aspiring system leaders with implications for the structure of national and local programmes

Importance of context and 'local responsiveness' makes work difficult to replicate

Hopkins and Higham (2007, p.150) argued that there was insufficient knowledge of what 'whole school capacity exists' in schools from which to launch system leaders effectively. I would agree from a system wide viewpoint LAs have not been in a position to know what capacity is in the schools. Therefore how many system leaders are available to be deployed is difficult to calculate or locate. A lack of opportunity for system leaders to access opportunities created by the government is potentially a problem for the school system. None of the 13 heads aged over 50, felt that retirement was an option and were looking to extend their working lives. However Ht 13 argued that the LAs and governors hadn't kept up with the needs of the system and might not provide the mechanisms of choice and opportunity for the system to operate in the future (see Key findings 2 and 3).

The roles of the LA are changing (see Key finding 3) but in addition my research agrees with the findings of Chapman et al. (2008) and Hopkins and Higham (2007, p.153) that 'local responsiveness' is fundamental in determining how system leadership roles are generated and in how schools leaders 'work to reform [local] systems.' It indicates quite strongly that the role of the local authority is important both for its local intelligence and also because of the role it plays in brokering the support of system leaders thereby establishing the importance of local stimulus for system leadership (Chapman et al.'s 2008). The effectiveness of system leadership depends on the extent to which they are deployed and this is largely at the behest of LAs. A question for the government is how it manages the compliance of the LAs to broker roles and the accuracy of how they are matched. I think the government needs to consider how to manage the distance in the system between the system leaders and the government's intention that they are used. 
Sustainability is dependent on individual LAs having the capacity in their schools to use heads in this way and those heads having the will and motivation to be used. In addition this is further complicated by the quality of the match of each school and of the evaluation of the process and the extent to which each party is flexible and willing and able to adapt to changing needs. There is not only an issue with attracting heads to work to the benefit of the system but also the extent to which they can take advantage. Small schools may indeed federate which would possibly be a solution to economies of scale. It is not however a solution to enable those heads of small schools who wish to be involved in external roles to do so as their schools lack the capacity to sustain their absence. This limits the number and scope of heads who can become the agents for 'sustainable educational change' identified as necessary by (Hopkins and Higham, 2007, p.148) and which found resonance with the views of my research and in particular with two heads $(1,9)$.

The heads in this study are all effective in their own schools. Their inspections all validate this. This doesn't necessarily however translate into other contexts. My research indicates that some success in structure such as co-locating schools or ways of working such as consultancy can be replicated but needs to be evaluated and established as valid and then communicated through professional development and opportunities. Leithwood et al. (1999a), Leithwood et al. (1999b) and Leithwood et al. (2006a, 2006b) argued that leadership was shaped by context and Hopkins and Higham (2007) and Chapman et al. (2008) extended this to allude to the importance of understanding the impact of system leadership in different contexts.

It could be argued that it is unfair to all concerned just to take a successful head out of context and place them in a different one as it is by no means certain that success in one context will lead to success in all. My research however is showing strong supporting evidence that heads are able to sustain success in more than one school due to their understanding of contingent leadership and management of change. The evidence is not just anecdotal but based also on that of Matthews (2007), Hill and Matthews (2008) and Ofsted evidence which shows that schools have been removed from category, or were likely to be removed shortly according to HMI interim reports, as a result of the intervention of the system leadership of nine of the headteachers $(5$, $13,14,15,16,17,19,20,21)$. 
An implication for the system is sustainability in terms of the capacity of the base school (see Key finding 5), sustaining the number of system leaders needed, and the client school's sustainability if or when the system leader exits (Chapman, 2008). Heads bring funding back to the base school which in some cases is considerable and can go to creating new resources or new roles and greater numbers of jobs in both schools.

\section{Sustainability of system leadership}

An issue for schools is the sustainability of any school improvement if the system leader leaves the client school. Hopkins and Higham (2007, p.150) pointed to 'an insufficient evidence base of effectiveness' and of the impact of system leadership 'in different contexts'.

If involvement with the client school is dependent on the interest and whim of the system leader then this has clear implications for sustainability of improvement and the roles of others as the supported school could be left in an even more vulnerable situation once the system leader has moved on. The intention is to build capacity in the client school to support itself once system leadership has ceased (Munby, 2007, interview with the writer) and my research is indicating that in the opinion of the heads there was some expectation that the system will be 'self-sustaining' providing that the head has implemented effective systems (21).

A complication is generated by the development of inter-school systems which make sustainability more likely but 'untangling' (20) the results of collaboration in terms of relationships and roles more difficult for system leadership generally, and particularly executive headship, should schools wish, or are required, to revert back to single institutions.

Clarke and Newman (1997) argue that innovations are 'transformed' by those engaged in the social process. If so, then this may be why success is seen as more likely in my research if there is a seconded or executive headteacher who has the power to make real and sustained change in the most vulnerable schools. This shouldn't lead to a diminished role for CLs but merely affect their deployment. The role of NLEs is specifically to work in schools most at risk of continual failure and the 
use of the support school is an important element in sustaining improvements and using a greater spread of expertise to do so. There are however, different degrees of need and the use of CLs in the short term or for less vulnerable schools can still lead to improvement. Notwithstanding all of this though the short term nature of external involvement will almost inevitably lead to problems of sustainability which is arguably what schools working in long term collaborations is meant to address.

How much capacity is there in the system to continue to use school leaders to develop leadership across the system was asked by Hopkins and Higham (2007, p.150) and I would add to avoid existing leadership being stretched across schools to the detriment of base schools. This is a difficult question and one which my research is indicating is a mixed picture. All the heads involved highlighted the importance of a strong 'secure' school (12) using distributed leadership to build capacity in the base school (see Key finding 4). Early stages of setting up the role in other schools was seen by all as causing an intensification of workload but as heads established themselves and put in workable systems this diminished.

My research is suggesting that the opportunities afforded through distributed leadership and 'acting up' in the absence of system leaders is both enhancing the skills of the team as a whole and so increasing the capacity in the base school. There is also evidence that due to the reputation of National Support Schools heads from these schools find no difficulty in recruiting high quality staff.

Having attracted system leaders my research indicates that another important aspect of the benefits of system leadership is not just the impact on the system by the supported school, but also on the increased expertise and skills of the leadership of the system leaders in the base school. This has implications for the professional development of school leaders and also of 'aspirant system leaders to ensure they gain the skills, experience and support needed to be effective.' (Hopkins and Higham 2007, p.151).

\section{$\underline{\text { Recruitment, retention, training and future leaders }}$}

My findings concur with those of Hatcher $(2008, p .24)$ in that there is developing in system leadership, especially with NLEs and executive heads 'a new top-level 
management cadre in the school system' who are transferring the knowledge from those schools which are considered to be innovative and creating an 'education epidemic' (Hargreaves, 2003) through the evocation of an 'ideas virus' (Godin, 2001, in Fullan, 2005) and Hopkins (2007). If there is a requirement for new forms of headship then this has implications for the training and development of future school leaders.

Hopkins and Higham (2007, p.150) argue that there is insufficient evidence of what constitutes 'best practice' in system leadership. If the Government sees the use of system leaders to spread the 'ideas virus' (Godin 2001) then it is essential that system leaders spread the ideas that are considered to work for the benefit of the system as the government sees it. 'Dissent therefore has to be managed and opposition delegitimised' (Hatcher, 2008, p.29). My research and personal experience suggests that the dominant discourse from the NDGAs and DCSF is that utilising 'moral purpose' and encouraging accepted heads to work across the system is to be promoted through training and development. Whether heads' 'hearts and minds' (Clarke and Newman, 1997) have been won or not is debatable. My research indicates that for all of them there is a core purpose of wanting to help others mixed with the more pragmatic desire to add resources to their own school and enhance their own reputations through the buzz of professional challenge. Whatever their motives for leadership styles and actions heads have been made aware of the agenda and the rewards to be gained either intrinsic or extrinsic through national training and development programmes and the exposure to selected leadership texts on NCSL's website.

I work on training and development programmes for aspirant leaders on behalf of both the LA and NCSL. My research supports my view that an element of these should contain modules about the new roles heads are undertaking and the skills and attributes needed for system leadership. I believe that there is also a potential for apprenticeship through programmes such as the PLP in that it gives leaders the opportunity to undertake small scale work and learn through training and experience how to work in this way and which furnishes them with the experience and the opportunity to build up the credibility to become system leaders or to be trusted to manage large scale extended provision. 
Both as a result of my research and as an experienced head who undertakes system leadership work I think building capacity through a menu of opportunities gives heads the necessary understanding of what is needed in these complex situations of system leadership. I believe it is not a coincidence for example that 17 out of the 21 individual heads had undertaken primary strategy consultant leadership (PSCL) under the PLP programme before moving on to other system leadership or extended role. This has important implications for the training and development of future school leaders. This is not just for the training programmes which offer competency based training on national programmes but also other forms of training and development which uses national or local programmes but gives practical opportunities to gain experience in the field in small bespoke school to school and other collaborations.

\section{$\underline{\text { System leadership as recruitment and retention }}$}

Another question for the future of leadership is the extent to which new roles are being successful in maintaining more heads in the system and so helping to create solutions for the retirement crisis. My research is indicating that heads are more likely to remain in headship after their mid fifties, if they have other opportunities $(3,5,7$, $10,11,12,13,14,17,1921)$ which are professionally challenging and personally refresh them and in common with the findings of Flintham (2003) in developing a 'portfolio' of work.

Reasons why heads were managing new roles included that they were very able and experienced and could manage change well or it could be that the concept of distributed leadership and collective leadership is working to the benefit of the schools as well as individual heads and the system. The extent to which this is a pattern across schools together with the implications for the schools that have to manage the frequent or sustained absence of the headteacher, are questions which would benefit from future research. In addition to this I would suggest that more needs to be known regarding the roles employed across schools if they cease to collaborate.

Further consideration needs to be given by the government as to how they manage the system leaders who state that they cannot revert back to traditional headship which was identified by those in my research. It would benefit future decision making in this 
context if further research identified why system leaders give up their roles. Reasons given for changing their roles away from system or other extended leadership were:

- Lack of time to pursue the role/s

- New and preferred opportunities offered

- Boredom or disappointment with the role

- Moving on from headship and no longer being in a position to continue

My research indicates that some 'new "prospective" identities' (Whitty, 2006, p.11) are being made as the result of people taking on the new opportunities offered through new models of leadership.

Government policy should generate a flexible and responsive system to deal with change due to new roles

My research is showing support for the need to allow the creation of 'space' though intelligent accountability (Fullan, 2005 in Hopkins and Higham, 2007, p.161) and Hopkins $(2005,2006,2007)$ and opportunities to innovate for local systems to operate and move quickly according to local need (Chapman et al. 2008). My research suggests some success for the government in the implementation of its policies for system leadership, but also some unintended consequences for the system as policy is translated into practice (Levin, 2003a).

An example of successful implementation of policy is that workforce reform creating new roles for staff and distributed leadership has been used successfully to sustain the absence of the head. In addition allowing the conditions for some negotiations on pay and conditions for heads who work outside school and for those who act up within one school or across schools has encouraged more heads to become system leaders. More needs to be done in this area because there is a large difference in the financial rewards earned by the system leaders in my research which causes some resentment and frustration (13).

Where government policy has been less successful in this research is regarding the use of 'intelligent accountability' (see Chapter 5 and Key finding 6). 
An important conclusion is the element of choice heads had to shape their role. Hopkins and Higham (2007, p.162) point to the government being 'an enabling state' which provides the circumstances for heads to lead on the ground. This gives increased power to heads as the decision as to whether to pursue external roles is theirs to accept or decline. An example of this is $\mathrm{Ht} 4$ who was invited to work as an adviser in a local school and quickly decided it wasn't for him and chose not to continue. Five heads $(12,13,14,17,18)$ had trained as Ofsted inspectors. Hts 13, 14 and 17 had taken a conscious decision not to undertake anymore inspections both because they didn't like the role with the changes to the new relationship $(14,17)$ or because in all three cases they had other roles they preferred. Hts 12, 18 however had chosen to undertake more work from this source but the choice was theirs and the level of commitment determined by them. Opportunities to undertake new roles came from a combination of application for roles by the heads themselves such as CL or NLE or roles within the DCSF or other NDGA or being asked by their LAs to undertake specific work in other schools on a more informal basis.

There is support in my research for the findings of writers on new roles (Earley and Weindling, 2006; Chapman et al. 2008) that some heads are purposively seeking a wide menu of opportunities and for a variety of reasons. The financial reward for the heads was variable but could be considerable with 'entrapment of salary' or the difficulty of being able to match a high salary elsewhere, being specifically mentioned (19). However financial reward wasn't the main motivation for any of them. Thirteen heads supported the evidence of Earley and Weindling (2006) in declaring that their main motivation was stimulus and professional challenge. This was followed by the satisfaction of being asked and 'needed' $(13,14)$ linked to a moral purpose advocated by Fullan (2005) and Hopkins (2006). New roles led to professional growth which was felt by the heads to increase their levels of knowledge, thus strengthening their leadership skills. It was also seen to offer development opportunities to staff gained by 'acting up' internally and across schools and accords with the benefits to this identified by NCSL in the section of their website devoted to 'Tomorrow's Leaders Today'. 
Heads who are motivated to undertake new roles do not have to retire to pursue other roles as some 'flexibility' is being built into the system (Chapman et al. 2008) as the Government uses heads to play a part in implementing their strategies (Gunter, 2008) which include the New Relationship, Primary Strategy and London Challenge (Earley and Weindling, 2004). My research supports these views and, in addition, indicates that heads were motivated to undertake a wide variety of roles not only because they realised the usefulness of creating a portfolio for retirement but also because they were using the opportunity to extend the time many of them stayed in headship. Leaving to undertake other roles full time, such as adviser in the LA, which was seen as a natural move for many after headship, was not attractive to the heads in this study. The reasons given were that it was more difficult to make a difference to children and the working practices and lack of autonomy. This is reinforced by the views of Hts 4, 11 and 20 who had worked as either substantive $(4,20)$ or seconded (11) advisers and who left that role for headship, either as a return $(4,11)$ to a previous role, or as a new role (20).

\section{Financial implications of new roles}

New forms of school leadership are causing there to be tensions in the system because of the way in which heads are paid. The tension lies in the disparity of payment for similar work. This is being recognised in that the STRB intends to provide a structure for the payment of system leaders and those of extended organisations by 2011. Traditionally the head of a three form entry urban primary school will have operated a similar role to that of another in the same context and similarly a head of a small rural primary school. Funding depends largely on a formula related to the number of children in school and this determines the leadership group in which heads are placed for the calculation of their salaries. There is some scope for governing bodies, made possible by the various pay and conditions documents, to reward experience and offer points for retention within this system but salaries will broadly have remained similar.

My research identified that there was further scope for enhanced salaries for heads who work in more than one school to be paid, along with other staff in their base schools out of the budget of the client school $(13,14,17,19,20,21)$ sometimes subsidised by the LA. These heads retained their substantive role while working in another. The extent to which salaries ranged in the subset above was from 2 points on 
the scale to exceptionaaly half the salary of the client school. I haven't included those who worked in a seconded context with the whole of their salary paid by the client school or those who worked as Consultant Leaders.

Consultant Leaders and NLEs not engaged in executive headship but with a large role in another school also in some cases negotiated with the governors of their base school a percentage of the extra funding they brought into school. Although it may not have been the main reason for heads undertaking system leadership, enhanced pay is certainly an important factor. Market oriented pay to this extent is a departure from previous practice and as governors have a crucial role to play in determining how much heads earn, this movement to consultancy and system leadership is crucially important in how it impacts on the relationship of governors with heads (see Key finding 2). The question of the pay and remuneration of headteachers therefore has an implication for the system in managing succession planning and for the role of governors in school.

\section{Key finding 2: There have been changes to the role of governors as a result of changes to the role of headteachers}

\section{The governors' internal and external role}

Jones (1999b) found that the role of the governors was largely unchanging but my research is suggesting that by 2008 their responsibilities and the types of decision they had to make had changed considerably. The role of governors has been identified as external to the school. Doughty (1998, in Bell and Rowley, 2002), argues that the governing body's role has an external dimension as they are concerned with holding the headteacher and the school to account. If the school is viewed as a single institution and accountable to the above then I would agree. However if governors have become part of the process where the school is situated as an organisation working with the system to provide local and system wide improvements then the role of the school as an organisation has shifted and changed.

The position of governors' role in the organisation is complicated by new roles for heads. If the governors are agreeing to the head taking on an external role then that is part of the head's accountability to the school and therefore the governors are external 
stakeholders. However if the governors are being proactive in seeking to be part of a federation or to take on the role of governance of a children's centre then I think that has an internal dimension. Governors are therefore being asked to make decisions about the 'direction' of a school (Chapman et al. 2008). If the head is a system leader it may be a part of the work that governors form a 'bridging governance structure' or can become members of the governing body of the client school (Harris et al. 2006, p.400). This has occurred in my own experience as a system leader although not in those of the heads in my research. Therefore the governors, due to the internal governance decisions they make as part of the school, have a role to play as internal stakeholders as the school becomes more outward facing and works as part of a wider system.

The role of the LA is important in heads working outside the school as they are used to influence the decision making of the governors if the services of the head are of use to the LA. However it is a position of influence for both the LA and heads and the power to make the decisions lies with governors. This reflects the findings of Earley and Weindling (2006) who recognised that governors have to give their support for heads to be consultant leaders, but my research extends this view to show that the decisions governors have to make have also widened in scope for consultancy (NLEs) and the number of different types of role heads wish to undertake and is in line with the later findings of Chapman et al. (2008). My research suggests that the compliance of governors was less because they understood or were interested in the benefits of system leadership to the wider system and more because they felt that not to comply might mean they would lose their headteacher, a prospect which left them 'scared' (2) as they realised the difficulty of replacing them in the current recruitment crisis and the dearth of school leaders.

No head was ultimately unsuccessful in pursuing the roles they wanted but the degree of difficulty in obtaining what they wanted was variable (see Chapter 6). To facilitate this process of accessing system leaders the NCSL is making governors more aware of the importance of the role and benefits to all parties through regional meetings and a place for them on its website (Growing Tomorrow's Leaders). In addition a wider role could be made an entitlement of the professional development of successful headteachers. 


\section{Governors and accountability}

The varied quality of governing bodies in their ability to undertake their duties is an ongoing issue for the government and LAs as they rely on governors to some extent to enable system leadership to take place. There was a benevolent attitude by most of the heads towards governors in so far as the heads appreciated the support they received as described by Levacic (1995) but some resentment over the position they had been granted by the government in holding heads to account. The requirement by government to explain complicated policies and agendas to governors in different ways and on several occasions was a source of frustration identified by many of the heads.

Heads were happy to use the power of the governors to facilitate their own roles. Ht 19 for example in telling them 'after the event' in terms of the way she worked due to the speed with which she had to implement initiatives in the federation and the degree of flexibility she needed to make radical decisions in new situations. Some heads were undertaking practices across schools which were comparatively new to the system such as the deployment of staff with substantive roles in two schools. While this worked in providing a successful school/s and professionally developed staff, it might not be so successful if the situation changed, such as that of a change of head or the break up of a soft federation. If the governing body is unable to understand the educational agenda in enough depth, and the school is treated as 'light touch' by the LA, it is possible to create a space through earned autonomy where the head can work with considerable independence unhindered by accountability to the governing body. Unless governors are able to hold heads to account effectively it could take some time for the system to 'catch up' through the traditional routes of accountability especially with new school structures.

Just to consider governors as blind in their support, or easily led, however could be unfair to those governors who were supporting their own headteachers. This judgement is based on the fact that all the heads in the sample were very good to outstanding. It could be argued that the issue of trust and professional respect felt by the governors towards the headteachers had a bearing on the latter's opportunity to enjoy a degree of earned autonomy. However earned autonomy doesn't in itself give power to heads and I believe my research supports the findings of Radnor et al. (1997, 
p.205) in their discovery that heads want an 'active, skilled and resourceful governing body, but not too active,' ensuring heads have the day to day control of the school. I would extend this to control over the direction of their professional lives. Levacic (1995, p.40 in Jones 1999b, p.446) suggests that governors need to ensure the 'trust and compliance' of the headteachers. From my research I would add that headteachers need to ascertain the trust and compliance of the governing body, to give them, as heads, the freedom to control their professional lives.

\section{Key finding 3: New roles for headteachers have led to new and changing relationships with Local Authorities and other agencies}

\section{Changing relationships with LAs}

Local authorities have had a reduced role with schools due to successive government legislation (Chitty, 2002; Southworth, 2008) but have been seen as reinventing themselves 'as competitive service-providers' (Crook, 2002, p.247). James et al. (2005) suggest that all LAs may not be inspired to do so and Maguire et al. (2006) argue that the quality of relationships heads have with the LA has been seen to be variable.

My research and experience as a practising headteacher working closely with the LA and NCSL indicates that some LAs have extended the role identified by Crook (2002) and embraced the notion of reinventing their role with schools and in particular responding to the changes following the College's restructuring and its new remit following the 2004 audit. Through their involvement with NCSL, LAs are strategically involved with headteachers' new roles. They were acting as brokers for NLEs, as well as becoming more involved with NCSL in projects such as those involved with succession planning (Local Solutions) and the CPD of aspiring heads (Associate Heads Programme). NCSL was given a remit for designing and implementing a programme for the leadership development of Directors of Children's Services (DCS), extending the involvement of LAs with the College (NCSL, 2009).

While the external roles for headteachers needed to be agreed by their governing bodies the number and variety of opportunities available to the heads were made available at local or 'mid tier level' (Fullan, 2005) and are dependent on context and 
'significant local stimulus' (Chapman et al. 2008, p.8). This has I believe resulted, if not in the 'cosy' and 'informal networks' of the 1950s (Chitty, 2002), at least in a form of renaissance for the LAs in their relationships with some headteachers and has perhaps developed more along the lines of LAs working to 'support networks of practitioners' (Hargreaves, 2003, p.52).

Earley and Weindling (2006) found that there had been some 'friction' between the LAs and consultant leaders. While there was some evidence of this from interviewees, due to the interpersonal skills and professionalism of the heads both in the base and client schools and individual LA staff involved, it was minimal. My research also supports the research of Harris et al. (2006, p.400) which identified the LA as playing a 'central supporting role to the executive head' through the support of a liaison group. However the extent of this supporting role differed widely depending on circumstances from considerable support for some executive heads $(5,13,14,16,17)$ to others, usually in federations, who had little additional contact for support other than that associated with routine monitoring of schools $(19,20,21)$. Ht 19 highlighted this point by commenting that the LA had started to turn to her to support others in the same circumstances as the expertise lay with the system leader and not the LA.

Monitoring the effectiveness of schools is a function of the LA. Some heads saw a danger that the LAs would lose their understanding of the effectiveness of schools (16) if SIPs were other heads from outside the area even though it was realised that the LAs would receive a report, it wasn't the same as the depth of knowledge some advisers might have. However there wasn't universal agreement that advisers as SIPs was a helpful development for schools as Ht 18 argued that she wouldn't know which ' $h a t$ ' the individual was wearing and so it was detrimental to her relationship with the LA based on trusted advice and discretion.

I didn't seek to determine the role of the LA in my research, however the evidence supports that rather than losing power and influence, LAs are finding new roles for themselves and being given them as leaders of children's services and as part of the governments drive to alter the structure of schooling through federating schools and introducing children's centres. This was identified by the LA senior staff interviewed and could be interpreted as ironic given that the reforms were meant in part to act as a control of the too powerful and independent LEAs (Chitty, 2002). This was 
acknowledged by Ht 20 who believed that the role of the SIP was meant to wrest any monitoring control from the LAs.

These new relationships will however call into question the leadership capacity of LAs to deliver system leadership. Those who have outsourced most of their work may find this more difficult. In addition being dependent on local negotiation makes role availability disjointed and fragmented and has implications for national policy as the system at national level has less control over the process and 'its replication' (Chapman et al. 2008).

\section{Relationships with NCSL}

Now that the standards have plateaued and there is a problem with recruitment the government needs to strengthen its partnerships with teachers (Bottery, 2003). Manifestations of this could be seen as the creation of the NCSL and its use of and relationships with teachers. Gunter (2008) recognised the increased use of serving and newly retired heads as consultants in schools. Echoing this Bush (2008, p.280) saw NCSL as being innovative in 'Its extensive use of current and recent school principals to lead College programmes' and its 'innovative learning approaches' which include mentoring and coaching.

My research indicates strong support for this view as $76 \%$ of heads accessed work which was directly related to programmes or opportunities which involved NCSL. These were manifested either directly through employment as facilitators on programmes, acting as consultants for them or part of working groups. In addition NLEs were validated through NCSL even though their work was brokered through the LA. In monitoring the work of NLEs and determining their continued status NCSL exerted considerable control on this aspect of the system. They were also influential indirectly as trainers for consultant leaders employed by the LAs. NCSL increased its influence on the system as LAs and heads accessed them, the latter in order to increase their skills and portfolio of work.

\section{Key finding 4: There has been an increase in the strategic role of the headteacher and the development of new roles for staff}


My research indicates that the new and developing roles of headteachers created new patterns of leadership requirements with heads who appear to have chosen to adopt Fullan's (1992) argument echoed by the PwC (2007) report that the heads' job is to ensure that the job gets done but not to do it all themselves. This included the need for distributing leadership and changing the roles of staff which echoes the findings of Chapman et al. (2008) who argued that the impact of distributed leadership in schools is creating roles for other staff and Maden (2001) and Maguire et al. (2006) who argued that a strong, supportive staff team is essential for headteachers to manage their roles.

Southworth (2008) claims that notwithstanding the work of (Wallace and Huckman, $1996,1999)$ there is an acceptance of the growth of the use of leadership teams in primary schools and distributed leadership but less understanding of what they do. My study contributes to the research because it indicates that heads are strategic in that they used 'leadership wisdom' in understanding what decisions to take and the right time to take them (Davis and Davis, 2004, p. 35). The heads were highly strategic in the way in which they used their understanding of the skills and abilities of staff and distributed leadership to manage their own roles and their schools as organisations. This strategy was undertaken to enable heads to manage:

- The work intensification they encountered as part of the increases in bureaucracy by implementing government policy.

- Their pursuit of other roles both internal and external.

I have used the framework defining the characteristics and 'organisational skills' of strategic leaders provided in the work of Davies and Davies (2004) to analyse the responses of the heads in my study as strategic. Davies (2002) and Davies and Davies (2004, p.30) defined strategy:

'... as encompassing direction-setting, broad aggregated agendas, a perspective to view the future and a template against which to evaluate current activities.'

Using this framework I have categorised the actions of the heads in three sections as building capacity by: 
- Creating new roles for staff

- Distributing leadership

- Creating a more strategic and less, or changing, operational role for themselves

In changing the roles of staff heads were being strategic by 'reconfiguring existing abilities and resources rather than having to seek new ones' (Davies and Davies, 2004, p.34). Workforce reform was extensively used by the majority of headteachers in my research to change the nature of the roles of existing staff and to create new ones and in many ways the decisions they made were dependent on the school's context.

\section{An emerging change of terminology}

Gunter (2008) notes a link between Morris's (2001) comments about the small pool of graduates from which future heads can be drawn, which is echoed in the PwC (2007) report, which also advocates that QTS isn't necessary to lead a school. To succeed in persuading schools of this and for the government to alleviate the problem of managing succession with the problems of the retirement of headteachers and the difficulty of recruiting more (NCSL), it could be argued that policies are in place to break down the barriers around role (Gunter, 2008).

My research indicates a changing attitude of heads towards roles in school due to a change in terminology used by many of them who were referring to the workforce as a single staff (Gunter, 2008) and were less likely to be referring to teachers and support staff separately when talking about the workforce as a whole. This view can be reinforced by reference also to a change in terminology in referring to the roles of staff. One example of this is from Ht (12) who has created 'directors' of different aspects of learning in her school. This is indicative of heads changing culture and expectations of roles in school by adding words which add gravitas to the role or change its definition making it easier to change roles or to create new ones.

\section{New roles for teaching staff}


My research indicates that workforce reform was used intentionally to create new roles for teachers or change existing ones. The use of workforce reform to increase the use of leadership teams in schools meant a tightening of mangerialist practice (Yukl 2002; Gronn 2003). Traditional hierarchy would suggest in most primary schools the use of SLTs which in my study consisted of a variation of deputy and assistant headships and TLRs 1 and 2. However, while the hierarchical structure for teachers was itself little changed in terms of types of role, what had changed was the number of these roles in some schools and how they were used in schools as heads employed this strategy to consider the 'long term future of their organisation' (Davies and Davies, 2004, p.30).

New and changing roles had been created by most heads as part of restructuring. Roles subject to the most change were that of the deputy head and/or the assistant heads. There was evidence that in common with the findings of Earley and Weindling (2006), senior leaders were frequently being used to undertake much of the operational role of heads when they were absent from school. Those heads that only employed assistant heads used them in ways similar to those who had deputies and all praised their senior leaders for the way they could be relied upon to manage the school in their absence. One consequence of this is that much of the teaching role of deputies has reduced to allow them to undertake their increased role of school management. In addition seven heads $(5,8,13,17,19,20,21)$ identified their motives to restructure the SLT were not only as a result of improving internal management systems but also directly to manage their own absence as system leaders. This is particularly significant given that the interviews above except Hts 5 and 8 were in the second round and that there may have been more heads in my study that would reflect the actions of the set above, but the interviews in the first round were too early to identify this.

\section{New roles for teaching and administrative support staff}

Gunter (2008) highlighted a blurring of roles between teaching and teaching support staff and Maguire et al. (2006) highlighted the importance of support staff to the heads in their research. My study shows some contrast in that there was resistance to the use of some support staff such as TAs in the place of teachers but not for administrative support staff seen as easing the burden of headteachers. Although she 
couldn't afford to employ them, only one head (9) advocated the use of HLTAs, others deeming them too restrictive in terms of what they were allowed to cover within their responsibilities. TAs were clearly used as support sometimes for group teaching and had increased in number in schools, but the general consensus was that if non QTS staff were to lead in the classroom 'what's the point of teachers in the first place?'(16). It was also suggested that TAs were too expensive and one head commented that for the same initial outlay he could employ an NQT (5).

My research points to a renaissance of headteachers as lead professionals as they delegated the role of chief executive, in contrast to the findings of Hellawell (1991) who found many heads were worried about the inevitability of becoming chief executives and a later study by Woods et al. (1997) who found heads were in reality increasingly becoming chief executives.

School business managers (SBM) are comparatively new in primary schools but in eight of the schools $(2,5,7,8,13,18,19,20)$ there was an officially recognised SBM or equivalent, often members of the SLT. Their role enabled heads to become more strategic and able to increase their role as leading professionals in their own schools or as system leaders. The SBM and other administrative staff managed much of what was the chief executive role of the headteacher with much of the responsibility for operational decision making for premises and personnel $(5,8,13,18)$. In addition other heads were purposively using members of support staff such as personal assistants to free them from bureaucracy where possible. This was considered an important aspect of making headship more attractive by NCSL (Munby, 2007; Southworth, 2008) and Ht 18 couldn't imagine taking another job in schools without a SBM to lighten the administrative burden.

The national figures show that while ' $60 \%$ ' of primary heads have some business management support, only ' $13 \%$ ' of primary schools have someone with overall responsibility for 'human resources, finance, health and safety, facilities and marketing.'(Munby, 2007). That eight or $38 \%$ of the heads employed officially designated school business managers with others considering it, is indicative of the increase in the strategic way the heads in my research were using the agenda for change to their advantage. Munby (2007) was describing the importance of the SBM and I think the message is largely understood in my research and the issue is 
affordability and the practicalities of sharing and confirms the findings of Southworth (2008) that determining factors of staff roles in primary schools are the size of the school and the inclinations of the headteacher. Of note is that all these SBMs were employed in two or more form entry schools. Southworth (2008) considered it necessary to have schools of at least 250 for an SBM to be affordable and if not for the cost to be shared between schools. None of the smaller schools in my sample shared an SBM and all felt the burden of administration.

\section{New roles for staff with ECM}

Heads were strategic in using their skills to 'translate strategy into action by converting it into operational terms' (Davies and Davies, 2004, p.31). Evidence to support this view can be illustrated by the heads' creation of new roles and changed educational practices for teaching, teaching assistant and administrative support staff in the development of the ECM agenda. This occurred both due to the perceived need to refine or change the curriculum to accommodate the ' 5 Outcomes of ECM' and because of the new internal roles created for headteachers through the development of extended schools.

While not being entirely sure what the extended schools agenda would look like in the early days of the interview schedule there was an assumption by most of the heads in the first round that it 'would come to us' to manage (7) resulting in an 'intensification of our workload' which 'could be disastrous' (3) This, as much as for any other reason, was why most of them discussed taking an early decision to plan strategically for the requirements for extended schools through workforce reform by creating roles for staff to manage them and had done so or were in the process of doing so in the second round.

Staff changes to take responsibility for 'all that ECM stuff down there' (2) were implemented which included in several cases creating 'Directors of ECM' (12) or assistant headships together with the employment of managers of children's centres. Ht 4 and Ht 13 had employed managers for children's centres which were still 'virtual'. 
The use of workforce reform to facilitate the implementation of the ECM agenda was anticipated by headteachers, which was a point a senior member of one of the larger LAs, believed would be missed by them. That it wasn't missed indicates that these head's had both an awareness of the national agenda and the understanding and will to make it work for them and an understanding of the best time to intervene to ensure the future well being of their organisation. Davies and Davies $(2004$, p.31) identified 'Being able to identify the key moment for strategic change' as an important characteristic of strategic leaders.

Remodelling the workforce has been recognised as a means by which heads can give a 'voice' to staff and create a collegiate framework of leadership (HammersleyFletcher, 2006, n.p). However I would question the extent to which distributing leadership to staff in my study has been delivered purposively to give voice for staff rather than for the more pragmatic reason of heads managing their own role by building capacity to mitigate their absence and work intensification.

\section{Building capacity, distributed leadership and delegated tasks}

Distributing leadership is a recognised strategy for building capacity (Davies and Davies, 2004; Spillane et al. 2001 Spillane et al. 2005; Spillane, 2006). Slater (2008, p.58) noted that 'Leaders who intentionally strive to build capacity promote leadership in others.' Where Slater (2008) sees the main reasons for distributing leadership to be improving student learning and like Earley and Weindling (2006) and Gunter (2008) contributing to the development and retention of staff, my heads also used it for securing opportunities to be strategic with their own wider roles. My evidence indicates that while retaining staff may be a consequence of distributing leadership it was not considered by the interviewees to be a main reason for the retention of staff due to difficulties in recruitment. It was believed by the majority of heads that due to the reputation of their schools and the opportunities for CPD in working across schools they had little difficulty in recruiting staff.

Being strategic by distributing leadership and offering new roles to staff required the heads to have a thorough knowledge of their schools and what worked, as well as the skills to manage change. They noted that care needed to be taken in building capacity by changing the roles or responsibilities in schools that the good practice which had 
been identified and was working in the school was not put at risk by their working innovatively or being stretched. Heads recognised that a balance needed to be struck between their own role as a leader and the need to distribute leadership and empower and trust staff. For some heads there was a reluctance to do this (2) but others were quick to mention the benefits of doing so with comments such as being able to leave work to his 'wonderful leadership team' (5) or another head who suggested that you had to let go to give staff the freedom to act (17).

That heads distribute leadership to increase capacity in the base school follows the findings of other writers (Earley and Weindling, 2006; Harris et al. 2006; Chapman et al. 2008). However one important aspect is that in addition my findings also support the argument of Hatcher (2005) in that the power to grant the autonomy lies firmly with the head and this limits the degree of leadership rather than management which can be undertaken by those to whom it is distributed.

The extent of the leadership distributed as against delegation of task is important. Despite the promotion of leadership in staff by heads in my research, there was some discrepancy between distributing leadership and accountability and delegating the management or operational role of the headteacher without corresponding decision making power. In some cases what was offered to staff was not power to undertake school improvement decisions and when heads described the need to make the school less 'dependent' (7) on them it was in terms of this routine management and not independent strategic direction. One head commented that 'no matter how good the deputy was, it still wasn't their school' (16) and so heads still needed to keep a close, if more detached eye on things. The main reasons given for this were that standards might drop (19) and that the head would lose overall control of the school $(7,8,9,13$, $14,16)$. The argument lies in the extent to which the leadership of the roles is distributed i.e. the degree of responsibility; autonomy, authority and associated accountability are devolved and shared against the extent to which the tasks are merely delegated.

Although there was some discrepancy as to the extent to which opportunities afforded to staff were a distribution of leadership or task, twelve heads $(5,7,9,11-14,17-21)$ identified that skills of leadership in staff were being enhanced by distributing leadership because of an extended role for headteachers. They identified these as 
being the opportunity for themselves or staff to work in different contexts (9) including opportunities for administrative support staff $(19,20)$ or equipping the staff with strategies to undertake classroom observation or self evaluation as a benefit of working as an inspector $(12,18)$. Further examples were using the ideas gained from the implementation of standard leadership programmes they might otherwise not use in schools such as ISP (13) or the experience gained from system leadership which meant that all of the heads echoed Ht 5 in that 'you come away thinking, that's a good idea, and you bring it back.'

Heads clearly saw the advantages of an external role as benefiting all concerned. Distributing leadership across schools was also seen to benefit the client schools in that they are trained alongside staff in the base school and in doing so improved their skills through working with good practice. I am aware that I only have the heads' views of the success of this, but they were also prepared to discuss disadvantages. These were identified as worry regarding overstretching the capacity of those left behind $(13,17,18)$ and that staff had acted contrary to the best interests of the school (16). Therefore it was seen as necessary to be aware of what was happening in both schools $(5,8,13,14,17,19,20,21)$ or to 'leave them to it' when undertaking secondment with no intention of returning (16).

Southworth $(2008$, p.417) found that the 'practice of distributed leadership is uneven.' It is a widespread practice in my research but possibly for pragmatic rather than intrinsic reasons. An important aspect of this finding is that although heads who had a new role, may have practised the use of distributed leadership, few heads were actually doing it and genuinely 'letting go' and being 'hands off' until the new roles took them away from their schools and they had to distribute leadership to manage and maintain the schools' success. Therefore the heads were not necessarily distributing leadership by choice but by necessity.

While the heads in my research felt that staffs needed to 'endorse the absence of the head' (12) or give 'permission' for other extended roles there is some evidence that staffs had to be 'persuaded' (19). I am mindful of the question posed by Bottery (2004, p. 21) 'what if those in formal positions don't wish to have their power redistributed?' This is potentially damaging to a system which relies on the distribution of power through collaboration both in terms of the headteacher 
relinquishing operational power and for the SLTs who themselves have relinquished some operational power to middle leaders and in turn to teaching support staff. Without the views of the staffs concerned further debate is outside the scope of my research.

\section{The strategic and operational role of the headteacher}

Headteachers have been exhorted to be more strategic and less operational in the leadership of their school (PwC, 2007). Headship in my research was shown to be still a 'doing job' ( $\mathrm{Ht} 7$ ) in that they were aware of what was happening and took decisions over the way teaching and learning was structured in schools but became increasingly strategic in the way they did so due to the demands on their role (Barnett, 2001) altering it in scope. This was particularly evident in larger schools where more senior leaders were employed to enable the headteacher to be more strategic.

My research supports the view of Chapman et al. (2008) and indicates that where context allowed, particularly in terms of budgetary constraints, heads are delegating much of the administration and project management to a support team and leading much of the teaching and learning themselves which is synonymous with their having 'strategic capabilities' providing that this isn't also accompanied by curriculum innovation to facilitate testing (Davies and Davies, 2004, p. 33). My research has found a mixed picture and has extended the work of Chapman et al. (2008) to find out why heads were still engaged in the teaching and learning process when they have such an extended role.

Firstly it depended on whether the heads felt they had to prove their credibility to staff as in the case of Ht 13 and 20. In common with the findings of Webb (2005) they wished to prove to their staff they still had the skills to manage planning and monitoring a curriculum area. Secondly, it depended on the extent to which schools had a sufficiently large budget to pay for the staff needed. In small schools there was evidence it hadn't leading to heads having a more operational role in small schools concurring with the argument of Southworth (2008) and showing little change from the challenges of the headteacher of small schools with 'pressing management demands' identified in the 1990s (Dunning, 1993, p.79). Ht 9 was SENCO and led on R.E but it was through necessity and not choice. Thirdly, it depended on the work 
intensification caused by the demands of new roles and the limit to the amount of work headteachers could undertake themselves. Fourthly, it depended on the importance heads attached to their being the lead learner to ensure the school delivered on performance of the standards. Failure to do so was seen to jeopardise the security and capacity of their schools, seen as essential to maintain if they were to have the credibility to pursue other work.

The extent of the involvement of headteachers in monitoring and evaluation

There was a new pattern of accountability in primary schools as a result of new roles, and the fact that heads were absent physically from their schools or had a more intensified work role within it meant they had to find different ways of monitoring education in their schools. However in common with the findings of Chapman et al. (2008) the heads in my research were heavily involved in monitoring and evaluating teaching and learning.

The increased strategic role of the head in my study can be seen in some cases $(5,7$, $8,10-13,17,19,20)$ to have led to another leadership layer of monitoring of the curriculum through the use of senior managers in the production of curriculum audit reports and the delegation by the head for some of the school's self evaluation particularly in larger primary schools and for those heads with an extended role. However that they aren't doing the monitoring themselves doesn't mean that they are not aware of what is happening in school, it is just that for some heads the knowledge of the performance of the children is obtained at a distance one removed from finding out by themselves

Performance management involving the use of team leaders has also enabled heads to be more strategic in monitoring the performance of staff and many now used it as a 'celebration' (12) of staff's achievement. Nevertheless some heads still felt there was a need to undertake some of the monitoring themselves. Different reasons were given for this such as a lack of trust in the team to do it $(2,4)$ context such as taking over a school in an Ofsted category $(15,16$,), inclination and style $(20)$, or necessity due to lack of time (14). While the reputations of both schools and the reputations of leaders are so crucially bound up with inspection of the performance of schools it is unlikely that heads will leave this aspect of leadership to chance and so trust is limited by fear 
as exemplified by Ht 5 who discussed trust and the need to scrutinise in the same sentence without a shred of irony in his tone:

I suppose as my role has changed there is very much more scrutiny than there used to be. I suppose because I am trusting people more to do things I have to scrutinise more. I do more monitoring now.' (5)

His trust typified the response of heads in that trust wasn' $t$ granted to the extent that they could withdraw their influence and power (Hatcher, 2005). Therefore it was a struggle for heads to be strategic because of the fear of losing control due to a diminished understanding of what was taking place in their schools in terms of day to day practice and even a degree of losing touch in relationships $(5,7,8,9,13,14,17$, $19,20)$ for example not being recognised by the children (13) or recognising people working in their schools (20). It is however another example of the success of the national agenda in that heads were beginning to care for children in schools not their own and rejecting the marketisation agenda and becoming more collaborative.

My evidence is indicating that there was a trade off in this situation by the heads who were ensuring that the structure in their base school was 'very very strong' (12) while they were absent in other roles but they were prepared to lose something of their own operational role to do so.

\section{Managing absence}

Strategies to manage absence depended on the extent to which the heads worked out of school. Berwick (2004, pp.24-25 cited in Earley and Weindling 2006, p.44) noted that 'this seems to be in practice to be set at one day per week though some have managed two days.' Most heads in my research believed that their schools could sustain their absence but not all heads agreed with this view. Four of them $(4,6,7,11)$ believed in common with the findings of Cox (1999 in Maguire et al. 2006) that the consistent presence of the head was crucial to the school and fair to the community. However others took considerable steps to ensure that they minimised their absence by being visible when there to the extent that one head (20) would drive backwards and forwards during the day if necessary for meetings with parents, another made sure that I am still around for them [parents] as much as before if I can' (21). The dangers of this were that it led to 'crisis management' for some because heads were stretched 
to ensure 'they were everywhere at once' (8). Ht 7 sought to strike a balance in work he would undertake and was prepared to do consultant leadership but not secondment or executive headship which would take him away from his school for too long.

Berwick (2004 in Earley and Weindling, 2006) continued that CLs often cannot commit to more than 6 months to a year for this type of work. He acknowledges that it depends on the quality of the system leaders, SLTs and other issues such as the proximity of an inspection or building projects occurring in the school. These issues were less likely to constrain heads in my research. Six of them $(2,3,5,8,13,19)$ had big projects occurring in their schools but it didn't curtail their pursuance of an external role. Heads were working in challenging contexts similar to those in London Challenge, but the difference is that the heads were becoming more experienced, strategic and skilful at managing their new roles by making new roles for staff and distributing leadership. The key to their success is that these heads identified permanence in their new roles and so prepared for sustainability and not a short term arrangement. If they ceased one external role such as consultant leadership (10) they did so to take up another more to their taste and circumstances, but not a return to traditional headship.

This need for heads to balance their absence with the need for them to be visible to the community could be interpreted as heads needing to be seen due to a lack of trust of staff, a need to be visible to protect the school from accusations of being 'rudderless' (7) or because of the desire to be needed on the part of the head (14). My research indicates that it is one or a combination of all these and that the reasons differ as circumstances change in schools. However having only the heads' view makes this difficult to determine and further analysis is outside the scope of this research.

\section{Power and centrality of headteachers}

The literature has stressed the central role of the head in the effective leadership and management of schools (Hughes, 1988; Southworth, 1993; Webb and Vuilliamy, 1996a; Ofsted, 1998, Webb, 2005). Hall and Southworth (1997) described the role of the head before the ERA (1988) as 'pivotal' and that the power dynamics within a school lay with the head and continued in the 1990s despite the increases in accountability with heads feeling personally responsible for the success of their 
schools a comment echoed by Crawford (2007). My study indicates they still feel personally responsible and all the heads' comments support this strongly.

I would question the extent to which the power of the head is 'softening' (Hall and Southworth 1997) with distributed leadership. I suggest that there is a variation of the way heads were 'pivotal' outlined in Hall and Southworth (1997) but not a move from the centrality of the heads in their organisation. Day el al (2000) believed unequivocally in the centrality of leadership but contrasted this with the need for the singular, heroic headteacher and stressed the need for collegiate leadership (see Key finding 5).

In spite of a degree of trust and distributed leadership, the headteachers were still central in my research to setting the direction of the school in common with the findings of MacBeath (2008) and the direction followed their view of how the school should be developed and should react to the educational agenda. The heads were acting strategically in trying to create a shared understanding and vision as to what the school was trying to achieve (Davis and Davis, 2004). A collective vision was achieved through consensus and through the operation of a 'learning organisation' where members learn from each other (Senge, 1998). Nevertheless because of the power of the head, albeit one removed and pushed through the use of SLTs, all the headteachers ultimately controlled the distribution of leadership and degree of autonomy enjoyed by others (Hatcher, 2005).

\section{Key finding 5: Leadership styles have been adapted to manage new roles and build capacity}

\section{The complexity of leadership styles}

Heads were transformational leaders in how they managed the agenda because they were emotionally involved (Crawford, 2007) and sort to empower others. They were also charismatic following the criteria laid down by House (1977, in Fidler and Atton, 2004) in that they tended to dominate the agenda, needed to influence others, and had strong conviction regarding the integrity of their beliefs. They expressed high ideals for the success of the organisation and confidence in the staff to follow these ideals 
but were simultaneously constrained to work within centrally determined policies (Whitty, 2005; Bush, 2008). (See Key finding 7.)

Charismatic leadership has been discredited because of its limitations. It situates leadership in the 'heroic' headteacher which is no longer suitable as headteachers cannot lead alone due to an undoable workload (Hall and Southworth, 1997;

Sergiovanni, 2001; West Burnham, 2005; Southworth, 2008). They are encouraged to be collegiate and distributive in how they deliver the agenda (Spillane et al. 2001; Spillane et al. 2005; Spillane, 2006; Harris, 2003; Hopkins, 2006; 2007). My research indicates that heads are still charismatic and pivotal in their schools but because they adopt a form of distributive element in their leadership they are not 'heroic' as defined in literature. Heads in MacBeath's (2008) study make the vision and direction of the school explicit, and so do the heads in my research but in doing so most of the heads believe they are taking into account the views of all the staff and in distributing leadership they are consulting and empowering the staff thereby displaying a form of collegiate leadership.

There is a further complexity to add to the issue of how heads' lead in that how directive they became changed with circumstances. In common with Moore et al. (2002) my research indicates that heads were acting in a form of collegiate leadership and trust if staff were working towards the school's vision which largely delivered the government's educational agenda. However there is evidence that they would become authoritarian if members of staff were not. Ht 20 clearly states that the school is dominated by her style of working and in doing this she acts in the 'autocratic' style identified by Bell and Rowley (2002). Other heads, while perhaps less confrontational and more benign in approach, are nevertheless clear about what they and their schools stand for and are unlikely to have brooked opposition. It is difficult to be specific with examples because none of the heads reported any form of real opposition and it was out of the scope of this research to find out the views of other members of staff. Therefore it is not possible to argue if the collaborative style of heads had led to a form of 'contrived collegiality' (Hargreaves, 2001) and one which didn't flow naturally through communities of practice (Wenger, 1999).

The level of collegiality was also dependent on context. Five heads $(4,15,16,20,21)$ who are in a challenging situation and have recently, or are in the process of taking 
their schools out of special measures, were more direct in how they were working and less inclined to empower due to having to move at speed and change things quickly and so couldn't take the time to build capacity and relationships slowly even if this was their preferred style. In addition they may not have had the staff with the experience or skills to work at this point within a distributed leadership model. Twelve other heads $(1,2,3,5,8-14,17)$ worked in a far more collegiate way with staff but they had an embedded system of practice built up over time and the experience to do so. Three heads $(4,6,7)$ were more in command and in control of how to implement policy even if they are not aware of being so. Ht 4 gave opportunities to his maths leader but when she wanted to take decisions of which he disapproved he 'had to rein her in'. These actions could be construed as a mirror of the attitude of the government seen as 'you can have any vision you like so long as it fits ours' (Glatter, 2006, p.71). Taking into account context and contingent leadership I believe that because heads are so personally and publicly accountable with their name on the front of the inspection report $(12,13)$, are reasons why heads are unlikely to relinquish any real control of their leadership.

\section{Leadership styles, system leadership and control}

Changes in leadership style depended on the extent of power, control and influence associated with the role. Consultant leader roles afforded the headteacher less direct control than experienced by executive headteachers. Apart from the individual inclinations and personalities of the heads which are outside the scope of this research, the role they played determined the leadership style and practice of system leaders.

My findings are in line with Simkins (2005) who sees difficulties arising with the need to work across agencies or inter-school collaboratives and that this calls for a different way of working. I would agree with this particularly for circumstances relating to 'client led consultancy' as advocated by NCSL and used for much of the work of CLs where a collegiate style is appropriate. Consultancy across schools where system leaders needed to operate through influence called for sensitive handling. Influence is 'intentional' (Yukl, 2002) in this sense, as it is exerted over others and generated in the form of relationships or expertise. Simkins (2005) suggests that collaboration and the use of co-operation will be more necessary than 
the use of formal hierarchical power in the future of leadership in this way and my findings would agree within the limitations of the consultancy outlined above.

It is a complicated picture however and many heads were practising 'contingent leadership' (Leithwood et al. 1999a; Leithwood et al. 1999b) and applying different styles of leadership in different circumstances. Many of these heads undertook a combination of roles and it was in their recent experience to have been consultant leaders and temporarily seconded heads. Collegiality is less likely to be successful in the circumstances where change needs to be directed by the system leaders such as those identified above where the system leader is the head in a failing situation and needs to act quickly. So Ht 21 for example had to think of ways of leading his school more directly to accommodate issues in his client school in special measures that he 'hadn't had to resort to as the leader of an outstanding school.'

Control over the direction of schools was more likely if it was formal and long term such as that of a federation or secondment rather than the short term nature of consultant leadership. If the role of the system leader was directly between the schools brokered by the LA then this gave the heads a degree of transferred authority from the LA and so autonomy and power to act. This role took the form of leadership to counter 'educational failure' (Chapman et al. 2008) through secondment for an agreed number of days, or through the NLE initiative. In these circumstances system leaders will have had overall control because there was no internal acting headteacher. This autonomy as a head on the one hand is countered on the other by the likelihood that as executive leaders or NLEs they are working in circumstances where Ofsted or the LA has 'generated an agenda for change in the school' (Harris et al. 2006, p.405). This was illustrated by Ht 16 who commented that HMI had stated 'We get you out of special measures'.

With the presence of an acting headteacher in the client school $(14,17)$ heads had slightly less control but the understanding given by the LAs was always that the final decision rested with the system leader but the authority of that was less overtly expressed. In some circumstances there was or had been in the heads recent experience, a form of shared secondment with another external head $(8,13,14,17)$ and this was seen to be a genuine form of shared leadership with roles clearly defined between them as identified by Hts 8 and 13 . 
The highest level of control and influence lay in those who were heads of federations some of whom were also NLEs and it was anticipated that they would be in the role of headteacher for a long, often indefinite period of time. These heads saw the schools they took over as executive head as an extension of their base school.

\section{Leadership practice and system leadership}

West Burnham (2007, p.6) has described the situation of 'super management' where 'the system works very well, rather than questioning the nature of the system.' To investigate the extent to which this was taking place in my research I wanted to find out if new roles for heads were encouraging new ways of working. I wanted to discover if heads were operating different leadership styles and practices, or were using traditional hierarchies in their base schools and across schools.

Chapman et al. (2008) found that radical solutions to problems such as securing the headship of more than one school did not in itself lead to innovative working and that leadership and management practices were often traditional and hierarchical and depended both on local context and the individual influence and style of the headteacher. My research agrees with (Chapman et al. 2008) in that similar roles such as deputy heads and assistant heads were used in base and client schools. However some of their job roles if not titles were different especially those created across schools.

Examples of how roles changed:

- A deputy with responsibility across schools as well as a lead learner in each which created another tier of management (19).

- A chosen future successor acting as an apprentice and 'practising' the job particularly in the absence of the head (21).

- The use of a specially created administrative post for an expert to lead on facilities and financial planning across the schools (20).

- The use of the deputy/assistant head 'acting up' in the absence of the headteacher for part of the week either formally or informally $(5,8,13,14,16$, 17). 
A conclusion is that more radical solutions are dependent on role and time. Where heads had more direct control and over a longer period of time such as in executive headship, there was more scope for changes in leadership practices. My findings also offer further support to the crucial importance of context (Chapman et al. 2008) in that traditional management practices and strong hierarchical leadership were more likely in those involving system leaders working in schools perceived as 'failing'. This is because the management of rapid change and strong leadership was perceived to be more likely to produce results quickly.

In addition I sought to discover whether heads were finding new and innovative ways of working or bolting on the existing leadership style and practice of their own school on to that of the client school. There was a mixed picture which supported the views of Steve Munby who suggested that it depended on the organisation, adding:

'However what they [executive headteachers] don't do or shouldn't do is think that every school has to be the same. Most of the chief executives I know - not all but most-don't run it as though every school has to be the same. They understand the culture and context of that school and adapt the leadership as appropriate to that school which may be different from the other school.'(Munby, 2007, interview with the writer).

My findings show a tendency for the heads in executive headteacher positions to treat the schools they work with as branches of one organisation. They did so to enable the client schools to operate under the same circumstances of 'entitlement' as the base schools. Examples to illustrate this are from Hts 20 and 21. In 2006 at a regional meeting for NLEs and the LAs a headteacher referred to the schools in which she was executive head as 'school 1 and school 2' and that she treated them both the same. However in contrast heads also differentiated for the needs of the client school. A typical example was when Ht 19 described how she might offer ' $a$ watered down version' of an initiative for the client school but in contrast when staff in the client school showed particular skill, she also used them in training others. Consequently I conclude that this is further evidence in common with Leithwood et al. (1999a) and Leithwood et al. (1999b) of heads acting contingently upon circumstances. 
The definition of the role of head is changing and what heads do to facilitate it is changing, but this isn't the same as their style of leadership changing. There is little real change to leadership and management structures with, if anything, increased use of distributed leadership bringing more trust but I feel this is superficial as it also brings more monitoring and audit of practice. So what they do in terms of distributing leadership is still heavily constrained within the need to monitor what happens and so in some ways the accountability systems within school have been strengthened.

The ability to manage change

A 'restlessness with the present' and ability to manage change is seen as key to being a successful strategic and transformative leader (Davies and Davies, 2004, p.34). Such leaders are required because they can adapt their behaviour according to need and effect change on the ground (Caldwell, 2006b; Hopkins, 2006, 2007; Hopkins and Higham, 2007).

The system has been successful in establishing the type of change it wants through the promotion and take up by heads of system leadership and leadership of children's centres and the implementation of workforce reform. Bottery and Wright (2000) argued that teachers were more concerned with problems created by the speed of implementation of policy or lack of consultation regarding its implementation rather than a disagreement with the nature of legislation itself. My findings suggest a mixed picture depending on the nature of the reform and the extent to which the heads can manage it or agreed with it. There is evidence in my research that while there were certainly issues which caused them work overload and stress, such as the speed of several important areas of implementation in $2005^{2}$, heads' level of concern however, seems to have diminished after this period as they were pragmatic in using the opportunities within the agenda such as employing more support staff to manage their roles (Frean, 2008). Either that or they were prepared to accept the legislation because it was for something they believed in such as ECM.

Unlike the findings of Southworth (1995a) which indicated the difficulty heads had with managing change my research indicates that for these types of head at least, the

\footnotetext{
${ }^{2}$ The introduction of the ' 5 outcomes' of ECM into the curriculum, the new expectation that schools would complete a SEF including the effectiveness of these outcomes, and the requirement to remodel the workforce all needed to be managed simultaneously from September 2005.
} 
problem of managing change was less, although not the pressure to perform. This was if anything strengthened by the New Relationship with Schools (DfES/Ofsted, 2004).

Heads actively seeking or at least not fighting the imposition of many of their new roles would indicate that they were not looking to reduce what they were doing. I think there were five reasons for this:

- Their experience, style and characteristics as headteachers allowed them to sift and prioritise what was best for their schools and their leadership without being 'diverted' by other policy agendas (20).

- There was more opportunity to shape their roles as they wished due to the increased flexibility in the system (Chapman et al. 2008) coupled with the fact that at times they were working in circumstances the system had not yet micro-managed.

- They recognised that new roles could be beneficial. In common with Earley and Weindling (2006) they took advantage of opportunities as professional development both to give something back to the profession and to enhance their expertise as heads.

- They took the opportunity through workforce reform and the precedent it set for shaping staffing to suit the needs of the school to create the workforce which suited the direction of the head and schools best.

- They distributed leadership with greater autonomy and responsibility and trusted staff more. However in trusting them more there was identification of a corresponding need for tighter strategic level monitoring, as far from being uncontrolled, distributed leadership and self-driven initiatives were set within the boundaries of a highly controlled surveillance system of comparison by results and league tables (Ball, 2003).

The opportunity to act as heads gauge what is of most benefit in a given situation is essential to enable them to manage in a period of rapid change. A degree of autonomy allowed the heads the freedom to display characteristics necessary to lead and the 
freedom to do so. The ability to manage change corresponds with an ability to prioritise (Maguire et al. 2006) according to the school's identification of its needs and the courage to do so.

\section{Courage to prioritise}

In common with Southworth's (2008, p.422) argument heads in my research were juggling tensions in the agendas such as inclusion and the 'breadth' of the ECM agenda and the accountability for standards. In addition they needed to be able to sift and sort what to action and what to ignore. Heads were acting as agents of change (Clarke and Newman, 1997) in doing this and also in managing the agenda in ways not anticipated by the policy designers. This can either be by shaping it deliberately themselves to suit their circumstances as in workforce reform, or the policy as designed had unintended consequences in that it created tension in the agendas such as teaching to the test to raise 'standards' and the need to provide a creative and fluid curriculum.

Often these policy limitations were noted and rectified by government (Thomson, 2008) as they did with the weakening of prescription over the content and way that literacy and numeracy is taught. However unless heads have the confidence and courage to prioritise in the way outlined by $\mathrm{Ht} 3$, who had to convince her staff it was all right to deviate from the strategies or not get diverted by the agenda (20), the education of the children can be damaged in the time it takes for the government to catch up with its mistakes if heads and schools adhere strictly to what is prescribed.

There is a growing divide too between the understanding heads have of different roles and their requirements. Some leaders believed that heads should be 'at the school gate' $(4,7,11)$ but others saw a less visible role as acceptable and a price to pay for the future and one which wouldn't damage the schools. There was however a similarity in the way in which these heads viewed leadership in terms of accountability and the desire to seek new opportunities and how they managed change which transcended differences between them in terms of school context such as location and relative levels of deprivations, school size, rural or urban or working in different authorities. 


\section{Key finding 6: The effects of accountability have impacted strongly on the actions and reactions of headteachers with consequences for the future of system leadership}

\section{The importance of performance}

That heads are under pressure to perform, particularly in securing expected standards of performance of the children, and validation of their leadership through inspection, has been well documented in literature (Ball, 1999; 2001, 2003; Gronn, 2003; Elkins and Elliott, 2004; Webb, 2006; Bottery, 2004, 2007a).

This was manifested mostly through accountability to Ofsted, which has been seen to be highly valued as a form of validation of their leadership by headteachers (MacBeath, 2008) and supports the views of Ball (2003) that the power in the system is in the hands of the government and not the parents as consumers of education. It gives support to the success of the government in its desire for the profession to accept the need for accountability (DfEE, 1998a). My study showed that if inspection was successful it dealt with the accountability of the headteacher to stakeholders because they would be secure in the knowledge that the standards and performance of the school were at an expected or satisfactory level. The higher the level of success of the school and the head's performance, the more secure they were and the more autonomy they were likely to experience. Reaching the level of expectation, at whatever level that was, was crucially important to the level of pressure the heads felt under as I will illustrate shortly.

There has been an explosion in recent times in the monitoring and production of information about schools which they have had to produce and it is a phenomenon that was referred to by all the interviewees. This has led to 'cultures of performativity' (Troman et al. 2007, p.549) with the creation of league tables and performance assessments where schools manage their accountability by performing to ensure a favourable set of judgements by external assessors. They are rewarded or sanctioned by incentives and controls which can be 'material and symbolic' (Ball, 2003, p.216). An example of this is the likelihood of a 'light touch' inspection if the school performs well (Avis, 2003). This is an argument endorsed by other writers (Gronn, 2003; Broadfoot, 2001; Webb, 2006; Bottery 2007a). 
In common with the findings of Case et al. (2000) and Hoyle and Wallace (2007) all the heads in my research were aware of the need to display their school in the best light possible or indulged in 'impression management' (Webb, 2006) by preparing for inspection similarly compared to preparing for a 'wedding'(Woods et al. 1997). While shorter notice and data led inspections may have reduced the opportunities to 'fabricate' to use Ball's (2001) term, nevertheless SEFs as they 'shine a light' (7) on schools were carefully constructed using information remembering 'less is more' (12) and offering a small number of documents but ones which are most likely to offer the best picture of the school's success for inspection as a form of 'impression management' (Webb, 2006). However for many the self evaluation system still created fear and concern with six heads $(3,7,8,10,14,18)$ who felt that their data didn't set them up for success (see Chapter 5).

It might be supposed that headteachers would have some security in being validated as successful through inspection and that this need for performativity and the stress and intensification of work it caused would be less for this group. However my research has revealed a mixed picture in that there is still a strong pressure to perform for all the headteachers and a greater pressure identified by some of those in danger of losing high profile reputations as system leaders $(13,14,17,19,20)$.

Now I will turn to my findings regarding the effects of the relentless drive for standards, of the impact of accountability on the role of the heads and the level of stress induced by accountability.

\section{Accountability for 'standards'}

The issue of standards was identified as being relentless and permeated the actions of the heads in all they undertook. Decisions about curriculum, how to deploy staff and their own strategic role and new roles, were all taken with a consideration of their impact on standards in the school. Heads were consciously trying to make sense of the tensions and contradictions of the policy environment considered necessary for effective leadership (Simkins, 2005). Several writers have considered the difficulties teachers have with the constraints of the curriculum (Webb, 2005; Brehony, 2005), the dilemma for teachers of teaching to the test (Jupp, 2001; Hargreaves, 2003; 
Hartley, 2003) and the subsequent concern about the plateauing of standards (Hargreaves, 2003; Barber, 2001, 2002a, 2005; Hopkins, 2006).

My research is suggesting that there was a trade off between ensuring a curriculum which was creative but would also maximise test results for the school. Ten heads $(2$, $4,5,6,8,9,11,12,13,21)$ specifically articulated their fear of being too creative at the expense of maintaining standards. This was creating a dilemma in how to balance the best interests of the children's education and well being with maintaining standards and the reputations of themselves and their schools.

There was some praise from two heads $(2,15)$ and acknowledgement from several others for the role of the National Strategies in raising standards by providing a structure for teachers. However, in common with the views of Docking (2000); Whitty (2005) and Brehony (2005) this was simultaneously perceived as constraining by them $(2,15)$ due to the Strategies' interference with pedagogy. The structure was perceived as useful generally by the majority of heads more because it would give a guide for what Ofsted inspectors would expect to see, the content of the tests and on what to focus teaching, rather than for their intrinsic worth as curriculum structure.

Another dilemma was managing children's special educational needs along with the need to maintain standards. The importance of this to the research is evident in that 17 heads commented on it. Some of the issues were lack of funding for ECM and SEN initiatives (16) others the difficulty of ensuring 'social redress' (Bottery, 2007a) and standards $(5,7,8,9,14,16,17)$ and the issue of inclusion for children with behaviour difficulties $(4,6,10,11)$. These issues permeated different contexts and were neither solely a rural nor an urban problem or one purely for those in circumstances serving economic deprivation. None of the heads disagreed with the principle of including children with SEN but did wish to have a system of fair accountability so that the tensions in the agenda and the issues of funding were recognised.

\section{Accountability and the heads' role}

There was general agreement by heads that they should be 'held to account' (Leithwood et al. 1999a, Ranson, 2003) and that it was a 'good thing' (15). In making this judgement they had largely internalised the managerialist agenda which locates 
accountability in performance through outcomes rather than a more traditional bureau-professional form of accountability. They even went some way to joining in the 'discourse of derision' (Ball, 1990) against such forms of professionalism with the belief that the previous arrangements were too ad hoc and open to systemic problems of lack of consistency of practice across schools. Only one head (6) was against Ofsted in principle referring to heads who pursued a career with them as 'Judas' and that inspections created only fear and constrained the actions of headteachers. All the others saw the process as part of the general reduction over the years of the intrinsically motivated professional to one who was constrained by working to the accountability agenda but nevertheless inspection was seen as a necessary evil.

While accepting accountability through Ofsted as a given, heads departed from any general approval when considering the fairness of its application. The new relationship which was intended to offer, through 'intelligent accountability' (Hopkins, 2005, 2006, 2007), some earned autonomy for those heads who were successful (Hopkins and Higham, 2007) received a mixed reaction from the heads in my study. Thirteen heads $(4,5,7,8,10-13,15,18-21$ found the shorter time and tighter focus on standards had made preparation easier and caused less concern as they could prepare information for the inspections through self evaluation.

Throughout these interviews heads were discussing self evaluation in the same terms as self inspection and in doing so they were 'translating' the 'protocols' of Ofsted and using them as an 'audit' for pre inspection (MacBeath, 2008, p.138). This builds on earlier findings of self-evaluation models such as school development planning and audits being used to inform inspection (Troman, 1996). Ofsted had in its use of the SEF not only promoted, but in its expectation of receiving a SEF prior to inspection almost mandated, government policy. In preparing a SEF it was necessary to include information about particular areas under certain headings thus ensuring that if schools were to report on areas such as the 5 outcomes of ECM they would have to be implementing them in their schools. They were unable to pursue an external role as system leaders without a suitable Ofsted inspection. Therefore the government has ensured the consent of the profession to adhere to its requirements and in some instances (such as the inclusion of evaluation of pupil voice being part of the SEF) hasn't needed to implement government policy for heads to do so. 
All saw the increased need to be prepared for inspection through self evaluation and two of them $(15,4)$ positively welcomed the change and weren't concerned by the performativity associated with the need for constant readiness. This fulfils an aim of the new relationship to provide a 'simplified process' (DfES/Ofsted, 2004) for accountability through improvements in the knowledge and production of data. However they and others $(9,14,16,17)$ have agreed with the findings of Earley and Weindling (2006) where the short notice has meant a lack of security for heads in the time they can be absent as system leaders if an inspection is due. It could be claimed that if leadership is distributed and the systems in school are robust it doesn't matter if the head is in school or not for the inspection as would be the case in no notice inspections, suggested as part of a new framework for September 2009. While acknowledging the logic of this view, I feel it misses the point that heads feel they have an obligation to support their staff through the trauma of inspection as well as needing to keep an eye on proceedings. This is due to the personal responsibility of the headteacher (Hall and Southworth, 1997; Crawford, 2007) and their emotional attachment to the school (Crawford, 2003; 2007).

MacBeath (2008, p.139) identified headteachers' relationship with Ofsted as one which is 'replete with paradox' in that 'endorsement' by Ofsted was valued and sometimes their advice was used in school's management but that there was still a need to 'play the game' with them. My research supports MacBeath's (2008) but in my research 'playing the game' is used not just to secure the school but also to gain validation as leaders to pursue wider roles. For the majority of heads in my research stress over inspection was affected by the paradox of their gaining recognition. I found that heads may have resented Ofsted because of the way they were forced to comply with nationally mandated change, but they also needed it as a reference to enhance their careers.

\section{Data and assessment}

Elmore (2005) recognised the importance of school leaders building internal capacity in schools to offset the demands of accountability by situating themselves well to manage its demands. One of the most important ways they do that is to ensure the data sets the school up for success. Hence the increased sharpened focus on performance management and focus on school leadership to deliver pupil progress 
against measurable criteria (Husbands, 2001). The ability to read, assess and manipulate data is clearly a skill which became increasingly more important as the research progressed and a 'water tight tracking system' (14) to facilitate this was seen as crucial by the heads in both rounds but particularly in round 2 with headteachers subject to the New Relationship's increased reliance on data. Due to this factor and its place in inspection and in SIPs' evaluations, the accuracy of the system for analysing data at all levels becomes critical.

Whitty (2002) found heads wanted recognition from the government and the authorities for the unfair pressures on urban heads caused by the comparison between schools due to standards of performance and unrealistic expectations. The DfES (2005b, in Gorard, 2006) claimed that the value added scores were a means of taking into account prior attainment of pupils and therefore measuring progress of children from $\mathrm{KS} 1$ to $\mathrm{KS} 2$ rather than a reliance on raw attainment scores.

Unfortunately there is strong evidence to show that the system of comparing schools according to value-added criteria is flawed and the 'apparent precision' is misleading (Gorard, 2006, p.241). In an interview with the TES (Stewart, 2009, n.p) Gorard reiterated CVA as 'meaningless' as a measurement to compare schools. In the same interview Harvey Goldstein, who helped to devise CVA, "now felt it had little to offer as guides to school choice'. Despite advice from HMI to use data as a guide or indicator of performance (Bell, 2003) and that 'CVA must not be viewed in isolation' (DCSF, 2009 in Stewart, 2009) there is evidence from my research that inspectors are relying on the results of CVA and VA in making their judgements.

There was general acceptance of the unfairness of the previous inspection system based on attainment but while an acknowledgement that some form of value-added was fair and necessary and something 'inspectors can manage' (16) as a means of making judgements, it was not supported if it became the main means of judging a school as heads recognised that flaws due to the potential inaccuracy around gathering data for FSM and SEN and the potential misuse of confidence intervals is not accounted for. This puts pressure on the system for those who inspect schools to have a deep understanding of the issues. However heads generally had little belief that those who inspected them had this understanding. The relationship SIPs would experience as part of the accountability system with Ofsted was unknown but 
speculated upon by five heads $(1,5,7,17,18)$. As so much potential power rests with an individual there was considerable apprehension about the future of the relationship and the accountability of heads. The fact that heads may be SIPs was no comfort to the interviewees who still saw them as a means of accountability and questioned their skills as well as those who had taken other routes to being a SIP in common with Chowcat (2008).

The perceived unfairness of the accuracy of marking identified by several heads reached a height in 2008 with the marking debacle which culminated in the sacking of the company responsible for testing. However small pockets of perceived inaccuracy have been identified in this research and some heads sent their papers back in 2005 as they 'were so badly marked' (8). Nine heads $(2,6,7,8,9,11,12,14,17)$ commented on the importance of ensuring accuracy of the attainment of children in Year 2 and their progress in Year 6 as identified by the SATs. Heads resented that they had to show the progress of their schools at the end of Year 6 compared with a time when the 'goal posts were different' (11) in Year 2. They highlighted that they needed to take 'brave' (12) action to rectify the problems created not by them but an imperfect system which reacted with little discretion and was predicated more on the luck of the draw with inspectors' (8) than on being well designed as a system of accountability.

\section{$\underline{\text { Stress and inspection }}$}

Inspections have been judged in the literature to have been stressful for schools since they were introduced in 1992 (Woods et al. 1997). Accountability for standards and managing their school as 'good' to 'outstanding' (Ofsted categorisation 2005) were issues common to all in the sample. However there was a differentiation of pressure caused by the likelihood of inspection ranging from being ' $g u n g$ ho for it' (20) to finding preparing for known expectations 'reassuring' (15) through to the fear of it as a constant and 'absent presence' (Troman, 1996) or 'shadow' (10) and one head (4) who purported not to care although this wasn't borne out in his preparations for it which contrasted with this assertion.

While there was some recognition that shorter inspections as identified by Hopkins (2007) were better due to the length and the lessening of pressure on $\operatorname{staff}(7,9,17)$ nevertheless there was pressure for the heads because of their personal responsibility 
(Crawford, 2003, 2005, 2007) for their schools and for managing a successful inspection and the need to be focused and accurate in proving themselves in one day (18).

Differentiation in the levels of stress this pressure caused were mainly related to feelings of helplessness over being held to account by a flawed system which could generate the 'panic' $(6)$ of a 'dip in performance' $(14,18)$ causing one head to be 'worried to death' about the prospect of being found 'satisfactory' (3). This problem was compounded by the public nature of inspection and the unfairness of the publication of their names $(12,13)$ especially for seven of the eight heads $(13-17,19$, 21) working as recently appointed substantive heads or system leaders in schools in special measures or who had just been removed from it.

\section{Workload and stress}

Work intensification over the last twenty years due to the 'frenzy' of legislation and bureaucracy (Tomlinson, 2001) has been identified as a cause of stress for headteachers (Cooper and Kelly, 1993; Southworth, 1995b; Webb, 1999a; Chaplin, 2001; Webb and Vulliamy, 2006). This remains the case for many of the heads with one of them identifying it having increased 100\% since her headship in 1996 (9) with the subsequent worry that no matter how hard she worked she would never quite be good enough. Coupled with the bureaucracy associated with multiple initiatives (5) this meant that heads felt torn by their multiple roles and accountabilities echoing the views of Leithwood (2001).

Heads in my research generally had high levels of personal control which allowed them to cope. Chaplin (2001, p.203) points to personal control being a 'double-edged sword' in that it could lead to people 'feeling they are responsible for everything which can lead to overwork, exhaustion and depression' and there are similarities with my research. For example Ht 13 when working in two schools and setting up a children's centre in her base school or Ht 19 when first federating two schools. However this is short-lived and a key feature of these heads is their ability to handle pressure and change. Stress was something which was seen to lessen as an issue identified by the heads from 2006 with the impact of workforce reform (see key finding 4) and the opportunity to afford more administrative support. However my 
research complements the findings of Chaplin (2001) in that this opportunity was dependent on the size of schools and the link this had on budget and opportunity to afford the staff to alleviate the workload of the head.

Chaplin (2001, p.202) claimed that 'the level of stress experienced by an individual is often viewed in terms of task demands that tax or exceed an individual's selfperceived capability to manage them.' However heads who have a high level of personal or professional self worth are therefore less likely to give up with stressful tasks and obstructions than someone who hasn't. All the heads in my research while suffering stress at times still had a high enough degree of professional self-efficacy to be able to cope with stress. They were able to pay the price of higher stress levels and did not allow this to deflect them from pursuing the roles they wished. It is also important to note that heads in this research are distinctive by being effective and by experience and not necessarily indicative of all headteachers and this helped them to see the 'routes through' (20) to successful management of change.

\section{The drug of leadership}

Gronn (2003) noted that school leaders became addicted to the job and found it all consuming. In addition to this I found that the heads were often overwhelmed by the intensity of their work but nevertheless they were choosing to find more intensified work and more challenging system leadership roles. There was a continuum of levels of stress with some heads who enjoyed working with high levels of pressure and needed the buzz (with Hts 4, 13, 16, 19, 20 most notably at the extreme end of this continuum) and who enjoyed a sense of achievement in succeeding against the odds (Maden and Hillman, 1996 in Maguire et al. 2006). Ht 15, 16, 17 and 20 described the 'excitement' of being in special measures which $\mathrm{Ht} 20$ felt 'suited her well'. Another head actively sought to work outside his 'comfort zone' (21). These findings would concur with Lazurus (1966 in Chaplin, 2001) where one aspect of stress was identified as a 'motivator.' I also found that stress depended on experience and success as well as personal management of stress. The heads who professed to manage stress easily and enjoyed it were experienced heads and had enjoyed success as system leaders and openly pursued challenges and thrived on 'making an impact' (Maguire et al. 2006). 
All heads were driven but for some there was a level of distress caused by overwork which engendered feelings of helplessness and fear over 'seemingly inescapable demands' (Chaplin, 2001, p.200) particularly for Hts 7 and 9. However this degree of stress over work intensification contrasts with Chaplin (2001) for most heads in my research in that the need for management of competing demands had lessened for them in their schools due to workforce reform. Where heads' stress levels over work had increased was when it was caused by the work involved with system leadership $(8,13,14,17,19,21)$.

Leadership has been described as 'greedy work' and a 'treadmill' (Gronn 2003). However I would extend this to suggest leadership is addictive and acts like a drug on its dependents who suffer from this addiction with the consequences of needing to be constantly performing but can't manage without the 'buzz' it brings.

Implications of my findings for the government on the impact of accountability on heads

Fullan (2005) believes that for sustainability to work there has to be a continual loop where each part of the system comes together to solve problems which keep arising. To accomplish this, the system needs to 'drive out' the fear of failure, so that mistakes honestly made can be rectified openly and that all levels in the system learn together from experience. However, the findings from my research indicate that while the system of accountability through inspection is so rigidly enforced in practice, whatever the rhetoric of government, fear, far from being driven out, is actually enhanced for many heads under a greater degree of stress to perform to maintain their reputation. One consequence of their failure to perform could potentially mean that there will be fewer opportunities for extensions to their role being presented to heads with implications for the system of a lack of leadership capacity to manage the problems which system leadership and extended schools are expected to alleviate.

Hopkins and Higham (2007, p.151) identified a tension in the system in the need to reconcile increased calls for collaboration between schools with the individual focus of accountability on schools. This may be the tension between accountability and collaboration as part of the marketisation and parental choice agenda. However I think there is another tension around accountability and system leadership in the lack of 
'joined up' thinking across the system. An example of the government's fragmented approach to policy can be identified from the concern raised by Hts 19 and 21 that instead of experiencing a single inspection for a federation, they will find themselves subject to inspections close together in both schools and until September 2008 there were separate child care inspections to the school's inspection. In addition it would seem that the system isn't sensitive enough to be able to make judgements about the leadership of heads across schools and one head involved (19) reported that inspectors had no understanding of or interest in her system leadership only in how it impacted on her role in the school under inspection at any given time.

Thus the 'shadow' of inspection looms constantly and in different contexts. Ofsted (1999) commented that working out of school could be seen to bring benefits to both the base and client schools. However this is not well publicised and the heads in my study were unaware of Ofsted's commitment to any form of system leadership and indeed felt their only consideration was how well 'standards' were maintained. I would extend the tensions around accountability in the elaborate compliance and fabrication some heads have to undertake to balance the role of system leader and maintain the high quality reports for their school. An 'outstanding' Ofsted grading for leadership for example is a prerequisite to be an NLE. In addition my research shows that these tensions and the emphasis on 'standards' in inspection are damaging the system they are meant to improve.

\section{The effectiveness of 'The New Relationship'}

Hopkins and Higham (2007, pp.160-161) speculate that an 'authentic commitment' by government to system leadership might 'mean a rebalancing of roles, agency and control between schools and the government.' The government could be seen to have gone some way to achieving this by granting 'effective' heads a degree of 'earned autonomy' (Morris, 2001) through external forms of validation such as the New Relationship with Schools (DfES/Ofsted 2004). 'Intelligent accountability' is promoting the notion of flexibility for schools deemed to be highly effective which together with sharper interventions for unsatisfactory schools, is viewed by Hopkins and Higham (2007, p.161) as bringing some necessary 'evolution' to accountability. 
My research indicates that the success of this is mixed. There is some freedom to lead in the system regarding how to implement policy but in addition to this the need to perform to secure a good inspection and the performance needed to do so isn't seen to be a fair and equitable system by the heads I interviewed. The effectiveness of the new relationship in determining those suitable for system leadership is diminished as there is some disquiet over its reliance on data to judge schools.

An example of unintelligent use of accountability can be cited with reference to schools which were deemed to be outstanding by Ofsted due to the high levels of CVA achieved but considered to be failing by the DCSF because they were attaining below the targets for passes at GCSE for A-Cs. This lack of reconciliation between the various elements in the system is bound to cause tensions in the form of unintended consequences (Levin, 2003a). The consequences of this for the system are that in only choosing 'outstanding' heads to be NLEs or in relying on the findings of Ofsted to provide the information for other forms of leadership is not necessarily going to ensure the 'right' heads or 'Level 5 leaders' (Collins, 2001 in Fullan, 2005) or 'master strategists' (Caldwell, 2006b) are chosen. The importance of attracting Level 5 leaders is due to the centrality of the headteacher in the system. They are the ones who the government is relying on to manage the mess on the ground (Hopkins and Higham, 2007) and so they need to be carefully and accurately chosen and assessed. One way of doing so is to rely on inspection results for schools and the performance of the children in tests. However if the system of data is flawed due to inaccuracies in the marking as widely shown by the SATs marking debacle of 2008 , and the anecdotal complaints of heads previously $(8,9)$ then this is an unstable foundation on which to build.

Hopkins and Higham (2007) build on a question posed by Fullan (2005) and Hopkins (2007) as to whether the New Relationship will be able to do enough to ensure that system leaders achieve the agency necessary for sustainable system reform. My research indicates that the fear of Hopkins and Higham (2007, p.161) that 'the Government's tendency to check and control does not seem to [have] significantly diminish[ed]' is indeed occurring. Those who have been granted earned autonomy are able to contribute to school improvement across schools by collaboration but I would suggest that those currently restrained by an inaccurately directed accountability system may also be able to contribute given the space and motivation. 
For this reason I would question the concept that there exists 'an enabling state' as identified by Hopkins and Higham $(2007$, p.162) as necessary to the effectiveness of system leadership. I would argue instead that barriers to collaboration are being imposed due to the insistence of the government on micro-managing the system and therefore on not sufficiently creating the space and climate for collaboration to flourish.

\section{Key finding7: There is evidence of earned autonomy and heads implementing government policy with a mixed picture of compliance, mediation and subversion}

\section{Whose vision?}

The vision and direction of the school was found by MacBeath (2008) in his research exploring 12 headteachers' responses to the policy environment to rest largely with the head and senior team and in terms of making the vision explicit my findings confirm this. The extent to which the direction of the schools was a product of the heads' own vision or that of the government is debatable and varied in my study in range and extent.

It was the intention of the government to offer a degree of earned autonomy to some heads (Morris, 2001) and in doing so to free them to make changes on the ground (Hopkins and Higham, 2007). However is that true? Can autonomy operate if the choices over which it is exercised are limited by government policy? West Burnham $(2007$, p.7) argues that future leadership should be 'focused on the school and its community, not implementing externally generated policy.' A complicating factor with the desirability of heads not blindly implementing government policy is the extent to which they have internalised the need for it. They may support policy not because of pragmatism but because the government has been successful in winning hearts and minds (Clarke and Newman, 1997). An example of this is those heads in my research that actively supported the need for heads to be held accountable through inspection for the performance of their schools $(4,15,18)$ or believe in the setting of targets for children's test performance for staff because it is 'for the children' (13). 
MacBeath (2008, p.141) argued that 'By virtue of their office heads have the freedom to decide, or impose, ways of working.' However this is a bounded freedom because it is also acknowledged that there are constraints that heads have been found to be under in managing centrally imposed practice (Hargreaves, 2003; Fullan, 2005; Webb, 2005; Webb and Vulliamy, 2006; Bottery, 2007a; Bush, 2008; MacBeath, 2008). Bush (2008, p.284 original emphasis) argues that 'School leaders and managers are able to choose how to carry out a new policy but not whether to do so.' My research suggests that heads could determine how to implement policy and also to a limited extent whether to do so and agrees with Bottery (2007a, p.158) that it is possible that heads will:

'find ways of subverting them [policies] or avoiding full implementation.' and particularly if they are 'surrounded by others sympathetic to their aims...'

\section{Earning autonomy by acting tactically}

It has been argued that a tension for the government was that the freedom for school leaders to lead creatively and transformationally was being restricted by 'undue emphasis on outcomes' (Davis, 2002, p.199). My research indicates that the extent to which heads could determine either how or whether to implement policy was precisely because of their success with government led outcomes and their securing a high performance for their school. This determined their validation as school leaders as in turn it led to outstanding Ofsted judgements and the freedom or earned autonomy this gave them to lead.

I would argue that the element of risk is higher for the heads in this study due to the importance of their reputations for their new and extended roles. The fall from grace through failure in Ofsted would be further, more public, and affect their ability to choose external roles. It is therefore essential that heads know which position to take when relating to government policy (MacBeath, 2008) and therefore to act tactically (Thomson, 2008). Examples of them doing so can be supported by comments such as 'we all know how to play the game' (8) over presentation for Ofsted or failing to adapt in a prescriptive manner to the National Strategies but doing enough and adapting them to escape censure, particularly as they were successful in doing so (12). 
Notwithstanding the stress caused by the pressure to perform to maintain their reputations, heads in my research were in a good position with a degree of 'conditional trust' (Avis, 2003) and independence (Elkins and Elliott, 2004) granted by the system to manage their schools by prioritising and making decisions which they believed would best fit their circumstances (McEwen, 2000; Day et al. 2000, Elkins and Elliott, 2004). While acknowledging the idea that they were being granted earned autonomy nevertheless heads were concerned about the 'fragility' of this autonomy (8), due to its dependence on their performance and that of their schools. They believed it to be a ' $m y t h$ ' because of the constraints of government policy (12), or that it was dependent on the vagaries of the governing body (3) and that most heads hadn't any faith in the reasons behind' (7) their being granted autonomy as being for anything other than achieving the required results at Ofsted and complying with government policy.

I wanted to discover the extent to which the heads were able to shape the vision of their schools independently of externally mandated policy and the extent to which they were constrained by it and reacting to it as suggested by Ball (1990). This question suggested the following options:

- The heads were acting independently and choosing whether to implement policy and know this as a form of resistance.

- They were acting as they thought independently but were actually only working within the parameters of government policy and tinkering around the edges of reform.

- They were aware that they were highly constrained but didn't fight it because of fear and were compliant or 'disturbed conformists' (Woods et al. 1997).

- They were strategically compliant (Moore et al. 2002) and implementing the national agenda in order to locate for themselves and their school a degree of earned autonomy.

\section{Compliance, Mediation and Resistance}


Bottery (2007a, p.160 original emphasis) noted that if a 'culture of compliance' exists then to alter it the government will have to 'change a culture of conformity which it has created.' To some extent the government has tried to do so with the urging of schools to be creative and to use the Strategies as a guidance and not as prescription for practice (DfES, 2003b) and in the work currently being undertaken to review the national curriculum by QCA (The Rose review - forthcoming, 2009). However my research is showing the limitations of this new 'freedom' to lead because heads are undertaking changes they wish to make while strongly aware of the need to "play the game' for Ofsted and keep their school safe with acts of 'simulated compliance' (Thomson, 2008) or 'irony of practice' (Hoyle and Wallace, 2007).

In addition to this I found that if heads were even fully aware of the main agenda for change they accepted it as a given to be implemented. They might query some aspects of how to do so, such as the content of the National Strategies and many saw the problems as the fault of previous government policy regarding attitudes to schools (12) or poor implementation of workforce reform in 2000 (6), and they may adapt it such as workforce reform and new roles for staff $(19,20)$, but none questioned the arguments behind the agenda such as the need for succession planning. In this they followed the findings of Bottery (1998) in that:

'teachers exhibited a dangerous mixture of overwork and lack of interest towards the wider picture as to why these changes had come about, and what should be their role with respect to them' (Bottery, 1998 cited in Bottery and Wright, 2000, p.481).

There are concepts which seek to identify the reasoning behind the decisions heads have to make and their actions and reactions to policy which I have outlined in the literature review. Two that I have found have resonance with my findings are those of Hoyle and Wallace (2007) who distinguish between 'ironies of adaptation' to describe how heads work around policy and expectations contingent upon their circumstances and 'ironies of representation' to describe how heads represent their work to government agencies, and principally for my findings, to Ofsted.

\section{Ironies of adaptation}

The heads in my research want to be independent and empowered themselves as well as to empower others to take the action as a form of 'innovative mediation' (Osborn et 
al. 2000, in Hoyle and Wallace, 2007) which meant going further than government policy required and to take action which was in 'the best interests of their school' $(\mathrm{Ht}$ 21; Day et al. 2000) such as organising the curriculum to maximise creativity and discovery in learning (12) and not teaching to the test, but to 'teach better' (Hargreaves, 2003). In doing this the heads in my sample are acting from a position of 'principled pragmatism' (Moore et al. 2002) and are using externally mandated change to various extents for the benefit of their organisation and mediating the agenda in balancing internal values and vision and external demands (Preedy et al. 2003).

It is difficult to find a pattern of response in that heads weren't consistent in whether or not they complied with policy as a general rule. Heads' actions were contingent on their own circumstances and those of their schools (Leithwood et al. 1999a; Leithwood et al. 1999b; Leithwood et al. 2006a; 2006b) and their reactions dependent on which aspect of policy or expectations they were reacting to and in this were showing a range of responses within compliance identified by Woods et al. (1997) as ranging from 'supporting' through 'surviving' to 'disturbed conformists'. They supported some policies such as those for ECM, but usually mediated and adapted policy in that they are not necessarily following highly prescriptive packages such as aspects of the National Strategies in the curriculum, or the guidelines of QCA (12). While Ht 12 had gone 'back to using the National Curriculum' tailored in some ways to her context in respect of the content, it was not changed to the extent she couldn't justify it to Ofsted or her governors. Therefore the actions of $\mathrm{Ht} 12$ were not really a 'risk' as identified by MacBeath (2008) in terms of non compliance with government policy.

Another example of adaptation was the issue of workforce reform as heads were reactive in that they 'went through the motions' and did what was necessary by December 2005 (19). However in keeping with other colleagues $(2,5,8,9,12-21) \mathrm{Ht}$ 19 quickly became pragmatic over its use to her advantage by continually changing the structure as she saw fitted the needs of her schools' changing circumstances. Another aspect of the successful management of workforce reform is performance management. Heads enacted it because they had to (18) but found ways of doing it which celebrated the work of the school staff $(12,15,16$,). In doing so they are balancing the needs of the staff and those of the organisation (Garrett, 1997) and 
deciding 'how' to implement change but not 'whether' to do so (Bush, 2008, original emphasis).

When the response of the heads could be 'mediation' (Hoyle and Wallace, 2007, original emphasis) and they could adapt statutory policy such as testing in the best interests of their children they did. This way of protecting children from the damage occurring through policy is a form of 'protective mediation' (Osborn et al. 2000 in Hoyle and Wallace, 2007). However heads became 'disturbed conformists' (Woods et al. 1997) when they were constrained by teaching to the test to protect their school but which then led to mediation to accommodate testing at Yr 2 to survive in Year 6 and to be sure of showing expected progress.

\section{Ironies of representation}

The heads' response to inspection can be regarded as an 'irony of representation' in that they ensured that what they presented to inspectors through self-evaluation was likely to highlight their best practice. When the system of accountability through self evaluation made this difficult in 'setting up data to fail them' (3) it caused frustration, a sense of deprofessionalisation and ensured they sought to minimise the risks to their school.

The government benchmarks schools using their own evaluation against national norms identified in the school's SEF. In doing this the government has reduced the opportunity for heads to use 'simulation' (Thomson, 2008) and manage the inspection agenda. In making heads self evaluate against the criteria they may have to admit to a degree of failure to reach VA targets. If they don't admit this then Ofsted inspectors will potentially fail their leadership by assuming that the schools had failed to recognise lack of achievement and so doesn't have the capacity to improve which is worse than failing to achieve the targets. In plugging this policy gap the government has adjusted its policy to account for its limitations (Thomson, 2008). By putting pressure on schools to self-evaluate and potentially fail themselves the government has arguably caused more reason for 'fabrication' (Ball 2001, 2003) and irony of representation (Hoyle and Wallace, 2007) than in the previous inspection system. They have simultaneously made it more difficult to fabricate as data is now more accurate and there is less scope for 'impression management' (Webb, 2006). 
In addition to this, headteachers' reactions to policy were differently affected by the same agenda. Some heads such as 5, 19 and 20 were all in favour of valued-added because it suited their circumstances and they intentionally promoted the consequences of it to external assessors. In contrast, others, such as 3 and 7-10, weren't in favour because they had to manage an agenda which was mandatory but which didn't suit them as they worried that their data set them up to fail.

That heads feel personal responsibility (Hall and Southworth 1997; Crawford, 2003, $2005,2007)$ is important and to some extent determines their stress and levels of fabrication. In some circumstances heads had been seconded or had been appointed substantively to schools which were in 'failing' $(15,16)$ circumstances. However as the current level of attainment was the responsibility of the school before they arrived, they didn't feel the need to indulge in 'ironies of representation' to make the school look as though it was performing better than it was. The lower the baseline of attainment they took over the more progress they could show. There was no evidence of an irony of representation to make the school look worse than it was in terms of attainment merely that the potential was there.

Nine heads $(2,6,7,8,9,11,12,14,17)$ described how the testing system at Yr 2 was referenced under criteria incompatible with that in $\operatorname{Yr} 6$ and so comparisons were flawed. They were undertaking 'ironies of representation' (Hoyle and Wallace, 2007) to ensure that what they saw as an accurate picture was presented both to Ofsted and the wider world. This deviance was an act of 'principled infidelity' (Hoyle and Wallace, 2007) which was deemed acceptable both as an act of survival and also because heads felt they were representing the truth in the only way they could.

\section{Overt Resistance}

However heads in all cases whatever their opinion of the agenda managed it in the interests of their school (Day et al. 2000) and in line with the heads in Bottery's (2007b) research were pragmatic rather than revolting against policy by refusing to comply for example by not sending data for collection or testing children. However potentially there were occasions and particularly if it was against her philosophy when one head commented that she would make a stand: 
'And if I have to risk professional embarrassment, or apparently public humiliation then I will because it's no further... I am not prepared to take certain routes. '(3)

Roche (1999, in Hoyle and Wallace, 2007) described four strategies to cope with such dilemmas including the moral stand identified above by Ht 3 . It could be argued that while exhorted to act with moral purpose to pursue their roles with principle that heads would be more subversive and overtly resistant. In my research only this head suggested she would act as overtly as this if necessary and this is exceptional. Mostly heads preserved themselves and their schools but reluctantly and with some resentment especially with testing (5).

\section{Simultaneous compliance and resistance}

To some extent their response to legislation has restricted heads' actions (McEwen 2000; Day et al. 2000) as heads were sometimes reactive and not proactive towards policy (Ball, 1990) but the findings of my research are more complicated than can be categorised by reverting to strategies encapsulated in an either/or definition of being proactive or reactive. They tried to create the context for learning and pedagogy (12) and to locate a space for themselves by being strategically pragmatic (Moore et al. 2002). They operate a form of 'strategic opportunism' (Davies and Davies, 2004) to respond to new opportunities which enabled them as much as possible to be true to what they would see as their core purpose and to act with some independence where their compliance to the agenda had granted them success and some autonomy. In this they are operating with a degree of simultaneous compliance and resistance.

All those with executive headship experience either federated heads $(19,20,21)$ or those who had worked in a loose, short term coupling $(5,7,8,13,16,14,17)$ agreed with the notion that they could be 'overtly defiant' (Bottery, 2007a) in some circumstances and not be 'diverted' (20) by staffing issues for example. They managed the agenda strategically as they knew their position gave them power. One head described working without 'interference' in that she informed governors 'after the event' due to the speed with which the agenda of the school needed to be implemented (19). Another (13) that she had the freedom to introduce programmes and initiatives as she thought fit in her client school 'unhindered' (13). One example of this was how they structured their team. It was not part of the general conditions of 
teachers' service to be employed across schools but because it was deemed as necessary a way around this was found by the heads and their governors. This evidence indicates that it was not a question of heads either complying or not but that they both resist and comply often simultaneously (Thomson, 2008).

My research indicates that the factor most determining the heads' ability to be resistant was their power and autonomy in the system granted because they were working in an unknown field which the government had not as yet micro-managed. The more scope the heads had to do so due to their powerful position the more independent and resistant they were. Heads were recognising and taking opportunities and being proactive with managing government policy as much as possible and mediating and resisting when necessary.

Heads are the determinants of where they go providing others agree, but they do not have to undertake roles they do not wish to, with the possible exception of hosting a children's centre on their site $(8,13)$. In turn they decide how to manage the need to sustain or build capacity in their own schools. MacBeath $(2008$, p.145) comments that it is 'hard to reconcile' that 'powerfully influential heads' in their schools are not more willing to challenge 'external authorities'. I believe they don't challenge more for two reasons. Firstly, to challenge alone risks isolation from the group of heads who have earned autonomy, because there may be an inherent danger that the agencies that will employ them won't trust a maverick. Secondly, there is little impact of an individual challenging the inspection system and there is no powerful authority operating on the behalf of heads which is strong enough to intervene successfully on their behalf against approved government policies. NAHT and ASCL may offer advice on implementing policies and may disagree openly with government (for example over Sats and league tables at the end of KS2) but no head commented on any official union action taken on their behalf that had successfully changed the direction of government.

\section{Conclusion}

Elkins and Elliott (2004, p.17) posed the question as to whether earned autonomy would make teachers more 'responsible for managing their own compliance to state compliance or not.' Bottery (2004) argued that the government created a statutory 
agenda for securing the headteacher as an implementer of its reforms and my research would concur. It shows evidence to support the view that in creating the 'flexibility' in the system (Chapman et al. 2008) to facilitate the existence of a designer group of school leaders (Gronn, 2003) or 'system thinkers' (Fullan, 2003, 2005 ) thinking in the 'right way' system leadership is spreading best practice across the system.

The government has been successful in its aims in that earned autonomy has indeed given more opportunity for heads that have performed to acceptable standards to shape their schools deemed as necessary by (Hargreaves 2003) and to do so across the system. The proviso however is they pursue the aims as outlined by the system designers and so system leaders are acting as 'policy entrepreneurs' (Kingdon, 2003, in Gunter, 2008; Gunter and Forrester, 2008). My research would suggest that they were not consciously aware of this in most cases, and if they were, still believe that the principle of helping the children in the school down the road was one worth pursuing $(13,15,17)$.

It isn't however a straightforward picture of heads becoming merely a conduit or middleman for the transmission of knowledge (MacBeath, 2008 building on an argument by Giroux, 1992). If they were such, they wouldn't be experimenting with the curriculum (12) or mediating the agenda in the ways already outlined in this chapter and specific change at local and institutional level wouldn't take place. They are at the very least values led pragmatists.

An issue for the government is that if true collaboration thrives in an environment free of fear and collusion how is this possible when heads are involved in ironies of adaptation and representation (Hoyle and Wallace, 2007) over policy and Ofsted in particular? The implications of this for government policy are that its intentions are not borne out by reality in that it hasn't created the conditions for the heads to deal with the mess at the micro-school level (Hopkins and Higham, 2007) that they required, or to the extent they anticipated. It has created a 'paradox' in that the policies of earned autonomy through the creation of 'informed professionals' (Barber, 2002a, 2005) has for many 'inhibited' leadership through the constraints of Ofsted (Fink, 2005). My research provides no evidence that heads have in fact undertaken any strategy which would risk them failing at the next inspection and lose their and their school's reputation. It is seen that the need to improve 'standards' is 
synonymous with being successful. However it is only the highly prescribed way of achieving success and the unfair nature of the judgements of performance made with inaccurate measures, such as VA or inconsistent quality within the inspectorate that is questioned, not the notion of inspection itself.

Schools are exhorted to become 'learning organisations' by those who see the need to redesign the system (Hargreaves, 2003; Mulford, 2003) but with what degree of independence? Can they be a learning organisation that learns from itself through collaboration between members to support children's learning or do schools have to be an organisation which delivers mandated government policy to maintain its position? It is clear from the interviews that the main driver for the development of the curriculum has to be to produce the standards which will deliver in inspection. This is not necessarily meant to suggest that heads don't see that to produce high results is also to offer effective learning opportunities. It isn't either or, but the tension is in the level of control of the process, of the prescription in pedagogy and in some of the policies such as inclusion and standards. It is the tension between the government offering self management and autonomy on the one hand but needing to control and manage the outcome through accountability on the other. In doing so they constrain to the point that it is difficult for schools to operate as learning organisations in ways which are reflective and flexible and able to adapt to need.

The heads in my research who are used as consultants by NCSL or the LAs as system leaders or change agents (Hopkins 2006; Hopkins and Higham 2007) are those referred to by Gunter (2008) as 'pro government'. They are rewarded both through an enhancement of their reputations, a degree of perceived earned autonomy and financial packages. They may be acting in this way either because they have come to internalise the vision of the government and to make it their own (Moore et al. 2002) or who see following it will bring them the best chance of furthering their career in the way they choose. In other words some heads might be actively choosing to 'play the game' for advancement as well as to survive Ofsted inspections. The degree to which heads were playing the game however is complicated and there wasn't one specific reason for the way in which heads managed the agenda but several and most acted in terms of their moral principle (Bottery 2007b) and reflected to some extent the heads' own values and visions (Moore et al. 2002). 
Currently system leaders are in a powerful position in terms of how they practice the agenda as need of their skills and experience seems to outstrip supply. They are being used and trusted to sort out the muddy mess on the ground principally because of the speed with which decisions have to be made and it is not possible for the government to effectively micro-manage the situation. An important result of this for the role of the head is that having achieved a degree of earned autonomy the power relationship with LAs and the government works in their favour provided that they have the proven skills that are required by these agencies.

The relationship between LAs and schools has shifted over time (see Chapter 6 and Key finding 3). My findings suggest that as more heads seek a wider role, some of which the LAs broker, this relationship will change and the power in the dynamics move back towards the LAs in so far as they broker the new roles heads want. It is ironic if the aim of the government was to diminish the role of the LAs and they end up providing the policies which strengthen them.

A question for future research is how long will it be before the level of autonomy granted to these heads lessens in line with the rest of the system as Ofsted and the DCSF gain more of an idea about how these new models of leadership are successfully led and managed? How long before we witness the constraints of a set of standards for system leaders against which to judge them? At the moment however I think the power and pivotal nature of the head in the extended structure is enhanced not diminished as they act largely free from constraints while they can prove their success. In the case of some policies, such as workforce reform, the heads are manipulating and extending the policies beyond the government's expectation which has been identified as an issue for those introducing policy (Scott 2000).

This independence of action is considered to be essential in a period of rapid change and is an example of the system giving heads permission to innovate (Fullan, 2005) and act in the best interests of their school (Day et al. 2000). The issue for the system is to allow enough slack for heads to work and solve the mess on the ground but with intelligent accountability to enable all participants in the system to be assured that the school was progressing and not following an unchecked 'slalom ride' to failure (19). 
Southworth (2008) argues that system leadership is likely to increase. My research supports this and that the headteachers are being successfully encouraged both to want to pursue external roles and to build and sustain the capacity needed to do so. In this they have become aware of the need to change and have the vision for it identified as an important element of successful system change (Anderson, 1993). My argument is that while this necessary element may be in place other aspects of the system are working against effective system change and so fragmentation caused by competing, non-aligned education policies (Hopkins and Levin, 2000) is acting as a barrier to the successful implementation of educational policy.

The accountability system needs to be sensitive and flexible enough to identify those schools which can be genuinely granted earned autonomy to take the risks needed for the system to grow and develop. The general belief of those headteachers in my research is that it isn't and isn't likely to become so in the near future. If the government is genuinely committed to spreading best practice then this is one tension in the agenda it needs to resolve. 


\section{APPENDICES}

Appendix 1: Interview list July 2005-February 2008 - Headteachers Bibliography

\begin{tabular}{|c|c|c|c|c|c|}
\hline $\begin{array}{l}\text { Headteacher } \\
\text { and date of } \\
\text { interview }\end{array}$ & Gender & $\begin{array}{l}\text { Type of } \\
\text { school } \\
\text { and } \\
\text { age } \\
\text { range } \\
\end{array}$ & $\begin{array}{l}\text { Number } \\
\text { on } \\
\text { Role }\end{array}$ & $\begin{array}{l}\text { Length of service } \\
\text { in years } \\
\text { as a headteacher } \\
\text { in } \\
\text { current school }\end{array}$ & $\begin{array}{l}\text { Number of } \\
\text { Headships }\end{array}$ \\
\hline Pilot 05 & Male & $\begin{array}{l}\text { Urban } \\
3-11\end{array}$ & 355 & 23 & 1 \\
\hline $\begin{array}{l}1 . \\
05\end{array}$ & Female & $\begin{array}{l}\text { Inner } \\
\text { City } \\
4-11\end{array}$ & 207 & 11 & 1 \\
\hline $\begin{array}{l}2 . \\
05\end{array}$ & Female & $\begin{array}{l}\text { Inner } \\
\text { City } \\
3-11 \\
\end{array}$ & 462 & 8 & 1 \\
\hline $\begin{array}{l}3 . \\
05 / 07\end{array}$ & Female & $\begin{array}{l}\text { Urban } \\
4-11\end{array}$ & 384 & $13 / 15$ & 1 \\
\hline $\begin{array}{l}4 . \\
05\end{array}$ & Male & $\begin{array}{l}\text { Inner } \\
\text { City } \\
7-11\end{array}$ & 183 & 2 & $\begin{array}{l}2 \text { with an interim break between } \\
\text { schools as a school's adviser }\end{array}$ \\
\hline $\begin{array}{l}5 . \\
05 / 07\end{array}$ & Male & $\begin{array}{l}\text { Inner } \\
\text { City } \\
3-11\end{array}$ & 654 & $6 / 8$ & 1 \\
\hline $\begin{array}{l}6 . \\
05\end{array}$ & Male & $\begin{array}{l}\text { Rural } \\
3-11\end{array}$ & 177 & 3 & $2+$ acting \\
\hline $\begin{array}{l}7 . \\
05 / 07\end{array}$ & Male & $\begin{array}{l}\text { Inner } \\
\text { City } \\
3-11\end{array}$ & 474 & $15 / 17$ & 1 \\
\hline $\begin{array}{l}8 . \\
06 / 08\end{array}$ & Female & $\begin{array}{l}\text { Inner } \\
\text { City } \\
3-11 \\
\end{array}$ & 176 & $7 / 9$ & 1 \\
\hline $\begin{array}{l}9 . \\
06\end{array}$ & Female & $\begin{array}{l}\text { Inner } \\
\text { City } \\
3-11\end{array}$ & 337 & 11 & 1 \\
\hline $\begin{array}{l}10 . \\
06\end{array}$ & Female & $\begin{array}{l}\text { Urban } \\
7-11\end{array}$ & 383 & 10 & 1 \\
\hline $\begin{array}{l}11 . \\
06\end{array}$ & Male & $\begin{array}{l}\text { Urban } \\
3-11\end{array}$ & 447 & 8 & 3 \\
\hline $\begin{array}{l}12 . \\
07\end{array}$ & Female & $\begin{array}{l}\text { Inner } \\
\text { City } \\
3-11\end{array}$ & 679 & 10 & 1 \\
\hline $\begin{array}{l}13 . \\
07\end{array}$ & Female & $\begin{array}{l}\text { Inner } \\
\text { City } \\
3-11\end{array}$ & 708 & 13 & 1 \\
\hline $\begin{array}{l}14 . \\
07\end{array}$ & Female & $\begin{array}{l}\text { Urban } \\
7-11 \\
\end{array}$ & 360 & 12 & 1 \\
\hline $\begin{array}{l}15 . \\
07\end{array}$ & Female & $\begin{array}{l}\text { Inner } \\
\text { City } \\
3-11\end{array}$ & 382 & 1 & 2 \\
\hline $\begin{array}{l}16 . \\
07\end{array}$ & Female & $\begin{array}{l}\text { Inner } \\
\text { City } \\
3-11\end{array}$ & 621 & 1 & 3 \\
\hline $\begin{array}{l}17 \\
07\end{array}$ & Female & $\begin{array}{l}\text { Urban } \\
3-7\end{array}$ & 323 & 14 & 1 \\
\hline $\begin{array}{l}18 \\
07\end{array}$ & Female & $\begin{array}{l}\text { Inner } \\
\text { City } \\
3-11\end{array}$ & 492 & 5 & 1 \\
\hline
\end{tabular}




\begin{tabular}{|l|l|l|l|l|l|}
\hline $\begin{array}{l}19 . \\
08\end{array}$ & Female & $\begin{array}{l}\text { Inner } \\
\text { City } \\
3-11\end{array}$ & 476 & 5 & 2 \\
\hline 20. & Female & $\begin{array}{l}\text { Inner } \\
\text { City } \\
3-11\end{array}$ & 669 & 5 & 2 \\
\hline 21 & Male & $\begin{array}{l}\text { Rural } \\
5-11\end{array}$ & 251 & 25 & 1 \\
08 & & & & \\
\hline
\end{tabular}

Please note: Hts 19,20,21 are involved in two school federations but these are soft and not yet permanent arrangements and so have not been included as part of this chart. 
Appendix 2: Interview list 1-11 July 2005-September 2006-Headteachers and leading outside their own school

\begin{tabular}{|c|c|}
\hline Interviewee & Nature and Extent of their leadership outside their own institution \\
\hline Pilot 05 & Took early retirement in 2006 \\
\hline 1. & $\begin{array}{l}\text { Resigned as a head (60) July } 06 \text { and works in } 3 \text { LAs, as a consultant leader and other } \\
\text { associate advisory work }\end{array}$ \\
\hline $\begin{array}{l}2 . \\
05 \\
\end{array}$ & PSCL but gave up after first year. \\
\hline $\begin{array}{ll}3 . \\
05\end{array}$ & PSCL. Leads the Consortium. Head of school within co-location \\
\hline $\begin{array}{ll}4 . \\
05\end{array}$ & Not involved in other schools but involved in business partnerships. \\
\hline $\begin{array}{l}5 . \\
05\end{array}$ & $\begin{array}{l}\text { Worked for LA on secondment to lead schools in challenging circumstances and as } \\
\text { heads performance management adviser to governors. Works extensively in leading the } \\
\text { consortium }\end{array}$ \\
\hline $\begin{array}{ll}6 . \\
05\end{array}$ & Not involved leading although member of the consortium \\
\hline $\begin{array}{l}7 . \\
05\end{array}$ & $\begin{array}{l}\text { Heavy involvement with consortium in which he plays a lead role. Seconded to other } \\
\text { schools. }\end{array}$ \\
\hline $\begin{array}{l}8 . \\
06 \\
\end{array}$ & $\begin{array}{l}\text { PSCL and worked part time as seconded head in special measures school. Seconded to } \\
\text { DfES and involved with research into leadership. }\end{array}$ \\
\hline $\begin{array}{l}9 . \\
06\end{array}$ & $\begin{array}{l}\text { PSCL for LA and PSCL in another LA. Works as part of think tank groups for NDGAs } \\
\text { Continues CL work in LA to date }\end{array}$ \\
\hline $\begin{array}{ll}10 . \\
06\end{array}$ & $\begin{array}{l}\text { Worked as PSCL but gave up due to work with DfES. Other consultancy and } \\
\text { involvement with national and international agencies }\end{array}$ \\
\hline $\begin{array}{ll}11 . \\
06\end{array}$ & $\begin{array}{l}\text { PSCL in LA and secondment to LA as headteacher for leadership links with schools. } \\
\text { Worked with London Challenge. }\end{array}$ \\
\hline
\end{tabular}


Appendix 3: Interview list July 2005-February 2008 - Headteachers and leading outside their own school

\begin{tabular}{|c|c|}
\hline Interviewee & Nature and Extent of their leadership outside their own institution \\
\hline Pilot 05 & Took early retirement in 2006 and works as SIP and also a CEA consultant in three LAs \\
\hline $\begin{array}{l}1 . \\
05\end{array}$ & $\begin{array}{l}\text { Resigned as a head (60) July } 06 \text { and works in } 3 \mathrm{LAs} \text {, as a consultant leader and other } \\
\text { associate advisory work }\end{array}$ \\
\hline $\begin{array}{l}2 . \\
05\end{array}$ & PSCL. Children's Centre as part of school governance \\
\hline $\begin{array}{ll}3 . \\
05 / 07\end{array}$ & $\begin{array}{l}\text { Continues to work as a PSCL but gave up leading the consortium during the year. Since } \\
\text { first visit she has led on the co location of a special school with her school. Leads on } \\
\text { networks for the LA. }\end{array}$ \\
\hline $\begin{array}{ll}4 . \\
05\end{array}$ & Not involved in other schools but involved in business partnerships. \\
\hline $\begin{array}{l}5 . \\
05 / 07\end{array}$ & $\begin{array}{l}\text { Worked for LA on secondment to lead schools in challenging circumstances and as } \\
\text { heads performance management adviser to governors. Leadership Advisory Group for } \\
\text { his professional association. SIP. Advisory work includes GTC, TDA, LA, a } \\
\text { professional association }\end{array}$ \\
\hline $\begin{array}{l}6 . \\
05 \\
\end{array}$ & Not involved leading although member of the consortium \\
\hline $\begin{array}{l}7 . \\
05 / 07\end{array}$ & $\begin{array}{l}\text { Heavy involvement with consortium and as a mentor head for LA. } \\
\text { Second visit he has trained as CL with NCSL undertakes CL work for LA }\end{array}$ \\
\hline $\begin{array}{l}8 . \\
06 / 08\end{array}$ & $\begin{array}{l}\text { PSCL and worked part time as seconded head in special measures school. Lot of } \\
\text { research interest in her school regarding leadership and she has undertaken this with } \\
\text { various universities and has undertaken international placements. }\end{array}$ \\
\hline $\begin{array}{l}9 . \\
06\end{array}$ & $\begin{array}{l}\text { PSCL for LA and PSCL in another LA. Works as part of think tank groups I.E NCSL } \\
\text { DCSF, continues CL work in LA. }\end{array}$ \\
\hline $\begin{array}{ll}10 . \\
06\end{array}$ & $\begin{array}{l}\text { Worked as PSCL very briefly but gave up due to work with DfES. } \\
\text { Member of advisory boards for national and international agencies }\end{array}$ \\
\hline $\begin{array}{ll}11 . \\
06\end{array}$ & $\begin{array}{l}\text { PSCL and secondment to LA for leadership consultancy. Worked with London } \\
\text { Challenge. Tutored on NCSL programmes. }\end{array}$ \\
\hline 12. & $\begin{array}{l}\text { Ofsted inspector and writer of educational papers. Experience of international } \\
\text { placements }\end{array}$ \\
\hline $\begin{array}{l}13 . \\
07\end{array}$ & $\begin{array}{l}\text { Seconded Headteacher part time while keeping her own school and leadership roles } \\
\text { within her local consortium. Ofsted inspector. }\end{array}$ \\
\hline $\begin{array}{ll}14 . \\
07\end{array}$ & NLE. Ofsted inspector. PSCL \\
\hline $\begin{array}{l}15 . \\
07\end{array}$ & Co-headteacher, CL, Consultant and external consultant with with NDGA. SIP \\
\hline $\begin{array}{ll}16 . \\
07\end{array}$ & $\begin{array}{l}\text { Extensively used as a seconded head although stays in seconded school once there and } \\
\text { has done this } 3 \text { times. After each she becomes its substantive headteacher. PSCL. }\end{array}$ \\
\hline $\begin{array}{l}17 \\
07 \\
\end{array}$ & $\begin{array}{l}\text { NLE and PSCL and used as a head to work in vulnerable circumstances by LA for some } \\
\text { time. Ofsted inspector }\end{array}$ \\
\hline $\begin{array}{l}18 \\
07\end{array}$ & $\begin{array}{l}\text { She had been seconded to Ofsted in a previous year and since I interviewed her has left } \\
\text { school permanently to work as HMI }\end{array}$ \\
\hline $\begin{array}{ll}19 . \\
08\end{array}$ & NLE and head of a two school federation \\
\hline $\begin{array}{l}20 . \\
08\end{array}$ & NLE and head of two school federation. \\
\hline $\begin{array}{l}21 \\
08 \\
\end{array}$ & Head of two school federation \\
\hline
\end{tabular}


1. Can you briefly explain the context of the school and your experience as a headteacher.

2. What are the main issues confronting you in your role as headteacher?

3. How have these changed while you have been in post?

4. Do you see the issues changing over the next one-three years?

5. How will this affect your role as headteacher?

6. In the context of all you have just said; do you use /will you use NCSL?

7. (Either way)What do you think is the main role of NCSL? (If they don't use it go to question 12)

8. How and when did you get to know about NCSL? How did you expect it to help you?

9. Can you describe some of the ways in which you have used the provision/programmes?

- Website i.e reason/time/frequency/purpose

- On line communities (list)

- Dialogues with NCSL/DfES

- Links ie DfES, TTA/BBC

- Forums for headship discussions i.e brainstorms, discussions, debates, consversations, hotseats

- Creating own forum ie me page etc

- Knowledge Pool

- Research Associates

- training programmes

- Bursar Development Programme

- Collaborative Leadership and Learning (pilot)

- Developing the Capacity for Sustained Improvement (DCSI)

- Development Programme for Consultant Leadership

- Equal Access for Promotion?

- Established Leaders Pilot Programme

- Headlamp

- Headteacher Induction Programme (HIP)

- International Placements for Headteachers

- Leadership Programme for Serving Headteachers

- Leading from the Middle (LftM)

- Leading Small Primary Schools

- New Visions Programme for Early Headship 
- National Professional Qualification for Headship (NPQH)

- National Professional Qualification in Integrated Centre Leadership (NPQICL)

- Partners in Leadership

- Personalised Leadership Learning Programme (PLLP)

- Research Associate Programme

- SIP

- Strategic Leadership of ICT (SLICT)

- Taking women's Leadership Forward

- teamSLICT pilot programme

- Trainee Headteachers Programme

- Working Together for Success

- Conferences

- Any work for NCSL ie facilitation, working groups

- Communications ie LDR, Research papers/self evaluation tools.

10. Which aspects were most/least effective? Why?

11. What has been the impact of the college on your leadership? (Has this changed during the time you have accessed them? How?)

12. Why don't you access NCSL?

13. What do you think NCSL should do to develop school leaders?

14. Do you think the college is changing? If so how do you think it is changing and how do you think this will affect your leadership?

15. What other sources of information/training/education are there? How do you make use of them?

- Universities

- Professional associations

- Private providers ie Capita/CEA/HTI/Individual consultants

- LEA 


\section{$\underline{\text { First round of iws revisited. }}$}

1. What are the main issues confronting you in your role as headteacher?

2. Do you see the issues changing over the next one-three years?

3. How will this affect your role as headteacher?

4. To what extent do you feel you have the opportunity to shape the destiny of your own school or have 'earned autonomy'? Why? (Do they mediate? How?)

5. What do you think are the effects of the new relationship with schools and 'intelligent accountability'

6. Can you describe your role outside your own school?

7. What motivated you to take on this role?

8. In undertaking the role what did you consider to be the barriers and opportunities afforded by it?

9. How has this impacted on your role in school? (collaboration and competition effects?)

10. Why do you think heads are being encouraged to work outside their own school?

11. How do you see the role developing in the future?

12. In what ways are you made aware of the national educational agenda?

13. Headteachers are being encouraged to move away from the idea of competition to improve schools and towards a collaborative approach aimed at spreading best practice. How will it affect you?

\section{New interviewees}

1. Can you briefly explain the context of the school and your experience as a headteacher?

2. What are the main issues confronting you in your role as headteacher?

3. How have these changed while you have been in post?

4. Do you see the issues changing over the next one-three years?

5. How will this affect your role as headteacher? 
6. To what extent do you feel you have the opportunity to shape the destiny of your own school or to have 'earned autonomy?' Why?

7. What do you think are the effects of the new relationship with schools and intelligent accountability?

8. Can you describe your role outside your own school?

9. What motivated you to take on this role?

10. In undertaking the role what did you consider to be the barriers and opportunities afforded by it?

11. How has this impacted on your role in school? (i.e.collaboration or competition effects)

12. Why do you think heads are being encouraged to work outside their own school?

13. How do you see the role developing in the future?

14. In what ways are you made aware of the national educational agenda?

15. Headteachers are being encouraged to move away from the idea of competition to improve schools and towards a collaborative approach. How will it affect you? 
Appendix 6: Codes Structure

\begin{tabular}{|c|c|}
\hline Name of Codes & $\begin{array}{l}\text { Abbreviation } \\
\text { used }\end{array}$ \\
\hline $\begin{array}{ll}\text { Staffing } & \\
\text { - } & \text { Fuality } \\
\text { - Nunding } \\
\text { - } \text { CPD } \\
\text { - Relationships with staff }\end{array}$ & $\begin{array}{l}\text { STF } \\
\text { STFQ } \\
\text { STFFD } \\
\text { STFN } \\
\text { STFCPD } \\
\text { STFRE }\end{array}$ \\
\hline $\begin{aligned} \text { Funding } & \\
\text { - } & \text { staffing } \\
\text { - } & \text { Sustainability } \\
\text { - } & \text { ECM } \\
\text { - } & \text { NCD } \\
\text { - } & \text { Budget }\end{aligned}$ & $\begin{array}{l}\text { FD } \\
\text { FDST } \\
\text { FDSUS } \\
\text { FDECM } \\
\text { FDCPD } \\
\text { FDNCSL } \\
\text { FDBD }\end{array}$ \\
\hline $\begin{array}{l}\text { Standards } \\
\text { - Size of School } \\
\text { - National Issue } \\
\text { - Effects on staff } \\
\text { - Effect on standards of behaviour } \\
\text { - Effect on curriculum design }\end{array}$ & $\begin{array}{l}\text { STD } \\
\text { STDSOS } \\
\text { STDNI } \\
\text { STDSF } \\
\text { STDBEH } \\
\text { STDCUR }\end{array}$ \\
\hline $\begin{array}{l}\text { NCSL } \\
\text { - } \text { headership messages from point of view of HT includes impact on } \\
\text { - Leadership messages from point of view of NCSL } \\
\text { - } \text { Attitudes to NCSL } \\
\text { - Quality of delivery } \\
\text { - Quality of programmes in general } \\
\text { - Knowledge of } \\
\text { - Most effective } \\
\text { - Least effective } \\
\text { - Other individual programmes NOT web } \\
\text { - Working as an employee/consultant } \\
\text { - Effect of Steve Munby } \\
\text { - Steve Munby links to national issues } \\
\text { - Funding } \\
\text { - } \text { Relationships with partners ie DfES } \\
\text { - Role/relationships with hts } \\
\text { - Relationship with LAs }\end{array}$ & $\begin{array}{l}\text { NC } \\
\text { NCHTLM } \\
\text { NCSLLM } \\
\text { NCATT } \\
\text { NCDEL } \\
\text { NCPRO } \\
\text { NCWEB } \\
\text { NCKNW } \\
\text { NCME } \\
\text { NCLE } \\
\text { NCOIP } \\
\text { NCEMP } \\
\text { NCSLSM } \\
\text { SMNI } \\
\text { NCSLFD } \\
\text { NCCHA } \\
\text { NCREP } \\
\text { NCRHT } \\
\text { NCSLLA }\end{array}$ \\
\hline Ethos & ET \\
\hline $\begin{array}{cl}\text { Networking } \\
\text { - } \text { Type } \\
\text { - } \text { Sustainability } \\
\text { - } \text { Reason for choice } \\
\text { - } \text { Success/failure } \\
\end{array}$ & $\begin{array}{l}\text { NET } \\
\text { NETTY } \\
\text { NETSUS } \\
\text { NETRC } \\
\text { NETSF } \\
\text { NETNI }\end{array}$ \\
\hline $\begin{array}{cc}\text { Local v National } \\
\text { - } \\
\text { - } & \text { NCsearch } \\
\end{array}$ & $\begin{array}{l}\text { LVN } \\
\text { LVNR } \\
\text { LVNNC }\end{array}$ \\
\hline Time $\quad$ NCSL & $\begin{array}{l}\mathrm{T} \\
\mathrm{TNCSL}\end{array}$ \\
\hline
\end{tabular}




\begin{tabular}{|c|c|}
\hline $\begin{array}{l}\text { Attitudes } \\
\text { - Pressure } \\
\text { - } \text { Brustration } \\
\text { - } \text { Compliant } \\
\text { - Reciprocity of perspective } \\
\text { - } \text { Leadership role } \\
\text { - } \text { Other hearpose } \\
\text { - Professional development } \\
\text { - Empathy from none hts }\end{array}$ & $\begin{array}{l}\text { ATT } \\
\text { ATTPR } \\
\text { ATTF } \\
\text { ATTSF } \\
\text { ATTC } \\
\text { ATTRP } \\
\text { ATTLR } \\
\text { ATTCP } \\
\text { ATTHT } \\
\text { ATTCPD } \\
\text { ATTEMP }\end{array}$ \\
\hline $\begin{aligned} & \text { ECM } \\
& \text { - } \text { National issue } \\
& \text { - } \text { Funding } \\
& \text { - } \text { Leadership role } \\
& \text { - Extended schools } \\
& \text { - Inclusion }\end{aligned}$ & $\begin{array}{l}\text { ECM } \\
\text { ECMNI } \\
\text { ECMFD } \\
\text { ECMLR } \\
\text { ECMEXS } \\
\text { ECMINC }\end{array}$ \\
\hline $\begin{array}{ll}\text { Accountability } \\
\text { - } & \text { Standards } \\
\text { - } & \text { Ofsted } \\
\text { - } & \text { Pational Issues } \\
\text { - } & \text { Govessional } \\
\text { - } & \text { Children } \\
\text { - } & \text { Staff } \\
\text { - } & \text { Community }\end{array}$ & $\begin{array}{l}\text { ACC } \\
\text { ACCS } \\
\text { ACCOFS } \\
\text { ACCNI } \\
\text { ACCPR } \\
\text { ACCG } \\
\text { ACCC } \\
\text { ACCST } \\
\text { ACCCOM }\end{array}$ \\
\hline $\begin{array}{l}\text { Leadership } \\
\text { - Pivotal role } \\
\text { - } \text { Distributed } \\
\text { - Stystem (leading beyond own school) } \\
\text { - Performance Management } \\
\text { - Changing role of HT } \\
\text { - Accountability to Govt } \\
\text { - Professional development } \\
\text { - } \text { Ureneral leadership role } \\
\text { - Succession planning } \\
\text { - Personal history }\end{array}$ & $\begin{array}{l}\text { LDR } \\
\text { LDRP } \\
\text { LDRD } \\
\text { LDRSY } \\
\text { LDRSTY } \\
\text { LDRMAN } \\
\text { LDRHTCR } \\
\text { LDRACC } \\
\text { LDRCPD } \\
\text { LDRGLR } \\
\text { LDRUB } \\
\text { LDRSUCPL } \\
\text { LDRPH }\end{array}$ \\
\hline Behaviour & $\mathrm{BEH}$ \\
\hline $\begin{array}{cl}\text { Remodelling } \\
\text { - Leadership } \\
\text { - National Issues } \\
\text { - Sustainability }\end{array}$ & $\begin{array}{l}\text { REM } \\
\text { REMLR } \\
\text { REMNI } \\
\text { REMSUS }\end{array}$ \\
\hline $\begin{aligned} \text { Ofsted } & \\
\text { - } & \text { Staffing } \\
\text { - } & \text { Pressure } \\
\text { - } & \text { Special measures }\end{aligned}$ & $\begin{array}{l}\text { OFS } \\
\text { OFST } \\
\text { OFPRE } \\
\text { OFSSM }\end{array}$ \\
\hline $\begin{array}{l}\text { Local Authority } \\
\text { - Role of LAs } \\
\text { - Local influences } \\
\text { - National Issues } \\
\text { - NCSL } \\
\text { - Accountability to govt } \\
\text { - Attitude to headteachers }\end{array}$ & $\begin{array}{l}\text { LA } \\
\text { LARAT } \\
\text { LARLO } \\
\text { LARNI } \\
\text { LANCSL } \\
\text { LAACC } \\
\text { LAAHT } \\
\end{array}$ \\
\hline
\end{tabular}




\begin{tabular}{|c|c|}
\hline $\begin{array}{ll}\text { Research } \\
\text { - } & \text { NCSL } \\
\text { - } & \text { By HT } \\
& \text { Other }\end{array}$ & $\begin{array}{l}\text { RES } \\
\text { RESNC } \\
\text { RESHT } \\
\text { RESO }\end{array}$ \\
\hline $\begin{aligned} \text { Inequality } \\
\text { - Parental issues } \\
\text { - Sducational provision } \\
\text { Standards }\end{aligned}$ & $\begin{array}{l}\text { INEQ } \\
\text { INEQP } \\
\text { INEQEP } \\
\text { INEQST }\end{array}$ \\
\hline Other Providers not NCSL or LA & $\mathrm{OP}$ \\
\hline $\begin{array}{l}\text { - Consultants } \\
\text { : } \text { PAHT } \\
\text { - } \text { TDA } \\
\text { : } \text { QCA } \\
\text { - } \text { Capita } \\
\text { GTC }\end{array}$ & $\begin{array}{l}\text { OPCON } \\
\text { OPNAHT } \\
\text { OPPUB } \\
\text { OPTDA } \\
\text { OPDfES } \\
\text { OPQCA } \\
\text { OPCAP } \\
\text { OPGTC }\end{array}$ \\
\hline $\begin{array}{l}\text { Community } \\
\text { Type of community } \\
\text { - Community's relationship with school } \\
\text { School's relationship with community }\end{array}$ & $\begin{array}{l}\text { COM } \\
\text { COMTYP } \\
\text { COMRESC } \\
\text { COMREHT }\end{array}$ \\
\hline $\begin{array}{l}\text { Sustainability } \\
\text { - Of Networks } \\
\text { - Of Remodelling } \\
\text { - Of ECM } \\
\text { Of Funding (Action zones, EIC, etc) }\end{array}$ & $\begin{array}{l}\text { SUS } \\
\text { SUSNET } \\
\text { SUSREM } \\
\text { SUSSC } \\
\text { SUSECM } \\
\text { SUSFD }\end{array}$ \\
\hline $\begin{array}{l}\text { Professional Associations } \\
\text { - Influences of }\end{array}$ & $\begin{array}{l}\text { PA } \\
\text { PAINF }\end{array}$ \\
\hline $\begin{array}{l}\text { Governing Body } \\
\text { - Role of } \\
\text { - Relationship with hts }\end{array}$ & $\begin{array}{l}\text { GB } \\
\text { GBRL } \\
\text { GBREHT }\end{array}$ \\
\hline School Context & SCHCON \\
\hline
\end{tabular}




\begin{tabular}{|c|c|c|c|c|}
\hline Headteacher & Code & Memos & Quote & $\begin{array}{l}\text { Line } \\
\text { Numbers }\end{array}$ \\
\hline 13-07 & ACCPR & $\begin{array}{l}\text { Inspection of children's centre } \\
\text { is unknown quantity and } \\
\text { therefore worrying. Links with } \\
\text { ECM and ACCPR for how it } \\
\text { affects her personally. OFPRE }\end{array}$ & $\begin{array}{l}\text { Does that mean you expect } \\
\text { that the children's centre } \\
\text { will be inspected at the } \\
\text { same time as your school as } \\
\text { part of it? } \\
\text { Yes I do, I do as part of our } \\
\text { school provision and that's } \\
\text { what I worry about with my } \\
\text { name on the front of it. } \\
\text { Is your governing body the } \\
\text { steering committee or part } \\
\text { of the steering committee } \\
\text { for the children's centre? } \\
\text { No not the whole governing } \\
\text { body although there is a } \\
\text { governor on the steering } \\
\text { committee and the } \\
\text { governors are the named } \\
\text { group responsible or } \\
\text { whatever the term is. But I } \\
\text { have to say we have } \\
\text { launched into it without } \\
\text { really investigating the } \\
\text { depth of accountability or } \\
\text { Ofsted. I think everybody is } \\
\text { the same. }\end{array}$ & $237-251$ \\
\hline
\end{tabular}

\begin{tabular}{|c|c|c|c|c|}
\hline $15-07$ & LDRMAN & $\begin{array}{l}\text { Links with ATTHT and other } \\
\text { professionals. Link with } \\
\text { ATTSF. She has earlier } \\
\text { recognised her own insecurity } \\
\text { and only remembers the bad } \\
\text { bits of the report and } \\
\text { emphathises with staff who } \\
\text { are the same. } \\
\text { Links with LDRACC and how } \\
\text { it is used for the monitoring } \\
\text { performance. Also link } \\
\text { LDRMAN using performance } \\
\text { management system to } \\
\text { empower staff. She sees it as } \\
\text { positive as tangible proof for } \\
\text { staff of a good performance. } \\
\text { Note the use of the word } \\
\text { 'good' staff? Link to heads } \\
\text { potentially less benign uses of } \\
\text { Per Man. }\end{array}$ & $\begin{array}{l}\text { What is the impact on the } \\
\text { school of performance } \\
\text { management? } \\
\text { I have to say that when you } \\
\text { can demonstrate as an } \\
\text { individual, when you are } \\
\text { insecure and I think a lot of } \\
\text { the teaching profession are, } \\
\text { I know that when you get an } \\
\text { inspection report they don't } \\
\text { highlight the good bits or } \\
\text { when you are doing } \\
\text { performance management or } \\
\text { a classroom observation } \\
\text { they will focus on things } \\
\text { they didn't do or didn't do } \\
\text { well - not on the things they } \\
\text { did do, so I think as a } \\
\text { profession we are full of } \\
\text { slightly neurotic individuals. } \\
\text { Therefore I think the fact } \\
\text { that people can demonstrate } \\
\text { the progress their children } \\
\text { have made is hugely }\end{array}$ & $352-368$ \\
\hline
\end{tabular}




\begin{tabular}{|l|l|l|}
\hline & $\begin{array}{l}\text { empowering for them as } \\
\text { individuals and for us as a } \\
\text { school. I think there is a } \\
\text { knowledge, and not just a } \\
\text { sense, that you have done a } \\
\text { good job and that's because } \\
\text { it is grounded in something } \\
\text { real and I think that is very } \\
\text { important for good staff. }\end{array}$ \\
\hline
\end{tabular}

An extract from the categories created from coding to show the multiple ways data were coded and categorised in different areas. In example (1) categories included ECM, Accountability (ACC) and Ofsted pressure (OFPRE).

In example (2) the links were between leadership accountability (LDRACC) the attitude of the headteacher (ATTHT) and the links to leadership and performance management(LDRMAN) and illustrates attitudes of the headteacher towards staff (ATTSF). 
Appendix 8: Main issues identified as impacting on their role by the interviewees between September 2005-February 2008

\begin{tabular}{|c|c|c|c|c|c|c|c|c|c|c|c|c|c|}
\hline Headteacher & Standards & $\underline{\mathrm{ECM}}$ & $\begin{array}{l}\text { Workforce } \\
\text { Reform } \\
\text { SS } \\
\text { PPA }\end{array}$ & $\begin{array}{l}\text { Ofsted/ } \\
\underline{\text { SIPs/ }} \\
\underline{\text { SSE }}\end{array}$ & $\begin{array}{l}\frac{\text { Role }}{\text { Acc }=a} \\
\text { Change }= \\
c\end{array}$ & Bureaucracy & Funding & Behaviour & Curriculum & $\begin{array}{l}\text { Community } \\
\underline{\text { and }} \\
\underline{\text { Parents }}\end{array}$ & Governors & $\begin{array}{l}\text { Staffing } \\
\text { Quality } \\
\text { Relationships } \\
\text { Appraisal } \\
\text { Succession } \\
\text { Organisation }\end{array}$ & Premises \\
\hline 01. & $\mathrm{X}^{*}$ & $\mathrm{X}$ & $\mathrm{X} \mathrm{ss}$ & $\mathrm{X}$ & $\mathrm{Xc}$ & $\mathrm{X}$ & $\mathrm{X}$ & & & & & $\mathrm{X} \mathrm{r} / \mathrm{q} / \mathrm{s}$ & \\
\hline 02. & $\mathrm{X}$ & $\mathrm{X}$ & $\mathrm{X}$ ss & $\mathrm{X}$ & $\mathrm{Xc}$ & & & & & & & $\mathrm{Xr} / \mathrm{a}^{*}$ & \\
\hline 03. & $\mathrm{X} * \mathrm{X} 2 *$ & $\mathrm{X} 2$ & $\mathrm{X}$ ss & $\mathrm{X}$ & $\begin{array}{l}\mathrm{X} \mathrm{a} / \mathrm{c} \\
\mathrm{Xa} / \mathrm{c} 2\end{array}$ & & & & $\mathrm{X}$ & $\mathrm{X}$ & & $\mathrm{Xs}$ & $\mathrm{X} \mathrm{X} 2$ \\
\hline 04. & $\mathrm{X}$ & $\mathrm{X}$ & $\mathrm{X}$ ss & & & $\mathrm{X}^{*}$ & $\mathrm{X}$ & & $\mathrm{X}$ & $\mathrm{X}$ & & $\mathrm{Xq}$ & $X$ \\
\hline 05 . & $\mathrm{X} \mathrm{X2}$ & $\mathrm{X}$ & $\mathrm{X} \mathrm{ss}$ & $\mathrm{X}$ & $\mathrm{X}$ a Xc2 & $\mathrm{X}^{*}$ & $\mathrm{X}$ & & & & $\mathrm{X} \mathrm{X2}$ & $\mathrm{Xs} 2 *$ & $\mathrm{XX2}$ \\
\hline 06. & $\mathrm{X}^{*}$ & $\mathrm{X}$ & X ss ppa & $\mathrm{X}$ & & $\mathrm{X}$ & & $\mathrm{X}$ & $\mathrm{X}$ & $\mathrm{X}$ & & & \\
\hline 07. & $\mathrm{X} \mathrm{X} 2$ & $\mathrm{X}$ & X ss & $\mathrm{X} * \mathrm{X} 2 *$ & $\mathrm{X} a$ & $\mathrm{X}$ & & $\mathrm{X}$ & & $\mathrm{X} \mathrm{X2}$ & & $\mathrm{XrXo}$ & \\
\hline 08. & $\mathrm{X} \mathrm{X2}{ }^{*}$ & $\mathrm{X}$ & $\mathrm{X} \mathrm{ss}$ & $\mathrm{X} \mathrm{X2}$ & & $\mathrm{X}^{*}$ & & & & $X$ & & $\mathrm{Xq}$ & \\
\hline 09. & $\mathrm{X}^{*}$ & $\mathrm{X}$ & X ss & $\mathrm{X}$ & & $\mathrm{X}$ & $\mathrm{X}$ & & & & & $\mathrm{Xq} / \mathrm{r}$ & \\
\hline 10. & $\mathrm{X}^{*}$ & $\mathrm{X}$ & $\mathrm{X}$ ss & $\mathrm{X}$ & & & & & $\mathrm{X}$ & $\mathrm{X}$ & & $\mathrm{Xs}$ & \\
\hline 11. & $\mathrm{X}$ & & & $\mathrm{X}^{*}$ & $\mathrm{Xa}$ & $\mathrm{X}$ & & $\mathrm{X}$ & & $X$ & $\mathrm{X}$ & & \\
\hline 12. & $\mathrm{X}$ & $\mathrm{X}$ & X ss & $\mathrm{X}^{*}$ & $\mathrm{X} \mathrm{a} / \mathrm{c}$ & & & & $\mathrm{X}$ & & & & \\
\hline 13. & $\mathrm{X}^{*}$ & $\mathrm{X}$ & $\mathrm{X} \mathrm{ss}$ & $\mathrm{X}$ & $\mathrm{Xc}$ & & & & & & & & \\
\hline 14. & $\mathrm{X}^{*}$ & & & $\mathrm{X}$ & $\mathrm{X} \mathrm{a} / \mathrm{c}$ & $\mathrm{X}$ & & & & & & & \\
\hline 15. & $\mathrm{X}$ & & $\mathrm{X} \mathrm{ss/ppa}$ & $\mathrm{X}$ & & $\mathrm{X}^{*}$ & & & & & & $\mathrm{Xq}$ & \\
\hline 16. & $\mathrm{X}$ & & $\mathrm{X} \mathrm{ss/ppa}$ & $\mathrm{X}$ & $\mathrm{X} \mathrm{c}$ & $\mathrm{X}^{*}$ & & & & & & & \\
\hline 17. & $\mathrm{X}^{*}$ & & X ss & $\mathrm{X}^{*}$ & $\mathrm{Xc}$ & & & & & & & $\mathrm{Xs}$ & \\
\hline 18. & $\mathrm{X}^{*}$ & & Xss & $\mathrm{X}$ & & & & & & & & & \\
\hline 19. & $\mathrm{X}$ & & & $\mathrm{X}^{*}$ & $\mathrm{Xc}$ & & & & & & & $\mathrm{Xo}$ & \\
\hline 20. & $\mathrm{X}^{*}$ & & & $\mathrm{X}$ & $\mathrm{X} \mathrm{a}$ & & & & & & & $\mathrm{X} \mathrm{q} / \mathrm{o}$ & \\
\hline 21. & $\mathrm{X}$ & & & $\mathrm{X}$ & $\mathrm{Xc}$ & & & & $\mathrm{X}$ & $\mathrm{X}$ & & $\mathrm{Xs}$ & $\mathrm{X}^{*}$ \\
\hline
\end{tabular}

- $\quad *=$ Main issues if indicated: Acc $=$ Accountability; SIP = School Improvement Partners; SSE = School Self Evaluation; SS = staffing structure; PPA = planning preparation and assessment

- $\mathrm{X} 2=$ revisit 
Appendix 9: Number of Headteachers identifying each issue as it impacted on their $\underline{\text { role }}$

\begin{tabular}{|l|c|c|}
\hline \multicolumn{1}{|c|}{ Issue } & $\begin{array}{c}\text { Number of heads } \\
\text { identifying issue }\end{array}$ & $\begin{array}{c}\text { Number of heads } \\
\text { identifying as main issue }\end{array}$ \\
\hline Standards & 21 & 11 \\
\hline Ofsted SIPs SSE & 20 & 5 \\
\hline Workforce Reform & 16 & 2 \\
\hline Staffing & 14 & 5 \\
\hline Bureaucracy/Workload & 14 & 0 \\
\hline ECM & 12 & 0 \\
\hline Community and Parents & 8 & 0 \\
\hline Curriculum & 6 & 1 \\
\hline Funding & 4 & 1 \\
\hline Premises & 4 & 0 \\
\hline Behaviour & 3 & 0 \\
\hline Governors & 2 & \\
\hline
\end{tabular}

Acc $=$ Accountability, SIP $=$ School Improvement Partners, SSE $=$ School Self Evaluation.

The reason the main issue is more than 21 or the total number of heads is because there was a change in the main issue identified for interviewees $\mathrm{Ht} 5$ and 8 in the revisit and Ht 17 gave two issues equal weighting. 


\section{BIBLIOGRAPY}

Ackoff, RL. (1974) Redesigning the Future, Wiley.

Adams, J. and Kirst, M. (1999) New demands and concepts for educational accountability. In J. Murphy and K.S. lewis (eds.) Handbook of Research on Educational Administration. San Francisco. C.A: Jossey - Bass.

Alexander, R. (2004) Still no pedagogy? Principle, pragmatism and compliance in primary education, Cambridge Journal of Education Vol. 34, No.1, pp. 7-34.

Alexander R; Rose, J. and Woodhead, C. (1992) Curriculum organisation and classroom practice in primary schools: a discussion paper (London DES).

Anderson, B. (September, 1993). "The Stages of Systemic Change." Educational Leadership, Vol. 51, No. 1, pp. 14-17. www.insites.org/documents/systemic.pdf accessed on 11th September 2007

Apple, M.W. (2001) The Rhetoric and Reality of Standards -Based School Reform Educational Policy, Vol. 15, No. 4, pp.601-610.

Argyris, C. and Schon, D. (1978) Organisational Learning: A Theory of Action Perspective. Reading, MA: Addison-Wesley.

Avis, J. (2003) Re-thinking trust in a performative culture: the case of education Journal of Education Policy, Vol.18, No. 3, pp. 315-332.

Ball, S. J. (1990) Politics and Policy Making in Education. London: Routledge.

Ball, S. J. (1993) 'Beachside Reconsidered: Reflections on a Methodological Apprenticeship', in B. Burgess (ed.) The Research Process in Educational Settings: Ten Case Studies, pp. 69-96. London: The Falmer Press.

Ball, S. J. (1994) Education Reform: A critical and post structural approach, Buckingham: Open University Press.

Ball, S.J. (1997) Policy Sociology and Critical Social Research: A Personal Review of Recent Education Policy and Policy Research'. British Educational Research Journal Vol. 23, No. 3, pp. 257-274.

Ball, S.J. (1998) Big policies/small world: an introduction to international perspectives in education policy, Comparative Education Vol. 34, No.2, pp.19-29.

Ball, S.J. (1999) Labour, learning and the economy: a 'policy sociology' perspective, Cambridge Journal of Education, Vol.29, No.2, pp.192-206.

Ball, S.J. (2001) Performativities and fabrication in the education economy: towards the performative society, in: D. Gleeson \& C. Husbands (eds) The Performing School: Managing, Teaching, and Learning in a Performance Culture London: Routledge Falmer pp. 210-226. 
Goleman, D. (2007) Key note speech at the NCSL Conference 'Seizing Success' Birmingham June, available online http:/www.ncsl.org.uk/media-1a0-33-danielgoleman-presentation.pdf accessed $21^{\text {st }}$ November 2008.

Gorard, S. (2006) Value-added is of little value, Journal of Education Policy Vol. 21, No.2, pp.235-243.

Grace, G. (1995) School Leadership: Beyond Education Management. London: Falmer.

Graham, D. (1993) Reflections on the first four years, in: M. Barber and D. Graham (eds) Sense, Nonsense and the National Curriculum London: Falmer, pp. 2-9.

Green, A. (1999) Education and globalisation in Europe and East Asia: convergent and divergent trends, Journal of Educational Policy, Vol.14, No. 1. pp. 55-72.

Gronn, P. (1999) The Making of Educational Leaders. London: Cassell.

Gronn, P. (2000) Distributed Properties: A New Architecture for Leadership, Educational Management and Administration, Vol. 28, No. 3, pp.317-338.

Gronn P (2003) The New Work of Educational Leaders: Changing Leadership Practice in the Era of School Reform. Paul Chapman London: Sage.

Groundwater-Smith, S and Sachs, J. (2002) The Activist Professional and the Reinstatement of Trust http://www.acij.uts.edu.au/archives/profprac/activist accessed $7^{\text {th }}$ April 2007.

Gunter, H. (1997) Rethinking Education: The Consequences of Jurassic Management. London: Cassell.

Gunter, H. (2001) Leaders and Leadership in Education, Paul Chapman London: Sage Publications

Gunter, H. (2008) Policy and Workforce Reform in England Educational Management Administration and Leadership Vol.36, No. 2, pp.253-270

Gunter, H. and Forrester (2008) New Labour and School Leadership British Journal of Educational Studies Vol. 56, No.2 pp.144-162.

Hall, V. and Southworth, G. (1997) Headship, School Leadership and Management, Vol.17, No.2, pp. 151-170.

Halpin, D. (1997) Editorial: New Labour: new hope for education?, British Journal of Educational Studies, 45 (3):231-234.

Hammersley, M. (1993) On the teacher as researcher, in: M Hammersley (Ed.) Educational Research: current issues London Paul Chapman Publishing. 
Hammersley-Fletcher, L. (2006) 'Workforce Remodelling - an opportunity for thinking about education? Paper presented at BERA Annual Conference University of Warwick, Sept $6^{\text {th }}-9^{\text {th }}$.

Hannon, V. (2004) Intelligent Networks, in The Future is Networked: How Schools are Working Smarter Together, National College of School Leadership, Nottingham

Hargreaves, A. (2001) Changing Teachers, Changing Times, Continuum International Publishing Group.

Hargreaves, A. (2005a) Leadership Succession The Educational Forum. Kappa Delta Pi. Vol. 69 Winter. Pp.163-173 http://www.findarticles.com/p/articles/mi qa4013/is 200501/ai n9473826. Accessed on $18^{\text {th }}$ October 2006.

Hargreaves, A. (2005b) Developing Leadership for Succession in M. H. Coles and G Southworth (eds) Developing Leadership: creating the schools of tomorrow, Maidenhead: Open University Press.

Hargreaves, A. and Fink, D. (2006) Sustainable Leadership Jossey, Bass, San Francisco, CA.

Hargreaves, A. and Tucker, E. (1991) Teaching and guilt: exploring the feelings of teaching, Teaching and Teacher Education Vol. 7, pp. 491-505.

Hargreaves, D.H. (2003) Education Epidemic: Transforming secondary schools through innovation networks. London: Demos.

Hargreaves, D. H. (2007a) 'The True Meaning of System Leadership'. Nottingham: NCSL. Online: http://www.ncsl.org.uk/media/0A8/43/david-hargreaves-presentationslides.pdf

Hargreaves, D.H. (2007b) Keynote Presentation: 'The new context: system re-design' at the SSAT Conference, Leading Learning: Deep learning and experience Birmingham $5^{\text {th }}$ July.

Hargreaves, D.H. (2007c) System Redesign - 1: The road to transformation in education SSAT.

Harris, A. (2001) Building the capacity for school improvement School Leadership and Management Vol. 21, No3, pp. 261-270.

Harris, A. (2003) 'The Changing Context of Leadership: Research, Theory and Practice', in A. Harris, C. Day, D. Hopkins, M. Hadfield, A. Hargreaves and C. Chapman Effective Leadership for School Improvement pp. 9-25; 72-83. London: Routledge Falmer

Harris, A. (2004) 'Distributed Leadership and School Improvement: Leading or Misleading?' Educational Management Administration and Leadership Vol.32, No.1, pp. 11-24. 
Harris, A. (2005) 'Leading from the Chalk-face: An Overview of School Leadership. Leadership, Vol.1, pp.73-87.

Harris, A. (2007), "Distributed leadership: conceptual confusion and empirical reticence", International Journal of School Leadership, Vol. 10, No. 3, pp. 31-325.

Harris, A. (2008) Distributed Leadership: according to the evidence Journal of Educational Administration Vol. 46, No.2, pp. 172-188.

Harris, A; Brown, A, Abbott, I. (2006) 'Executive leadership: another lever in the system? School Leadership and Management, Vol.26, No.4, pp.397-409.

Hartley, D. (2003) New economy, new pedagogy? Oxford Review of Education, Vol.29, No. 1, pp.81-94

Hatcher, R. (1994) Market relationships and the management of teachers British Journal of Sociology of Education, Vol. 6, No.1, pp. 41-61.

Hatcher, R. (1998) Labour, official school improvement and equality Journal of Educational Policy, Vol.13, no. 4, pp. 485-499.

Hatcher, R. (2005) The distribution of leadership and power in schools. British Journal of Sociology of Education Vol. 26, No. 2, pp.253-267.

Hatcher, R. (2008) System leadership, networks and the question of power Management in Education Vol. 22, pp. 24-30.

Hatcher, R. and Troyna, B. (1994) The 'Policy Cycle': A Ball by Ball Account Journal of Education Policy, Vol. 9, No. 2, pp. 155-170.

Hay, A.C. (1996) Re-stating Social and Political Change. Buckingham, Open University Press.

Haynes, G; Wragg, T; Wragg, C. and Chamberlin, R. (2003) 'Performance management for teachers: headteachers' perspectives', School Leadership and Management, Vol.23, No.1, pp.75-89.

Heifetz, R. A. (1994) Leadership Without Easy Answers Harvard, MA, Belknap Press.

Hellawell, D. (1991) Primary Headteacher Appraisal: A Research Study of the Attitudes of Headteachers Sheffield Papers in Education Management Sheffield City Polytechnic.

Hellawell, D. (2006) Inside-out: analysis of the insider-outsider concept as a heuristic device to develop reflexivity in students doing qualitative research Teaching in Higher Education Vol. 11, No. 4, pp.483-494.

Hill, R. and Matthews, P (2008) Schools leading schools: the power and potential of National Leaders of Education NCSL.

Hill, T. (1994) Developing a Career in Primary Education London: David Fulton. 
Hitchcock, G. and Hughes, D. (1995) Research and the Teacher: A Qualitative Introduction to School-based Research London: Routlege.

Hobsbawn, E. (1994) Age of Extremes: the short twentieth century 1914-1991. London: Michael Joseph.

Hockey, J. (1993) Research Methods-researching peers and familiar settings, Research Papers in Education Vol. 8, No. 2, pp.199-225.

Hook, C. (1985) Studying Classrooms, Deakin, Australia Deakin University Press.

Hopkins, D. (2001) School Improvement for Real London: Falmer Press.

Hopkins, D. (2003) 'Instructional Leadership and School Improvement', in A. Harris, C. Day, D. Hopkins, M. Hadfield, A. Hargreaves and C. Chapman Effective Leadership for School Improvement pp. 55-72. London: Routledge Falmer

Hopkins, D. (2005) "Every School a Great School: Meeting the Challenge of Large Scale, Long Term Educational Reform", inaugurate lecture for The London Centre for Leadership in Learning, Institute of Education, 30th June 2005, iNet series, Specialist Schools Trust, London.

Hopkins, D. (2006) A Short Primer on System Leadership. Paper given at The International Conference International perspectives on School Leadership for Systemic Improvement. OECD $6^{\text {th }}$ July.

Hopkins, D. (2007) Every School a Great School. Realising the potential of system leadership. McCraw Hill Education Open University Press.

Hopkins, D. (2008) SSAT conference 'System Leaders as Change Agents' Sheffield, February.

Hopkins, D and Higham R. (2007) System leadership: mapping the landscape, School Leadership and Management, Vol.27, No.2, pp. 147-166.

Hopkins, D and Levin, B. (2000) Government Policy and School Development, School Leadership and Management, Vol.20, No.1, pp. 15-30.

House, R.J.(1977) ‘A 1976 Theory of Charismatic leadership', in Hunt, J.G and Larson, L.L. (eds) Leadership: The Cutting Edge, Carbondale, IL: Southern Illinois University Press.

Hoyle, E. and Wallace, M. (2007) Educational Reform: An Ironic Perspective Educational Management Administration and Leadership Vol. 35, No. 1, pp 9-27.

Huberman, M. (1992) Teacher development and instructional mastery in A. Hargreaves and M. Fullan. (eds), Understanding Teacher Development. Cassell, 1992) 
Hughes. M. (1988) 'Leadership in professionally staffed organisations' in Glatter, R; Preedy, M; Riches, C. and Masterton, M. Understanding School Management. Open University Press, Milton Keynes pp. 3-28.

Husbands, C. (2001) Managing performance in performing schools, in D. Gleeson and C. Husbands (eds) The Performing School: Managing Teaching and Learning in a Performance Culture. London: Routledge-Falmer.

Hyman, P. (2005)1 out of 10: From Downing Street Vision to Classroom Reality. London: Vintage.

Istance, D. and Kobayashi, M. (2003) Inroduction in OECD Networks of Innovation: Towards New Models for Managing Schools and Systems, OECD, Paris.

James, C; Connelly, M; Dunning, G; Elliot, T (2005) Systemic leadership for schools, Presented at the British Educational Research Association Annual Conference, University of Glamorgan, 14-17 September 2005.

Jones, G. and Hayes, D. (1991) Primary headteachers and ERA two years on: the pace of change and its impact on school School Organisation Vol.11, pp. 210-218.

Jones, K. (1996) Cultural Politics and Education in the 1990s in R. Hatcher and K. Jones (eds) Education after the Conservatives: The Response to the New Agenda of Reform, Stoke: Trentham.

Jones, K. (2003) Education in Britain: 1944 to the present. Cambridge Polity Press.

Jones, N. (1999a) The changing management agenda for primary heads The International Journal for Public Sector Management Vol.12, No.4 pp.324-327. MCB University Press.

Jones, N. (1999b) The Changing Role of the Primary School Head: Reflections from the Front Line Educational Management and Administration. Vol. 27, No. 4, pp. 441451.

Jones, N. (1999c) The real world management preoccupations of primary school heads, School Leadership and Management, Vol. 19, No. 4, pp. 483-495.

Jones, N. and Connolly, M. (2001) The Competent Primary Headteacher: Broadening the Management Competence Approach or Abandoning it? Public Money and Management April-June pp.53-60.

Jones R. and Noble, G. (2007) Grounded theory and management research: a lack of integrity? Qualitative Research in Organisations and Management Vol.2, No.2, pp.84-103.

Judd, J. (2008) 'A Sip can still be great ... even if there are hiccups' Times Educational Supplement February $22^{\text {nd }}$

http://www.tes.co.uk/article. aspx? storycode $=2583927$ accessed $15^{\text {th }}$ September 2008. 
Jupp, R.; Fairly, C; Bentley, T; Demos \& Design, C. (2001) What learning needs: the challenge for a creative nation London, Demos/Design Council. Available online http://www.demos.co.uk/publications//learningneeds accessed $12^{\text {th }}$ June 2008.

Kelly, A. (1999) The curriculum: theory and practice London: Paul Chapman.

Kelly, R. (2005) 'Education and Social Progress', keynote speech, Institute of Public Policy Research, July. Available at:

http://www.dfes.gov.uk/speeches/speech.cfm?SpeechID $=242$

Kingdon, J.W. (2003) Agendas, Alternatives and Public Policies. New York: Addison-Wesley.

Kogan, M. (2002) The Subordination of Local Government and the Compliant Society Oxford Review of Education, Vol. 28 (2 and 3), pp.331-342.

Kofman F. \& Senge, P. M. (1995) Communities of commitment: the heart of learning organizations, in: S. Chawla \& J. Renesch (Eds) Learning Organizations: Developing Cultures for Tomorrow's Workplace (Productivity Press, Oregon).

Kouzes, J. and Posner, B. (1987) The Leadership Challenge San Francisco. JolleyBass

Kvale, S. (1996) Interviews: an introduction to qualitative interviewing Sage.

Labour Party (1997) New Labour. Because Britain deserves better. Election Manifesto London, Labour Party.

Lacey, C. (1977) The Socialization of Teachers London: Methuen.

Lawton, D. (1980) The Politics of the School Curriculum Routledge and Kegan Paul, London.

Lawton, D. (1989) The Education Reform Act: choice and control London:

Routledge.

Lawton, D. (1992) Education and Politics in the 1990s: Conflict or Consensus? London, Falmer Press.

Lawton, D. (2004) Education and Labour Party Ideologies 1900-2001 and Beyond Routledge-Falmer Press

Lazurus, R.S. (1966) Psychological Stress and the Coping Process. New York: McGraw Hill.

Learner, S. (2001) 'Soft-touch style but tough on standards' Times Educational Supplement $14^{\text {th }}$ September available online

http://www.tes.co.uk/article.aspx?storycode $=351724$ accessed $21^{\text {st }}$ November 2008

Lee, V. (1993) Educational choice: the stratifying effects of selecting schools and courses. Educational Policy Vol. 7, No. 2, pp. 125-148. 
Le Gallais, T.A (2003) Strangely native? An exploration of a researcher's journey from familiar settings into the strange world of FE. LSDA National Conference, Warwick University December available online www.lsda.org.uk/files/1sda/lsrn2003/TrackedSession2_Day2/TriciaLeGallais abstract paper.pdf Accessed 18th June 2007.

Le Gallais, T.A (2008) 'Where ever I go there I am: reflections on reflexivity and the research stance' Reflective Practice Vol. 9, No. 2, pp. 145-155.

Leggett, B. (1997) Pressures of Managerialism and its Implications. Australian Journal of Education, Vol. 41, no. 3, pp. 276-288.

Leithwood, K. (2001) School leadership in the context of accountability policies. International Journal of Leadership in Education, Vol. 4, No.3, pp 217-235.

Leithwood, K. (2005) Educational Accountability: Issues and Alternatives. Research Report 05-01 Saskatchewan School Board Association.

Leithwood, K., Day, C., Sammons, P., Harris, A. \& Hopkins, D. (2006a) Seven Strong Claims about Successful School Leadership. London: DfES

Leithwood, K., Day, C., Sammons, P., Harris, A. and Hopkins, D. (2006b), Successful School Leadership. What It Is and How It Influences Pupil Learning, Research Report RR800. London: DfES

Leithwood, K; Edge, K, Jantzi, D, (1999a) Educational Accountability: the state of the art. Gütersloh, Germany, Bertelsmann Foundation Publishers.

Leithwood, K; Jantzi, D and Steinbach, R. (1999b) Changing Leadership for Changing Times, Buckingham: Open University Press.

Leithwood, K, and Louis K. (1999) Organisational Learning in Schools (Amsterdam: Swets Zeitlinger).

Leonard, L.E. and Leonard, P.E (2001) The collaborative prescription: remedy or reverie? International Journal Leadership in Education, Vol.4, No.4, pp.383-399

Levacic, R. (1995) Local Management of Schools: Analysis and Practice. Milton Keynes: Open University Press.

Levin, B. (1998) 'An Epidemic of Education Policy: what can we learn from each other?' Comparative Education, Vol. 34, No. 2, pp.131-141.

Levin, B. (2003a) Conceptualising Educational Reform in Preedy et al (eds.) Strategic Leadership and Educational Improvement Open University Press and Paul Chapman Publishing.

Levin, B. (2003b) 'Educational Policy: Commonalities and Differences', in B. Davies and J. West-Burnham (eds) Handbook of Educational Management and Leadership London: Pearson. 
Levin, B. (2006) Keynote speech delivered to the Regional Conference in Birmingham. NCSL March.

Levitas, R. (1998) The 'Inclusive' Society: social exclusion and New Labour. Houndmills: Macmillan.

Lloyd, K. (1985) Management and leadership in the primary school, in: M. Hughes et al (eds) Managing Education: the system and the institution, pp.291-307 London:

Holt, Reinehart and Winston

Lowe, R. (2002) A Century of Local Education Authorities: what has been lost? Oxford Review of Education, 28 (2\&3)

Lyotard, J.F. (1984) The postmodern condition: a report on knowledge (Minneapolis, University of Minnesota Press).

MacBeath, J. (2008) 'Stories of Compliance and Subversion in a Prescriptive Policy Environment. Educational Management Administration and Leadership Vol.36, No.1, pp.123-148.

Maden, M. (2001) (Ed) Success Against the Odds: Five Years On Revisiting Effective Schools in Disadvantaged Areas Routledge

Maden, M. and Hillman, J. (1996) 'Lessons in Success'. In National Commission on Education. Success Against the Odds. London: Routledge.

Maguire, M; Wooldridge,T, Pratt-Adams, S. (2006) The Urban Primary School Open University Press

Mahony, P. Hextall, I. (2000) Reconstructing Teaching: standards, performance and accountability. London, Routledge. Falmer.

March, J and Olsen, J. (1989) Rediscovering Institutions: the Organizational Basis of Politics. New York: Free Press.

Matthews, P. (2007) Attributes of the first National Leaders of Education in England: What do they bring to the role? Paper presented to NCSL.

Matthews, P and Sammons, P. (2004) Improvement through Inspection: An Evaluation of Ofsted's Work London: Ofsted

McEwen, A; Carlisle, K; Knipe, D; Neil, Peter and McClune, B. (2002) Primary School Leadership: values and actions, Research Papers in Education Vol. 17. No.2, pp.147-163.

McHugh, M. and McMullan, L. (1995) Headteacher or manager? Implications for training and development, School Organisation Vol.15, pp. 25-34.

Menter, I; Muschamp, Y; Nicolls, Pollard, A, and Ozga, J. (1995) Still carrying the can: primary school headship in the 1990s, School Organisation, Vol 15, pp.301-312 
Menter, I; Muschamp, Y; Nicolls, P; Ozga, J. and Pollard, A. (1997) Work and

Identity in the Primary School. Buckingham, Open University Press.

Mercer, J. (2007) The challenges of insider research in educational institutions: wielding a double-edged sword and resolving delicate dilemmas Oxford Review of Education Vol. 33, No. 1, pp. 1-17.

Merton. R. (1972) Insiders and Outsiders, a chapter in the sociology of knowledge, American Journal of Sociology Vol.7, No. 8, pp. 9-47.

Miles, M.B and Huberman, A.M(1994) Qualitative Data Analysis $2^{\text {nd }}$ Edition, Thousand Oaks Sage Publications.

Miliband, D. (Minister of State for School Standards, DfES) (2004) Personalised Learning: building a new relationship with schools, address to North of England Education Conference, Belfast, 8 January.

Millett, A. (1997) 'Trained to tackle teaching's top job', The Times Educational Supplement September 19.

Moore, A; George, R. and Halpin, D. (2002) The Developing Role of the Headteacher in English Schools: Management, Leadership and Pragmatism, Educational Management and Administration Vol. 30, No. 2. pp.175-198.

Morris, E, (2001) Professionalism and trust- the future of teachers and teaching, A speech by the secretary of state for education to the social market foundation, 12 November, London, SMF.

Mortimore, P; Sammons, P; Stoll, L. Lewis, D. and Ecob, BR. (1988) School Matters Wells Open Books.

Mortimore, P. and Mortimore, J. (1991) The Primary Head: roles, responsibilities and reflections London: Paul Chapman.

Mulford, B. (2003) School Leaders: Changing Roles and Impact on Teacher and School Effectiveness. A paper commissioned by the Education and Training Policy Division, OECD, for the Activity Attracting, Developing and Retaining Effective Teachers. April.

Munby, S. (2007) 'Share the burden, save some cash, The Times Educational Supplement Magazine November $16^{\text {th }}$ http://www.tes.co.uk/article.aspx?storycode $=2463270$ accessed $22^{\text {nd }}$ August 2008.

Murgatroyd, S. and Morgan, C. (1992) Total Quality Management and the School. Milton Keynes: Open University Press.

National College for School Leadership (2005a) Best Leadership for Toughest Schools gets NCSL Support Nottingham: NCSL.

National College for School Leadership (2005b) Corporate Plan 2005-2008, Nottingham: NCSL 
National College for School Leadership (2005c) Executive Headship: a study of heads who are leading two or more secondary or special schools, Summary Report of the NCSL Research Group. Nottingham: NCSL

National College for School Leadership (2005d) Leadership in Complex Schools: Advice to the Secretary of State Nottingham: NCSL available online http://www.ncsl.org.uk/media-897-0a-leadership-in-complex-schools.pdf

National College for School Leadership (2005e) School Leadership Report: Concepts and Evidence Nottingham: NCSL.

National College for School Leadership (2006a) Corporate Plan 2006-2009, Nottingham:NCSL

National College for School Leadership (2006b) Succession Planning Formal Advice to the Secretary of State Nottingham: NCSL available online http://www.ncsl.org.uk/ncsl-succession-planning-advice.pdf

National College for School Leadership (2007a) System leadership-lessons from the literature Nottingham: NCSL.

National College for School Leadership (2007b) Primary leadership: advice to the Secretary of State Nottingham: NCSL available online http://www.ncsl.org.uk/mediaad4-e3-advice-to-sos-primary-leadership-oct07.pdf

National College for School Leadership (2008) 'Headteachers are doing a better job than 10 years ago' Nottingham: NCSL available online http://www.ncsl.org.uk/newsindex/headteachers-are-doing-better-job-than-10-years-ago.htm accessed 10th November 2008

National College for School Leadership (2009) 'National College for School Leadership (NCSL) Priorities 2009-2010, Remit letter from the Secretary of State. Available online http://www.ncsl.org.uk/remit-letter-2009-2010a.pdf accessed $22^{\text {nd }}$ March 2009.

Nias, J; Southworth, G. and Yeomans, R. (1989) Staff Relationships in the Primary School London: Cassell

National School Board Association (NSBA) (no date) What is systemic change? available online http://www.nsba.org/sbot/toolkit/whatsc.html accessed 13th September 2006.

OECD (2001) Report on Hungary/OECD seminar on Managing Education for Lifelong Learning, 6-7 December 2001, Budapest.

OECD/CERI (2006) Futures Thinking for Education: Policy, Leadership and the Teaching Profession Summary Report Phase 3: Futures Thinking in Action 6-8 November Hiroshima, Japan. Available online http://www.oecd.org/dataoecd/44/47/37606431.pdf accessed $3^{\text {rd }}$ December 2007. 
Oduro, G. (2004) 'Distributed Leadership' In Schools: What English Headteachers Say About The 'Pull' And 'Push' Factors. A paper prepared for the BERA Annual Conference 2004 UMIST, Manchester 14-18 September.

Ofsted, (1996) The Annual Report of Her Majesty's Chief Inspector of Schools: Standards and Quality in Education 1994/1995 London: Ofsted.

Ofsted (1998) Making Headway, London: Ofsted.

Ofsted (1999) Primary Education: a review of primary schools in England, 19941998 London HMSO.

Ofsted (2002a) The national literacy strategy: the first four years 1998-2002 London: Ofsted.

Ofsted (2002b) The national numeracy strategy: the first three years 1999-2002 London: Ofsted

Ofsted (2003) Leadership and Management: What Inspection tells us, HMI 1646. London: Ofsted.

Ofsted (2004a) Standards and Quality 2002/2003: The Annual Report of Her Majesty's Chief Inspector of Schools London: Ofsted

Ofsted (2004b) The Primary Leadership Programme London: Ofsted

Osborn, M; McNess, E. and Broadfoot, P; with Pollard, A. and Triggs, P. (2000) What Teachers Do. Changing Policy and Practice in Primary Education. London: Continuum.

Paterson, L. (2003) 'The Three Educational Ideologies of the British Labour Party', Oxford Review of Education Vol. 29, No. 2, pp.165-185.

Peters, T. (1987) Thriving on Chaos: Handbook for a Management Revolution. London, Pan.

Philips, R. (2001) Education the State and the Politics of Reform, in R.Philips \& J Furlong (Eds) Education, Reform and the State: Twenty-five years of Politics, Policy and Practice (London: Routledge Falmer) pp.12-27.

Phillips, R. \& Harper-Jones, G. (2002) From Ruskin to the Learning Country: education policy, the State and educational politics n England and/or Wales, 19762001 Educational Review, Vol 54 (3):297-305.

Pierson, C. (1998) 'The New Governance of Education: the Conservatives and education 1988-1997', Oxford Review of Education, Vol. 24, No.1, pp.131-142.

Plewis, I. \& Goldstein, H. (1998) Excellent in Schools - a failure of standards British Journal of Curriculum and Assessment 8 No.1. pp.17-20.

Plowden Report (1967) Children and their Primary Schools, HMSO, London. 
Pollard, A; Broadfoot, P; Croll, P; Osborn, M. and Abbott, D. (1994) Changing

English Primary Schools the Impact of the Educational Reform Act at Key Stage One.
London: Cassell.

Pollard, A, Tann, S. (1993) Reflective Teaching for the Primary School: A Handbook for the Classroom $2^{\text {nd }}$ Edition Cassells

Pollitt, C. (1993) Managerialism and the Public Sector, $2^{\text {nd }}$ edition. Oxford: Basil Blackwell

Poulson, L. (1998). Accountability, Teacher Professionalism and Educational Reform in England, Teacher Development. Vol. 2, No. 3. pp.419-432

Powell, J.L \& Edwards, M. (2005) Surveillance and Morality: Revisiting the

Education Reform Act (1988) in the United Kingdom Surveillance \& Society, Vol. 3, No.1, pp. 96-106.

Power, S. \& Whitty, G. (1999) New Labour's education policy: first, second or third way? Journal of Education Policy, Vol.14, No.5, pp.:535-546

Preedy, M; Glatter, R and Wise, C (2003) Strategic Leadership Challenges, in Preedy, $\mathrm{M}$; Glatter, R and Wise, C (eds) Strategic Management and Educational Improvement Open University and London, Sage.

Price Waterhouse Coopers (2001) Teachers Workload Study London: DfES

Price Waterhouse Coopers (2007) Independent Study into School Leadership London: DfES.

Radnor, H. A. \& Ball, S. J. (1996) Local education authorities: Accountability and control. Stoke-on-Trent: Trentham Books

Radnor, H; Ball, S. and Vincent, C. (1997) 'Whither democratic accountability in education? An investigation into headteachers' perspectives on accountability in the 1990s with reference to their relationships with their LEAs and governors', Research Papers in Education Vol. 12, No.2, pp.205-222.

Ranson, S (2003) Public accountability in the age of neo-liberal governance. Journal of Education Policy Vol.18, No. 5, pp.459-480.

Rein, M.(1973) From Policy to Practice (London: Macmillan).

Ribbins, P. (1993) 'Telling tales of Secondary Heads on reform and the national curriculum in Chitty, C. (Ed) The National Curriculum, Is It working? London: Longman

Riddell, R. (2005) Government policy, stratification and urban schools: a commentary on the Five - year strategy for children and learners. Journal of Education Policy Vol. 20, No. 2, pp.237-241.

Robson, C. (1996) Real World Research Blackwell, Oxford 
Roche, K. (1999) Moral and Ethical Dilemmas in Catholic School Settings, in P. Begley (ed) Values and Educational Leadership, pp. 255-272. Albany, NY: SUNY Press.

Rutherford, D. (2004) Headteachers' reflections on primary headship from 19882003: an exploratory study Journal of Educational Administration Vol. 43, o. 3, pp.

Sammons, P; Hillman, J, and Mortimore, P. (1995) Key Characteristics of Effective Schools: A Review of School Effectiveness. London: Ofsted

Sampson, S. (2004) Navigating the waves: the usefulness of a pilot in qualitative research. Qualitative Research, Vol. 4, No. 3, pp. 383-402.

Schutz, A. (1976). The stranger. In G. Bowker, \& J. Carrier (Eds.), Race and ethnic relations. London: Hutchison.

Scott, D. (2000) Reading Educational Research and Policy Texts Routledge

Senge, P. (1990) The Fifth Discipline: The Art and Practice of the Learning Organisation. London: Random House.

Senge, P. (1998) Interview with Peter Senge author anonymous 'Rethinking Leadership' Executive Excellence Vol. 15, No. 5, p.16.

Sergiovanni, T.J. (1998) 'Leadership as Pedagogy, Capital Development and School Effectiveness', International Journal of Leadership in Education Vol. 1 No. 1, pp.3746.

Sergiovanni, T.J. (2001) Leadership: What's in it for school? London: Routledge Falmer.

Shaw, I; Newton, D; Aitken, M. and Darnell, R. (2003) Do Ofsted inspections make a difference to GCSE results? British Educational Research Journal, Vol, 29, No.1, pp. $63-75$.

Slater, L. (2008) Pathways to Building Leadership Capacity Educational Management, Administration and Leadership, Vol. 36, No. 1, pp. 55-69.

Simkins, T. (1997) Autonomy and Accountability, In B. F idler, S. Russell and T. Simkins (eds.) Choices for Self-Managing Schools. London: Paul Chapman Publishing.

Simkins, T. (2003) Reform, Accountability and Strategic Choice in Education in Education in Preedy et al (eds.) Strategic Leadership and Educational Improvement Open University Press and Paul Chapman Publishing

Simkins, T. (2005) Leadership in Education Educational Management \& Leadership London. Sage Vol.33, No.1, pp.9-26 
Simon, B. (1991) Education and the Social Order, 1940-1990 (London: Lawrence
and Wishart).

Spillane, J; Halverson, R. and Diamond, B. (2001) Investigating school leadership practice: A distributed perspective. Educational Researcher, Vol. 30 No.3, pp.23-28.

Spillane, J; Diamond, B; Sherer, J, Coldren, A. (2005) Distributing leadership in Coles, M. and Southworth G. (Eds) Developing Leadership creating the schools of
tomorrow, OUP.

Spillane, J. (2006) Distributed Leadership Chicago: Jossey-Bass.

Southworth, G. (1993) School leadership and school development: reflections from research, School Organisation, Vol. 13, pp. 73-87.

Southworth, G. (1995a) Looking into Primary Headship: A Research Based Interpretation, London Falmer.

Southworth, G. (1995b) Talking Heads: Voices of Experience, University of Cambridge Institute of Education, Cambridge.

Southworth, G. (1998a) Leading Improving Primary Schools: The Work of Heads and Deputy Headteachers. London: Falmer Press.

Southworth, G. (1998b) 'Change and Continuity in the Work of Primary Headteachers in England', International Journal of Educational Research Vol 29, pp. 311-321.

Southworth, G. (1999) Primary School Leadership in England: policy, practice and theory. School Leadership and Management, Vol. 19, No. 1, pp.49-65.

Southworth, G. (2004) Primary School Leadership in Context: Leading Small Medium and Large Sized Schools. London: Routledge: Falmer.

Southworth, G. (2005) The Essentials of School Leadership, London: Paul Chapman Publishing and Corwin Press.

Southworth, G. (2008) Primary school leadership today and tomorrow School Leadership and Management Vol.28, No.5, pp.413-434.

Southworth, G. and Connor, C. (1999) Managing Improving Primary Schools: Using Evidence-based Management and Leadership Falmer Press.

Southworth, G. and Du Quesnay, H. (2005) School Leadership and System Leadership The Educational Forum Vol. 69, No.2, pp. 212-220.

Stewart, W. (2008) Serving heads not so good at Sip support Times Educational Supplement September $12^{\text {th }}$ available online at http://www.tes.co.uk/article.aspx? storycode $=6002313$ accessed $25^{\text {th }}$ September 2008. 
Stewart, W. (2009) Academics demolish 'useless' CVA system Times Educational Supplement Feb $27^{\text {th }}$ available online at http://www.tes.co.uk/article.aspx?storycode $=6009334$ accesssed $10^{\text {th }}$ March 2009.

Strauss, A., Fagerhaugh, S., Suczek, B. and Wiener, C. (1985), Social Organization of Medical Work, University of Chicago Press, Chicago, IL.

Suchman, L.(1995) Making work visible, Communications of the ACM, Vol.38, No.9. pp. 56-64.

Teacher Training Agency (1997) Training curriculum and standards for new teachers (London: TTA)

Teacher Training Agency (1998) National Standards for Headteachers London:

Teacher Training Agency.

TES (1997) Editorial 'Crisis comes to a head' Editorial Times Educational Supplement September $12^{\text {th }}$

www.tes \%20to\%20print/TES\%20ARTICLES/crisis\%20comes\%20to\%20a\%20head $\% 201997 \% 20$ recruitment.htm accessed $14^{\text {th }}$ August 2008.

Thomson, P. (2008) Headteacher critique and resistance: a challenge for policy, and for leadership/management scholars Journal of Educational Administration and History Vol.40, No. 2, pp-85-100.

Thrupp, M. (2005) School Improvement: An Unofficial Approach London: Continuum

Tomlinson, S. (2001) Education in a post-welfare society. Buckingham: Open University Press.

Troman, G. (1996) Self Management and School Inspection: complementary forms of surveillance and control in the primary school. Paper presented at the BERA Conference University of Lancaster, Sept. Accessed from http://www.leeds.ac.uk/documents/000000079.doc accessed $9^{\text {th }}$ April 2007.

Troman, G, Jeffrey, B and Raggl, A (2007) 'Creativity and performativity policies in primary school cultures', Journal of Education Policy, Vol. 22, No. 5, pp. $549-572$

Trowler, P. (1998) Education Policy: A policy sociology approach. The Gildredge Press Ltd.

Tymms, P. and Coe, R. (2003) Celebration of the success of distributed research with schools: the CEM Centre, Durham, British Educational Research Journal, Vol,29, No.5, pp.639-654.

Walford, G. (2005) Introduction: education and the Labour Government Oxford Review of Education Vol.31, No.1, pp.3-9

Wallace, M. (2001) Sharing leadership of schools through teamwork: a justifiable risk? Educational Management and Administration Vol. 29, No.2, pp. 153-167. 
Wallace, M. and Huckman, L. (1996) Senior management teams in large primary schools: a headteacher's solution to the complexities of post-reform management? School Organisation, Vol. 16, NO.3, pp 309-323.

Wallace, M. and Huckman, L. (1999) Senior Management in Primary Schools: The Quest for Synergy London: Routledge.

Wallace, R. (1981) Origins and authorship of the 1944 Education Act, History of Education, Vol. 10, No. 4, pp.283-295.

Walsh, K. (1994) Marketing and Public Sector Management. In European Journal of Marketing, Vol. 28, No. 3, pp.63-71.

Walsh, K. (1995) Public Services and Market Mchanisms: Competition, Contracting and the New Public Management. Basingstoke, Macmillan.

Webb, P. T. (2006) The choreography of accountability Journal of Education Policy, Vol. 21. No. 2, pp. 201-214.

Webb, R. (2005) Leading Teaching and Learning in the Primary School: From 'Educative Leadership' to Pedagogical Leadership' Educational Management and Leadership Vol. 33, No.1, pp.69-91.

Webb, R. and Vulliamy, G. (1996a) 'The Changing Role of the Primary School Headteacher' Educational Management and Administration Vol. 24, No. 3, pp. 307 317

Webb, R. and Vulliamy, G. (1996b) A deluge of directives: conflict between collegiality and managerialism in the post-ERA primary school, British Educational Research Journal, Vol. 22, No. 4, pp.441-458.

Webb, R. and Vulliamy, G. (1996c) 'Headteachers as social workers', Education 3-13 (June) pp. 23-31.

Webb, R. and Vulliamy, G. (1996d) Roles and Responsibilities in the Primary School: Changing Demands, Changing Practices. London: Falmer.

Webb, R. and Vulliamy, G. (2002) 'The Social Work Dimension of the Primary School Teachers' Role', Research Papers in Education Vol. 17, No.2, pp. 165-184.

Webb, R. and Vulliamy, G. (2006) Coming Full Circle? The Impact of New Labour's Education Policies on Primary School Teachers' work. http://www.atl.org.uk accessed $18^{\text {th }}$ June 2007.

Weindling, D. (1992) Marathon running on a sand dune: The changing role of the headteacher in England and Wales. Journal of Educational Administration, Vol. 30, No. 3, pp. 63-76. Retrieved 29-12- 2008, from ABI/INFORM Global database. (Document ID: 1064813).

Wenger, E. (1999) Communities of practice: Learning, meaning and identity. Cambridge. Cambridge University Press. 
West, M. (2000) Supporting school improvement. School Leadership and Mangagement Vol.20, No.1 pp. 43-61.

West- Burnham, (2005) Workshop at a regional leadership conference (NCSL. Birmingham March)

West- Burnham, (2007) 'Leadership for Education in the Future' in Primary Leadership Paper No 22. November, pp.6-7. NAHT Publications.

Whitty, G. (2002) Making Sense of Education Policy. London: Paul Chapman.

Whitty, G. (2005) The State and the Market in English Education Policy. Paper presented at Beijing Normal University, October 2005

Whitty, G. (2006) Teacher professionalism in a new era. Paper presented at the first General Teaching Council for Northern Ireland Annual Lecture Belfast March

Whitty, G. (2008) 'Twenty Years of Progress?: English Education Policy 1988 to the Present, Educational Management Administration and Leadership Vol. 36, No. 2, pp. 165-184.

Whitty, G; Power, S. and Halpin, D. (1998) Devolution and Choice in Education: the School, the State and the Market. Buckingham: Open University Press

Williams, T.R. (2001) Unrecognised Exodus, Unaccepted Accountability: The Looming Shortage of Principals and Vice Principals in Ontario Public School Boards, Working Paper 24, School of Policy Studies, Queens University, Toronto.

Wohlsetter, P. and Sebring, P.B. (2000) School-based management in the United States, in M.A. Arnott and C.D.Raab (eds) The Governance of Schooling: Comparative Studies of Devolved Management, London: Routledge Falmer.

Woodhead, C. (1999) Platform: why inspections set you free, Times Educational Supplement, $14^{\text {th }}$ May.

Woods, P. (1995) Creative Teachers in Primary Schools. Buckingham Open University Press.

Woods, P; Jeffrey, B, (2002) The reconstruction of primary teachers' identities, British Journal of Sociology of Education, Vol. 23, No.1, pp. 89-106.

Woods, P; Jeffrey, B Troman, G. and Boyle, M. (1997) Restructuring Schools, Reconstructing Teachers: Responding to change in the primary school Buckingham: Open University Press.

Wright N. (2001) Leadership, 'Bastard Leadership' and Managerialism: Confronting Twin Paradoxes in the Blair Education Project: Education Management and Administration. Vol. 29, No.3, pp. 275-290. 
Wright, N. (2003) Principled bastard leadership? A rejoinder to Gold, Evans, Earley, Halpin, and Collarbone, Educational Management and Administration. Vol. 29. No. 3 , pp. 139-143.

Wyse, D. (2003) The National Literacy Strategy: a critical review of empirical evidence, British Educational Research Journal, Vol. 29, No. 6, pp.903-916

Yukl, G, (2002) Leadership in Organisations $5^{\text {th }}$ edition Upper Saddle River. NJ:

Prentice - Hall. 